\title{
Cooperación \\ de las organizaciones del conocimiento con el entorno productivo y social de Baja California
}

Rodolfo García Galván, Juan Carlos Rodríguez Macías

y Alicia Alelí Chaparro Caso López

(Coordinadores)
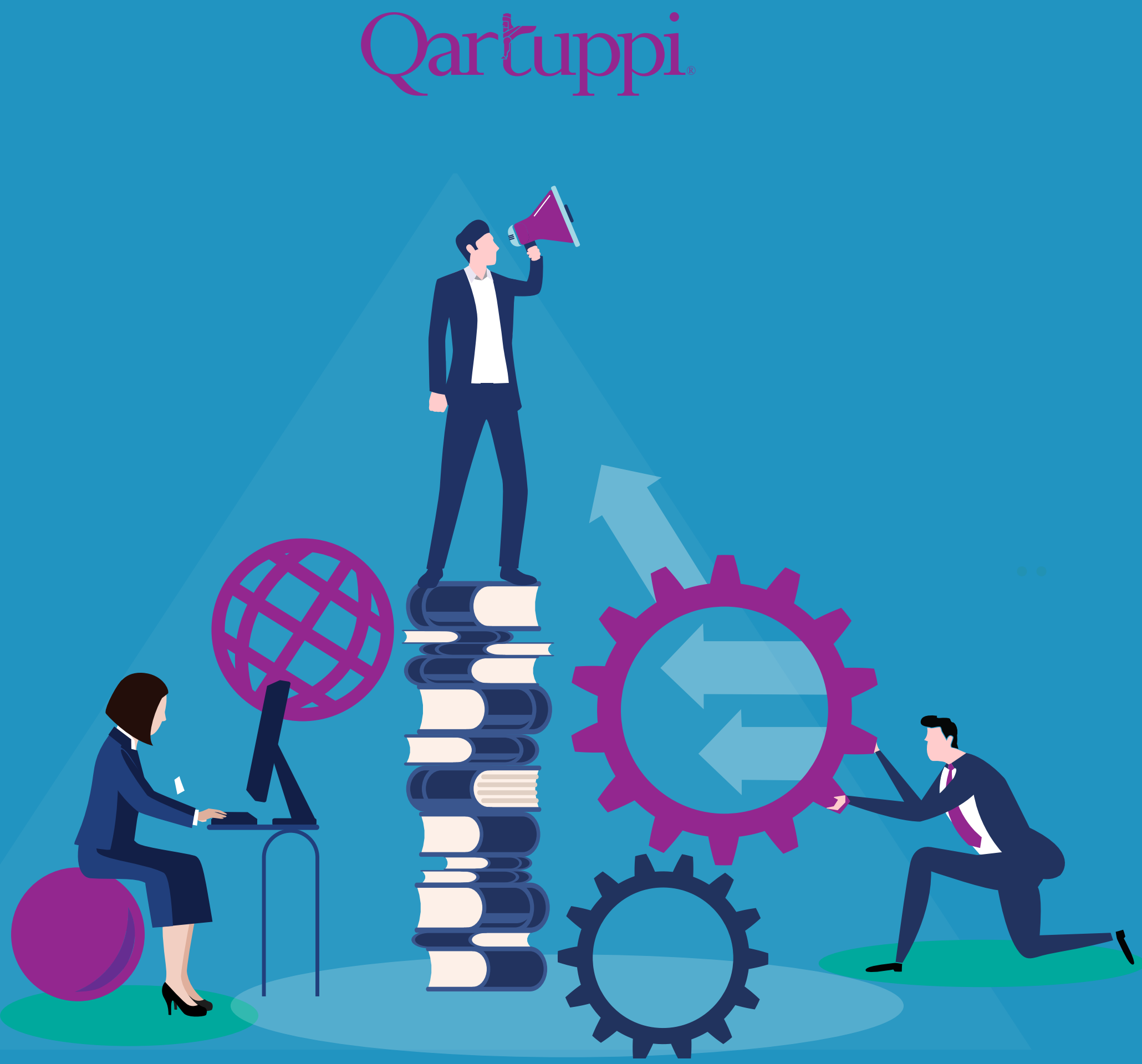



\section{Cooperación \\ de las organizaciones del conocimiento \\ con el entorno productivo y social \\ de Baja California}

Rodolfo García Galván, Juan Carlos Rodríguez Macías

y Alicia Alelí Chaparro Caso López

(Coordinadores) 
Esta obra fue dictaminada por:

Martha Guerrero Ortiz, Universidad Autónoma de Zacatecas

Geovana Esparza Jasso, Universidad Autónoma de Zacatecas

Cooperación de las organizaciones del conocimiento con el entorno productivo y social de Baja California

1era. edición, enero 2021

ISBN 978-607-8694-04-4

DOI 10.29410/OTP.21.02

D.R. ( 2021. Qartuppi, S. de R.L. de C.V.

Villa Turca 17, Col. Villas del Mediterráneo

Hermosillo, Sonora 83220 México

http://www.qartuppi.com

Edición y diseño: Qartuppi, S. de R.L. de C.V.

Diseño de portada: Qartuppi con base en Adobe Stock @ mmustafabozdemir 


\section{Tabla de Contenido}

7 Prólogo

David Guadalupe Toledo Sarracino

11 Capítulo 1

Panorama general de la cooperación de las organizaciones públicas

del conocimiento con su entorno regional

Rodolfo García Galván y Ricardo Lindquist Sánchez

28 Capítulo 2

Percepción de los investigadores de Baja California sobre la cooperación tecnocientífica en las instituciones de educación superior

Marcela Morales Páez y Juan Carlos Rodríguez Macías

49 Capítulo 3

Cooperación tecnocientífica en Baja California: diferencias y similitudes entre el discurso institucional y la opinión de los académicos

Marcela Morales Páez y Ricardo Lindquist Sánchez

76 Capítulo 4

Cooperación de la Universidad Autónoma de Baja California con el entorno.

Perspectiva de los usuarios

Rodolfo García Galván y Alicia Alelí Chaparro Caso-López 
89 Capítulo 5

Factores que favorecen la empleabilidad de los egresados de las organizaciones del conocimiento en Baja California

Dalia Lizzett Acosta Cárdenas y Juan Carlos Rodríguez Macías

112 Capítulo 6

¿Posicionamiento o legitimidad? Estado actual y rutas para la cooperación de la Universidad Autónoma de Baja California con el sector social Ricardo Lindquist Sánchez y Rodolfo García Galván

133 Capítulo 7

Servicio social universitario como forma de cooperación con los actores sociales: Estudio en la Universidad Autónoma de Baja California

Viviana Medrano Gallegos y Alicia Alelí Chaparro Caso-López 


\section{Prólogo}

El Programa Nacional de Extensión de los Servicios, Vinculación y Difusión de la Cultura (2011), publicado por la Asociación Nacional de Instituciones de Educación Superior (ANUIES), señala que las universidades, al igual que el sector pruductivo, enfrentan desafíos que limitan el crecimiento, la calidad educativa y la innovación. En virtud de estos retos, las universidades requieren reforzar su estrategia de vinculación escuela-empresa, pues el sector académico enfrenta un decenso en su adscripción con universidades y centros de investigación, dando pie a la baja productividad, falta de competitividad, niveles deficientes para la obtención de recursos, esquemas desdibujados de capitalización, incipiente capacitación laboral, inadecuada organización interna e ineficiente cultura de apoyo a la micro, mediana y gran empresa. Sin lugar a dudas, las universidades son las que deben brindar apoyo al sector empresarial con el fin de capitalizar el recurso humano y generar un emprendimiento con responsabilidad social.

En las universidades, la vinculación es una actividad sustantiva para el desarrollo de sus tareas. Los programas de innovación, transferencia de conocimiento, y emprendimiento de alto impacto se vinculan de manera directa entre escuela, empresa, gobierno y banca, fortaleciendo las tareas de servicio a la comunidad con un bien común, cuyo único fin es coordinar las políticas educativas con las políticas públicas asociadas al sector social y productivo.

Cooperación de las organizaciones del conocimiento con el entorno productivo y social de Baja California es un trabajo colectivo que consta de siete capítulos en los que se exponen las reflexiones y los hallazgos de destacados investigadores que muestran, no solo el resultado de su trabajo, sino el panorama de la vinculación en la Universidad Aautónoma de Baja California (UABC).

Esta obra es un ejercicio que permite retroalimentar la tarea de la vinculación y el quehacer académico. Es una lectura obligada para quienes toman decisiones en torno al desarrollo de la vinculación universitaria.

En el primer capítulo, "Panorama general de la cooperación de las organizaciones públicas del conocimiento con su entorno regional", escrito por Rodolfo García Galván y Ricardo Lindquist Sánchez, se identifican los rasgos preeminentes de la colaboración de las organizaciones públicas del conocimiento (OPC) con el sector productivo, gubernamental y social en el ámbito regional. Ofrece asimismo, recomendaciones para intensificar la colaboración de las OPC con las organizaciones o empresas fincadas en 
la región. Los autores sugieren una reinvención de la colaboración para dar el paso de la transferencia del conocimiento a la investigación y el desarrollo regional.

El segundo capítulo, "Percepción de los investigadores de Baja California sobre la cooperación tecnocientífica que se realiza en las instituciones de educación superior", de Marcela Morales Páez y Juan Carlos Rodríguez Macías, comparte las opiniones de la comunidad científica respecto a la cooperación tecnocientífica (CT) en las instituciones de educación superior en el estado de Baja California. A partir de un análisis de tipo cuantitativo, esta investigación se enfocó en identificar las características sociodemográficas, académicas e institucionales de la comunidad científica que realiza transferencia de conocimiento e investigación. Los autores proponen que este tipo de estudio se socialice con quienes toman decisiones en torno a las estrategias de vinculación, para generar una sinergia entre la comunidad científica, el sector empresarial y las instituciones de educación superior (IES).

En el tercer capítulo, "Cooperación tecnocientífica en Baja California: diferencias y similitudes entre el discurso institucional y la opinión de los académicos", escrito por Marcela Morales Páez y Ricardo Lindquist Sánchez, se contrasta el discurso institucional de las IES estudiadas a partir de los documentos oficiales (normatividades, estatutos y reglamentos de vinculación o transferencia de conocimiento), así como de sus planes de desarrollo, con la opinión de los profesores-investigadores miembros del Sistema Nacional de Investigadores (SNI) que laboran en estas. Los resultados de este estudio fueron más allá de la retórica institucional y de las apreciaciones de los científicos, tomando en consideración que se requiere legitimar y apoyar la vinculación como un elemento esencial para la tranferencia de conocimiento.

El cuarto capítulo denominado "Cooperación de la Universidad Autónoma de Baja California con el entorno. Perspectiva de los usuarios", escrito por Rodolfo García Galván y Alicia Alelí Chaparro Caso-López, enmarca a las IES en la región y establece la relación de las unidades receptoras de servicio social y prácticas profesionales con un entorno real que propicie espacios formativos que incidan en la preparación del futuro egresado. Los autores hacen una aportación significativa en torno a la necesidad de que la universidad encamine su esfuerzo hacia la tecnociencia con el sector empresarial, para conseguir una visión de construcción de una real reconversión que propicie alcances significativos de productividad, competitividad y posicionamiento. Desde una mirada crítica, los autores proponen revolucionar la gestión de los recursos públicos para invertir en innovación y tecnología. Asimismo, este trabajo ofrece una aportación esencial en donde la universidad, con los recursos económicos y el capital humano, potencialice su capacidad de profesionalizar y mejorar los servicios públicos (estatal y municipal), para trabajar de la mano con el sector empresarial y con ello posicionar una verdadera vinculación universitaria. 
En el quinto capítulo, "Factores que favorecen la empleabilidad de los egresados de las organizaciones del conocimiento en Baja California", los autores Dalia Lizeth Acosta Cárdenas y Juan Carlos Rodríguez Macías hablan de la empleabilidad y su relación con las competencias transversales en la formación del universitario. En él se describe el papel de las IES para habilitar a los estudiantes y facilitar su trazabilidad de egreso hacia una inserción laboral. Los resultados de este estudio marcan de manera significativa la participación de los empresarios empleadores como informates y parten de la idea de que las organizaciones del conocimiento formarán un capital humano de alto nivel, y proveerán instalaciones con equipamientos que atiendan la formación y el aprendizaje de competencias aplicadas en su máxima expresión.

En el sexto capítulo, "¿Posicionamiento o legitimidad? Estado actual y rutas para la cooperación de la Universidad Autónoma de Baja California con el sector social", de Ricardo Lindquist Sánchez y Rodolfo García Galván, se describe a las universidades que se vinculan con los diversos sectores $y$, a través de los resultados de esta investigación, se hace un llamado de atención y una crítica sobre el rol de la universidad y las estrategias para fortalecer y mantener la vinculación con los diversos sectores, estableciendo desde el ingreso y a partir de proyectos, convenios para la realización de la formación situada, el capital humano con competencias para una inserción inmediata al sector laboral y la valoración de sus egresados. Sin duda - afirman los autores-, la universidad debe reinventarse, atender la interacademia y el posionamiento social, además de mantener sus actividades sustantivas: desde formar profesionales aptos, producir conocimiento en beneficio del entorno social y mantener la vinculación con un impacto en vías de una mejor calidad de vida para los que habitan en la región. Los autores hacen una invitación para alejarse de los documentos programáticos (planes de desarrollo y misiones/visiones administrativas) de los modelos educativos $y$, a partir de una vinculación real, atender las verdaderas demandas de la sociedad.

En elúltimo capítulo, "Servicio social universitario como forma de cooperacióncon los actores sociales: Estudio en la Universidad Autónoma de Baja California", Viviana Medrano Gallegos y AliciaChaparro Caso-López reflexionan sobre la forma en que opera el servicio social en la UABC y cuáles son sus alcances y áreas de oportunidad. Con toda seguridad, el servicio social incorpora en el estudiante las competencias profesionales que debe desarrollar, sin menoscabo de la puesta en marcha de sus conocimientos, habilidades, aptitudes y valores, como lo menciona el Modelo Educativo de la UABC. En este trabajo las autoras ofrecen una aportación significativa en el tema: señalan que el servicio social es considerado una actividad similar a las prácticas porfesionales en las que se vislumbra una oportunidad para la incersión inmediata del estudiante a su ejercicio profesional. Sin embargo, las autoras nos hacen pensar en la verdadera tarea del servicio social y su impacto; es decir, en la importancia de observarlo, más que 
como un espacio de formación con fines laborales, como una actividad de formación al servicio de la sociedad bajo una perspectiva de responsabilidad social universitaria, donde el estudiante vincula directamente las competencias aprendidas en el aula con un beneficio directo. Por lo tanto, debe considerarse como un espacio formativo que contribuyan a la sociedad.

Cooperación de las organizaciones del conocimiento con el entorno productivo y social de Baja California plasma con claridad el rumbo que debe tomar la vinculación en la UABC. Este trabajo colectivo representa mucho más que una colección de informes de investigación. Es un compendio único para profesores e investigadores que se especializan en el tema o que buscan otras visiones sobre esta actividad sustantiva. Esta obra ofrece a la comunidad académica información de avanzada sobre la vinculación universitaria, marca pautas a seguir para un mejor desarrollo de la extensión de los servicios, vinculación y difusión cultural de las instituciones de educación superior mexicanas.

David Guadalupe Toledo Sarracino

Coordinador General de Vinculación y Cooperación Académica Universidad Autónoma de Baja California 


\title{
Capítulo 1
}

\section{Panorama general de la cooperación de las organizaciones públicas del conocimiento con su entorno regional}

\author{
Rodolfo García Galván y Ricardo Lindquist Sánchez
}

Desde hace algunas décadas, el estudio de la cooperación de las organizaciones del conocimiento con los actores del entorno en México se ha intensificado, probablemente porque se considera que pueden realizar contribuciones importantes para la solución de diversos y complejos problemas, tanto de carácter económico como social, complementando así las acciones realizadas desde el ámbito empresarial, gubernamental y social.

Las organizaciones del conocimiento (OC) son todas aquellas que tienen como finalidad la producción, difusión-divulgación y socialización del conocimiento científico y tecnológico. Dentro de estas, se distinguen las organizaciones públicas del conocimiento (OPC), que se financian mayoritariamente con fondos públicos para el logro de sus objetivos; se incluyen en esta categoría los centros públicos de investigación y algunas universidades públicas con una fuerte actividad investigadora. Es importante destacar que en ocasiones se utiliza como sinónimo de las OC a las instituciones de educación superior (IES), las cuales incluyen a todas aquellas organizaciones que imparten estudios superiores, pero que no necesariamente realizan investigación tecnocientífica, por lo tanto, deben diferenciarse.

Las OC son actores clave para la creación y transmisión de conocimiento, así como la movilización de recursos para enfrentar problemas. Sin embargo, la relación con los actores del entorno regional como empresas, organizaciones sociales y comunitarias, y entes gubernamentales suele ser compleja, debido a la naturaleza de cada uno, "sus roles en la economía y la sociedad, y la trama institucional que requieren para interactuar" (CEPAL, 2010, p.59). Sin embargo, existen diversos factores que pueden facilitar la cooperación entre estos actores.

En virtud de lo anterior, el propósito de este capítulo es identificar los rasgos preeminentes de la cooperación de las OPC con el sector productivo, gubernamental y social del ámbito regional. Para ello, cabe señalar que los términos colaboración y cooperación pueden utilizarse de manera indistinta a lo largo del texto, y en el ámbito universitario cuando se discute sobre las diversas y complejas formas de colaboración con el entorno, puede que éstas sean referidas como actividades de vinculación o de extensión universitaria. 


\section{Contexto internacional y latinoamericano}

En el mundo occidental anglosajón (esencialmente los Estados Unidos y el Reino Unido), desde finales de la década de 1970, se dio un giro radical en las políticas económicas, cuyos principales objetivos fueron reivindicar el libre mercado como principal mecanismo de coordinación económica, y reducir o mitigar la carga en gastos e inversión del gobierno. Conforme las nuevas políticas se fueron consolidando, las organizaciones del conocimiento (universidades, institutos y centros de investigación) también fueron alcanzadas con estos nuevos preceptos.

En la década de 1980, en los países mencionados se llevaron a cabo reformas institucionales (legislativas y relacionadas con los lineamientos sobre el financiamiento de las actividades de educación superior y de ciencia, tecnología e innovación); por ejemplo, se puso atención al fortalecimiento de los derechos de propiedad intelectual, se revisó el papel de las organizaciones del conocimiento $(\mathrm{OC})$ en el desarrollo económico y social, y se modificaron las reglas de financiamiento y patrocinio de la investigación emprendida por las organizaciones del conocimiento (Etzkowitz et al., 2000; Etzkowitz, 2003; Mowery \& Sampat, 2004).

Los cambios inherentes a las OC no solo se supeditaron a las nuevas reglas de la política económica pro libre mercado y las reformas legislativas suprainstitucionales, sino que, al interior de estas, comenzaron a surgir perspectivas académicas y epistémicas que marcaban una diferencia clara con los cánones precedentes. De acuerdo con Gibbons et al. (1997), Gibbons (1999), y Hessels y van Lente (2008), la función y actividad universitaria —concretamente la investigación científica - registró cambios significativos, en lo que se refiere a los centros hegemónicos de la producción del conocimiento (las universidades y los centros públicos de investigación comienzan a perder hegemonía y emergen otros espacios como las empresas o la sociedad organizada). Además, se modificaron las modalidades del conocimiento más demandadas o requeridas por los usuarios; de esta manera, las persuasiones y presiones directas para que las OPC incrementen su producción de conocimiento aplicado específico se hacen más fuertes.

Según Gibbons et al. (1997) y Gibbons (1999) estas condiciones de cambio permitieron el surgimiento de un tipo de conocimiento con mayor aplicación, que demanda multidisciplinariedad, interdisciplinariedad y transdisciplinariedad. Las necesidades de nuevo conocimiento van más en función de los problemas prácticos que se observan en el mundo cotidiano y, por lo tanto, los filtros para evaluar y valorar la calidad del conocimiento cambian; ahora no solo es función y responsabilidad de los científicos y tecnólogos, intervienen otros actores con diversos intereses, que terminan siendo usuarios intermedios o finales, por lo cual adquieren mayor relevancia, e incluso en múltiples ocasiones sus valoraciones son decisivas sobre el tipo y las características del nuevo conocimiento requerido. De este modo, el rol de los políticos y funcionarios públicos, así como de los empresarios y de las organizaciones sociales o comunitarias, es de crucial importancia. 
Las OPC han sumado a su función de formación de recursos humanos, la investigación científica y tecnológica; $y$, desde la década de 1980, la exigencia de que estas se involucren en el fomento del desarrollo económico y social ha sido más directa y de mayor intensidad (figura 1). En consecuencia, la última función se concretiza en acciones como el fortalecimiento de la propiedad intelectual, la comercialización o cuasi-comercialización de los resultados de los proyectos de investigación, el fomento directo del emprendimiento universitario, el impulso de la innovación tecnológica, la fundación y operación de incubadoras de empresas de base tecnocientífica, la promoción de convocatorias de investigación que atiendan problemáticas específicas del sector productivo o social, y el impulso de la formación y la educación continua. En los casos más ambiciosos y desafiantes, las OPC se han involucrado directamente en la creación de empresas tecnocientíficas, en la fundación o conformación de parques o ciudades del conocimiento tecnocientífico, e incluso algunas han entrado en el mercado financiero.

El mayor interés por impulsar el desarrollo económico y social desde las OPC se relaciona con dos fuentes de presión. Por un lado, las directrices generales de la política económica y las nuevas reglas del juego para definir y acotar el financiamiento público de estas, y por el otro, las presiones que surgen por la pérdida de hegemonía y legitimidad ante la sociedad. Por consiguiente, como lo sostiene De Sousa (2017), ante la crisis de hegemonía, legitimidad

\section{Figura 1}

Funciones y actividades de la universidad

\begin{tabular}{|c|c|}
\hline & $\begin{array}{l}\text { Primera función. Docencia. } \\
\text { Construcción de capacidades y habilidades (formación) para la interacción } \\
\text { con el entorno. Aproximadamente un tercio de todo el tiempo laboral se } \\
\text { destina a la formación. }\end{array}$ \\
\hline \multirow[t]{3}{*}{$\begin{array}{l}\text { Funciones universitarias } \\
\text { (si el personal universitario } \\
\text { destinara su tiempo } \\
\text { de manera equilibrada } \\
\text { a sus funciones sustantivas) }\end{array}$} & $\begin{array}{l}\text { Segunda función. Primera revolución universitaria. Investigación. } \\
\text { Incremento de la proporción de la investigación avanzada con posibilida } \\
\text { des aplicadas, de compartimiento práctico, y de innovaciones tecnológi } \\
\text { cas desde la universidad. Aproximadamente un tercio de todo el tiempc } \\
\text { laboral se destina a la investigación. }\end{array}$ \\
\hline & $\begin{array}{l}\text { Tercera función. Segunda revolución universitaria. Desarrollo. } \\
\text { Fomento del desarrollo económico y social por medio de la interacción con } \\
\text { el entorno (sector productivo, organizaciones sociales y comunitarias, y } \\
\text { entes gubernamentales). Aprovechamiento de la capacidad instalada uni- } \\
\text { versitaria para impactar en el entorno. Aproximadamente, se destina un } \\
\text { tercio del tiempo laboral. }\end{array}$ \\
\hline & $\begin{array}{l}\text { Las funciones y actividades de gobernación, administración y gestión se man- } \\
\text { tienen como funciones sustantivas de la universidad. }\end{array}$ \\
\hline
\end{tabular}

Nota: Elaboración propia. 
e institucionalidad, la universidad tiene que reinventarse, haciéndose más significativa para los actores que la circundan. Ante la ola de críticas externas e internas, es natural que las OPC respondan con una serie de estrategias para mitigar los indicadores que podrían profundizar la crisis tridimensional. No obstante, la precipitación por responder podría llevar a las organizaciones del conocimiento a tomar decisiones improvisadas y sin mayor reflexión, que lejos de disminuir drásticamente las fuentes de conflicto o de crisis, termine por extenderlas y profundizarlas.

Los problemas arrastrados desde el siglo $X X$, y los nuevos y más complejos de inicios del siglo XXI, no deben ser resueltos con las mismas medidas utilizadas para resolver los problemas de antaño. Ante la crisis multidimensional que enfrentan las OPC es menester llevar al límite la creatividad y la innovación, en la búsqueda de soluciones relevantes y pertinentes ante la vasta lista de problemáticas que enfrentan las sociedades de nuestro tiempo. Si las OPC asumen una postura inteligente ante los actores del entorno, podrían encontrar oportunidades para reposicionar a estas instituciones-organizaciones estratégicas.

El avance de la tercera función universitaria -que comenzó a consolidarse en el mundo anglosajón - poco a poco se fue esparciendo en el mundo entero. En los países latinoamericanos, sus antecedentes pueden ubicarse en la década de 1980, cuando el modelo económico de industrialización por sustitución de importaciones cambió abruptamente, para dar paso al modelo derivado del Consenso de Washington, inspirado en un decálogo de políticas pro libre mercado, luego ampliado con más políticas (reformas de segunda generación) que continuaban profundizando dicho giro. Casi de manera inmediata, los ajustes estructurales impactaron en las políticas y los lineamientos de financiamiento en las OPC en América Latina, y más específicamente en México. Por ejemplo, se pasó de un presupuesto asegurado por las universidades públicas - basado en las dimensiones de la matrícula-a un presupuesto basado en una mayor competencia y condicionado a la realización de cambios institucionales internos, como el mejoramiento sustancial de indicadores académicos, así como la calidad, la relevancia y la pertinencia social y productiva del conocimiento universitario. Las transformaciones comenzaron a reflejarse más nítidamente a partir de la década de 1990, con varias reformas en las normas relacionadas con la educación superior, la ciencia, la tecnología y la innovación.

La serie de ajustes abruptos en el modelo económico y político en América Latina, pronto se reflejó en sendas crisis económicas, políticas y sociales en varios países de la región. Por ejemplo, entre 1994 Y 1995 México registró una de las peores crisis del siglo XX; igualmente, a finales de la década de 1990 y principios de la del 2000, Argentina padeció una terrible crisis tridimensional (política, económica y social). Fue en este último país, donde las universidades jugaron un rol trascendental, para contener la debacle económica y social. De acuerdo con Llomovatte et al. (2006), Riquelme (2008) y Naidorf (2014), las OPC jugaron un rol muy activo durante las crisis para mitigar los terribles efectos de la crisis, auxiliando a la población 
más vulnerable ante la desprotección total de parte del gobierno y del sector empresarial. Los autores resaltan que estos fueron los momentos en los que las OPC se emplearon a fondo para movilizar el conocimiento en la solución y atención de las demandas sociales más elementales, pero también las universidades fueron decisivas en la recuperación de las capacidades productivas.

En general, pese a que el discurso oficial corre muy de cerca con las demandas del sector productivo respecto a que el conocimiento público, por su financiamiento, sea mayormente aplicado a los problemas de este sector y que se tenga posibilidades de escalar desarrollos tecnológicos e industriales; la realidad es que las OPC tienen que buscar el equilibrio entre la generación de conocimiento útil para la producción de mercancías, y el conocimiento necesario para la solución y atención de las demandas de los grupos sociales más vulnerables económica y políticamente.

\section{Tabla 1}

Particularidades de la función de desarrollo económico y social

\begin{tabular}{|c|c|c|}
\hline $\begin{array}{c}\text { Actores de la cooperación } \\
\text { interinstitucional }\end{array}$ & $\begin{array}{l}\text { Áreas preeminentes } \\
\text { del conocimiento }\end{array}$ & $\begin{array}{l}\text { Modalidades de interacción } \\
\text { que favorecen el desarrollo }\end{array}$ \\
\hline $\begin{array}{l}\text { Favorecimiento de lo } \\
\text { social }\end{array}$ & $\begin{array}{l}\text { - Ciencias sociales } \\
\text { - Educación y } \\
\text { humanidades } \\
\text { - Ciencias de la salud } \\
\text { - Ciencias agrícolas y } \\
\text { marinas }\end{array}$ & $\begin{array}{l}\text { - Educación continua y seguimiento de } \\
\text { - } \text { egresados } \\
\text { Prestación de servicio social (comunitario y } \\
\text { - Prácticas profesionales } \\
\text { - Proyectos de investigación vinculada } \\
\text { - Promoción de eventos culturales } \\
\text { - Servicios universitarios a la comunidad }\end{array}$ \\
\hline $\begin{array}{l}\text { Impulso del lado } \\
\text { económico }\end{array}$ & $\begin{array}{l}\text { - Ingenierías y tecnologías } \\
\text { - Ciencias naturales } \\
\text { - Ciencias agrícolas y } \\
\text { marinas } \\
\text { - Ciencias de la salud } \\
\text { - Ciencias económico- } \\
\text { administrativas }\end{array}$ & $\begin{array}{l}\text { - Educación continua y seguimiento de } \\
\text { - } \text { Presados } \\
\text { - Profesión de servicio social (comunitario y } \\
\text { - Prácticas profesionales } \\
\text { - Proyectos de investigación vinculada } \\
\text { - Promoción de eventos culturales } \\
\text { - Servicios universitarios a la comunidad }\end{array}$ \\
\hline $\begin{array}{l}\text { Contribuciones al } \\
\text { desarrollo gubernamental }\end{array}$ & $\begin{array}{l}\text { - Campos del } \\
\text { conocimiento de las } \\
\text { ciencias económico- } \\
\text { administrativas, y de las } \\
\text { ciencias sociales }\end{array}$ & $\begin{array}{l}\text { - Investigación bajo contrato o por convenio } \\
\text { - Servicios de consultoría avanzada } \\
\text { - Educación o capacitación continuas } \\
\text { - Análisis de políticas públicas y } \\
\text { gubernamentales }\end{array}$ \\
\hline
\end{tabular}

Nota: Elaboración propia. 
La función de desarrollo de las OPC tiene que observarse como un conjunto de actividades realizadas y fomentadas desde las unidades académicas de las universidades para contribuir al desarrollo económico y social (tabla 1). Por lo que, la universidad no tiene que pretender la suplantación del gobierno o las empresas en esta tarea, pero sí aportar recursos en los distintos sentidos para alcanzar el anhelado desarrollo. Sin embargo, para llevar a cabo exitosamente esta nueva función, las OPC requieren un mayor financiamiento; debido a que, mayores exigencias implican más medios o instrumentos para cumplirlas de manera adecuada.

Los egresados de las instituciones de educación superior son un actor fundamental, que se desempeña como un ente envolvente de las otras modalidades de colaboración universitaria. La formación y la calidad de los egresados es muy importante para dinamizar la cooperación con el entorno y para elevar la reputación de las organizaciones del conocimiento.

Para el fomento del desarrollo económico y social, las OPC tienen que observarse como socias estratégicas del gobierno, las empresas y las organizaciones sociales y comunitarias, y no como competidoras. Así, mediante la retroalimentación, estas organizaciones pueden cooperar para el desarrollo de los ámbitos gubernamentales, productivos y sociales. Por lo tanto, impulsar la ciencia, la tecnología y la innovación desde las OPC es fomentar la innovación de alta tecnología en todo el sistema económico y social.

\section{El contexto mexicano}

Uno de los factores que explican el estancamiento del desarrollo de la tercera función sustantiva en las OPC mexicanas, es la enorme escasez de inversión pública y privada en las actividades científicas, tecnológicas y de innovación. La falta de inversión en estos rubros estratégicos se da por un desinterés sistemático, comprobado históricamente, tanto del gobierno como de los actores productivos (García-Galván, 2014, 2015, 2017; Vázquez, 2015). Este diagnóstico es compartido en la mayor parte de la región latinoamericana (Arocena \& Sutz, 2005; Arza, 2010; Comisión Económica para América Latina y el Caribe [CEPAL], 2010). En efecto, la escasez de inversión es un factor común en la historia de América Latina.

Una de las estrategias para salir del marasmo es reconsiderar la relevancia de las empresas paraestatales, las cuales podrían impulsar los avances tecnocientíficos en los sectores estratégicos, aprovechando los recursos y capacidades de aprendizaje y conocimiento que se tienen, proyectando la consolidación de las que ya operan y la construcción de otras que sean el vehículo para alcanzar claras ventajas competitivas. Por ejemplo, que cada firma tenga un alto número de científicos-tecnólogos en relación con el total de empleados (una mayor intensidad laboral tecnocientífica), y como lo describe Cimoli (2008), refiriéndose al caso brasileño, que esas firmas paraestatales se acompañen de centros de investigación

El desarrollo entendido como un concepto multidimensional, pero cuya meta fundamental es el mejoramiento del bienestar en el sentido amplio. 
tecnocientífica, extiendan el conocimiento al resto de las empresas y organizaciones, y simultáneamente integren un fondo de capital semilla para los emprendimientos tecnocientíficos emergentes. También podrían ensayarse otros esquemas como la participación privada nacional y extranjera con mayoría de capital del Estado-gobierno. Otros autores como Velázquez (2015) señalan que fomentar empresas tecnocientíficas paraestatales multinacionales podría ser una vía interesante.

Otros mecanismos, mediante los cuales el gobierno puede contribuir a intensificar la cooperación de las OPC con las empresas, son:

a. Fomentándola directamente a través de las políticas, por ejemplo, esquemas de estímulos fiscales y convocatorias para proyectos y actividades colaborativas.

b. Diseñando y estableciendo regulaciones que demanden esfuerzos de investigación avanzada y especializada, que puedan ofrecer las universidades y los centros públicos de investigación.

c. Contratando directamente servicios de investigación avanzada donde estén convocados ambos actores. De manera de que si no hay concurrencia no se establecen los contratos.

Aunque a nivel nacional se han realizado varios estudios sobre el impacto de las OPC en el desarrollo económico y social regional (Casas, 2001; De Fuentes \& Dutrénit, 2012, 2014; García-Galván, 2013), también se han hecho esfuerzos por dar cuenta de la manera en que estas despliegan sus estrategias para cooperar más estrechamente con los actores del entorno regional (Villasana, 2011; Torres \& Jasso, 2019). Además, otras investigaciones trascienden los ámbitos de las entidades federativas, y se lanzan al análisis de vastas regiones como la frontera norte de México (López-Leyva, 2002; Bajo, 2006).

\section{Situación en el noroeste de México (Baja California)}

Los casos más relevantes para esta obra son los que se refieren a la región noroeste de México (Baja California, Baja California Sur, Sonora y Sinaloa), cuyas aproximaciones pueden encontrarse en López-Leyva (2002) y Bajo (2006), ambos estudios obtienen como parte de sus resultados y conclusiones que una de las entidades donde más ha avanzado la cooperación de las OPC con su entorno regional es Baja California.

Son varios los elementos que posicionan a Baja California como la entidad federativa que se encuentra a la vanguardia en la región noroeste del país:

- Las OPC de mayor prestigio en el noroeste se encuentran en esta entidad (López-Leyva, 2002; Bajo, 2006). Dos de las instituciones emblemáticas son la Universidad Autónoma de Baja California (UABC), considerada la máxima casa de estudios de la entidad; y el Centro de Investigación Científica y de Educación Superior de Ensenada (CICESE), considerado como uno de los primeros y más importantes centros públicos de investigación del Consejo Nacional de Ciencia y Tecnología en México. 
- La ciudad y puerto de Ensenada, es una de las localidades del país con el mayor número de científicos y tecnólogos (miembros del Sistema Nacional de Investigadores, SNI) per cápita, con una producción de conocimiento reconocida a nivel nacional e internacional por su calidad y rigor académico (Cabrera et al., 2017).

- La ubicación geoestratégica de Baja California, con ciudades industriales prometedoras y con mucho potencial como Tijuana y Mexicali, es un recurso que se constituye como parte de las ventajas comparativas y competitivas de esta entidad. Estas características se ven potenciadas por el avance en procesos de innovación del estado de California (Estados Unidos), concretamente en la ciudad de San Diego, que en la transfrontera se une con Tijuana. De esta manera, para algunos autores (Cabrera et al., 2017; López, \& Serrano, 2017) se va consolidando una macrorregión transnacional muy propicia para la innovación tecnológica, denominada como la región Cali-Baja donde el papel de las OPC mexicanas será de gran relevancia.

- Además, por su ubicación geoestratégica, cuenta con una interesante combinación de ventajas económicas (absolutas, comparativas y competitivas); su enorme riqueza terrestre y marítima - de manera casi natural-, la convierten en un polo de atracción para la inversión en rubros tan disímiles como el turismo nacional e internacional, la agroindustria, la industria manufacturera de alta tecnología y el turismo médico. Adicionalmente, el Consejo Nacional de Ciencia y Tecnología (Conacyt, 2015) señala que esta entidad federativa posee un enorme potencial para el desarrollo de tecnologías alternativas para la generación de energía, la investigación e innovación biotecnológica y la industria aeroespacial.

En años recientes se han realizado diversas investigaciones enfocadas en la interacción de los centros de investigación y de las universidades con actores del entorno regional (empresas, organizaciones sociales y comunitarias, así como entes gubernamentales). Por su parte, Alcántar et al. (2006) analizan los mecanismos y estrategias por medio de los cuales la $\cup A B C$ colabora y se posiciona con los diversos sectores y actores sociales regionales; Celaya y Barajas (2012) estudian las modalidades y la intensidad de interacción de las organizaciones del conocimiento con los actores del entorno; García-Galván (2018) y García-Galván et al. (2018) analizan la dinámica y las modalidades mediante las cuales los investigadores de la $U A B C$ interaccionan con el sector productivo principalmente, pero también con los actores comunitarios y las organizaciones sociales; en esta última línea se ubica el trabajo de Lindquist (2018). Asimismo, Morales (2019) estudia la cooperación mediada por el conocimiento entre las organizaciones del conocimiento de Baja California y el sector productivo. Cabe destacar que las dos últimas investigaciones mencionadas tienen como unidades de análisis a los académicos miembros del SNI, lo que garantiza que los vínculos intersectoriales sean determinados por el conocimiento tecnocientífico generado por las OC de Baja California. 


\section{Tabla 2 \\ Importancia y regulación de la propiedad intelectual en la $\cup A B C$}

Cada vez es más notoria la necesidad de una actualización (adaptación) institucional y organizacional de las OPC, que esté en sintonía con los nuevos requerimientos sociales y productivos. En este sentido, los planes de estudio tienen que ser compatibles con la necesidad de incorporar temas relevantes como la propiedad intelectual e industrial, la innovación y el emprendimiento, así como las políticas educativas relacionadas con estos temas. Los planes de estudio tienen que responder plenamente a las necesidades de la sociedad. Por lo tanto, se requiere una actualización y reestructuración organizacional (por ejemplo, una mayor centralización de la vinculación y de la transferencia de los resultados de investigación), acorde con las reformas legislativas universitarias y con las propias necesidades de los universitarios.

Las OPC en la consolidación de la tercera función sustantiva tienen que asumir un rol importante en la promoción del desarrollo económico y social, así como del crecimiento. Además, en el marco de la economía y sociedad basadas en el conocimiento, las organizaciones del conocimiento deben ser los principales actores que propicien la competitividad de la región.

Existe escasez de personal especializado en gestión de la propiedad intelectual. También, hace falta capacitación y actualizaciones de quienes ya trabajan en esos ámbitos. Esto se refleja en una falta de claridad en cuanto a la necesidad, según las circunstancias, de solicitar el registro de una obra (por ejemplo, para el desarrollo de software) o una patente*. Hasta ahora, los esfuerzos han sido incipientes, a pesar de que la propiedad intelectual e industrial, así como la imagen institucional, cada vez se consolidan más como parte de la reputación institucional-organizacional. Sin embargo, hay evidencias claras de que la UABC puede aprovechar muchas oportunidades y potencialidades que tiene para consolidar su stock de propiedad intelectual.

Hay grandes áreas de oportunidad para impulsar la innovación en productos y procesos más amigables con el medio ambiente. Algunos de los casos más notorios son las lámparas LED y el reciclaje de materiales como el unicel, los cuales se consideran casos de éxito de innovaciones estudiantiles.

El desarrollo tecnológico no llega al registro de la propiedad industrial o intelectual, que para cerrar el ciclo tendría que llegar hasta una auténtica aplicación y comercialización, de lo contrario, el proceso queda trunco. Así, pese a que en las ferias de emprendimiento e innovación se registra gran presencia y riqueza en las presentaciones, aunque algunos proyectos sean muy buenos, no se les da un seguimiento profesional, y por lo mismo, se puede incurrir en plagio. Adicional a esto, en las actividades inventivas e innovativas de las OPC, se tiene que considerar el registro de modelos de utilidad, diseños industriales y otras modalidades, ya que al contemplar únicamente el registro de patentes se da un excesivo reduccionismo.

Se requiere un uso más estratégico y efectivo de las Tecnologías de la Información y la Comunicación (TIC) para la gestión de la propiedad intelectual, por ejemplo, oficinas virtuales y simulación de procesos; así como para promover las potencialidades tecnocientíficas (productos, servicios) de la UABC. Adicionalmente, al margen del activismo para la promoción de la propiedad intelectual y de una vinculación más estrecha de la universidad con su entorno, se tiene que trabajar en mejorar tanto las relaciones interpersonales como las prácticas comunicativas entre todos los actores.

Finalmente, no se encuentra una forma sencilla de proteger las ideas y los hallazgos cuando no son susceptibles de registro a través de una patente o cualquier otro tipo de protección de la propiedad industrial, o cuando no se delimitan claramente los derechos de autor. Por ejemplo, los resultados de proyectos de licenciatura, maestría y doctorado. La protección mediante cláusulas específicas en los convenios de colaboración puede ser una idea poco conveniente, pero no se encuentran salidas fáciles. Adicionalmente, la cultura de la protección intelectual e industrial es deficiente en México, lo cual puede observarse en el bajo número de solicitudes y titularidades de patentes en relación con otros países.

Nota: * Aunque se reconoce que hay un conflicto insalvable entre la necesidad de la pronta difusión-divulgación de los resultados de la investigación y la necesidad de mantenerlos reservados cuando hay la intención de gestionar. Elaboración propia con base en Buenrostro (2017). 
Otras investigaciones recientes que han tenido como punto de interés las interacciones o contribuciones de las organizaciones del conocimiento al desarrollo económico y social son aquellas realizadas por Buenrostro (2017), Cabrera et al. (2017), y López y Serrano (2017).

Buenrostro (2017) coordinó una extensa obra sobre la importancia de la propiedad intelectual y su regulación en la universidad pública mexicana en su relación con el sector productivo del entorno, teniendo como centro de análisis a la UABC, los puntos más relevantes se rescatan en la tabla 2.

Como complemento de estos resultados, las contribuciones que se presentan en este texto tienen como propósito general ensanchar las fronteras del conocimiento regional sobre la cooperación de las OPC con los diversos actores y sectores del entorno regional; asimismo, pretenden aportar evidencias empíricas adicionales sobre las modalidades de interacción y la intensidad con la que se dan las mismas.

\section{Las organizaciones públicas del conocimiento frente al contexto socioeconómico regional}

Aunque históricamente las OPC siempre han estado conectadas de manera indirecta a los diversos y complejos problemas que padecen los principales actores locales y regionales que las circundan, en los últimos años, se ha hecho más importante su participación deliberativa e interactiva para la solución de los problemas en el ámbito productivo, gubernamental y de la sociedad organizada o la vida comunitaria. Por ello, es importante dar una mirada general a las principales problemáticas en cada uno de los ámbitos mencionados.

México viene arrastrando viejos problemas estructurales en el ámbito productivo. Desde la década de 1980 se registra un estancamiento secular en el crecimiento económico, con una tasa promedio anual aproximada del $2 \%$, en un lapso que alcanza ya casi los 40 años; considerando que, si se descontara el crecimiento poblacional y se agregara la excesiva concentración del ingreso y la riqueza, el crecimiento del ingreso per cápita sería ínfimo o cercano a cero. De este modo, el estancamiento económico generalizado ha impactado severamente en las actividades agrícolas e industriales; por ejemplo, el país es importador neto y creciente de granos básicos y de lácteos; sumado a esto, la mayor pobreza, precarización y disparidades se encuentran en las zonas rurales, en las cuales puede coexistir la agroindustria de alta tecnología con prácticas productivas consideradas como de traspatio y de subsistencia. Además, el cambio climático y el calentamiento global están causando verdaderos estragos en los ciclos productivos agrícolas.

Respecto a las actividades industriales, desde esa misma década, el país abandonó el modelo de industrialización por sustitución de importaciones, en el cual se tenía el objetivo de llegar hasta la sustitución de bienes más elaborados y de mayor intensidad tecnológica (pasando por la sustitución de importaciones de mercancías básicas y necesarias, así como de insumos intermedios). Pero después de la crisis de la deuda externa, pareció que 
las élites gobernantes y empresariales de México no querían saber nada más de la emancipación industrial, y la política económica nacional recibió con los brazos abiertos los preceptos del Consenso de Washington². En los gobiernos de Miguel de la Madrid Hurtado, Carlos Salinas de Gortari y de Ernesto Zedillo Ponce de León se privatizaron una gran cantidad de empresas paraestatales en los diferentes giros económicos; de manera que se pasó de desincorporar empresas no prioritarias, según el gobierno, a privatizar empresas que en su momento fueron consideradas estratégicas para el desarrollo nacional, como las relacionadas con la petroquímica secundaria y las telecomunicaciones. Se suponía que la privatización de empresas tenía el objetivo de volver competitiva y eficiente la estructura productiva, y ensanchar la frontera de posibilidades de la producción industrial. Sin embargo, sucedió todo lo contrario, pues de monopolios públicos se pasó a monopolios privados, y el cambio de propiedad de las paraestatales significó la expulsión de más de un millón de empleados tan solo en las primeras fases del nuevo modelo, y una proporción importante de esos nuevos desempleados terminaron irremediablemente engrosando el sector informal de la economía. Y, cuando la política económica de un país lejos de contener o reducir la informalidad económica la hace crecer, evidentemente se trata de un fracaso colosal.

En un estudio desarrollado por Palma (2019), con una muestra de más de 100 países entre ellos México-, se demostró que, desde la década de 1970, se ha registrado una desindustrialización, la cual puede considerarse como parte de la evolución del sistema capitalista, cuando los países altamente industrializados han alcanzado una elevada productividad en el sector industrial derivado de la subcontratación de una parte de los procesos productivos, o por la división internacional del trabajo, en la que los países avanzados tecnológicamente han desplazado buena parte de la industria manufacturera tradicional, o a la industria maquiladora intensiva en mano de obra a los países de ingresos medios como México.

Palma (2019) también hizo hincapié en que la desindustrialización puede darse a través de medidas deliberadas dirigidas a debilitar las estructuras industriales; estas medidas no son exclusivas de los países menos desarrollados, ya que algunos de los altamente industrializados han experimentado el síndrome holandés', como los Países Bajos y el Reino Unido. También se puede interrumpir abruptamente la trayectoria industrializadora adoptando una serie de medidas de política económica, que de manera deliberada buscan la desindustrialización; esto es precisamente lo que pasó en la mayor parte de América Latina, particularmente, en México durante los años 1980 y 1990. Este último país registró la enfermedad holandesa en dos frentes: uno por el descubrimiento de grandes yacimientos de petróleo a finales de la década de 1970, y el otro por el cambio de modelo económico. Ambos frentes influyeron fuertemente en la desindustrialización prematura.

2 Para profundizar en las implicaciones de este Consenso, se sugiere revisar el trabajo de Martínez y Soto (2012).

Entendido como el efecto que se genera cuando los países dan un giro abrupto a una actividad económica en la que se obtienen altos ingresos; por ejemplo, aumento de los precios de las materias primas o el desarrollo deliberado de actividades del sector servicios. 
Con el cambio de modelo económico y la apertura general de la economía mexicana, incluyendo la firma del Tratado de Libre Comercio de América del Norte (renegociado ahora como Tratado México, Estados Unidos y Canadá), aparentemente el país había entrado en una nueva fase de industrialización basada en las exportaciones, incluso de alta y media tecnología. Sin embargo, casi todo lo relacionado a esa aparente reindustrialización no ha significado otra cosa más que un efecto ilusión, pues la mayor parte de las firmas industriales establecidas en México son manufactureras ensambladoras, en cuyos productos finales se incorporan hasta más de $70 \%$ de insumos importados; o empresas maquiladoras, muy intensivas en mano de obra sin registrar mayores derramas tecnológicas en el sistema económico.

La ubicación geoestratégica de México y la firma de tratados de libre comercio influyen categóricamente para que las empresas decidan instalarse en México (Palma, 2019). Pero, dónde queda la transferencia de tecnología, dónde están los encadenamientos productivos hacia atrás y hacia adelante, dónde están los efectos multiplicadores de las actividades industriales; es evidente que esto no ha sucedido, o en el mejor de los casos las derramas han sido muy escasas. Esto se ha reflejado directamente en el crecimiento mediocre que México ha registrado por un periodo de casi 40 años.

La pérdida del peso relativo de la industria en la actividad económica global ha implicado un mayor dinamismo y crecimiento de las actividades clasificadas en el sector servicios. Dentro de estos, ha sido muy marcado en México la expansión del turismo, los servicios bancario-financieros y algunos relacionados con ciertas modalidades de transporte y comunicaciones. De la misma manera que sucedió con muchas de las firmas industriales, varias de las empresas de transportes y comunicaciones fueron privatizadas, sin que esto significara servicios más eficientes y competitivos. Pues, en general, el gran problema que tiene el país respecto a la prestación de servicios es que son ineficientes e implican altos costos. Por un lado, los servicios públicos (salud, educación, transporte, infraestructura y equipamiento de ciudades) son deficientes e inequitativos; y los servicios del sector privado, normalmente implican precios altos y la calidad no es necesariamente buena; por ejemplo, los servicios de telefonía con tarifas muy altas y un servicio deficiente.

Además de las actividades productivas directas, todas las relacionadas con las actividades gubernamentales, como los servicios públicos han recibido poca atención de las OPC, salvo las que están muy relacionadas con ese ámbito. Sin embargo, la administración y gestión de los servicios públicos requiere profesionalización, especialización y capacitación, así como una modernización integral a gran escala, pues hasta ahora los gobernantes han privilegiado la oferta de servicios sin preocuparse por cumplir un estándar de calidad. En referencia a los niveles gubernamentales, el ente que requiere mayor atención es sin duda el municipal, pues en general se carece de una profesionalización en la administración pública que permita ofrecer a la población servicios adecuados. Lamentablemente, las OPC hacen 
eco de las políticas y los preceptos de los diferentes niveles gubernamentales y no viceversa, lo cual sería muy importante. Por lo tanto, como parte de la reivindicación universitaria, las OPC tienen que ir de la mano con la modernización de la administración pública, principalmente la municipal.

En general, las OPC han reservado su atención - a veces obsesiva- al sector empresarial, dejando a un lado a sectores y grupos sociales considerados como muy vulnerables. Más allá del servicio social y de algunos proyectos aislados, no se observa una preocupación genuina por los problemas sociales que demandan una atención prioritaria. Las propias universidades no pueden garantizar equidad y justicia en el acceso a los estudios profesionales, por lo que grandes grupos poblacionales precarizados (como campesinos, indígenas, obreros y trabajadores informales) o con discapacidad siguen padeciendo la exclusión. Como se ha documentado en algunos trabajos (García-Galván, 2018; Lindquist, 2018), cuando las universidades dan cuenta de los convenios o acuerdos de colaboración con actores externos, resulta que los suscritos con las organizaciones sociales y comunitarias se encuentran en los últimos lugares. En consecuencia, las OPC tienen que innovar en la forma en la que se relacionan con la sociedad, pues de no hacerlo es previsible que sigan perdiendo hegemonía y legitimidad social como lo ha señalado De Sousa (2017).

Para lograr un mayor impacto en el entorno regional, las OPC tienen tareas impostergables, como buscar nuevos mecanismos y estrategias en pro de la reindustrialización de las regiones y del país que, junto con la prestación de servicios, dé mayor valor agregado y calidad, lo cual representaría una gran contribución para dejar atrás cuatro décadas de estancamiento económico y social.

Con el desarrollo de los distintos campos del conocimiento, las OPC pueden dar en diferentes flancos, incluyendo a las actividades del sector primario y a la vasta lista de servicios públicos que requieren un mejoramiento sustancial. Pero quizá el actor que requiere una mayor urgencia en la atención es el representado por los grupos sociales más vulnerables y desfavorecidos, es con ellos que las funciones y actividades universitarias podrían redimensionar su gran valor estratégico.

Una reivindicación universitaria a gran escala requiere la revisión e intensificación de sus actividades colaborativas con el sector productivo — desde la atención a las actividades agrícolas hasta las ramas económicas que integran los servicios-, con los entes gubernamentales y con los actores sociales y comunitarios más necesitados.

\section{Conclusiones}

En este capítulo se hizo un esfuerzo por destacar los rasgos principales de la cooperación de las OPC con su entorno regional, enfocada en las actividades de actores productivos, entes gubernamentales y organizaciones sociales-comunitarias. 
Desde hace varios años, este fenómeno de interacción ha sido estudiado a profundidad; no obstante, hay aspectos que requieren refinarse o ampliarse, ya sea en el ámbito teóricoepistémico, o en los esfuerzos por recolectar más y mejores evidencias empíricas, que se conviertan en insumos básicos para los tomadores de decisiones. Al respecto, se hizo evidente la necesidad de contextualizar la cooperación de las OPC latinoamericanas, pues hasta el momento, la persuasión para intensificar los nexos con el entorno regional se ha sesgado hacia el lado empresarial, sin embargo, también se requiere considerar las problemáticas de los grupos sociales más vulnerables y menos favorecidos, así como redimensionar la cooperación con el gobierno.

Las diferentes ramas y actividades económicas requieren atención, pero se tienen que superar las nociones y visiones convencionales que suceden en las propias universidades; en este texto, se ha enfocado la atención en la urgente necesidad de reindustrializar las regiones y el país, pues son las actividades industriales las que pueden generar las mayores derramas y encadenamiento con el resto de las actividades económicas; aunque por su rol estratégico tampoco deben descuidarse las actividades primarias y las relacionadas con los servicios. Sin embargo, una mayor intensificación de la cooperación de las OPC con las empresas debe implicar transferencia, investigación y desarrollo, así como innovación tecnológica, de lo contrario no se superará el estatus de economía manufacturera ensambladora y maquiladora.

Por su parte, los nexos cooperativos con el gobierno, en sus diferentes niveles y dimensiones, tienen que revalorarse, pues la sociedad mexicana demanda servicios públicos de mayor calidad y eficiencia. En este sentido, la necesidad de actualización y modernización es más apremiante en la administración pública local (municipal), donde las OPC pueden hacer grandes contribuciones y traducirse en amplias posibilidades para que estas organizaciones afiancen y estrechen sus vínculos.

También es de suma importancia responder a las diversas problemáticas de la sociedad; pues en esta última se ubica la ontología de la universidad y de los centros de investigación; y, por lo tanto, para una mayor hegemonía y legitimidad de las OPC deben atender las necesidades de quienes dan sustento a la misma universidad. Las OPC en México ya no pueden retraerse de estudiar $y$ atender los principales problemas sociales y comunitarios.

Por último, la agenda de investigación en el ámbito empírico requiere llevar a cabo diagnósticos más documentados y apegados a la realidad, al tiempo de buscar y ampliar las evidencias sobre el estado y la prospectiva de la cooperación de las OPC con su entorno regional. Todo ello con la finalidad de tomar mejores decisiones basadas en evidencias y en argumentos más contundentes. 


\section{Referencias}

Alcántar, V., Arcos, J., \& Mungaray, A. (2006). Vinculación y posicionamiento de la Universidad Autónoma de Baja California con su entorno social y productivo. Universidad Autónoma de Baja California.

Arocena, R., \& Sutz, J. (2005). Latin American Universities: from an original revolution to an uncertain transition. Higher Education, 50(4), 613-630.

Arza, V. (2010). Channels, benefits and risks of public-private interactions for knowledge transfer: conceptual framework inspired by Latin America. Science and Public Policy, $37(7), 473-484$.

Bajo, A. (2006). Vinculación e innovación en la región noroeste de México. Universidad Autónoma de Sinaloa.

Buenrostro, A.F. (Coord.). (2017). Propiedad intelectual: su regulación en la universidad pública mexicana. Universidad Autónoma de Baja California.

Cabrera, M.R., López-Leyva, S., \& Serrano, A. (2017). Relevancia, pertinencia y socialización del conocimiento, ¿cómo contribuyen los investigadores a la innovación de Ensenada, México? Investigaciones Regionales-Journal of Regional Research, (37), 31-53.

Casas, R. (2001). La formación de redes de conocimiento. Una perspectiva regional desde México. Instituto de Investigaciones Sociales de la UNAM.

Celaya, M., \& Barajas, M. (2012). La academia y el sector productivo en Baja California. Los actores y su capacidad de vinculación para la producción, difusión y transferencia del conocimiento y la innovación. Región y Sociedad, (55), 41-80.

Cimoli, M. (2008). Las políticas tecnológicas en América Latina: una revisión crítica. En G. Valenti (Coord.), Ciencia, tecnología e innovación. Hacia una agenda de política pública (pp. 57-92). Facultad Latinoamericana de Ciencias Sociales.

Comisión Económica para América Latina y el Caribe. (CEPAL). (2010). Espacios iberoamericanos: vínculos entre universidades y empresas para el desarrollo tecnológico. CEPAL. $\quad$ https://www.cepal.org/es/publicaciones/1417-espacios-iberoamericanosvinculos-universidades-empresas-desarrollo-tecnologico

Consejo Nacional de Ciencia y Tecnología (Conacyt). (2015). Agenda de innovación de Baja California. Resumen ejecutivo. http://www.agendasinnovacion.org/wp-content/ uploads/2015/01/Agenda-Baja-California.pdf

De Fuentes, C., \& Dutrénit, G. (2012). Best channels of academia-industry interaction for long-term benefit. Research Policy, 41(9), 1666-1682.

De Fuentes, C., \& Dutrénit, G. (2014). Geographic proximity and university-industry interaction: the case of Mexico. The Journal ofTechnology Transfer, 41(2), 329-348.

DeSousa, B. (2017). La universidad en el sigloXXI. Para una reforma democrática yemancipatoria de la Universidad. Siglo XXI editores. 
Etzkowitz, H., Webster, A., Gebhardt, C., \& Terra, B.R.C. (2000). The future of the university and the university of the future: Evolution of ivory tower to entrepreneurial paradigm. Research Policy, 29(2), 313-330.

Etzkowitz, H. (2003). Researh grupos as "quasi-firms": the invention of entrepeneurial university. Research Policy, 32, 109-121.

García-Galván, R. (2013). ¿El conocimiento universitario puede promover el desarrollo industrial? Percepción sobre las promesas de la biotecnología en México. En E. Gaona, \& D. Velázquez (Coords.), Conocimiento para el crecimiento económico (pp. 87-103). Universidad Autónoma del Estado de Hidalgo.

García-Galván, R. (2014). Desempeño económico y factores que se encuentran detrás del rezago tecnocientífico en México. Cofactor. Revista del Consejo de Investigación y Evaluación de la Política Social, (9), 111-146.

García-Galván, R. (2015). Cinco factores que inhiben la colaboración tecnológica universidadempresa en los países en desarrollo. Tiempo Económico, 29(10), 67-80.

García-Galván, R. (2017). Cooperación tecnológica, innovación y competitividad: una perspectiva teórica institucional. Análisis Económico, 32(79), 177-199.

García-Galván, R. (2018). Cooperación tecnocientífica universidad-empresa e interfirma: Análisis teórico integrado desde la perspectiva de la economía institucional contemporánea. Ciencia y Universidad. Revista de economía, (37), 5-30.

García-Galván, R., Cabrera, M.R., \& McAnally, L.S. (2018). La colaboración tecnocientífica de la universidad con su entorno en México: El Caso de la Universidad Autónoma de Baja California. Archivos Analíticos de Políticas Educativas, 26(140), 1-32.

Gibbons, M., Limoges, C., Nowotny, H., Schwartzman, S., Scott, P., \& Trow, M. (1997). La nueva producción de conocimiento. Ediciones Pomares-Corredor.

Gibbons, M. (1999). Science's new social contract with society. Nature, (402), C81-C84. https://doi.org/10.1038/35011576

Hessels, L.K., \& van Lente, H. (2008). Re-thinking new knowledge production: A literature review and a research agenda. Research Policy, 37, 740-760. https://doi.org/10.1016/j. respol.2008.01.008

Lindquist, R. (2018). La colaboración mediada por el conocimiento entre la UABC y el Tercer Sector (Tesis de licenciatura). Universidad Autónoma de Baja California, México.

Llomovatte, S., Juarros, F., Naidorf, J., \& Guelman, A. (2006). La vinculación universidadempresa: miradas críticas desde la universidad pública. Laboratorio de Políticas Públicas/ Miño y Dávila.

López-Leyva, S. (2002). La vinculación y los investigadores. Perfiles Educativos, 24(97-98), 76-95. 
López, C.G., \& Serrano, A. (2017). Hacia el surgimiento de una cultura de la innovación en un centro público de investigación en México: Hallazgos y aprendizajes. Revista Electrónica Nova Scientia, 9(9), 313-341.

Martínez, R., \& Soto, E. (2012). El Consenso de Washington: la instauración de las políticas neoliberales en América Latina. Política y Cultura, 37, 35-64.

Mowery, D.C., \& Sampat, B.N. (2004). The Bayh-Dole Act of 1980 and university-industry technology transfer: A model for other OECD governments? Journal of Technology Transfer, 30(1-2), 115-127.

Morales, M. (2019). Cooperación tecnocientífica IES-sector productivo desde la perspectiva del cambio institucional. Evidencias de Baja California (Tesis Doctoral). Universidad Autónoma de Baja California, México.

Naidorf, J. (2014). Knowledge Utility: From Social Relevance to Knowledge Mobilization. Education Policy Analysis Archives, 22(89), 1-31. https://doi.org/10.14507/epaa. v22n89.2014

Palma, J.G. (2019). Desindustrialización, desindustrialización "prematura" y "síndrome holandés." El Trimestre Económico, 86(344), 901-966.

Riquelme, G. (Ed.). (2008). Las universidades frente a las demandas sociales y productivas. Capacidades de los grupos de docencia e investigación en la producción y circulación de conocimiento. Miño y Dávila Editores.

Torres, A., \& Jasso, J. (2019). Capabilities and knowledge transfer: Evidence from a university research center in the health area in Mexico. Contaduría y Administración, 64(1), 1-16.

Vázquez, J.C. (2015). El papel de los sectores público y privado mexicanos en el financiamiento de la investigación científica y tecnológica. En E. Rodríguez \& R. García (Coords.), El desastre económico mexicano, 1982-2011 (pp. 275-309). Universidad Autónoma del Estado de Hidalgo.

Velázquez, D. (2015). El modelo neoliberal y su efecto en el crecimiento: el caso de la economía mexicana.EnE.Rodríguez \&R.García-Galván(Coords.), Eldesastreeconómico mexicano, 1982-2011 (pp. 27-61). Universidad Autónoma del Estado de Hidalgo.

Villasana, M. (2011). Fostering university-industry interactions under a triple helix model: the case of Nuevo Leon, Mexico. Science and Public Policy, 38(1), 43-53. 


\title{
Capítulo 2
}

\section{Percepción de los investigadores de Baja California sobre la cooperación tecnocientífica en las instituciones de educación superior}

\author{
Marcela Morales Páez y Juan Carlos Rodríguez Macías
}

Desde hace seis décadas, existe una iniciativa mundial para intensificar la relación entre las instituciones de educación superior (IES) ${ }^{1}$ y el sector productivo (SP); esta intención es alimentada por factores tanto endógenos como exógenos a las IES. En el caso particular de México, el fomento del estrechamiento de la interacción IES-SP comenzó a intensificarse a partir de la década de 1990.

En Baja California, México, las IES que destacan en la producción de conocimiento son (a) los centros públicos de investigación, dependientes del Consejo Nacional de Ciencia y Tecnología (Conacyt): Centro de Investigación Científica y de Educación Superior de Ensenada (CICESE), Centro de investigación y Desarrollo Tecnológico en Electroquímica (CIDETEQ), Colegio de la Frontera Norte (COLEF); (b) los institutos de investigación integrados en la estructura organizacional de las instituciones públicas nacionales: Centro de Nanociencias y Nanotecnología (CNyN-UNAM), Instituto de Astronomía de la Universidad Nacional Autónoma de México (IA-UNAM), Centro de Investigación y Desarrollo de Tecnología Digital (CITEDI-IPN); (c) la universidad e instituto tecnológico estatales: Universidad Autónoma de Baja California (UABC), Instituto Tecnológico de Tijuana (ITT); y (d) la universidad privada de mayor renombre en el estado: Centro de Enseñanza Técnica y Superior (CETYS). Como se puede apreciar el potencial que tienen las IES de Baja California para la generación de conocimiento es muy amplio, en comparación con otras entidades de la república mexicana.

Por otro lado, conocer las distintas vocaciones de cada región permite tener una idea de las fortalezas del sector productivo por municipio (vocaciones consolidadas), así como las áreas de oportunidad a mediano plazo (vocaciones por promover) en las cuales pudieran incidir las IES estatales para coadyuvar en el desarrollo de estos sectores. Un aspecto también importante son las vocaciones por incubar, ya que implica trabajar en la generación

En el presente capítulo el uso del término instituciones de educación superior (IES) incluye tanto a universidades (enfocadas primordialmente a la formación de recursos humanos de nivel licenciatura) como a centros de investigación (enfocados en la generación y aplicación de conocimientos, además de la formación de recursos humanos a nivel posgrado). 
de empresas desde el SP, pero también desde el ámbito académico (a través de spin-offs y start-ups). A continuación, se presentan los principales municipios de Baja California, con sus vocaciones respectivas.

Las vocaciones consolidadas del municipio de Mexicali incluyen los sectores industriales de manufactura metalmecánica, de aparatos eléctricos, automotriz y de plásticos; en tanto, las vocaciones por promover son la aeroespacial y la agricultura; por último, las vocaciones por incubar se enfocan en las industrias de electrónicos especializados, microelectrónica y fuentes de energía. En el caso de Tijuana, la manufactura de aparatos eléctricos es la principal vocación consolidada; las vocaciones por promover incluyen la tecnología de la información, así como la industria automotriz y la de productos médicos; mientras la vocación por incubar es la manufactura de autos de lujo. En el caso de Ensenada corresponde el turismo como vocación consolidada; en tanto, la acuicultura, la pesca y la industria vitivinícola se presentan como vocaciones por promover; finalmente, las vocaciones por incubar incluyen la tecnología de la información, la biotecnología y la agroindustria (Gobierno de la República-Consejo Nacional de Ciencia y Tecnología, 2015).

Con base en lo expuesto anteriormente, el objetivo del presente capítulo es dar a conocer algunos hallazgos acerca de la percepción de los profesores-investigadores sobre la cooperación tecnocientífica entre las IES y el sector productivo de Baja California.

\section{Marco teórico}

Con el propósito de profundizar en el análisis teórico-conceptual sobre la cooperación IESSP, a continuación, se presentan las aportaciones de algunos representantes del Institucionalismo Contemporáneo Integrado a las nociones de cooperación entre empresas y cooperación tecnocientífica.

De acuerdo con Teece et al. (1997), la postura estratégica de una empresa es determinada no solo por sus procesos de aprendizaje y por la coherencia entre los procesos internos y externos con los incentivos, sino también por sus activos específicos; estos últimos determinan su ventaja competitiva en cualquier punto del tiempo. Los autores identificaron diferentes clases de activos, los cuales son determinantes para establecer relaciones de competencia o cooperación. Dentro de estos, destacan los institucionales, que les dan sustento y son elementos críticos para sobresalir en el ambiente de los negocios; mientras que los sistemas regulatorios, así como los regímenes de propiedad intelectual y las leyes antimonopolio son parte del ambiente. Las empresas de distintos países y regiones pueden tener distintos activos institucionales debido a que sus marcos político-institucionales son muy diferentes.

A decir de González (2003), el interés por el estudio de la cooperación entre empresas comenzó a desarrollarse a finales del siglo XIX (a partir de la creación de la empresa conjunta) y principios del siglo XX (cuando se instauran nuevos modelos contractuales como la franquicia). El autor destacó que, tanto el incremento de la competencia a nivel mundial 
como la globalización de los mercados, ocasionaron un cambio en el tipo de relaciones que establecían las empresas, al pasar de la competencia a la cooperación. Por su parte, Taboada (2004) definió la cooperación interfirma (entre empresas) como:

el vínculo de colaboración que establecen empresas con la finalidad de alcanzar una meta basada en intereses comunes y expectativas mutuas. La relación involucra más que el intercambio de satisfactores disponibles en el mercado; no hay un control jerárquico completo por parte de alguna de ellas $y$, las mismas aceptan algún grado de obligación y, por lo tanto, ofrecen cierto grado de garantía con respecto a su conducta futura. (Taboada, 2004, p.88)

En lo que respecta a un acuerdo de cooperación, García-Galván (2011) lo define como un convenio de largo plazo entre dos o más empresas, el cual puede contemplar una remuneración financiera [o no], o incluir el pago de algún bien o servicio; también pueden acordar el intercambio de información y otros productos o servicios. El autor menciona que cuando varias empresas forman una alianza lo hacen con la intención de obtener mayores beneficios que los obtenidos sin cooperación.

A manera de síntesis, a continuación, se presentan las características de la cooperación empresarial establecidas por González (2003):

- Inexistencia de subordinación. Las empresas conservan la autonomía en actividades que no están incluidas en los acuerdos de cooperación.

- Coordinación de acciones futuras. Establecimiento de dependencia mutua a partir de los acuerdos (escritos o verbales) o compromisos asumidos por los socios.

- Consecución de un objetivo común. La actividad a la que se circunscribe el acuerdo debe beneficiar a todas las partes involucradas.

Esta cooperación no se limita a la alianza entre empresas, también puede hacerse entre empresas y organizaciones del conocimiento, por ejemplo, IES y centros públicos de investigación (Fernández-Sánchez, 1991; García-Galván, 2011). Según Fernández-Sánchez (1991), los acuerdos de cooperación también se pueden dar entre un grupo de investigadores y una empresa, los cuales son necesarios para incrementar la aplicación de las innovaciones tecnológicas al sector industrial; por medio de estos contratos la empresa generalmente consigue los derechos de una patente generada a partir de las actividades de investigación contratadas, y a cambio proporciona recursos económicos al grupo de investigadores para la realización de investigación básica, aplicada o de desarrollo experimental.

García-Galván (2011) definió la cooperación interorganizacional como un tipo de cooperación entre las empresas y otras organizaciones —universidades, centros públicos de investigación u organizaciones civiles-, con el propósito de desarrollar proyectos conjuntos 
de investigación que beneficien a todas las partes. Asimismo, señaló que las empresas establecen acuerdos de cooperación interorganizacionales cuando estiman que un mercado insuficiente de información es un obstáculo para la innovación, o cuando dichos acuerdos resultarán en recursos complementarios que les permitan funcionar en la frontera tecnológica. Además, algunas empresas pertenecientes a sectores de alta tecnología, o muy competidos, prefieren colaborar con las IES a hacerlo con otras empresas, para evitar vincularse con rivales que puedan ser un riesgo a su competitividad (García-Galván, 2017).

De acuerdo con García-Galván (2008), el fenómeno de la colaboración interempresarial e interinstitucional (interorganizacional) ha sido abordado desde dos posturas teóricas distintas, a saber: el análisis neoclásico de las externalidades, conocido como spillovers del conocimiento, y la Nueva Economía Institucional (NEI), la cual incluye categorías y variables no consideradas desde el otro enfoque.

La teoría de las externalidades tiene grandes aportaciones para el análisis de la colaboración empresa-universidad, entre estas se encuentran:

las propiedades económicas inherentes al conocimiento, la demostración de que la ciencia básica genera un mayor bienestar social, y que su desarrollo puede dar paso a un vector de nuevos productos y procesos, así como el problema de la "gorronería" de aquellos agentes que no invierten en investigación pero que sí se benefician de ella. (García-Galván, 2008, p.60)

No obstante, estas contribuciones sugieren que para las empresas no es muy rentable invertir en la producción de conocimiento. Por su parte, desde la perspectiva de la NEI, si las empresas desean explotar nuevos conocimientos requieren una enorme inversión en aprendizaje para alcanzar una capacidad de absorción que permita aprovecharlos (García-Galván, 2008). Al respecto, Cohen y Levinthal (1990) definen la capacidad de absorción de una empresa como la habilidad que posee para reconocer el valor de las innovaciones y de la información generada por su entorno, así como su asimilación y aplicación a fines comerciales.

Sin embargo, dado que la producción de conocimiento científico requiere grandes inversiones, al mismo tiempo que las empresas invierten en su aprendizaje, también se vinculan con instituciones (generalmente IES) para conocer, entender y explotar nuevos descubrimientos científicos (García-Galván, 2008). Dándose así, un vínculo entre IES y el sector productivo.

Podemos decir que el concepto de cooperación tecnocientífica incluye el conjunto de acciones y actividades de investigación básica y aplicada encaminadas a generar vínculos entre las IES y el sector productivo, a partir del reconocimiento de los procesos innovadores desde su origen hasta su comercialización. 
Este tipo de colaboración puede ser concebida como cooperación interinstitucional o interorganizacional, y deriva de los beneficios que pueden obtener ambas partes al complementar cada una sus capacidades. Asimismo, al darse esta cooperación entre instituciones cuyos objetivos —en principio—son distintos, también puede denominarse cooperación transversal.

\section{Estrategia metodológica}

El diseño de investigación utilizado en el estudio fue de métodos complementarios o metodología múltiple, que según Plano-Clark y Creswell (2008), es una combinación del enfoque explicativo secuencial con el enfoque concurrente; la recolección y análisis de los datos constó de dos fases: una correspondiente a los datos cuantitativos (a través de una encuesta) y otra enfocada en los datos cualitativos (a través de entrevistas semiestructuradas). Ambos tipos de datos se analizaron en conjunto con el propósito de encontrar puntos de convergencia entre las opiniones de los profesores-investigadores y los representantes empresariales.

Las técnicas de recolección de datos incluyeron: (a) revisión de documentos institucionales de las IES seleccionadas y estudios empíricos, (b) encuesta a profesores-investigadores miembros del Sistema Nacional de Investigadores (SNI) que laboran, tanto en nivel de licenciatura como en posgrado, y (c) entrevistas con representantes clave del sector productivo. En particular, para cumplir con el propósito de obtener los datos cuantitativos, se utilizó la técnica de la encuesta, la cual fue implementada a través de un cuestionario administrado en línea. El alcance de este estudio fue exploratorio-descriptivo.

\section{Participantes}

La decisión de conocer la percepción de los profesores-investigadores se sustentó en el hecho de que son los agentes de las IES directamente involucrados en las actividades de investigación y cooperación tecnocientífica con el sector productivo. En México, tanto los profesores-investigadores de las universidades como los de centros públicos de investigación (CPI) pueden acceder al reconocimiento e incentivos del SNI, como parte de las estrategias del Conacyt para el fomento de la investigación, la innovación y el desarrollo tecnológico. La elección de los participantes fue intencional, y se consideró solamente a los académicos que formaban parte del SNI a la fecha de la aplicación de la encuesta.

De los 841 profesores-investigadores listados en el padrón de beneficiarios del SNI para el año 2017 en Baja California, solo se enviaron correos a 817 (97.15\%) y pertenecían a las siguientes instituciones: CICESE, CIDETEO, COLEF, CNyN-UNAM, IA-UNAM, CITEDI-IPN, UABC, ITT, y CETYS. La invitación a responder el cuestionario se hizo de forma censal, es decir, se les envió un correo electrónico a todos los investigadores que aparecían en padrón de investigadores. La tasa de respuesta global fue de $23.77 \%$, en consecuencia, los análisis se realizaron con base en las 184 respuestas recibidas. 


\section{Instrumentos}

El instrumento utilizado en la encuesta, denominado Cuestionario para medir la percepción de la cooperación tecnocientífica entre las IES y el sector productivo, incluyó 24 ítems: 16 de opción múltiple, 2 de respuesta construida y 6 escalas tipo Likert. En el cuestionario se incluyeron los ámbitos individual, organizacional e institucional. Al ámbito individual pertenecen las escalas relativas a los ítems 6, 7, 8 y 11; al organizacional corresponde la escala del ítem 18 , y al institucional, la del 21.

\section{Análisis de confiabilidad}

Para obtener evidencias de validez y confiabilidad del instrumento, se calculó el Alpha de Cronbach. Según los resultados, la confiabilidad de las escalas va de alta a muy alta (.655 a .910); en tanto, la confiabilidad general podría calificarse como muy alta (0.918). En consecuencia, dado el valor encontrado del coeficiente $\alpha$, puede decirse que las escalas tienen una consistencia aceptable, que permiten medir el constructo correspondiente (tabla 1).

\section{Tabla 1}

Resultados del análisis de confiabilidad mediante el Alpha de Cronbach

\begin{tabular}{clcc}
\hline Escala & \multicolumn{1}{c}{ Nombre de la escala } & Ítems de la escala & Alpha de Cronbach \\
\hline 6 & Componente cognitivo de la actitud hacia la CT-I & 4 & .712 \\
\hline 7 & Componente afectivo de la actitud hacia la CT & 8 & .856 \\
\hline 8 & Percepción sobre los apoyos institucionales hacia la CT & 3 & .867 \\
\hline 11 & Componente cognitivo de la actitud hacia la CT-II & 15 & .910 \\
\hline 18 & Percepción sobre la infraestructura y gestión de la CT & 7 & .655 \\
\hline 21 & Percepción del marco institucional de la CT & 9 & .684 \\
\hline & Total & 46 & .918 \\
\hline
\end{tabular}

Nota: $\mathrm{CT}$ = Cooperación tecnocientífica. Elaboración propia con base en los resultados de la encuesta a través del programa estadístico SPSS.

\section{Análisis y discusión}

En este apartado se exponen las características de los profesores-investigadores que respondieron la encuesta. Por último, se presentan las percepciones de los participantes acerca de las condiciones en las que se lleva a cabo la cooperación tecnocientífica IES-SP en Baja California.

\section{Características sociodemográficas y académicas de los participantes}

A continuación, se presenta la información a través de la cual se puede caracterizar la muestra de profesores-investigadores que dieron respuesta al cuestionario sobre la cooperación 
tecnocientífica. La recopilación se relaciona con los resultados de estudios en los cuales se encontró que algunos de los factores individuales explican la probabilidad de que los académicos se comprometan en interacciones con la industria.

Como parte de las características de los participantes se aprecia que, del total de los 184 profesores-investigadores encuestados, solamente el $28 \%$ son mujeres; tal dato es inferior al proporcionado por Conacyt, acerca de que el 37\% de los integrantes del SNI en 2018 fueron mujeres. Respecto a los rangos de edad de los participantes, destaca el hecho de que poco más de la mitad de ellos (51\%) tenía 45 años o menos, lo anterior pone de manifiesto la juventud de la planta académica de las IES más importantes de Baja California.

En relación con las características académicas de los participantes, en la figura 1 puede observarse que dos terceras partes (66\%) de los encuestados se concentran en una sola institución (UABC). Si comparamos tal dato con el porcentaje de profesores-investigadores de la $U A B C$ a los que se envió la invitación para participar en la encuesta, el cual es del 50.1\%, podría ser un indicio de una mayor predisposición de estos a responder, dado que el origen de la encuesta es la propia institución; o podría denotar una mayor apertura de dichos profesores-investigadores a la colaboración académica. Cabe destacar que no se recibió ninguna respuesta de los profesores-investigadores del Centro de Investigación y Desarrollo Tecnológico en Electroquímica (CIDETEQ).

\section{Figura 1}

Institución de adscripción

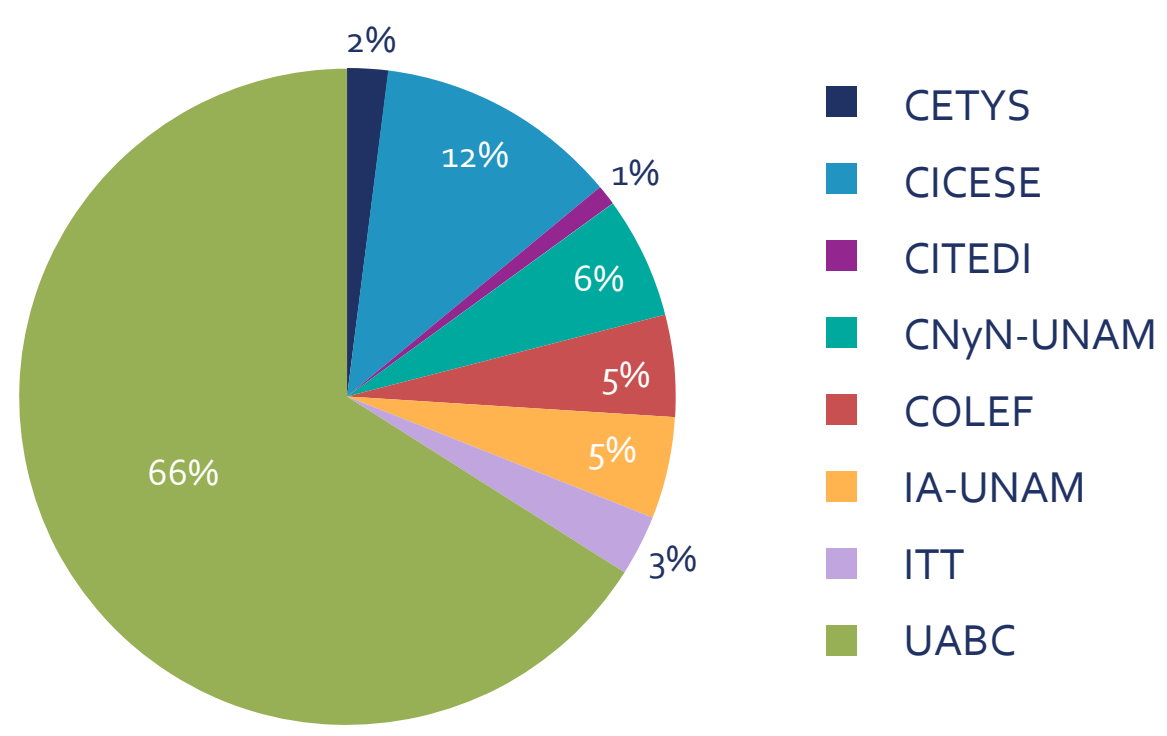

Nota: Elaboración propia con base en los resultados de la encuesta.

Respecto de la antigüedad laboral de los participantes, se puede observar que más de una cuarta parte (28\%) tiene 5 años o menos laborando como profesor-investigador, lo cual confirma la "juventud" de la planta laboral (figura 2). 


\section{Figura 2}

Antigüedad laboral como profesor-investigador

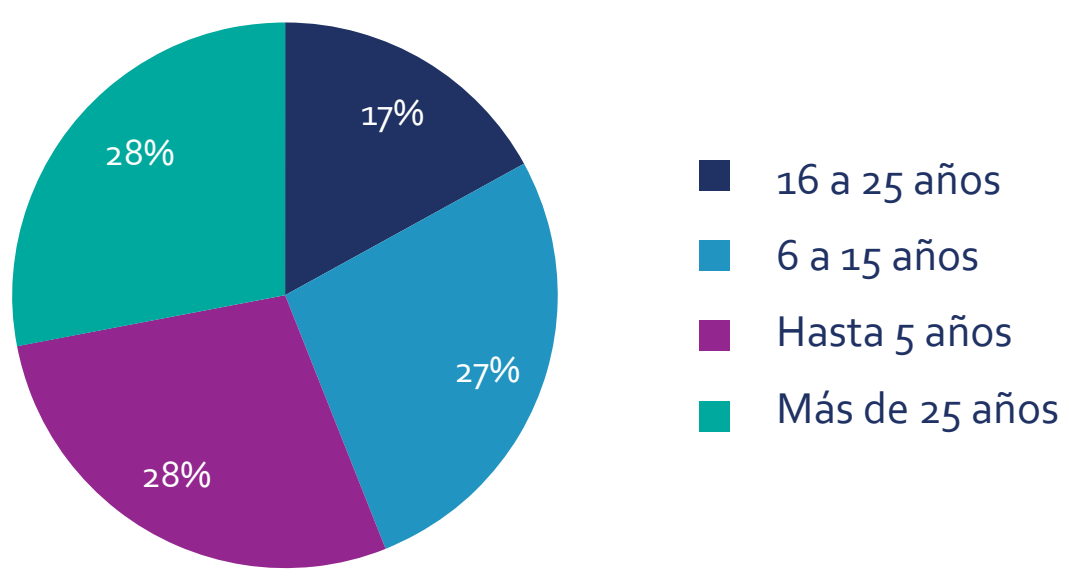

Nota: Elaboración propia con base en los resultados de la encuesta.

La distribución de los participantes en relación con las áreas de conocimiento establecidas por el SNI (figura 3), indica que las áreas I (Físico-Matemáticas y Ciencias de la Tierra) y $V$ (Ciencias Sociales) tuvieron el porcentaje más elevado de participación, con 23\% cada una; en tanto, el área con menor participación (4\%) fue el área III (Medicina y Ciencias de la Salud).

\section{Figura 3}

Área de conocimiento SNI

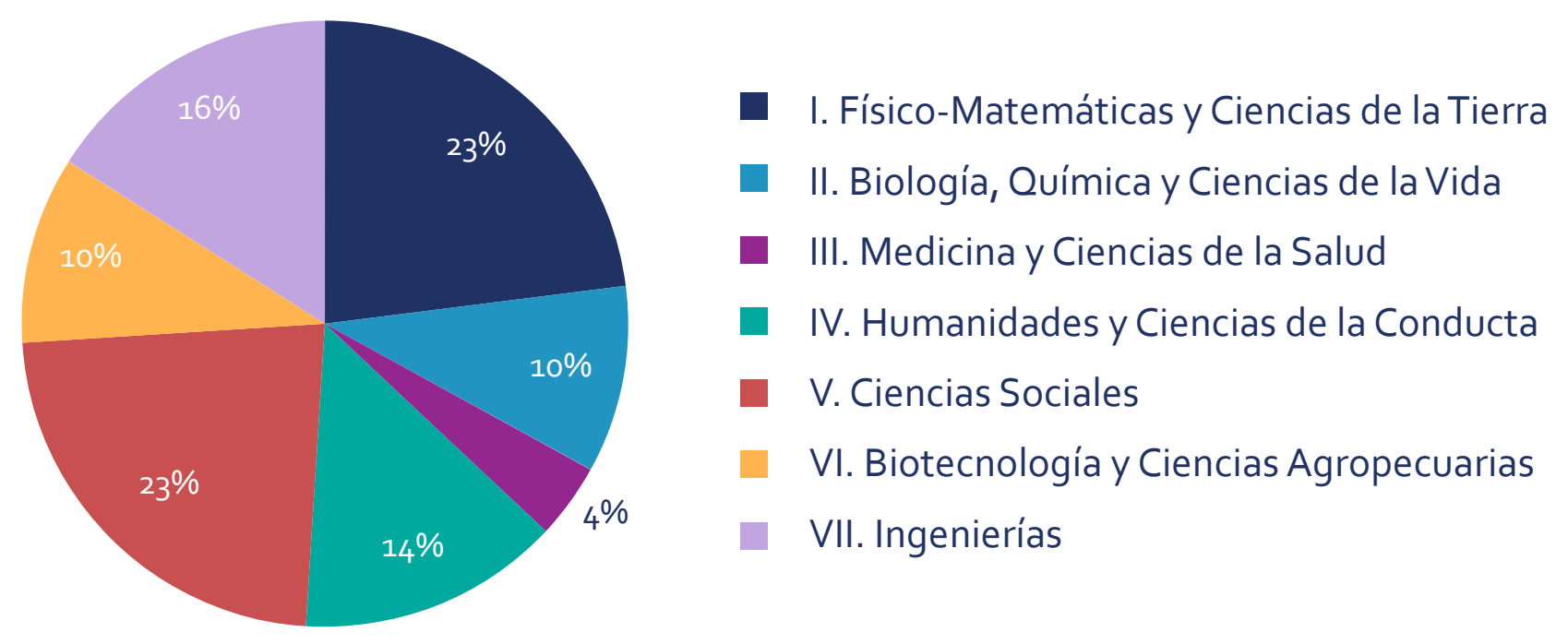

Nota: Elaboración propia con base en los resultados de la encuesta.

También se indagó sobre el nivel al cual pertenecían dentro del SNI (figura 4); destaca que más de la mitad de los miembros (54\%) se encontraban en el nivel 1 , el $20 \%$ en el nivel 2 y solamente el $5 \%$ en el nivel 3. Lo anterior contrasta con lo encontrado por Cabrera, López-Leyva y Serrano (2017), quienes aplicaron un cuestionario a 95 investigadores de Ensenada, Baja California; eligiendo esta ciudad porque la consideraban intensiva en conocimiento y con potencial para convertirse en un entorno innovador, dado que contaba con una alta concentración de profesores-investigadores, investigadores, técnicos y estudiantes de 
posgrado. Estos autores encontraron que alrededor del $40 \%$ de los encuestados declararon pertenecer a los niveles 2 y 3 . Al comparar este dato con lo arrojado por esta investigación, se observa una reducción importante de investigadores en dichos niveles.

\section{Figura 4}

Nivel de los participantes en el SNI

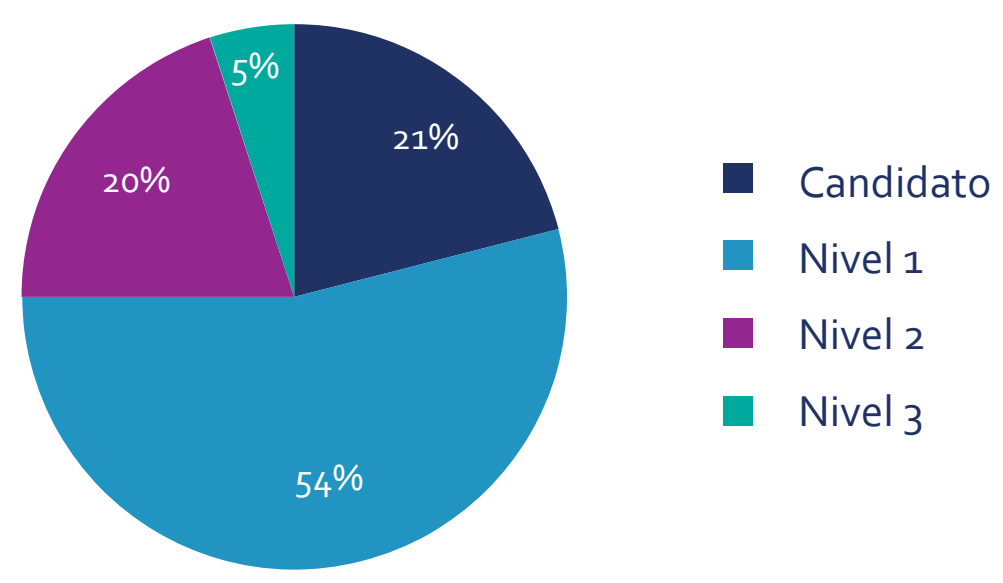

Nota: Elaboración propia con base en los resultados de la encuesta.

Otra característica de los participantes que se exploró fue el número de colegas (investigadores SNI) con los que colaboran frecuentemente (figura 5). La opción que obtuvo mayor porcentaje de respuesta fue de " 3 a 6", lo cual da indicios de que la mayoría prefieren grupos medianos para el trabajo colaborativo.

\section{Figura 5}

Número de colegas con los que colaboran los participantes con mayor frecuencia

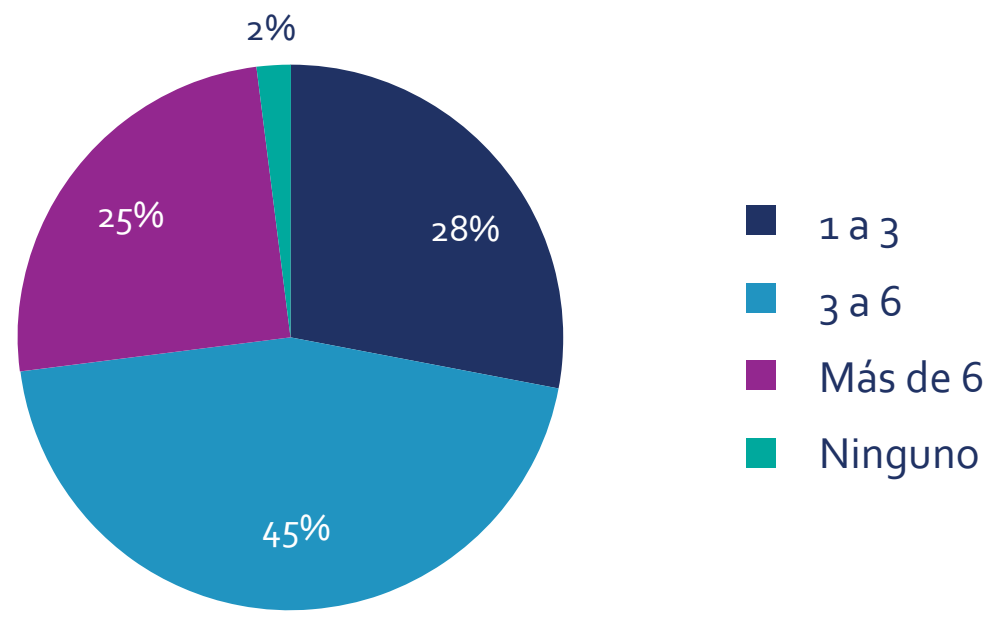

Nota: Elaboración propia con base en los resultados de la encuesta.

Los resultados anteriores se pueden relacionar con lo mencionado por De Fuentes y Dutrénit (2012), quienes señalaron que las características de los investigadores que generan beneficios a largo plazo para las empresas son: el grado académico, el campo de conocimiento al que pertenecen, el tamaño del equipo de investigación y la capacidad para obtener 
fondos públicos; específicamente, los investigadores que tienen título de doctorado, que colaboran en pequeños equipos de investigación, y que trabajan en determinados campos del conocimiento, tienen mayor probabilidad de influir de forma positiva en el entorno productivo.

\section{Percepción de los investigadores sobre la cooperación tecnocientífica}

En esta sección se presentan los resultados obtenidos a partir de las escalas desarrolladas para conocer las características y condiciones de los participantes de las IES respecto a la cooperación tecnocientífica (CT). Los resultados de la escala número 6 , en la cual se explora el componente cognitivo (pensamientos y creencias), se presentan en la tabla 2. Las respuestas a la afirmación 6.1 implican que casi el 90\% de los participantes (suma de los que están "De acuerdo" y "Totalmente de acuerdo") no la considera como una función sustitutiva de las IES, sino adicional o complementaria a las de docencia e investigación. Asimismo, los resultados de la afirmación 6.2 dan cuenta de una actitud positiva de los profesores-investigadores hacia la cooperación tecnocientífica como parte necesaria de la formación de los estudiantes; este elemento en particular coincide con algunos documentos de planeación institucional, por ejemplo, el Plan de Desarrollo Institucional 2015-2019 de la UABC (UABC, 2015).

Respecto de la afirmación 6.3 , es importante destacar que más de una quinta parte (20.11\%) de los participantes no considera que las actividades relacionadas con la cooperación tecnocientífica puedan generar recursos de importancia para las IES. Además, la afirmación con mayor consenso en "Totalmente de acuerdo" (50.54\%) es la 6.4, lo cual indica el nivel de convencimiento que tienen los académicos sobre el impacto social de su trabajo, denotando la presencia del sentido social, al menos en el terreno discursivo. Lo anterior co-

\section{Tabla 2}

Componente cognitivo de la actitud hacia la cooperación tecnocientífica (primera parte)

\begin{tabular}{llccc}
\hline \multicolumn{1}{c}{ Afirmaciones } & $\begin{array}{c}\text { Totalmente } \\
\text { en desacuerdo }\end{array}$ & $\begin{array}{c}\text { En } \\
\text { desacuerdo }\end{array}$ & $\begin{array}{c}\text { De } \\
\text { acuerdo }\end{array}$ & $\begin{array}{c}\text { Totalmente } \\
\text { de acuerdo }\end{array}$ \\
\hline $\begin{array}{l}\text { Las actividades de cooperación tecnocientífica } \\
\text { complementan mis actividades de docencia e } \\
\text { investigación. }\end{array}$ & $3.80 \%$ & $6.52 \%$ & $54.35 \%$ & $35.33 \%$ \\
\hline $6.2 \quad \begin{array}{l}\text { Las actividades de cooperación tecnocientífica } \\
\text { apoyan la formación de los estudiantes. }\end{array}$ & $1.63 \%$ & $5.98 \%$ & $47.83 \%$ & $44.57 \%$ \\
\hline $\begin{array}{l}\text { Las actividades de cooperación tecnocientífica } \\
\text { son una fuente importante de recursos para la } \\
\text { institución. }\end{array}$ & $3.26 \%$ & $16.85 \%$ & $43.48 \%$ & $36.41 \%$ \\
\hline $\begin{array}{l}\text { Realizar actividades de cooperación tecnocien- } \\
\text { tífica es una forma de retribuir a la sociedad lo } \\
\text { que se invirtió en mi formación universitaria. }\end{array}$ & $2.72 \%$ & $11.96 \%$ & $34.78 \%$ & $50.54 \%$ \\
\hline
\end{tabular}

Nota: Elaboración propia con base en los resultados de la encuesta. 
rrobora el hallazgo de Lindquist (2018) acerca de que los académicos están interesados en apoyar el progreso social a pesar de las limitaciones institucionales.

Los resultados de la escala 7, denominada Componente afectivo de la actitud hacia la cooperación tecnocientífica, se presentan en la tabla 3. En el caso de la afirmación "Me gusta realizar actividades empresariales" (7.3), los valores se encuentran más equilibrados entre el acuerdo (53.26\%) y el desacuerdo (46.74\%), por lo cual se infiere que el gusto por realizar actividades empresariales está presente solamente en la mitad de los profesoresinvestigadores.

En particular, el interés por resolver problemas prácticos del ámbito productivo (afirmación 7.5) coincide con el hallazgo de García-Galván et al. (2018), para quienes la principal satisfacción de los investigadores acerca de las actividades de interacción se relaciona con la oportunidad de resolver diversos problemas del entorno. Con respecto a las afirmaciones 7.7 y 7.8 , las respuestas se entienden en función del interés de los directivos en los diferentes niveles de las distintas IES; que, en general, está en función de las políticas institucionales, las cuales se ven reflejadas en los documentos de normatividad y planeación.

\section{Tabla 3}

Componente afectivo de la actitud hacia la cooperación tecnocientifica

\begin{tabular}{llcccc}
\hline \multicolumn{1}{c}{ Afirmaciones } & $\begin{array}{c}\text { Totalmente } \\
\text { en desacuerdo }\end{array}$ & $\begin{array}{c}\text { En } \\
\text { desacuerdo }\end{array}$ & $\begin{array}{c}\text { De } \\
\text { acuerdo }\end{array}$ & $\begin{array}{c}\text { Totalmente } \\
\text { de acuerdo }\end{array}$ \\
\hline 7.1 & Siempre me ha gustado trabajar en equipo. & $1.09 \%$ & $4.35 \%$ & $34.24 \%$ & $60.33 \%$ \\
\hline 7.2 & $\begin{array}{l}\text { Me gusta emprender nuevas actividades cons- } \\
\text { tantemente. }\end{array}$ & $0.00 \%$ & $3.80 \%$ & $34.24 \%$ & $61.96 \%$ \\
\hline $7.3 \quad$ Me gusta realizar actividades empresariales. & $7.61 \%$ & $39.13 \%$ & $39.13 \%$ & $14.13 \%$ \\
\hline $7.4 \quad \begin{array}{l}\text { Me gusta llevar a cabo actividades de coopera- } \\
\text { ción tecnocientífica. }\end{array}$ & $0.54 \%$ & $3.26 \%$ & $58.15 \%$ & $38.04 \%$ \\
\hline 7.5 & $\begin{array}{l}\text { Me interesa resolver problemas prácticos del } \\
\text { ámbito productivo. }\end{array}$ & $3.80 \%$ & $11.96 \%$ & $40.76 \%$ & $43.48 \%$ \\
\hline $\begin{array}{l}\text { Simpatizo con los profesores-investigadores } \\
\text { que realizan actividades de cooperación tecno- } \\
\text { científica. }\end{array}$ & $0.54 \%$ & $4.89 \%$ & $47.28 \%$ & $47.28 \%$ \\
\hline $\begin{array}{l}\text { Estoy a favor de que los directivos actuales de } \\
\text { la administración central impulsen la coopera- } \\
\text { ción tecnocientífica. }\end{array}$ & $1.63 \%$ & $3.80 \%$ & $42.39 \%$ & $52.17 \%$ \\
\hline $\begin{array}{l}\text { Estoy a favor de que los directivos actuales de } \\
\text { las unidades académicas impulsen la coopera- } \\
\text { ción tecnocientífica. }\end{array}$ & $2.17 \%$ & $5.43 \%$ & $42.93 \%$ & $49.46 \%$ \\
\hline
\end{tabular}

Nota: Elaboración propia con base en los resultados de la encuesta. 
Por otra parte, respecto a los apoyos institucionales hacia la cooperación tecnocientífica, más de la mitad de los participantes tiene la percepción de que son insuficiente (tabla 4). En particular, los participantes perciben que su institución no proporciona apoyos financieros suficientes para el desarrollo de estas actividades (afirmación 8.1); resultado que coincide con lo encontrado por García-Galván (2018), quien identificó la escasez de recursos para la promoción de la cooperación con el entorno como uno de los principales inhibidores.

\section{Tabla 4}

Percepción sobre los apoyos institucionales hacia la cooperación tecnocientífica

\begin{tabular}{|c|c|c|c|c|c|}
\hline & Afirmaciones & $\begin{array}{c}\text { Totalmente } \\
\text { en desacuerdo }\end{array}$ & $\begin{array}{c}\text { En } \\
\text { desacuerdo }\end{array}$ & $\begin{array}{c}\text { De } \\
\text { acuerdo }\end{array}$ & $\begin{array}{l}\text { Totalmente } \\
\text { de acuerdo }\end{array}$ \\
\hline 8.1 & $\begin{array}{l}\text { Su institución proporciona apoyos financieros } \\
\text { suficientes para el desarrollo de las actividades } \\
\text { de cooperación tecnocientífica. }\end{array}$ & $9.78 \%$ & $45.65 \%$ & $38.04 \%$ & $6.52 \%$ \\
\hline 8.2 & $\begin{array}{l}\text { Su institución proporciona formación a los } \\
\text { profesores-investigadores en materia de } \\
\text { cooperación tecnocientífica. }\end{array}$ & $12.50 \%$ & $45.65 \%$ & $32.07 \%$ & $9.78 \%$ \\
\hline 8.3 & $\begin{array}{l}\text { Su institución establece procedimientos claros } \\
\text { en relación con los procesos de cooperación } \\
\text { tecnocientífica. }\end{array}$ & $10.33 \%$ & $46.20 \%$ & $35 \cdot 33 \%$ & $8.15 \%$ \\
\hline
\end{tabular}

Nota: Elaboración propia con base en los resultados de la encuesta.

Los resultados de la escala 11 referentes al ámbito individual, se presentan en la tabla 5. En relación con la afirmación 11.1, más del 90\% de los encuestados expresa que las actividades de cooperación tecnocientífica ayudan a resolver problemas de la sociedad. Sin embargo, una cuestión discutible es en qué sentido se entienden estas actividades como vía para retribuir a la sociedad. Según Lindquist (2018), en general, los académicos tienen una concepción "consecuencialista" (versión menos evolucionada de la colaboración social) de la cooperación, ya que se convierte en una actividad que parte del "tengo que" y de la presión moral, y no de la responsabilidad social de las IES.

Respecto a la afirmación 11.2, "Si la cooperación tecnocientífica es una función de la universidad, entonces tengo el compromiso de coadyuvar en el óptimo desarrollo de la misma", el 86.96\% de los participantes está de acuerdo. Sin embargo, como mencionan Etzkowitz et al. (2000), la cuestión clave es qué tan posible es para los investigadores combinar sus valores científicos y empresariales en una identidad común de ciencia empresarial, en la cual sean compatibles la difusión y capitalización del conocimiento, ya que existen tensiones continuas entre movilizar el conocimiento como bien público y controlar su valor como bien privado. 
En la afirmación 11.3 se puede observar que un alto porcentaje de los profesores-investigadores (67\%) consideran que sus pares se abstienen de realizar actividades de cooperación tecnocientífica por sentirse más cómodos en la investigación y la docencia. Este resultado podría explicarse según lo mencionado por García-Galván (2008), para quien algunos académicos universitarios consideran que la colaboración con el sector empresarial pudiera ser una amenaza, ya que un elevado interés por este tipo de recursos económicos ocasionaría que la universidad dejara de ser una institución independiente y crítica.

En particular, más del $60 \%$ de los profesores-investigadores están "De acuerdo" o "Totalmente de acuerdo" con el enunciado 11.6, que cita "La cooperación tecnocientífica IESSP se intensificó debido a la reducción del financiamiento público a las IES". Este resultado coincide con lo mencionado por López-Leyva (2002), acerca de que los investigadores se involucran en actividades de vinculación como respuesta a la necesidad de generar recursos para sus proyectos de investigación, debido a la reducción de los apoyos gubernamentales.

Las afirmaciones 11.8, "La consolidación de la cooperación tecnocientífica IES-SP implica un papel más directo de las IES en el desarrollo económico y social de las regiones", con un $82.61 \%$ de acuerdo, y la afirmación 11.14, "Las actividades de investigación desarrolladas en las IES deben tener el perfil de aplicaciones prácticas para la resolución de problemas reales del entorno, principalmente del SP", con 66.31\%, respaldan lo mencionado por Morales y Herrera (2016), para quienes: "la interacción del sector productivo con la educación superior para la búsqueda de solución a los problemas se convierte en una alternativa que fomenta la creatividad del sector productivo y prevé un cambio en la cultura" (p.141).

Al analizar la calidad de la formación de los egresados en relación con los lazos colaborativos de las IES y el sector productivo (afirmación 11.9), se observa que casi dos terceras partes de los participantes (64.13\%) consideran que es necesaria la profundización de dichos lazos para que exista un incremento en la cooperación tecnocientífica. Este resultado refuerza lo establecido por Rama (2010), quien indica que desde la década de los ochenta se han desarrollado nexos entre la formación profesional y la innovación, una nueva lógica de educación especializada más cercana al mercado, y paradigmas emergentes acerca de la economía del conocimiento y de la educación. Es decir, el cambio en la dinámica económica subyacente ocasionó modificaciones en los mercados de trabajo, entre los cuales destacaron: (a) impulsar la productividad a través de la adquisición de competencias profesionales, (b) incremento de la tecnología, (c) especialización del capital humano, (d) digitalización y automatización de los procesos. Estas modificaciones ocasionaron ajustes en la economía de la educación, los cuales plantean la necesidad de establecer un marco teórico, fundamentado en una economía del conocimiento, para analizar los procesos de creación, distribución, intercambio y uso de la información.

Por otra parte, debido tanto a las condiciones del entorno de las IES modernas como a la relevancia del conocimiento aplicado, el creciente ritmo de innovación, y el uso de las TIC, 
se otorga una mayor importancia a las universidades, en términos de resultados de investigación (Comisión Económica para América Latina y el Caribe, 2010). La idea anterior se ve reforzada por el hecho de que más de la mitad de los profesores-investigadores (58.16\%) consideró que la calidad de la investigación desarrollada en las IES está estrechamente relacionada con la profundización de los lazos colaborativos de las IES con el sector productivo (11.10).

Asimismo, el $85.78 \%$ de los participantes en el estudio coinciden en que "a medida que se fortalece la cooperación tecnocientífica IES-SP, las IES adquieren mayor prestigio ante los diversos sectores de la sociedad" (afirmación 11.12). Su opinión fortalece algunos hallazgos de Alcántar et al. (2006), quienes destacaron que: (a) la vinculación es un medio que favorece significativamente el posicionamiento de las universidades en su entorno, y (b) la baja valoración del posicionamiento obtenida en su estudio demuestra el efecto de la insuficiente vinculación de la UABC con el sector productivo, el gobierno y la población en general.

Con respecto a la afirmación 11.12, la cual cita "A medida que se fortalece la cooperación tecnocientífica IES-SP, las IES adquieren mayor legitimidad ante los diversos sectores de la sociedad", el 25.54\% de los participantes estuvo en desacuerdo. Esto implica que más de una cuarta parte de los profesores-investigadores no consideran que realizar actividades de cooperación tecnocientífica con el sector productivo se traduzca en una mayor legitimidad ante los diversos sectores de la sociedad. Este resultado puede ser explicado desde la perspectiva de Lindquist (2018), quien indicó que los académicos tienen una visión de impacto a largo plazo, en donde la contribución social (en particular, hacia el tercer sector) tiene tintes aspiracionales y no operativos. Según su estudio, los profesores-investigadores consideran que la formación de estudiantes, la generación de ciencia y la gestión universitaria son elementos suficientes de esta contribución.

El 46.74\% de los encuestados no está de acuerdo con la afirmación 11.13, acerca de que la formación en los posgrados debe responder de manera directa a los requerimientos del mercado. Este resultado pone en evidencia la existencia de una opinión dividida entre los participantes sobre esta temática. A este respecto, es destacable la opinión de la Organización para la Cooperación y el Desarrollo Económicos (OCDE), según la cual la informalidad y la sobrecalificación son dos de los desafíos más graves y persistentes en el proceso de integración de los egresados universitarios al mercado laboral. Para solventar esta problemática, dicho organismo propone: "alinear el sistema de educación superior con el mercado laboral, a través de un marco (jurídico) de alto impacto; fortalecer la calidad de planes y programas de estudio, certificando su calidad; incrementar el financiamiento y hacerlo más transparente [...]" (Poy, 2019, párr.3).

Con respecto a la afirmación 11.15, es destacable que la mayoría de los participantes considera que el gobierno debe tomar acciones remediales para dinamizar los procesos de cooperación tecnocientífica entre las universidades y el sector productivo. Este resultado confirma lo expresado por Etzkowitz y Leydesdorff (2000), para quienes la solución del enigma 
de la producción típicamente incluye al gobierno, lo cual implica el cambio de las dinámicas de interacción desde una hélice doble (universidad-empresa) a una triple (universidad-empresa-gobierno). Al respecto, García-Galván (2014) destacó que, en el caso de México, es necesario que el gobierno se interese genuinamente en canalizar las fuerzas productivas del país hacia una sociedad basada en el conocimiento. En su opinión, debe darse un cambio institucional en las funciones del gobierno, destacando su papel como: (a) promotor de firmas del conocimiento, (b) agente clave en la consolidación de los mercados tecnológicos, y (c) ente innovador, para evitar las fallas internas y corregir las del mercado (ya que este no es capaz de destinar los recursos adecuados para la generación de conocimiento tecnocientífico).

\section{Tabla 5}

\section{Componente cognitivo de la actitud hacia la cooperación tecnocientífica (segunda parte)}

\begin{tabular}{|c|c|c|c|c|c|}
\hline & Afirmaciones & $\begin{array}{l}\text { Totalmente } \\
\text { en desacuerdo }\end{array}$ & $\begin{array}{c}\text { En } \\
\text { desacuerdo }\end{array}$ & $\begin{array}{c}\text { De } \\
\text { acuerdo }\end{array}$ & $\begin{array}{l}\text { Totalmente } \\
\text { de acuerdo }\end{array}$ \\
\hline 11.1 & $\begin{array}{l}\text { Las actividades de cooperación tecnocientífica } \\
\text { ayudan a solucionar problemas de la sociedad. }\end{array}$ & $1.63 \%$ & $7.07 \%$ & $42.93 \%$ & $48.37 \%$ \\
\hline 11.2 & $\begin{array}{l}\text { Si la cooperación tecnocientífica es una fun- } \\
\text { ción de la universidad, entonces tengo el com- } \\
\text { promiso de coadyuvar en el óptimo desarrollo } \\
\text { de la misma. }\end{array}$ & $3.80 \%$ & $9.24 \%$ & $49.46 \%$ & $37.50 \%$ \\
\hline 11.3 & $\begin{array}{l}\text { Cuando los profesores-investigadores no rea- } \\
\text { lizan actividades de cooperación tecnocientí- } \\
\text { fica es debido a que se sienten más cómodos } \\
\text { dedicándose solo a la docencia e investigación. }\end{array}$ & $10.87 \%$ & $26.09 \%$ & $37.50 \%$ & $25.54 \%$ \\
\hline 11.4 & $\begin{array}{l}\text { Los profesores-investigadores realizan activi- } \\
\text { dades de cooperación tecnocientífica porque } \\
\text { conocen los beneficios de llevarla a cabo. }\end{array}$ & $2.17 \%$ & $19.02 \%$ & $58.15 \%$ & $20.65 \%$ \\
\hline 11.5 & $\begin{array}{l}\text { Los profesores-investigadores realizan activi- } \\
\text { dades de cooperación tecnocientífica porque } \\
\text { han tenido buenas experiencias en el pasado } \\
\text { en materia de cooperación tecnocientífica. }\end{array}$ & $2.17 \%$ & $21.74 \%$ & $53.26 \%$ & $22.83 \%$ \\
\hline 11.6 & $\begin{array}{l}\text { La cooperación tecnocientífica IES-SP se } \\
\text { intensificó debido a la reducción del financia- } \\
\text { miento público a las IES. }\end{array}$ & $5.43 \%$ & $34.24 \%$ & $42.39 \%$ & $17.93 \%$ \\
\hline 11.7 & $\begin{array}{l}\text { La cooperación tecnocientífica de las IES con } \\
\text { el sector productivo denota un mayor com- } \\
\text { promiso de las IES con la sociedad en general. }\end{array}$ & $5.43 \%$ & $24.46 \%$ & $46.74 \%$ & $23.37 \%$ \\
\hline 11.8 & $\begin{array}{l}\text { La consolidación de la cooperación tecnocien- } \\
\text { tífica IES-SP implica un papel más directo de } \\
\text { las IES en el desarrollo económico y social de } \\
\text { las regiones. }\end{array}$ & $2.72 \%$ & $14.67 \%$ & $50.00 \%$ & $32.61 \%$ \\
\hline
\end{tabular}




\begin{tabular}{llccc}
\hline \multicolumn{1}{c}{ Afirmaciones } & $\begin{array}{c}\text { Totalmente } \\
\text { en desacuerdo }\end{array}$ & $\begin{array}{c}\text { En } \\
\text { desacuerdo }\end{array}$ & $\begin{array}{c}\text { De } \\
\text { acuerdo }\end{array}$ & $\begin{array}{c}\text { Totalmente } \\
\text { de acuerdo }\end{array}$ \\
\hline $\begin{array}{l}\text { La calidad de la formación de los egresados } \\
\text { está estrechamente relacionada con la profun- } \\
\text { dización de los lazos colaborativos de las IES } \\
\text { con el SP. }\end{array}$ & $9.24 \%$ & $26.63 \%$ & $40.22 \%$ & $23.91 \%$ \\
\hline $\begin{array}{l}\text { La calidad de la investigación desarrollada en } \\
\text { las IES está estrechamente relacionada con la } \\
\text { profundización de los lazos colaborativos de } \\
\text { las IES con el SP. }\end{array}$ & $11.41 \%$ & $30.43 \%$ & $36.96 \%$ & $21.20 \%$ \\
\hline $\begin{array}{l}\text { A medida que se fortalecela cooperacióntecno- } \\
\text { científica IES-SP, las IES adquieren mayor pres- } \\
\text { tigio ante los diversos sectores de la sociedad. }\end{array}$ & $1.63 \%$ & $13.59 \%$ & $50.54 \%$ & $34.24 \%$ \\
\hline $\begin{array}{l}\text { A medida que se fortalece la cooperación tec- } \\
\text { nocientífica IES-SP, las IES adquieren mayor } \\
\text { legitimidad ante los diversos sectores de la } \\
\text { sociedad. }\end{array}$ & $4.89 \%$ & $20.65 \%$ & $44.57 \%$ & $29.89 \%$ \\
\hline $\begin{array}{l}\text { La formación en los posgrados debe respon- } \\
\text { der de manera directa a los requerimientos del } \\
\text { mercado. }\end{array}$ & $15.22 \%$ & $31.52 \%$ & $28.26 \%$ & $25.00 \%$ \\
\hline $\begin{array}{l}\text { Las actividades de investigación desarrolladas } \\
\text { en las IES deben tener el perfil de aplicaciones } \\
\text { prácticas para la resolución de problemas rea- } \\
\text { les del entorno, principalmente del SP. }\end{array}$ & $10.33 \%$ & $23.37 \%$ & $38.59 \%$ & $27.72 \%$ \\
\hline $\begin{array}{l}\text { Si la demanda de innovaciones, profesionistas } \\
\text { y posgraduados, y servicios avanzados que se } \\
\text { producen en las IES en general es insuficien- } \\
\text { te, entonces el gobierno debe intervenir para } \\
\text { dinamizar dicha demanda. }\end{array}$ & $4.89 \%$ & $16.85 \%$ & $41.85 \%$ & $36.41 \%$ \\
\hline
\end{tabular}

Nota: $\mathrm{IES}=$ Instituciones de educación superior; $\mathrm{SP}=$ sector productivo.

Elaboración propia con base en los resultados de la encuesta.

En la tabla 6 se presentan los resultados de la escala 18, sobre la percepción que tienen los investigadores sobre la infraestructura, equipo y condiciones que favorecen la gestión de la cooperación tecnocientífica.

Según la percepción de la mayoría de los profesores-investigadores, las condiciones de la infraestructura (afirmaciones 18.1 y 18.2) necesaria para la investigación —base de las actividades de CT- son buenas. También, consideran que el uso de las TIC para la promoción de dichas actividades (afirmación 18.3), y para el desarrollo de actividades emprendedoras y de vinculación con el sector productivo (afirmación 18.5) son buenas. En contraparte, perciben que existe una gran deficiencia con respecto al personal especializado en la gestión de la cooperación tecnocientífica (18.4). Por último, el porcentaje de respuesta a las afirmaciones 18.6 y 18.7 pone de manifiesto la necesidad de crear un andamiaje apropiado, basado en agentes profesionales, que permita cerrar la brecha entre las IES y las empresas en materia de cooperación tecnocientífica. 


\section{Tabla 6}

Percepción sobre la infraestructura y gestión de la cooperación tecnocientífica

\begin{tabular}{|c|c|c|c|c|c|}
\hline & Afirmaciones & $\begin{array}{l}\text { Totalmente } \\
\text { en desacuerdo }\end{array}$ & $\begin{array}{c}\text { En } \\
\text { desacuerdo }\end{array}$ & $\begin{array}{c}\text { De } \\
\text { acuerdo }\end{array}$ & $\begin{array}{l}\text { Totalmente } \\
\text { de acuerdo }\end{array}$ \\
\hline 18.1 & $\begin{array}{l}\text { En general, las condiciones de las instalaciones } \\
\text { dedicadas a la investigación son buenas. }\end{array}$ & $5.98 \%$ & $20.65 \%$ & $47.83 \%$ & $25.54 \%$ \\
\hline 18.2 & $\begin{array}{l}\text { En general, las condiciones del equipo } \\
\text { utilizado para la investigación son buenas. }\end{array}$ & $4.89 \%$ & $21.74 \%$ & $56.52 \%$ & $16.85 \%$ \\
\hline 18.3 & $\begin{array}{l}\text { La institución aprovecha de manera eficiente } \\
\text { las TIC para el desarrollo y promoción de las } \\
\text { actividades de cooperación tecnocientífica. }\end{array}$ & $6.52 \%$ & $38.04 \%$ & $44 \cdot 57 \%$ & $10.87 \%$ \\
\hline 18.4 & $\begin{array}{l}\text { La institución cuenta con personal especiali- } \\
\text { zado para gestionar la cooperación tecnocien- } \\
\text { tífica (por ejemplo, ejecutivos de vinculación, } \\
\text { brokers del conocimiento, gestores de innova- } \\
\text { ción). }\end{array}$ & $20.65 \%$ & $43.48 \%$ & $29.35 \%$ & $6.52 \%$ \\
\hline 18.5 & $\begin{array}{l}\text { La institución promueve el desarrollo de habi- } \\
\text { lidades emprendedoras y de vinculación con } \\
\text { el sector productivo. }\end{array}$ & $9.24 \%$ & $36.41 \%$ & $45.11 \%$ & $9.24 \%$ \\
\hline 18.6 & $\begin{array}{l}\text { Existen discrepancias entre las necesidades de } \\
\text { los que demandan un servicio y los que ofrece } \\
\text { la institución. }\end{array}$ & $2.72 \%$ & $25.54 \%$ & $56.52 \%$ & $15.22 \%$ \\
\hline 18.7 & $\begin{array}{l}\text { Los académicos y los empresarios hablan un } \\
\text { "lenguaje" distinto. }\end{array}$ & $4.89 \%$ & $22.83 \%$ & $44.57 \%$ & $27.72 \%$ \\
\hline
\end{tabular}

Nota: Elaboración propia con base en los resultados de la encuesta.

Finalmente, se indagó sobre los aspectos relacionados con las normas formales e informales que existen en las IES respecto a sus actividades de cooperación tecnocientífica. En particular, se hace referencia a leyes, reglamentos y disposiciones generales al respecto. En la tabla 7 se presentan los resultados de la escala 21, a través de la cual se explora la percepción del marco institucional.

Los resultados de los dos primeros elementos de la escala fueron muy similares. Respecto a la afirmación 21.1, "La reglamentación de las actividades de cooperación tecnocientífica de su institución es adecuada", el 53.26\% de los encuestados no estuvo de acuerdo; y respecto a la afirmación 21.2, "La planeación institucional de su centro de trabajo incluye elementos relacionados con la cooperación tecnocientífica", el 52.71\% no estuvo de acuerdo; estos resultados son similares a los presentados por García et al. (2018) en su estudio. 


\section{Tabla 7}

\section{Percepción del marco institucional de la cooperación tecnocientífica}

\begin{tabular}{|c|c|c|c|c|c|}
\hline & Afirmaciones & $\begin{array}{l}\text { Totalmente } \\
\text { en desacuerdo }\end{array}$ & $\begin{array}{c}\text { En } \\
\text { desacuerdo }\end{array}$ & $\begin{array}{c}\text { De } \\
\text { acuerdo }\end{array}$ & $\begin{array}{l}\text { Totalmente } \\
\text { de acuerdo }\end{array}$ \\
\hline 21.1 & $\begin{array}{l}\text { La reglamentación de las actividades de coo- } \\
\text { peración tecnocientífica de su institución es } \\
\text { adecuada. }\end{array}$ & $5.43 \%$ & $47.83 \%$ & $40.76 \%$ & $5.98 \%$ \\
\hline 21.2 & $\begin{array}{l}\text { La planeación institucional de su centro de } \\
\text { trabajo incluye elementos relacionados con la } \\
\text { cooperación tecnocientífica. }\end{array}$ & $11.41 \%$ & $41.30 \%$ & $40.76 \%$ & $6.52 \%$ \\
\hline 21.3 & $\begin{array}{l}\text { El modelo educativo de su institución exhibe } \\
\text { elementos relacionados con la cooperación } \\
\text { tecnocientífica. }\end{array}$ & $5.98 \%$ & $26.63 \%$ & $57.07 \%$ & $10.33 \%$ \\
\hline 21.4 & $\begin{array}{l}\text { Conoce los trámites necesarios para realizar un } \\
\text { convenio. }\end{array}$ & $11.41 \%$ & $28.80 \%$ & $45.11 \%$ & $14.67 \%$ \\
\hline 21.5 & $\begin{array}{l}\text { Los mecanismos de fiscalización de recursos } \\
\text { relacionados con la cooperación tecnocientífi- } \\
\text { ca inhiben la participación de los profesores-in- } \\
\text { vestigadores en la misma. }\end{array}$ & $4.35 \%$ & $25.00 \%$ & $50.00 \%$ & $20.65 \%$ \\
\hline 21.6 & $\begin{array}{l}\text { Es conveniente que los profesores-investiga- } \\
\text { dores con experiencia en la cooperación tec- } \\
\text { nocientífica compartan sus conocimientos en } \\
\text { la materia con los profesores-investigadores } \\
\text { nóveles. }\end{array}$ & $0.54 \%$ & $6.52 \%$ & $49.46 \%$ & $43.48 \%$ \\
\hline 21.7 & $\begin{array}{l}\text { Es necesario establecer protocolos de actua- } \\
\text { ción relacionados con las actividades de coope- } \\
\text { ración tecnocientífica (manuales de operación, } \\
\text { organización y procedimientos). }\end{array}$ & $0.54 \%$ & $6.52 \%$ & $50.54 \%$ & $42.39 \%$ \\
\hline 21.8 & $\begin{array}{l}\text { Son necesarios cambios en las políticas públi- } \\
\text { cas que coadyuven en el fomento de la coope- } \\
\text { ración tecnocientífica. }\end{array}$ & $1.63 \%$ & $5.98 \%$ & $47.83 \%$ & $44.57 \%$ \\
\hline 21.9 & $\begin{array}{l}\text { Es importante integrar a los profesores-inves- } \\
\text { tigadores en la revisión de la normatividad en } \\
\text { materia de cooperación tecnocientífica. }\end{array}$ & $1.63 \%$ & $4.89 \%$ & $45.11 \%$ & $48.37 \%$ \\
\hline
\end{tabular}

Nota: Elaboración propia con base en los resultados de la encuesta.

\section{Conclusiones}

Los resultados del análisis del componente cognitivo de la actitud hacia la cooperación tecnocientífica indican que un alto porcentaje de investigadores consideran importante las acciones y actividades relacionadas con esta. Sin embargo, más de la mitad de los participantes indicaron que los apoyos institucionales son insuficientes.

La percepción sobre la infraestructura y gestión de la cooperación tecnocientífica obtuvo un resultado positivo, pues la mayoría de los participantes perciben que las condiciones de las instalaciones y del equipo utilizado para la investigación son buenas. Por otra parte, 
hay un aprovechamiento eficiente de las TIC para el desarrollo y promoción de esta actividad, y se promueve el desarrollo de habilidades emprendedoras y de vinculación con el sector productivo. Sin embargo, existen áreas de oportunidad relacionadas con: (a) el personal dedicado a la gestión de la cooperación tecnocientífica, ya que más de la mitad de los profesores-investigadores considera que no está especializado en dicha actividad; y (b) las acciones encaminadas a generar un acercamiento más puntual con el sector productivo, ya que casi tres cuartas partes considera que los académicos y los empresarios hablan un "lenguaje" distinto.

Respecto a la percepción del marco institucional de la cooperación tecnocientífica, más de la mitad de los participantes indicaron que la reglamentación es adecuada, y que tanto la planeación como el modelo educativo institucional exhiben elementos sobre esta. Sin embargo, se puso de manifiesto el desconocimiento de más de la mitad de los profesores-investigadores acerca de los trámites necesarios para realizar un convenio, hecho que se agrava con la consideración acerca de que la fiscalización excesiva por parte de las autoridades universitarias desincentiva las actividades de cooperación tecnocientífica. Por lo tanto, casi todos están de acuerdo en la necesidad de crear protocolos de actuación y políticas públicas destinadas a mejorar la gestión y organización de estas actividades.

Es importante destacar que las principales limitaciones del estudio se derivaron de la imposibilidad de generalizar los resultados; por lo que, se espera en un futuro continuar investigando sobre el tema, considerando lo siguiente: realizar ajustes al cuestionario para incrementar su confiabilidad; obtener información puntual por cada una de las IES estudiadas y, también, por áreas del conocimiento del $\mathrm{SNI}_{\text {; }}$ conocer la percepción de profesores-investigadores no adscritos al SNI, directivos y administrativos de las IES, así como de funcionarios del gobierno en Baja California.

A partir del estudio se pretende generar nuevo conocimiento respecto a la cooperación tecnocientífica en el ámbito regional, así como los cambios institucionales que se han gestado a partir de esta, con el propósito de proporcionar a los tomadores de decisiones elementos suficientes para elaborar estrategias de vinculación de las IES con el sector empresarial y coadyuvar en la generación de mecanismos que promuevan la innovación tecnocientífica en Baja California. Por tanto, dada la relevancia social, se cree conveniente socializar los resultados de este tipo de estudios con diversos actores: (a) autoridades y profesores-investigadores de las IES, con el propósito de coadyuvar en la generación de políticas de vinculación IES-SP mejor contextualizadas, con reglamentos de vinculación, oficinas de atención y profesionales de vinculación, así como mayor difusión de los resultados de la investigación hacia el sector productivo; (b) representantes empresariales y empresarios (en particular de pequeñas y medianas empresas), para contribuir a la generación de vínculos que beneficien a ambas partes; (c) autoridades gubernamentales, en un intento de cerrar la brecha entre lo establecido por la normativa y prospectiva oficial, y la realidad operativa de la cooperación tecnocientífica. 


\section{Referencias}

Alcántar, V.M., Arcos, J.L., \& Mungaray, A. (2006). Vinculación y posicionamiento de la Universidad Autónoma de Baja California con su entorno social y productivo. UABCI ANUIES.

Cabrera, M.R., López-Leyva, S., \& Serrano, A. (2017). Relevancia, pertinencia y socialización del conocimiento, ¿cómo contribuyen los investigadores a la innovación de Ensenada, México? Investigaciones Regionales-Journal of Regional Research, 37, 31-53. https:// investigacionesregionales.org/wp-content/uploads/sites/3/2017/og/02-CABRERA.pdf

Cohen, W., \& Levinthal. D. (1990). Absortive Capacity: A New Perspective on Learning and Innovation. Administrative Science Quarterly, 35(1), 128-152.

Comisión Económica para América Latina y el Caribe (CEPAL). (2010). Espacios iberoamericanos: vínculos entre universidades y empresas para el desarrollo tecnológico. CEPAL. $\quad$ http://repositorio.cepal.org/bitstream/handle/11362/1417/S2010990_ es.pdf;jsessionid=1AE9oFAB397D1BCD8B46BC 5 F9873B603? sequence $=1$

De Fuentes, C., \& Dutrénit, G. (2012). Best channels of academia-industry interaction for long-term benefit. Research Policy, 41(9), 1666-1682.

Etzkowitz, H., \& Leydesdorff, L. (2000). The dynamics of innovation: from National Systems and "Mode 2 " to a Triple Helix of university-industry-government relations. Research Policy, 29, 109-123.https://www.academia.edu/866737/The_dynamics_of_innovation_ from_National_Systems_and

Etzkowitz, H., Webster, A., Gebhardt, C., \& Cantisano, B.R. (2000). The future of the university and the university of the future: evolution of ivory tower to entrepreneurial paradigm. Research Policy, 29, 313-330.

Fernández-Sánchez, E. (1991). La cooperación empresarial. Concepto y tipología. Documento de trabajo 29. Universidad de Oviedo, España. https://dialnet.unirioja.es/servlet/ articulo?codigo $=4081534$

García-Galván, R. (2008). Análisis teórico de la transferencia de conocimientos universidadempresa mediante la colaboración. Economía: Teoría y práctica, (29), 51-86. http:// www.scielo.org.mx/scielo.php?script=sci_arttext\&pid=S0188-33802008000200003

García-Galván, R. (2011). Revisión de los elementos teórico-conceptuales en torno a la cooperación interfirma e interorganizacional. Análisis Económico 26(62), 185-208. http://www.redalyc.org/articulo.oa?id=41319914010

García-Galván, R. (2014). Desempeño económico y factores que se encuentran detrás del rezago tecnocientífico en México. Cofactor. Revista del Consejo de Investigación y Evaluación de la Política Social, (9), 111-146. http://cofactor.edomex.gob.mx/sites/ cofactor.edomex.gob.mx/files/files/cofactor\%209/COFACTOR_9_ART4.pdf

García-Galván, R. (2017). Cooperación tecnológica, innovación y competitividad: una perspectiva teórica institucional. Análisis Económico, 32(79), 177-199. http://www. analisiseconomico.azc.uam.mx/index.php/rae/article/view/9/9 
García-Galván, R. (2018). El papel de las instituciones y de la colaboración universidadempresa en el desarrollo: evidencias de la UAEMÉX y la UABC. Paradigma económico, (1), 81-118. https://paradigmaeconomico.vaemex.mx/article/download/11009/8901/

García-Galván, R., Cabrera, M.R., \& McAnally, L.S. (2018). La colaboración tecnocientífica de la universidad con su entorno en México: El Caso de la Universidad Autónoma de Baja California. Archivos Analíticos de Políticas Educativas, 26(140), 1-32. https://epaa.asu. edu/ojs/article/viewFile/2994/2157

Gobierno de la República-Consejo Nacional de Ciencia y Tecnología. (2015). Agenda de innovación de Baja California. Resumen ejecutivo. http://www.agendasinnovacion.org/ wp-content/uploads/2015/01/Agenda-Baja-California.pdf

González, L. (2003). Cooperación y Empresas. Retos, Presente y Futuro. Thomson.

Lindquist, R. (2018). La colaboración mediada por el conocimiento entre la UABC y el tercer sector (Tesis de licenciatura). Universidad Autónoma de Baja California, México. https:// drive.google.com/file/d/136_6HFW5pzF7m2/2Y5qkYk52-8xF-Oqn/view

López-Leyva, S. (2002). La vinculación y los investigadores. Perfiles Educativos, 24(97-98), 76-95. http://www.redalyc.org/pdf/132/13209806.pdf

Morales, M., \& Herrera, Y. (2016). La interacción universidad-sector productivo. Un estudio de caso en Cienfuegos, Cuba. En J. Núñez \& A. Alcázar (Coords.), Universidad y desarrollo local: contribuciones latinoamericanas (pp. 131-143). UDUAL/Ministerio de Educación Superior de Cuba. https://www.oei.es/historico/cienciayuniversidad/spip. php?article6539

Plano-Clark, V. L., \& Creswell, J. W. (2008). The Mixed Methods Reader. Sage Publications.

Poy, L. (11 de enero de 2019). Insta la OCDE a eliminar el desfase entre egresados y mercado laboral. La Jornada. https://www.jornada.com.mx/2019/01/11/sociedad/035n1soc

Rama, C. (2010). La irrupción de nuevos modelos socieconómicos, paradigmas educativos y lógicas económicas de la educación. Universidades, 6o(46), 3-16. https://core.ac.uk/ download/pdf/25652940.pdf

Taboada, E. (2004). ¿Qué hay detrás de la decisión de cooperar tecnológicamente? Propuesta teórica integradora para explicar la cooperación tecnológica inter-firma (Tesis doctoral). Universidad Autónoma Metropolitana, México. http://tesiuami.izt.uam.mx/uam/ aspuam/presentatesis. php?recno=12398\&docs=UAMl12398.PDF

Teece, D.J., Pisano, G., \& Shuen, A. (1997). Dynamic capabilities and strategic management. Strategic Management Journal, 18(7), 509-533. https://www.business.illinois.edu/ josephm/BA545_Fall\%202015/Teece,\%20Pisano\%20and\%20Shuen\%20(1997).pdf

Universidad Autónoma de Baja California (UABC). (2015). Plan de Desarrollo Institucional 2015-2019. http://www.uabc.mx/planeacion/pdi/2015-2019/PDI-2015-2019.pdf 


\title{
Capítulo 3
}

\section{Cooperación tecnocientífica en Baja California: diferencias y similitudes entre el discurso institucional y la opinión de los académicos}

\author{
Marcela Morales Páez y Ricardo Lindquist Sánchez
}

Las instituciones de educación superior (IES) juegan un papel importante en la creación de conocimiento y en el avance técnico, no solamente como lugares donde los científicos son entrenados, sino también como fuente de descubrimientos de investigación y técnicas relevantes para la innovación en las industrias (Vertova, 2014). Por lo tanto, las universidades, institutos tecnológicos y laboratorios públicos de investigación deben interactuar con las empresas para ayudarlas a innovar.

La cooperación tecnocientífica (CT $)^{1}$ entre las IES y el sector productivo ha sido un fenómeno relevante en las últimas décadas, por ser un medio para la generación y transmisión del conocimiento, así como para la innovación. Dada su importancia para cualquier región, en este capítulo se presentan los resultados de un estudio enfocado en contrastar el discurso de las IES de Baja California acerca de la cooperación tecnocientífica versus la opinión de los profesores-investigadores.

El estado de Baja California está ubicado en la región noroeste de la república mexicana; al norte comparte frontera con el estado de California (EE. UU.), al sur está delimitado por el paralelo 28, al este es separado del estado de Arizona (EE. UU.) por el río Colorado y tiene colindancia con el mar de Cortés, mientras que, al oeste, colinda con el océano Pacífico.

Los municipios que constituyen este estado son Mexicali, Tijuana, Tecate, Ensenada y Playas de Rosarito (Gobierno del Estado de Baja California, 2019). Al respecto, según Celaya y Barajas (2012), la colindancia con California, uno de los estados más importantes de EE. UU., le otorga ciertas ventajas comparativas a Baja California en el aspecto económico en relación con el resto de los estados de México, ya que en ese estado norteamericano se han establecido importantes centros de investigación y empresas de alta tecnología.

1 Se entiende como cooperación tecnocientífica al conjunto de acciones y actividades de investigación básica y aplicada, encaminadas a generar vínculos entre diversas organizaciones, a partir del reconocimiento de los procesos innovadores desde su origen hasta su aplicación en el ámbito productivo. 


\section{Tabla 1}

\section{Centros públicos de investigación en Baja California}

\begin{tabular}{|c|c|c|c|}
\hline IES & Fundación & Ubicación & Objetivos \\
\hline $\begin{array}{c}\text { Centro de Investigación } \\
\text { Científica y de Educa- } \\
\text { ción Superior de Ense- } \\
\text { nada } \\
\text { (CICESE) }\end{array}$ & 1937 & Ensenada & $\begin{array}{l}\text { 1. Generar conocimiento científico a través de proyectos } \\
\text { de investigación en las áreas de especialidad del cen- } \\
\text { tro. } \\
\text { 2. Formar recursos humanos a nivel de maestría y doc- } \\
\text { torado en las áreas de especialidad del centro a través } \\
\text { de programas de posgrado de calidad reconocida. } \\
\text { 3. Fortalecer la vinculación con los sectores público, pri- } \\
\text { vado y social a través de proyectos de investigación } \\
\text { y desarrollo, servicios tecnológicos, de consultoría y } \\
\text { programas de capacitación. }\end{array}$ \\
\hline $\begin{array}{c}\text { Centro de Investigación } \\
\text { y Desarrollo Tecnológico } \\
\text { en Electroquímica S. C. } \\
\text { (Cideteq) }\end{array}$ & 1991 & Tijuana & $\begin{array}{l}\text { 1. Fortalecer y ampliar las líneas de investigación institu- } \\
\text { cionales y la planta académica con generación y apli- } \\
\text { cación de conocimiento original. } \\
\text { 2. Mantener la oferta académica de posgrado acredita- } \\
\text { da y pertinente e incrementar la competitividad in- } \\
\text { ternacional en la matrícula de alumnos extranjeros, la } \\
\text { movilidad académica y los proyectos y productos en } \\
\text { colaboración. } \\
\text { 3. Desarrollary transferir paquetes tecnológicos propios. } \\
\text { 4. Duplicar la presencia con los tres sectores de influen- } \\
\text { cia del Centro: instituciones, industrias y académica. } \\
\text { 5. Desarrollar las capacidades organizacionales para } \\
\text { protección intelectual e industrial y transferencia for- } \\
\text { mal de conocimiento. }\end{array}$ \\
\hline
\end{tabular}

1. Producir el conocimiento científico de los procesos sociales, económicos, culturales, demográficos, de salud, de género, políticos, gubernamentales, urbanos y del medio ambiente de México y de sus regiones colindantes con Estados Unidos.

2. Transformar este conocimiento en herramientas susceptibles de ser utilizadas en la planeación regional y

El Colegio de la Frontera Norte A. C. (Colef)
1982 Tijuana en políticas e iniciativas públicas y sociales.

3. Identificar y analizar los fenómenos que puedan convertirse en obstáculos al progreso de la región fronteriza, en su integración al desarrollo nacional y en las relaciones entre México y Estados Unidos.

4. Formar profesionistas y personal de investigación de alto nivel académico, capaz de estudiar con rigor científico las realidades regionales, nacionales e internacionales, así como intervenir en su transformación.

Nota: Para el caso del Cideteq se presentan los objetivos estratégicos más relevantes. Elaboración propia con base en información de CICESE (2020), Cideteq (2018a), y Colef (2020). 


\section{Tabla 2}

\section{Institutos de investigación de instituciones públicas nacionales en Baja California}

\begin{tabular}{|c|c|c|c|}
\hline IES & Fundación & Ubicación & Objetivos \\
\hline $\begin{array}{c}\text { Centro de Nanociencias } \\
\text { y Nanotecnología } \\
(\mathrm{CNyN}) \text { de la UNAM }\end{array}$ & $\begin{array}{l}1997 \\
(\text { como } \\
\text { Centro de } \\
\text { Ciencias de } \\
\text { la Materia } \\
\text { Condensa- } \\
\text { da) }\end{array}$ & Ensenada & $\begin{array}{l}\text { 1. Dar entrenamiento multidisciplinario a los jóvenes in- } \\
\text { vestigadores e ingenieros. } \\
\text { 2. Vincularse con su entorno, particularmente en el esta- } \\
\text { do de Baja California, donde hay polos importantes de } \\
\text { innovación tecnológica. } \\
\text { 3. Colaborar con Institutos, Universidades y empresas } \\
\text { de tecnología avanzada particularmente en el área de } \\
\text { San Diego y Los Ángeles. }\end{array}$ \\
\hline $\begin{array}{l}\text { Instituto de Astronomía } \\
\text { (IA) de la UNAM }\end{array}$ & 1974 & Ensenada & $\begin{array}{l}\text { 1. Realizar investigación y generar conocimientos nuevos } \\
\text { en los campos de astrofísica estelar, planetaria, galác- } \\
\text { tica, extragaláctica, medio interestelar e intergalácti- } \\
\text { co, cosmología, altas energías; y otros campos afines, } \\
\text { así como el desarrollo de la instrumentación astronó- } \\
\text { mica y de nuevas tecnologías. } \\
\text { 2. Formar recursos humanos de alta calidad con están- } \\
\text { dares internacionales impartiendo cursos, dirigiendo } \\
\text { tesis e incorporándolos a proyectos de investigación, } \\
\text { en colaboración con institutos y facultades afines de la } \\
\text { UNAM y de otras instituciones educativas y científicas } \\
\text { nacionales e internacionales. } \\
\text { 3. Operar y mantener en óptimas condiciones el Obser- } \\
\text { vatorio Astronómico Nacional en San Pedro Mártir, B. } \\
\text { C., y en Tonantzintla, Puebla; así como generar proyec- } \\
\text { tos de gran envergadura que sitúen a nuestros obser- } \\
\text { vatorios dentro del marco competitivo internacional. } \\
\text { 4. Conformar una red de instituciones nacionales que ela- } \\
\text { bore un Plan Nacional de Desarrollo de la Astronomía. } \\
\text { 5. Llevar a cabo la difusión y divulgación de la astronomía } \\
\text { en particular, y de la ciencia en general. }\end{array}$ \\
\hline $\begin{array}{l}\text { Centro de Investigación } \\
\text { y Desarrollo de } \\
\text { Tecnología Digital (CI- } \\
\text { TEDI) del IPN }\end{array}$ & 1984 & Tijuana & $\begin{array}{l}\text { 1. Realizar investigación aplicada para crear tecnología } \\
\text { digital y promover el desarrollo de la industria } \\
\text { nacional competitiva. } \\
\text { 2. Apoyar a las diversas escuelas, centros y unidades del } \\
\text { IPN, en las investigaciones que realizan. } \\
\text { 3. Desarrollar la tecnología de procesos y la ingeniería } \\
\text { industrial para culminar los ciclos de investigación. }\end{array}$ \\
\hline
\end{tabular}

Nota: Elaboración propia con base en información de CNyN (2020), IA (2012), y CITEDI (2010). 


\section{Tabla 3}

\section{Universidades estatales y locales en Baja California}

\begin{tabular}{|c|c|c|c|}
\hline IES & Fundación & Ubicación & Objetivos \\
\hline $\begin{array}{c}\text { Universidad Autó- } \\
\text { noma del Estado } \\
\text { de Baja California } \\
\text { (UABC) }\end{array}$ & 1957 & $\begin{array}{l}\text { Mexicali } \\
\text { Tijuana } \\
\text { Ensenada } \\
\text { Tecate }\end{array}$ & $\begin{array}{l}\text { (...) dar enseñanza preparatoria y superior para formar } \\
\text { profesionales; fomentar y llevar a cabo investigaciones } \\
\text { científicas, dando preferencia a las que tienden a resolver los } \\
\text { problemas estatales y nacionales; y extender los beneficios } \\
\text { de la cultura. }\end{array}$ \\
\hline $\begin{array}{c}\text { Instituto Tecnológico } \\
\text { de Tijuana (ITT) } \\
\text { del Tecnológico } \\
\text { Nacional de México }\end{array}$ & 1971 & Tijuana & $\begin{array}{l}\text { 1. Formar profesionales e investigadores aptos para la aplica- } \\
\text { ción y generación de conocimientos que les proporcionen } \\
\text { las habilidades para la solución de problemas, con pensa- } \\
\text { miento crítico, sentido ético, actitudes emprendedoras, } \\
\text { de innovación y capacidad creativa para la incorporación } \\
\text { de los avances cientíicos y tecnológicos que contribuyan } \\
\text { al desarrollo nacional y regional; } \\
\text { 2. Diseñar y establecer programas para atender el modelo } \\
\text { de educación dual que propicie el aprendizaje de los alum- } \\
\text { nos, por la vía de su incorporación a la vida laboral y a los } \\
\text { procesos productivos de las empresas, bajo la supervisión } \\
\text { académica de "EL TECNOLÓGICO", en coordinación con } \\
\text { las propias empresas; } \\
\text { 3. Desarrollar e impulsar la investigación aplicada, científica } \\
\text { y tecnológica que se traduzca en aportaciones concretas } \\
\text { para mantener los planes y programas de estudio, actuali- } \\
\text { zados y pertinentes, así como para mejorar la competitivi- } \\
\text { dad y la innovación de los sectores productivos y de servi- } \\
\text { cios y elevar la calidad de vida de la sociedad. } \\
\text { 4. Colaborar con los sectores público, privado y social en la } \\
\text { consolidación del desarrollo tecnológico y la innovación en } \\
\text { el país. } \\
\text { 5. Diseñar y establecer, en coordinación con los sectores so- } \\
\text { cial, público y privado, modelos de vinculación para la in- } \\
\text { novación. }\end{array}$ \\
\hline $\begin{array}{l}\text { Centro de Enseñanza } \\
\text { Técnica y Superior } \\
\text { (CETYS) }\end{array}$ & 1961 & $\begin{array}{c}\text { Tijuana } \\
\text { Ensenada }\end{array}$ & $\begin{array}{l}\text { 1. Impulsar un claustro académico de alto nivel. } \\
\text { 2. Validar la vocación como una institución formadora de } \\
\text { personas. } \\
\text { 3. Operar un sistema multicampus con infraestructura con- } \\
\text { solidada. } \\
\text { 4. Integrar los mejores sistemas y plataformas tecnológicas. } \\
\text { 5. Promover la innovación y diversificar la oferta educativa. }\end{array}$ \\
\hline
\end{tabular}

Nota: En el caso de la UABC, se presentan los fines; en tanto para el ITT, se hace alusión a los objetos más relevantes del Tecnológico Nacional de México, y para el caso del CETYS se presentan algunos de los objetivos estratégicos. Elaboración propia con base en la información de CETYS (2020), Secretaría de Educación Pública (SEP, 2018), y UABC (1957). 
Las IES motivo de investigación pueden ubicarse en un continuo según el potencial que tienen para la generación de conocimiento, el cual se infiere a partir de sus respectivos objetivos. Desde este enfoque, en la tabla 1 se presentan algunos aspectos relevantes de los centros públicos de investigación (CPI), dependientes de Conacyt. En la tabla 2, se analizan los institutos de investigación integrados en la estructura organizacional de las instituciones públicas nacionales: Universidad Nacional Autónoma de México e Instituto Politécnico Nacional. Finalmente, en la tabla 3, las instituciones estatales y locales, dos públicas (Universidad Autónoma de Baja California e Instituto Tecnológico de Tijuana), y una privada, siendo la de mayor renombre de su tipo en el estado (Centro de Enseñanza Técnica y Superior).

El estudio fue guiado por la siguiente pregunta: ¿Existe diferencia entre lo que se menciona en los documentos normativos de las IES y la opinión de sus profesores-investigadores acerca de la cooperación tecnocientífica?

La estrategia de recolección de datos fue la revisión documental y la aplicación de una encuesta de sondeo de opinión a profesores-investigadores de las IES antes mencionadas. La perspectiva metodológica desde la cual se analizaron las respuestas de los profesores-investigadores fue el enfoque mixto.

\section{Marco teórico}

Según Antonelli (2008), a partir de la década de 1980, se comenzaron a generar algunos cambios en los procesos económicos que llevaron al sistema académico (universidades y centros de investigación) a convertirse en un actor clave en la gobernanza (gestión y organización) de la producción del conocimiento. Sin embargo, este modelo de gobernanza solamente funciona si la institución proporciona las gratificaciones suficientes a los investigadores. En el caso particular de los procesos de transferencia de tecnología, la capacidad en el uso de conocimiento científico por parte de las empresas había disminuido — debido a la reducción de la investigación al interior de estas-, por lo que se hacía necesaria la generación de una interfaz que coadyuvara en dicho proceso.

Con respecto a la transferencia de tecnología, Etzkowitz (2003) describió el proceso de vinculación de las universidades con las empresas para el caso particular de Estados Unidos,

el cual ha sido una referencia para otros sistemas académicos del mundo. Durante el siglo $X X$, universidades, académicos y representantes industriales establecieron una serie de relaciones que involucraban consultorías, contratos de investigación, centros de investigación y generación de empresas - comenzando con el Instituto Tecnológico de Massachusetts (MIT) - Etzkowitz (2003) destacó que esta integración de nuevas misiones académicas ha generado serias controversias en cada fase de su desarrollo, por ejemplo, en tanto algunos investigadores propusieron una disminución en la carga docente para dedicar más tiempo a la investigación, otros acusaban a los primeros de abandonar su vocación de educadores. El autor concluyó que la falta de involucramiento de las universidades está cambiando debido 
a las presiones que sufre el sistema académico para contribuir al desarrollo económico y a las nuevas oportunidades de generar mayor riqueza personal.

Adicionalmente, las actividades de la tercera misión que involucran interacciones con personas y organizaciones externas (y que son afectadas por las actividades de las universidades) pueden producir efectos positivos con respecto a la coordinación de las actividades de docencia e investigación, al promover el establecimiento de redes de comunicación que proporcionen retroalimentación positiva a los procesos entre la academia y la industria (Rossi, 2008).

Lo descrito anteriormente da cuenta del proceso de la consolidación de la tercera función sustantiva de las universidades, la cual se puede enunciar como "la función de desarrollo económico y social" parte del cambio institucional que se registra en las IES. En síntesis, estas últimas han tenido tradicionalmente una relación indirecta con el sector productivo (SP) a través de su función docente, es decir, de la formación de egresados que se integran al sector laboral. Al formalizarse la función de investigación en las IES, se dio paso a otro tipo de relaciones más directas, pero unidireccionales, a través de la prestación de servicios y de la investigación bajo contrato. Más recientemente, se ha iniciado una interacción bidireccional en la que las IES aportan conocimiento científico, el cual es utilizado por el sector productivo como base para la generación de innovaciones tecnológicas; en correspondencia, el sector contribuye con recursos económicos o en especie (por ejemplo, infraestructura, laboratorios, facilidades para utilizar equipos industriales) para financiar dichos proyectos de investigación, lo cual conlleva un mejoramiento en la situación económica de las IES (Etzkowitz, 1998; Etzkowitz et al., 2000; García-Galván, 2008).

Existen otros factores que han influido en el alcance de la cooperación IES-SP, tales como: la tendencia internacional a la privatización y a la supremacía del mercado como mecanismos de desarrollo; la reducción del financiamiento de las IES; y la presión hacia las IES ante el fracaso del gobierno y las empresas para impulsar el desarrollo económico y social.

Según Cavazos y García-Galván (2015), en el caso particular de México, el financiamiento a la educación superior se ha dado, en su mayoría (alrededor del 75\%) a través de los recursos públicos; asimismo, el límite a estos recursos está dado por los ingresos del Estado, los cuales dependen de: (a) la proporción entre ingresos públicos y el producto y (b) la magnitud del producto interno bruto (PIB); de forma que, en los países que cuentan con una amplia oferta de servicios públicos, los gobiernos captan una proporción elevada del producto por medio de impuestos.

En consecuencia, a decir de Cavazos y García-Galván (2015), la baja recaudación fiscal de México explicaría la insuficiencia de la oferta de los servicios públicos. Además, en los modelos sustentados en el financiamiento privado, los ingresos generados por las universidades provienen de las cuotas pagadas por los estudiantes, de los ingresos derivados de los contratos de investigación, asesorías y formación continua, y de donaciones particulares. Así, las IES de México podrían ubicarse en diferentes puntos del continuo financiamiento 
público-financiamiento privado según sea el nivel de ingresos de ambas fuentes (Cavazos \& García-Galván, 2015).

\section{Cambio institucional en las IES mexicanas}

Para North (1990), "el cambio institucional configura la forma en que evolucionan las sociedades a través del tiempo y, por lo tanto, es la clave para entender el cambio histórico" (p.3). En otras palabras, el cambio institucional implica todos los procesos tendientes a modificar las instituciones vigentes, tanto informales como formales; el cambio institucional informal puede originar un cambio institucional formal y viceversa. En consecuencia, analizar un fenómeno desde esta perspectiva permite explicar la manera en que los hechos pasados inciden en nuestras acciones y decisiones presentes y futuras.

García-Galván (2018) mencionó que el cambio institucional que se ha venido dando en las organizaciones del conocimiento mexicanas (universidades y centros de investigación) para promover el desarrollo económico, está representado, principalmente, por las siguientes manifestaciones: (a) presión sobre las IES para incrementar la generación de recursos propios; (b) incremento o establecimiento de cuotas; (c) procesos rigurosos de selección, permanencia y promoción para los académicos; (d) contratación de académicos cada vez más jóvenes con el propósito de que su vida productiva sea más larga; (e) asignación de recursos para proyectos de investigación aplicada, y para desarrollos tecnológicos; (f) mayor implicación de las universidades y centros de investigación en la comercialización del conocimiento; y (g) tensión al interior de las IES, entre los partidarios de la apertura a dicha comercialización y aquellos que no lo están.

\section{Estrategia metodológica}

Las técnicas de recolección de datos incluyeron: (a) revisión de documentos oficiales de las IES con potencial de generación de conocimiento tecnocientífico, y $(b)$ encuesta para sondear la opinión de los profesores-investigadores miembros del Sistema Nacional de Investigadores (SNI) que laboran en las IES motivo de análisis. El alcance del estudio fue exploratorio.

Se decidió conocer la opinión de los profesores-investigadores debido a que, según la literatura, son los agentes de las IES que se involucran directamente en las actividades de investigación y cooperación tecnocientífica con el sector productivo. Los investigadores de las universidades y centros de investigación de México están sujetos a un conjunto de incentivos común, otorgado por el Sistema Nacional de Investigadores (SNI), esta situación ayuda a entender la forma en que dichas organizaciones interactúan con el sector productivo (De Fuentes \& Dutrénit, 2012). La elección de los participantes fue intencional, considerando únicamente a los académicos que formaban parte del SNI a la fecha de la aplicación de la encuesta. 
Los profesores-investigadores adscritos a los casos de estudio - CICESE, Cideteq, Colef, CNyN-UNAM, IA-UNAM, CITEDI-IPN, UABC, ITT, y CETYS- representaron el $97.15 \%$ (817 de 841) del padrón de beneficiarios del SNI para el año 2017 en Baja California. De estos 817 que conformaron el marco muestral, únicamente se obtuvieron 774 direcciones de correo electrónico; es decir, la tasa de recuperación global fue de 95\%. La invitación a responder la encuesta se hizo, en primera instancia, mediante una muestra probabilística, pero ante la baja tasa de respuesta se optó por enviarla de forma censal con la información de los participantes obtenida para cada institución. Los análisis se realizaron con base en las 184 respuestas recibidas $(23.77 \%)$.

\section{Análisis y discusión}

A continuación, se presentan los resultados tanto de la revisión documental como del sondeo de opinión descritos anteriormente.

\section{Revisión documental}

En este apartado se presenta la revisión de los documentos de normatividad y prospectiva relacionados con las actividades de cooperación tecnocientífica que llevan a cabo las IES seleccionadas para esta investigación.

\section{Documentos de normatividad de las IES de Baja California}

Se presentan los elementos más relevantes relacionados con la cooperación tecnocientífica, incluidos en los documentos normativos de los Centros de investigación del Consejo Nacional de Ciencia y Tecnología (Conacyt), de las universidades y del Tecnológico Nacional de México (tablas 4 y 5 ).

A partir de la información, se resaltan los siguientes elementos de convergencia. Los documentos de los centros Conacyt (CICESE, Cideteq y Colef) exhiben mayor claridad y profundidad con respecto a las condiciones para la realización de actividades de transferencia de conocimiento y vinculación con los sectores público, social, privado y educativo de los investigadores adscritos a los mismos; en particular, el Colef se distingue del CICESE y del Cideteq, en el fomento de la "innovación social". Asimismo, entre los derechos de los investigadores titulares de estos centros destacan: (a) participar en alianzas tecnológicas, consorcios, unidades de vinculación y transferencia de conocimiento, empresas de base tecnológi$c a$, y redes de innovación e incubadoras de empresas; (b) percibir la remuneración y regalías generados a partir de trabajos realizados al servicio del Centro, por concepto de derechos de propiedad intelectual. Este último punto también es considerado en los estatutos de personal académico de la UNAM y la UABC, en los cuales, además, se establecen los lineamientos respecto del tiempo permitido para realizar este tipo de actividades. 


\section{Tabla 4 \\ Aspectos relacionados con la cooperación tecnocientífica en documentos normativos de los centros Conacyt}

\begin{tabular}{|c|c|}
\hline Documento & Aspectos relevantes \\
\hline $\begin{array}{l}\text { Estatuto del personal } \\
\text { académico Cideteq } \\
(2018)\end{array}$ & $\begin{array}{l}\text { Una de las principales actividades de los investigadores es su contribución en la } \\
\text { transferencia tecnológica, generación de propiedad intelectual y vinculación con } \\
\text { los sectores público, social, privado, educativo o empresarial (Art. 6). Entre las } \\
\text { obligaciones del personal académico, se incluye su participación en la vinculación con } \\
\text { los sectores público, social, privado, educativo o empresarial de bienes o servicios, } \\
\text { así como en alianzas estratégicas, alianzas tecnológicas, consorcios, unidades de } \\
\text { vinculación y transferencia de conocimiento, empresas de base tecnológica, redes de } \\
\text { innovación e incubadoras de empresas (Art. 13). }\end{array}$ \\
\hline $\begin{array}{l}\text { Estatuto del personal } \\
\text { académico CICESE } \\
(2018)\end{array}$ & $\begin{array}{l}\text { Lasfunciones sustantivas deICICESE, a cargo del personalacadémico, incluyen: realizar } \\
\text { investigación científica básica y aplicada, tecnológica y de innovación; coadyuvar en la } \\
\text { transferencia tecnológica al sector productivo; y desarrollar actividades de innovación } \\
\text { tecnológica y vinculación (Art. 5). Entre los derechos del personal académico destacan: } \\
\text { (a) el desempeño de actividades en otras organizaciones, (b) su participación en } \\
\text { asociaciones estratégicas, alianzas tecnológicas, consorcios, unidades de vinculación } \\
\text { y transferencia de conocimiento, empresas de base tecnológica, redes de innovación } \\
\text { e incubadoras de empresas, y (c) la remuneración y regalías por concepto de derechos } \\
\text { de propiedad intelectual. Entre sus obligaciones sobresalen: (a) la vinculación con } \\
\text { los sectores público, social, privado, educativo o empresarial de bienes y servicios, } \\
\text { (b) su participación en eventos de docencia, investigación, desarrollo tecnológico, } \\
\text { innovación o vinculación, y (c) la colaboración en asociaciones estratégicas, alianzas } \\
\text { tecnológicas, consorcios, unidades de vinculación y transferencia de conocimiento, } \\
\text { empresas de base tecnológica, redes de innovación e incubadoras deempresas (Art. g). }\end{array}$ \\
\hline $\begin{array}{l}\text { Estatuto del personal } \\
\text { académico Colef } \\
\text { (2018) }\end{array}$ & $\begin{array}{l}\text { Como actividad adicional a la investigación, docencia y vinculación, se incluye la de } \\
\text { "Contribuir a la innovación social mediante la generación de conceptualizaciones, } \\
\text { metodologías, diseños, procesos y servicios en el área de las ciencias sociales" (Art. 6). } \\
\text { El personal de investigación tiene derecho a participar en los procesos de innovación } \\
\text { y vinculación dentro su campo de especialidad, asimismo, a percibir la remuneración } \\
\text { y las regalías por derechos de propiedad intelectual (Art. 9). Entre sus obligaciones, } \\
\text { destaca la de llevar a cabo actividades de investigación, docencia, difusión del } \\
\text { conocimiento, desarrollo tecnológico y vinculación, así como la vinculación con los } \\
\text { sectoressocial, públicoyprivado, educativo oempresarial debienesoservicios(Art.10). }\end{array}$ \\
\hline
\end{tabular}

Nota: Elaboración propia con base en información de CICESE (2018), Cideteq (2018) y Colef (2018).

\section{Tabla 5}

Aspectos relacionados con la cooperación tecnocientífica en documentos normativos de las universidades 
Estatuto del personal

académico de la UNAM

(1970)

Ley orgánica del Instituto

Politécnico Nacional (1981)

No se incluyen elementos relacionados con la CT.

Entre las atribuciones del Instituto Politécnico Nacional destaca la oferta de servicios de asesoría a los sectores público, social y privado para la elaboración y desarrollo de planes y programas de investigación científica y tecnológica, asimismo, la promoción de industrias y servicios que lo vinculen con el sistema nacional de producción (Art. 4). Paralelamente, entre lasfacultadesyobligaciones del Director General se incluye la de "Celebrar convenios de cooperación tecnológica, asesoría técnica, prestación de servicios y de intercambio de experiencias, con otros centros educativos, dependencias del gobierno federal, entidades federativas, municipios y en general, con organismos de los sectores público, social y privado" (Art. 14).

Reglamento interior de trabajo del personal docente de los institutos No se incluyen elementos relacionados con la CT. tecnológicos (2008)

Estatuto del personal académico de la $U A B C$ (1982)

Reglamento de Propiedad Intelectual de la $\cup A B C$ (2017)
No se incluyen elementos relacionados con la CT.

La UABC tiene la custodia del conocimiento, que resulte susceptible de propiedad, intelectual generado a través de sus programas y proyectos, así como del derivado de las actividades realizadas por su personal (Art. 5). Las funciones del Órgano de Propiedad Intelectual son: administrar y operar lo relativo a esta materia en la UABC (Art. 35).

Se establece que las unidades académicas organizarán sus programas de trabajo considerando la vinculación, entendida como: "las acciones que permitan la incidencia directa del trabajo que se desarrolla en cada unidad académica en el entorno social, económico, político, cultural y administrativo" (Art 21, Fracción III). También se considera la figura de los consejos de vinculación, definidos como: "la instancia académica de comunicación y orientación formal entre la Universidad y su entorno" (Art. 28). Existe la figura de una coordinación general de Extensión de la Cultura y Divulgación de la Ciencia. Asimismo, se considera una coordinación general de Vinculación y Cooperación Académica, que tiene como propósito: "promover, facilitar y registrar los convenios y contratos con los sectores públicos, privado y social, y registrar resultados de sus evaluaciones" (Art. 95, Fracción I).

El Modelo Educativo de la UABC, considera que "la extensión de los beneficios de la cultura y los servicios constituye un excelente canal de comunicación y retroalimentación con la sociedad. Y que es el medio idóneo para enriquecer la formación de su comunidad interna y externa. A través de sus diversas modalidades, la extensión universitaria permite que la institución se mantenga firmemente vinculada al contexto, tanto como difusora, promotora y divulgadora de cultura, como en su carácter de institución capaz de prestar servicios y contribuir a la atención de algunos problemas sociales del entorno, en particular, de aquéllos asociados a los sectores más desprotegidos y menos beneficiados de la sociedad" (p. 82). 
En cuanto al término vinculación, se le entiende como "toda actividad que involucra cuatro actores fundamentales: universidad, empresa, sociedad y Estado. La vinculación no se concibe como un proceso aislado, sino se sitúa en distintos contextos y coyunturas que conllevan diversas acciones que la relacionan con otros conceptos como el desarrollo científico y la innovación tecnológica, en las cuales la investigación científica es piedra angular" (p. 82). En el Modelo, se considera que la vinculación tiene impacto en la formación profesional de los estudiantes, propiciando: (a) contribuir a la formación profesional a través de la prestación de servicios; (b) complementar la enseñanza en el aula con un aprendizaje centrado en enfoques de solución de problemas o en el análisis de casos; (c) Complementar el aprendizaje del alumno desde la perspectiva del aprender a hacer y aprender en servicio; (d) Promover y estimular la interacción del docente con los sectores productivos; (e) Favorecer la incorporación, como invitados en el aula, de profesionistas exitosos que participan como docentes o conferencistas y aplican su experiencia profesional y conocimientos de vanguardia en la formación integral del futuro profesionista, y en su interacción dinamizan el quehacer académico de la institución; (f) asociar los contenidos de las unidades de aprendizaje al desarrollo de una práctica profesional en escenarios reales en el ámbito laboral y en el desarrollo de proyectos de investigación que apliquen o generen nuevo conocimiento (p. 84). En cuanto a las modalidades, la vinculación considera las acciones de: "contratación de servicios, prácticas profesionales, servicio social, investigación aplicada, desarrollo e innovación tecnológicos, educación continua, formación de emprendedores, consultoría y asistencia técnica que propician el desarrollo social, cultural, económico y productivo de la región" (p. 84). Asimismo, puntualiza que el proceso de vinculación "parte del diagnóstico de necesidades regionales y nacionales, el cual se construye a partir de las demandas de acciones de vinculación que tienen su origen en los sectores social, privado o público y que determinarán el nivel de involucramiento de la institución o las unidades académicas en el planteamiento de las acciones de vinculación que deberán proponerse para dar respuesta a las demandas de origen" (p. 84).

Las funciones sustantivas del CETYS Universidad tienen, entre otras, las siguientes características: la vinculación con los diversos sectores productivos y

Estatuto General del Sistema CETYS Universidad otros, y el compromiso para dar respuesta a los retos que plantea el desarrollo de la región y el país (Art. 11). El CETYS Universidad debe propiciar la investigación científica aplicada y de desarrollo tecnológico, encaminada tanto a la generación de nuevos conocimientos y tecnologías como a la aplicación práctica de los conocimientos existentes (Art. 13).

Nota: Elaboración propia con base en información de Instituto Educativo del Noroeste (s.f.), Ley orgánica del Instituto Politécnico Nacional (1981), Ley orgánica de la Universidad Nacional Autónoma de México (1945), UNAM (1970), Tecnológico Nacional de México (2008), UABC (1982; 2014; 2017; 2019a).

En síntesis, algunos aspectos de particular importancia para el análisis de la cooperación tecnocientífica son: (a) la Ley Orgánica del IPN es el único documento en el que se explicita la necesidad de generar industrias y servicios que vinculen a la institución con el sistema nacional de producción $y$, en consecuencia, le permitan impulsar el desarrollo nacional; (b) a través del Reglamento de Propiedad intelectual, la UABC protege el conocimiento derivado de sus programas, proyectos y actividades realizadas por su personal, y establece las condiciones para la creación y funcionamiento del Órgano de Propiedad Intelectual; y 
(c) el Estatuto General del Sistema CETYS Universidad hace énfasis en la vinculación con los diversos sectores productivos y otros, así como en el compromiso con la región y el país.

Una observación relevante se da en el sentido de que los documentos de legislación de las IES no exhiben elementos relacionados con la cooperación con el sector productivo hasta inicios de la década de 1980, lo cual da cuenta del cambio institucional que se ha venido dando en las IES estatales, encaminado a regular las actividades de cooperación tecnocientífica.

\section{Documentos de planeación de las IES de Baja California}

Enseguida se presentan los documentos de planeación institucional que orientan las acciones de las IES, en los cuales se incluyen elementos de interés en relación con las actividades de cooperación tecnocientífica (tablas 6 y 7 ).

Es importante destacar que el Programa Estratégico de Mediano Plazo (2014-2018) del Colef, fue el único documento de planeación de los tres centros Conacyt al que pudo accederse vía Internet. Por otra parte, la UNAM y el IPN, como universidades nacionales, tienen en común líneas de acción encaminadas a la generación de políticas institucionales para: (a) el fomento de actividades de innovación y desarrollo tecnológico, (b) la promoción de la cultura de la innovación y del desarrollo tecnológico y (c) la formación de investigadores y académicos comprometidos con la divulgación y aplicación del conocimiento. Por su parte, además de coincidir con los aspectos anteriores, concentran sus esfuerzos de vinculación en lograr que la Universidad tenga mayor presencia entre la sociedad, lo que podría interpretarse como un ejercicio para mejorar la imagen y el posicionamiento. Asimismo, se plantea la necesidad de vincularse para la obtención de ingresos propios que posibiliten el desarrollo de las actividades universitarias.

\section{Tabla 6}

Aspectos relacionados con la cooperación tecnocientífica en documentos de planeación de los centros Conacyt

\begin{tabular}{cl}
\hline Documento & \multicolumn{1}{c}{ Aspectos relevantes } \\
\hline & Los resultados relevantes del diagnóstico en materia de vinculación incluyeron las siguientes \\
& debilidades: (a) comunicación insuficiente, con áreas específicas, en los niveles local, \\
& regional, nacional e internacional; $y$ (b) personal designado a la realización de las actividades \\
de vinculación con bajo nivel de calificación. Asimismo, la oportunidad más relevante & \\
Colef Programa & fue la necesidad, por parte de las instituciones gubernamentales, académicas, sociales y \\
Estratégico de & empresariales, deestudioscientíficoscomo insumo paralatomade decisionesyaccionespara \\
Mediano Plazo & el desarrollo. En contraparte, la principal amenaza residió en la existencia de "restricciones \\
(2014-2018) & normativas y presupuestales que no facilitan estrategias de comunicación masivas ni \\
& la contratación de personal con mayores calificaciones en estas áreas" (p. 5). Respecto \\
& a la difusión, la debilidad más destacable fue la poca experiencia que tienen los sectores \\
& empresariales para relacionarse con instituciones científicas de investigación social (p. 6). \\
\hline
\end{tabular}

Nota: Elaboración propia con base en información de Colef (2014). 


\section{Tabla 7 \\ Aspectos relacionados con la cooperación tecnocientífica en documentos de planeación de las universidades}

\begin{tabular}{|c|c|}
\hline Documento & Aspectos relevantes \\
\hline $\begin{array}{c}\text { UNAM } \\
\text { Plan de Desarrollo } \\
\text { Institucional 2015- } \\
\text { 2019* }\end{array}$ & $\begin{array}{l}\text { Se establece que la estructuración del Plan de Desarrollo Institucional se sustenta } \\
\text { en las funciones sustantivas y en las tareas esenciales de la institución: docencia, } \\
\text { investigación, extensión, difusión, vinculacióny gestión (p. 2). El programa estratégico } \\
\text { 8, denominado Investigación, está "dirigido al fomento, apoyo y evaluación de la } \\
\text { investigación, para la generación de conocimientos de frontera y enfocados a atender } \\
\text { los problemas nacionales y globales" (p. 32). En este programa destaca la necesidad de } \\
\text { implementar estrategias para la acreditación de los laboratorios universitarios, con la } \\
\text { finalidad de ofrecer servicios a los sectores productivos del país. A su vez, el programa } \\
\text { estratégico 9, Innovación y desarrollo tecnológico, está encaminado a "incrementar } \\
\text { la capacidad de respuesta de la Universidad a los requerimientos contemporáneos } \\
\text { y futuros en materia de innovación y desarrollo tecnológico" (p. 34). Las líneas de } \\
\text { acción asociadas a este programa incluyen: (a) definir políticas de ciencia, tecnología } \\
\text { e innovación; (b) impartir cursos para fomentar una actitud emprendedora que } \\
\text { propicie en los estudiantes; (c) promover la transferencia tecnológica, de las patentes } \\
\text { registradas por la UNAM, hacia organizaciones nacionales e internacionales; (d) crear } \\
\text { unprogramaparafavorecerlatransferenciadelconocimiento, (e)consolidarunsistema } \\
\text { institucional de información en el cual se integren patentes, servicios y laboratorios; } \\
\text { (f) crear un consejo asesor integrado por representantes de las entidades que } \\
\text { realizan investigación con posibilidad de transferencia tecnológica y de innovación, } \\
\text { así como miembros del sector empresarial; y (g) crear un catálogo de las capacidades } \\
\text { de vinculación y de los instrumentos de protección de la propiedad intelectual. }\end{array}$ \\
\hline $\begin{array}{c}\text { IPN Programa de } \\
\text { Desarrollo Institucional } \\
2019-2024\end{array}$ & $\begin{array}{l}\text { En el eje fundamental 3, Conocimiento para la solución de problemas nacionales, se } \\
\text { proponen tres grandes componentes: (a) investigación, desarrollo tecnológico } \\
\text { e innovación de alto impacto social y científico; (b) formación y consolidación } \\
\text { de investigadores y (c) difusión de la ciencia, la innovación y la cultura científica y } \\
\text { tecnológica. En cuando al primer componente mencionado, se establece el objetivo } \\
\text { de: "Implementar un nuevo esquema de la investigación en el Instituto a través de } \\
\text { la generación del 'Sistema Institucional de Investigación, Desarrollo e Innovación } \\
\text { Tecnológica', la participación activa de la comunidad y la consolidación de redes de } \\
\text { innovación, investigación y de expertos que fomenten el trabajo multidisciplinario } \\
\text { y multired, para la obtención de productos de alta calidad que aporten soluciones a } \\
\text { problemas nacionales" (p. 43). Por su parte, el componente de difusión de la ciencia, } \\
\text { la innovación y la cultura científica y tecnológica, se propone: "Divulgar los logros de } \\
\text { la ciencia, el desarrollo tecnológico y la innovación entre la comunidad politécnica y } \\
\text { la sociedad mexicana, para generar vocaciones científicas, promover la apropiación } \\
\text { social del conocimiento y resaltar la importancia de la cultura científica y tecnológica } \\
\text { para la resolución de problemas nacionales y la comprensión de la naturaleza y la } \\
\text { sociedad" (p.45). }\end{array}$ \\
\hline $\begin{array}{l}\text { Plan de desarrollo } \\
\text { CETYS } 2020\end{array}$ & $\begin{array}{l}\text { En el objetivo estratégico 1, orientado a "impulsar un claustro académico de alto nivel } \\
\text { de formación que enriquezca las tareas de docencia, investigación y extensión, con } \\
\text { enfoque hacia medición del aprendizaje y uso de la tecnología" (p. 29), destaca la } \\
\text { iniciativa relacionada con los Centros de Excelencia, los cuales son espacios destinados } \\
\text { tanto al impulso y desarrollo de la investigación y la vinculación como al mejoramiento } \\
\text { de la calidad académica de la institución. Los Centros de Excelencia del Sistema }\end{array}$ \\
\hline
\end{tabular}


CETYS (Cexcu) nacen en asociación con los colegios del Sistema CETYS (Ingeniería, Administración y Negocios, y Ciencias Sociales y Humanidades), A través de los Cexcu, se pone a disposición de los distintos sectores, principalmente del estado, servicios de alta calidad para potenciar el desarrollo regional); sus funciones incluyen tanto la generación de nuevo conocimiento como la aplicación del existente.

En el apartado del diagnóstico destinado a la vinculación se hace referencia a que, en 2012 el Modelo de Incubación de Empresas del Sistema Nacional de Institutos Tecnológicos ya se había implantado en 58 institutos tecnológicos, lo cual permitió la creación de 1,742 empresas. Además, con el propósito de fortalecer la vinculación con los diversos sectores de la sociedad, sobre todo con el sector productivo, se fomentó la integración de los Consejos Institucionales de Vinculación de los Institutos Tecnológicos, tal que, para ese mismo año, el $95 \%$ de los institutos ya contaban con este órgano de apoyo, asesoría y consulta (p.30).

Entre los problemas detectados en esta área, destacan: (a) mecanismos rudimentarios para la transferencia de conocimiento y desarrollo tecnológico hacia el sector productivo; (b) marco normativo inapropiado para impulsar el desarrollo de la

Tecnológico Nacional de México

Programa Institucional de Innovación y Desarrollo 20132018* propiedad intelectual y la transferencia de conocimiento; y (c) no se considera a los Centros de Incubación e Innovación Empresarial en la estructura orgánica (p. 30). Al respecto, destaca el Objetivo 5. Consolidar la vinculación con los sectores público, social y privado. Así, de la estrategia 5.1. Fortalecer los esquemas de vinculación institucionales, la línea de acción de relevancia se enfoca en fortalecer los mecanismos de vinculación con la iniciativa privada. Asimismo, a la estrategia 5.3. Impulsar la transferencia de conocimiento y de desarrollo tecnológico al sector productivo, corresponden las líneas de acción encaminadas a: (a) la generación de un marco normativo para la creación y operación de Oficinas de Transferencia de Tecnología en los institutos; (b) la difusión y comercialización de los productos generados en la investigación científica y tecnológica; (c) la generación de proyectos de desarrollo tecnológico que involucren la inversión pública y privada. Por último, la estrategia 5.4. Desarrollar el talento emprendedor y la creación de empresas de base tecnológica, incluye las siguientes líneas de acción: (a) consolidación del Modelo Talento Emprendedor para fomentar la cultura emprendedora y la incubación de empresas; (b) consolidación del Modelo de Incubación del Tecnológico Nacional de México; (c) operación de los Centros de Incubación e Innovación Empresarial para incrementar la creación de empresas, preferentemente de base tecnológica; y (d) impulso al Modelo de Atención y Aceleración Empresarial, con enfoque al desarrollo tecnológico de micro, pequeñas y medianas empresas.

En su eje 3, Investigación, desarrollo tecnológico e innovación, la UABC establece el objetivo de: "Generar, aplicar y difundir conocimientos en los distintos campos disciplinares, que contribuyan al desarrollo regional, nacional e internacional" (p.102). Por otra parte, en su eje 4, Extensión y Vinculación, se identifica el objetivo de "contribuir al desarrollo regional y nacional mediante el fortalecimiento de las

UABC Plan de relaciones de la universidad con los sectores público, privado y social, con base en la divulgación de los conocimientos científicos, humanísticos y tecnológicos, así como de la cultura, las artes y las actividades deportivas" (p.104). Con este propósito, se reconocen las estrategias: (a) Fortalecer la presencia de la universidad en la sociedad a través de la divulgación del conocimiento y la promoción de la cultura y el deporte; (b) consolidar los esquemas de vinculación institucional con los sectores público, privado y social, y (c) impulsar mecanismos para la generación de ingresos propios a través de la vinculación con el entorno social y productivo.

Nota: *Al corte de la revisión (junio de 2020) no se contaba con un programa actualizado. Elaboración propia con base en la información de Instituto Educativo del Noroeste (2011), IPN (2019), Tecnológico Nacional de México (2014), UABC (2019b), y UNAM (2017). 
En el caso del ITT (ahora parte del Tecnológico Nacional de México), se observa un mayor interés en la apertura de Oficinas de Transferencia Tecnológica, la incubación de empresas de base tecnológica y el fomento del talento emprendedor; coincidiendo también en el primer punto con la UABC y en el tercero con el IPN. Finalmente, CETYS (universidad privada) destaca con un modelo innovador de colaboración con el entorno productivo, a través de los Centros de Excelencia del Sistema CETYS (Cexcu), en los cuales se planea poner a disposición de los distintos sectores servicios de alta calidad para potenciar el desarrollo regional.

Los documentos de planeación de las IES de Baja California, con potencial para la generación de conocimiento tecnocientífico, exhiben numerosos elementos encaminados a dar una estructura institucional y organizacional a las actividades de cooperación tecnocientífica. El desafío es llevar a la práctica todo lo establecido en dichos documentos, para ello se requiere de la voluntad de todos los sectores involucrados y destinar los recursos suficientes para alcanzar las metas planteadas.

A continuación, se presentan algunas conclusiones generales de los documentos normativos de las IES de Baja California:

- Los documentos de legislación de las IES no exhiben elementos relacionados con la vinculación, colaboración o cooperación con el sector productivo hasta inicios de la década de 1980.

- En los documentos de planeación de las IES de Baja California se establecen numerosos elementos encaminados a dar una estructura institucional y organizacional a las actividades de cooperación tecnocientífica.

Una vez revisados el discurso oficial de las IES motivo de estudio, en el siguiente apartado se detallan los resultados del sondeo de la opinión de los profesores-investigadores acerca de cuestiones relevantes para la cooperación tecnocientífica.

\section{Análisis de opinión}

Se presenta la opinión de los participantes acerca de las condiciones en las que se lleva a cabo, actualmente, la cooperación tecnocientífica IES-SP en Baja California; obtenida a través de preguntas abiertas.

Las respuestas de los profesores-investigadores a las preguntas fueron analizadas y codificadas; en particular, para la segunda pregunta, los códigos resultantes se agruparon con base en criterios teóricos. Posteriormente, se calculó la densidad de respuesta por cada código; dichas densidades se representaron por medio de gráficas.

Como resultado de los análisis cualitativos, también se presentan las percepciones de los profesores-investigadores de cada IES motivo de estudio, en voz propia de los encuestados.

Las respuestas de los profesores-investigadores en relación con la pregunta ¿Cómo considera que serán dentro de 10 años las funciones sustantivas (docencia, investigación y 
vinculación) ${ }^{2}$ ? fueron codificadas bajo los criterios de mejoría, estancamiento o deterioro (figura 1). Como puede observarse, los comentarios respecto de que "Todas" las funciones sustantivas seguirán igual o mejorarán sobrepasan las densidades de 40 y 60 respectivamente, con pocos comentarios (menos de 10) relacionados con su deterioro. Los casos particulares de la investigación y la vinculación presentan un comportamiento muy similar entre sí, ya que ambas densidades se inclinan hacia la mejoría. Caso contrario es el de la docencia, para la cual la mayoría de las respuestas se dieron en el sentido de su deterioro.

\section{Figura 1}

Opinión sobre las funciones sustantivas de las IES dentro de 10 años

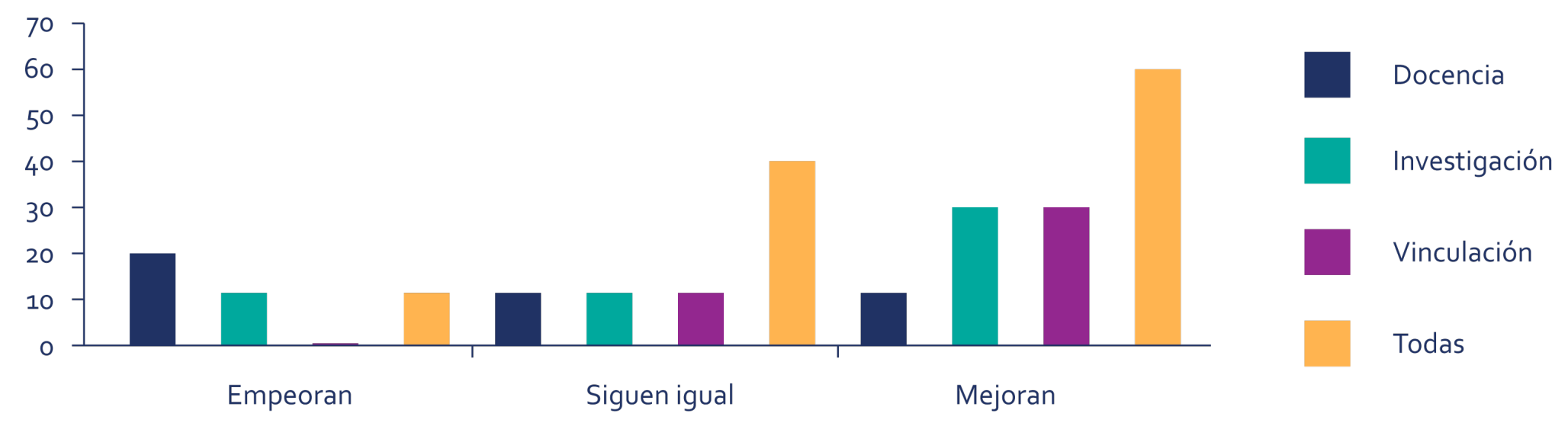

Nota: Elaboración propia con base en las respuestas del cuestionario.

Desde el enfoque cualitativo, respecto a la pregunta ¿Cómo considera que serán dentro de 10 años las funciones sustantivas (docencia, investigación y vinculación)? Algunos de los participantes centraron sus respuestas en la función de investigación. Por ejemplo, un profesor-investigador de la UABC comentó:

Si las políticas institucionales no cambian la investigación será de menor calidad. (P2O_UABC)

En esta afirmación se encuentra implícita la necesidad de realizar mejoras en el marco institucional de la universidad, el cual incluye la normatividad y prospectiva. La aportación anterior puede complementarse con otro señalamiento de un participante de la misma institución:

El problema es que la mayoría de las empresas locales maquilan, no diseñan. Entonces, resolverles problemas prácticos implica que requieren muy buenos ingenieros, no investigadores. (P157_UABC)

2 Las categorías de agrupación implican la opinión de los encuestados acerca de su visión de las funciones de las IES a futuro, o del ideal de cómo deberían ser. 
En este caso, el encuestado hace alusión a la baja capacidad de absorción de conocimiento tecnocientífico, originado a partir de la investigación, que tienen las empresas del estado. Respecto de la vinculación, se destaca el siguiente comentario de un profesor-investigador del ITT, a través del cual se corrobora la necesidad de contar con personal especializado para coordinar estas actividades:

Considero que en 10 años la docencia e investigación puede ser tarea que puede llevar a cabo un investigador por sí solo, sin embargo, para que se dé la vinculación es necesario personal que dé fuerte apoyo a los investigadores, para efectuar el enlace adecuado para vinculación. (P48_ITT)

En el caso de las respuestas de los participantes, enfocadas en la función de docencia, es preocupante que la mayoría de los comentarios sean en el sentido del detrimento de esta. Por ejemplo, entre los comentarios de los profesores-investigadores de la UABC, destacan los siguientes:

Docencia: una profesión en desuso, dado el avance de la tecnología que hará que los alumnos sean más autodidactas y necesiten menos al docente. (P25_UABC)

Al desempeñarme en una universidad es fundamental la docencia, sin embargo, considero que la interacción con la empresa y la cooperación con esta no se favorece. En 10 años probablemente la vinculación sea preponderante para el desarrollo local y regional, la docencia si bien seguirá siendo importante, la presión del sistema por vincularnos demeritará nuestra función como docentes. (P76_UABC)

Se pudo observar que la mayoría de los investigadores hicieron comentarios acerca del comportamiento de las tres funciones sustantivas a largo plazo, entre los cuales destacan los siguientes:

La docencia será más un acompañamiento, donde el estudiante aplique los conocimientos en contextos reales. Con relación a la investigación, las empresas deberán financiar la mayoría de las investigaciones, actualmente su aportación al GIDE es mínima. ${ }^{3}$ En cuanto la colaboración mediada por el conocimiento, se intensificarán los lazos entre IES, sectores productivos, sociales y gobierno para resolver problemas y aprovechar oportunidades. (P38_UABC) ván, 2015), la función del gobierno como financiador de la tecnociencia es indispensable. Una vez alcanzado un piso mínimo de inversión como proporción del PIB, la inversión privada comenzará a fluir. 
Las IES le darán prioridad a la vinculación, sin embargo, se deja de lado que la investigación no siempre da resultados con aplicaciones a corto y mediano plazo: esa visión tan corta es parte de lo que mantiene al país rezagado. La docencia es cada vez de peor calidad porque se favorece el graduar a un alto número de estudiantes, pero no se pone atención en la calidad de la formación de los mismos. Y todo por cumplir criterios internacionales que mantienen a ciertos países (como México) formando obreros. (P132_UABC)

Se esperarían relaciones más estrechas con el sector productivo. Por una parte, para el fortalecimiento del perfil práctico de los estudiantes $y$, en segundo lugar, porque cada vez será más difícil conseguir financiamiento para realizar investigación. La inserción al campo laboral por parte del docente es cada vez más compleja, por lo que veo a una IES ocupada en la formación de egresados capaces de entrar al sistema educativo, pero también preparados para la creación de fuentes de empleo. (P169_UABC)

En la tabla 8 se presentan las categorías resultantes de la codificación de las respuestas de los encuestados a la pregunta: ¿Qué aspectos de la investigación que se realiza actualmente deben cambiar para facilitar la cooperación tecnocientífica?

Además, se agruparon las categorías con base en el análisis teórico. Su clasificación obedece a los diversos enfoques encontrados en las respuestas, tales como: investigación, procesos administrativos y de gestión, cambio institucional, recursos y capacidades, y procesos académicos.

En particular, los procesos académicos (con 19 menciones) no son considerados como factor de cambio relevante para mejorar la cooperación tecnocientífica. Caso contrario, son los aspectos relacionados con la investigación (con 67 menciones).

En relación con las respuestas a la pregunta: ¿Qué aspectos de la investigación que se realiza actualmente deben cambiar para facilitar la cooperación tecnocientífica? se realizó un análisis cualitativo utilizando los siguientes criterios: institución de adscripción y enfoques de las aportaciones (investigación, procesos administrativos y de gestión, cambio institucional, recursos y capacidades, y procesos académicos). A continuación, se presentan las aportaciones de los profesores-investigadores desde cada uno de los contextos laborales particulares, es decir, centros públicos de investigación (CPI) o universidades.

En los CPI, los comentarios respecto a la investigación se centraron en la necesidad de superar la dicotomía ciencia básica-ciencia aplicada, en desarrollar ambos tipos de investigación, así como en la importancia de la investigación para el desarrollo económico regional, por ejemplo: 
Dejar de pensar que todo lo que se investiga debe tener una aplicación, si volvemos a las bases que formaron la ciencia lograremos mejores desarrollos tecnológicos, que actualmente muchos de ellos no tienen fundamentos fuertes para continuar $y$ que muy pronto se vendrán abajo. (P35_CICESE)

\section{Tabla 8}

Aspectos de la investigación que deben cambiar (agrupados por enfoque)

\begin{tabular}{lc}
\multicolumn{1}{c}{ Categoría } & Número de menciones \\
\hline Investigación & 67 \\
Delimitar líneas estratégicas de investigación & 3 \\
Enfoque hacia la investigación aplicada & 46 \\
Enfoque hacia la investigación básica & 18 \\
\hline Procesos administrativos y de gestión & 57 \\
Hacer más eficientes los procesos burocráticos & 27 \\
Racionalizar funciones sustantivas & 10 \\
Mejorar mecanismos de vinculación & 20 \\
\hline Cambio institucional & \\
Sobrevaloración de indicadores cuantitativos & 57 \\
Generación de propiedad intelectual & 9 \\
Enfoque multidisciplinario para la cooperación tecnocientífica & 2 \\
Mayor cooperación con PyMES & 6 \\
Fomento a la creación de empresas tecnocientíficas & 1 \\
Reformas institucionales y políticas & 2 \\
Interacción de diversos sectores & 11 \\
Sensibilización del sector productivo en cuanto a la cooperación tecno- & 5 \\
científica & 18 \\
Fomento del emprendimiento & 3 \\
\hline Recursos y capacidades & 55 \\
Mayores apoyos financieros & 33 \\
Infraestructura y equipo & 10 \\
Incrementar el personal de apoyo a la investigación & 5 \\
Contratación de especialistas en cooperación tecnocientífica & 7 \\
\hline Procesos académicos & 19 \\
Mayor movilidad académica & 2 \\
Reestructuración de programas académicos & 5 \\
Capacitación en cooperación tecnocientífica & 12 \\
\hline
\end{tabular}

Nota: Elaboración propia con base en las respuestas del cuestionario.

En la categoría denominada procesos administrativos y de gestión se destacaron aspectos a mejorar como el exceso de trámites burocráticos, la comunicación entre las IES y el sector productivo, así como incrementar los vínculos:

Mayor vinculación con los sectores demandantes. (P38_UABC) 
En relación con el cambio institucional, se obtuvieron propuestas enfocadas en diversos aspectos, como el uso de las publicaciones académicas, la necesidad de realizar cambios en el marco normativo de las IES, aspectos relacionados con los cambios necesarios en el sector productivo, la inclusión de las actividades de cooperación tecnocientífica en los esquemas de incentivos institucionales, así como la importancia de una interacción más intensa entre los diversos actores involucrados en la generación y transferencia de conocimiento:

En la evaluación de la productividad del investigador (para la asignación de incentivos monetarios) debe incluir la calidad y cantidad de la cooperación tecnocientífica personal de cada investigador. (P114_Colef)

Se necesita un mejor conocimiento y adecuación con las reglas y normativas asociadas. Invitar a los sectores productivos a beneficiarse de los conocimientos generados por los investigadores. (P115_Colef)

Con respecto a los recursos y capacidades de las IES, se obtuvieron respuestas encaminadas a la mejora de los apoyos financieros:

Mayor financiamiento ángel a proyectos de desarrollo tecnológico no basados en proyectos de investigación. (P167_CICESE)

En la última categoría, procesos académicos, los comentarios incluyeron aspectos de formación de estudiantes y académicos:

Fortalecimiento en conocimientos y actitudes de los egresados de pregrado. (P83_ CICESE)

La capacitación para la vinculación con empresas. (P133_CICESE)

Por otra parte, los comentarios de los profesores-investigadores de las universidades respecto de la investigación se centraron en mejorar aspectos del desarrollo de ciencia básica y aplicada, así como en la pertinencia de las investigaciones realizadas:

Considero que particularmente la investigación básica puesto que, la información básica es el punto de partida para saber "cómo aplicar" el conocimiento y desarrollar tecnología. (P131_UABC) 
Orientación hacia demandas sociales y sectores, donde la universidad pueda generar vínculos estables y duraderos que aprovechen conocimiento acumulativo desarrollado por los investigadores y cuerpos de investigación. (P184_UABC)

No solo deben ser relevantes académicamente, sino que deberán garantizar su pertinencia social. (P179_CETYS)

En relación con los procesos administrativos y de gestión, los encuestados de las universidades comentaron sobre la necesidad de mejorar la administración y de hacer más eficientes los procesos burocráticos:

Reducción de la notable carga administrativa y barreras burocráticas que los investigadores enfrentan para el desarrollo de sus proyectos de investigación. ( $\mathrm{P}_{172}$ $\mathrm{UABC}$ )

En la categoría de cambio institucional, se incluyeron comentarios relacionados con aspectos como la mejora del marco institucional, la evaluación de los profesores-investigadores, y la necesidad de incentivar el desarrollo tecnocientífico del sector productivo:

[...] los centros de investigación y los posgrados deben considerar el enfoque de vinculación tecnocientífica para diversificar los perfiles de egresados, para lograr programas que usen recursos mixtos, para tener mayor participación en el sector productivo y para mejorar los lazos entre sociedad e instituciones. (P121_IA-UNAM)

Tener un mayor peso en las evaluaciones, la cooperación tecnocientífica. (P776IAUNAM)

Para que haya cooperación tecnocientífica es necesario que la iniciativa privada demande e incorpore a la ciencia y a la tecnología dentro de su esquema de producción. (P21_IA-UNAM)

Respecto a los recursos y capacidades de las IES, las respuestas incluyeron aspectos relacionados con mayor financiamiento, mejoras en la infraestructura, y personal especializado:

Mayores apoyos financieros para creación de redes temáticas de investigación y para proyectos estratégicos de alcance regional y nacional. (P1_IA-UNAM)

Que se cuente con la infraestructura necesaria y que la institución atienda de manera sistemática su relevancia. (P158_CETYS) 
Hace falta una persona de enlace en las diferentes facultades, encargada de hacer los trámites y dar seguimiento a los desarrollos tecnológicos, para descargar de esta tarea a los mismos investigadores. (P81_UABC)

Por último, en la categoría de procesos académicos se obtuvieron respuestas enfocadas en los planes y programas de estudio, y en la capacitación de los académicos en materia de cooperación tecnocientífica:

Darungiro a la visióny misión de los programas académicos [...](P16_CNyN-UNAM)

Personas preparadas para incubar este tipo de cooperaciones dentro de cada IES, es decir, que haya un grupo gestor de este tipo de actividades especializado y preparado, tanto administrativamente como disciplinariamente, para bridar asesoría. Ya que los investigadores tienen muchas otras actividades, la falta de un plan estratégico, desde mi punto de vista, resultará siempre en un resultado incompleto, esto es, la probabilidad de que la propuesta-proyecto obtenga los resultados esperados para las dos partes, la IES y el solicitante de la demanda específica, se reduce sin seguimiento adecuado. (P183_UABC)

Finalmente, en la tabla 9 se presenta una síntesis del contraste entre lo que se explicita en los documentos normativos y de prospectiva de las IES, y la opinión de los profesoresinvestigadores.

\section{Tabla 9}

Contraste entre el discurso institucional y la opinión de los encuestados

\begin{tabular}{|c|c|c|c|}
\hline Dimensión & $\begin{array}{l}\text { Documentos de } \\
\text { normatividad de las IES }\end{array}$ & $\begin{array}{l}\text { Documentos de } \\
\text { planeación de las IES }\end{array}$ & $\begin{array}{l}\text { Opinión de los } \\
\text { profesores-investigadores }\end{array}$ \\
\hline mica & $\begin{array}{l}\text { Reconocimiento, como función sus- } \\
\text { tantiva, de la generación de conoci- } \\
\text { miento científico y de su aplicación } \\
\text { para resolver problemas regionales. } \\
\text { Reconocimiento, como función sus- } \\
\text { tantiva, de la vinculación con los ac- } \\
\text { tores públicos, sociales y privados. } \\
\text { Presencia de objetivos relacionados } \\
\text { con el registro de patentes, el desa- } \\
\text { rrollo de propiedad intelectual y la } \\
\text { transferencia de tecnología. }\end{array}$ & $\begin{array}{l}\text { Elementos de vinculación } \\
\text { poco especializados. } \\
\text { Falta de promoción entre } \\
\text { los académicos acerca del } \\
\text { registro de patentes y la } \\
\text { transferencia tecnológica. }\end{array}$ & $\begin{array}{l}\text { Falta de capacitación en los } \\
\text { académicos para la coope- } \\
\text { ración tecnocientífica. } \\
\text { Necesidad de fortalecer la } \\
\text { investigación básica, rele- } \\
\text { gada por el énfasis en la in- } \\
\text { vestigación aplicada. }\end{array}$ \\
\hline
\end{tabular}




\begin{tabular}{|c|c|c|c|}
\hline Dimensión & $\begin{array}{l}\text { Documentos de } \\
\text { normatividad de las IES }\end{array}$ & $\begin{array}{c}\text { Documentos de } \\
\text { planeación de las IES }\end{array}$ & $\begin{array}{l}\text { Opinión de los } \\
\text { profesores-investigadores }\end{array}$ \\
\hline Institucional & $\begin{array}{l}\text { Los productos de investigación de- } \\
\text { ben estar alineados con las necesida- } \\
\text { des (económicas, políticas o sociales) } \\
\text { del entorno. } \\
\text { Reconocimiento de la IES como una } \\
\text { instancia que realiza esfuerzos inter- } \\
\text { disciplinarios con otras instituciones } \\
\text { sociales. } \\
\text { Modelos educativos-formativos que } \\
\text { consideran el compromiso social. }\end{array}$ & $\begin{array}{l}\text { Ausencia de un catálogo } \\
\text { de capacidades de inves- } \\
\text { tigación/vinculación. } \\
\text { Necesidad de acreditar es- } \\
\text { pacios universitarios para } \\
\text { que sean utilizados por los } \\
\text { sectores productivos. } \\
\text { Problemáticas de comu- } \\
\text { nicación entre la acade- } \\
\text { mia y las instancias exter- } \\
\text { nas. } \\
\text { Falta de transparencia en } \\
\text { las actividades de vincula- } \\
\text { ción. } \\
\text { Fortalecer las capacida- } \\
\text { des de incubación empre- } \\
\text { sarial. }\end{array}$ & $\begin{array}{l}\text { Falta de sensibilización del } \\
\text { sector empresarial hacia la } \\
\text { cooperación tecnocientífica. } \\
\text { Necesidad de hacer más } \\
\text { eficientes los procesos bu- } \\
\text { rocráticos. } \\
\text { Importancia de realizar re- } \\
\text { formas institucionales y po- } \\
\text { líticas. } \\
\text { Falta de apoyos financieros } \\
\text { para la cooperación tecno- } \\
\text { científica. } \\
\text { Necesidad de mejorar los } \\
\text { mecanismos de vincula- } \\
\text { ción. }\end{array}$ \\
\hline
\end{tabular}

\section{Conclusiones}

Desde la década de 1980, con el auge de la mercantilización y la progresiva reducción del financiamiento de la educación superior, el sector productivo y las IES han sostenido una alianza estratégica mediada por las relaciones de conocimiento. En las IES, esto ha propiciado un cambio institucional que puede observarse en la adecuación de su tercera función sustantiva. Así, donde antes se hablaba de vinculación, extensión o difusión de la cultura, hoy se discute la importancia de una función de desarrollo económico y social.

En este sentido, las IES han considerado desde entonces la cooperación tecnocientífica en sus documentos normativos. Principalmente, se observa como un eje común que las tres funciones sustantivas se encuentren supeditadas a la respuesta de las demandas del entorno. Buscando así que los modelos formativos fomenten el emprendimiento y el compromiso social, que la investigación considere la producción de conocimiento pertinente, y que la vinculación (o función del desarrollo social y económico) se realice de forma óptima para dar respuesta a las problemáticas de los actores públicos, privados y sociales.

A pesar de que estas actividades se encuentran consideradas en la normatividad, las IES reconocen, en sus documentos de planeación estratégica, que existen factores académico-institucionales que deben fortalecerse para propiciar la cooperación tecnocientífica. En la dimensión institucional, las IES identifican la necesidad de contar con elementos responsables de vinculación debidamente capacitados y con mecanismos más eficientes y transparentes para vincularse con los actores del entorno. Los académicos, por su parte, coinciden 
en que las autoridades institucionales deben sensibilizar y capacitar a sus elementos para que realicen este tipo de actividades. Pero puntualizan que esto no conducirá a relaciones exitosas con el sector productivo mientras no se agilicen los procesos administrativo-burocráticos, se incremente el financiamiento, se realicen reformas políticas e institucionales y se aligere la saturación laboral.

En suma, hemos podido observar que existe consenso, tanto en las autoridades institucionales como en su personal académico, al afirmar que la cooperación tecnocientífica es un elemento indispensable para el desarrollo de las IES. Sin embargo, existen discrepancias en cuanto a las formas de incentivarla. Por un lado, las autoridades institucionales consideran que el cambio en los académicos —sea en procesos de sensibilización o capacitaciónincrementará esta actividad. Mientras que los académicos señalan que dicho cambio no podrá desarrollarse mientras no existan las condiciones institucionales para hacerlo: financiamiento óptimo, procesos administrativos eficientes y políticas institucionales que coadyuven y no obstaculicen la cooperación.

En este sentido, el reto para las IES radica en la conjunción de esfuerzos. Por un lado, en el compromiso institucional para garantizar las condiciones para la cooperación tecnocientífica $y$, en correspondencia, en la disposición de los académicos para que el conocimiento producido contribuya a satisfacer las demandas del entorno. Esto, desde luego, requerirá de elementos de vinculación altamente especializados que puedan optimizar las relaciones de comunicación intrainstitucionales, para después llevar a cabo procesos de cooperación tecnocientífica con el sector productivo y el resto de los actores sociales. 


\section{Referencias}

Antonelli, C. (2008). The new economics of the university: a knowledge governance approach. Journal of Technology Transfer, 33, 1-22.

Cavazos, G., \& García-Galván R. (2015). Fundamentos teórico-empíricos del financiamiento de la educación superior en México. En E. Rodríguez \& R. García-Galván (Coords.), El desastre económico mexicano, 1982-2011 (pp.135-229). Universidad Autónoma del Estado de Hidalgo.

Celaya, M., \& Barajas, M.R. (2012). La academia y el sector productivo en Baja California. Los actores y su capacidad de vinculación para la producción, difusión y trasferencia del conocimiento y la innovación. Región y sociedad, (55), 41-80. https://www. researchgate.net/publication/262736436_La_academia_y_el_sector_productivo_en_ Baja_California_Los_actores_y_su_capacidad_de_vinculacion_para_la_produccion_ difusion_y_trasferencia_del_conocimiento_y_la_innovacion

Centro de Enseñanza Técnica y Superior (CETYS). (2020). ¿Quiénes somos? https://www. cetys.mx/quienes-somos/

Centro de Investigación y Desarrollo de Tecnología Digital (CITEDI). (2010). Conócenos. https://www.citedi.ipn.mx/portal/conocenos.php

Centro de Investigación Científica y de Educación Superior de Ensenada (CICESE). (2018). Estatuto del personal académico. https://cicese-at.cicese.mx/int/index. php?mod=acd\&op=norma

Centro de Investigación Científica y de Educación Superior de Ensenada (CICESE). (2020). Acerca del CICESE. https://www.cicese.edu.mx/welcome/acerca/

Centro de Investigación y Desarrollo Tecnológico en Electroquímica (Cideteq). (2018a). Informe de rendición de cuentas de conclusión de la administración 2012-2018. https:// www.cideteq. $\mathrm{mx} /$ rendicion-de-cuentas/

Centro de Investigación y DesarrolloTecnológico en Electroquímica (Cideteq). (2018). Estatuto del personal académico. https://www.cideteq.mx/wp-content/uploads/2018/04/16.7.1Estatuto-del-Personal-Acad\%c3\%agmico-Revisado.pdf

Centro de Nanociencias y Nanotecnología (CNyN). (2020). Objetivo. https://www.cnyn.unam. $\mathrm{mx} /$ index.php?option=com_content\&view=article\&id=78\&/temid=112\&lang=en

De Fuentes, C., \& Dutrénit, G. (2012). Best channels of academia-industry interaction for long-term benefit. Research Policy, 41(9), 1666-1682.

El Colegio de la Frontera Norte. (Colef). (2014). Convenio de Administración por resultados (Anexos), periodo 2014-2018. https://www.colef.mx/transparencia/rendicion-decuentas/

El Colegio de la Frontera Norte. (Colef). (2018). Estatuto de personal académico. https://www. colef.mx/normatecainterna/wp-content/uploads/2014/11/EPA-Vigente-aprobado-16julio-2018.pdf 
El Colegio de la Frontera Norte. (Colef). (2020). Acerca de El Colegio de la Frontera Norte. https://www.colef.mx/el-colef/\#objetivos

Etzkowitz, H. (1998). The norms of entrepreneurial science: cognitive effects of the new university-industry linkages. Research Policy, 27(8), 823-833.

Etzkowitz, H. (2003). Research groups as 'quasi-firms': the invention of the entrepreneurial university. Research Policy, 32(1), 109-121. https://doi.org/10.1016/S00487333(02)00009-4

Etzkowitz, H., Webster, A., Gebhardt, C., \& Cantisano, B.R. (2000). The future of the university and the university of the future: evolution of ivory tower to entrepreneurial paradigm. Research Policy, 29(2), 313-330. https://doi.org/10.1016/S0048-7333(99)00069-4

Foray, D. (2004). Economics of Knowledge. The MIT Press.

García-Galván, R. (2008). Análisis teórico de la transferencia de conocimientos universidadempresamediante la colaboración. RevistaEconomía:Teoríay práctica, (29), 51-86. http:// www.scielo.org.mx/scielo.php?script=sci_arttext\&pid=S0188-33802008000200003

García-Galván, R. (2015). Cinco factores que inhiben la colaboración tecnológica universidadempresa en los países en desarrollo. Tiempo Económico, 29(10), 67-80. http:// tiempoeconomico.azc.uam.mx/wp-content/uploads/2017/08/29te5.pdf

García-Galván, R. (2018). Cooperación tecnocientífica universidad-empresa e interfirma: Análisis teórico integrado desde la perspectiva de la economía institucional contemporánea. Ciencia y Universidad. Revista de economía, (37), 5-30.

Gobierno del Estado de Baja California. (2019). Ubicación del Estado de B.C.

Instituto de Astronomía (IA). (2012). Objetivos. https://www.astroscu.unam.mx/IA/index. php?option=com_content\&view=article\&id=409: mision-vision -ia\&catid=2: uncategor ised\&ltemid=95\&lang=es

Instituto Educativo del Noroeste A. C. (s.f.). Estatuto General del Sistema CETYS Universidad. https://wasc.cetys.mx/institutional/CD_Institutional_Portfolio/31_GENERAL\%20 STATUTE/Spanish/ESTATUTO\%20GENERAL_CETYS.pdf

Instituto Educativo del Noroeste A. C. (2011). Plan de Desarrollo CETYS 2020. https://www. cetys.mx/wp-content/uploads/2017/02/PlanFINAL.pdf

Instituto Politécnico Nacional (IPN). (2019). Programa de Desarrollo Institucional 2019-2024. https://intranet.ciidiroaxaca.ipn.mx/avisos/wp-content/uploads/2020/o1/Programade-Desarrollo-Institucional-PDI-2019-2024.pdf

Ley Orgánica de la Universidad Nacional Autónoma de México (1945, enero 6). Diario Oficial de la Federación de México. Cámara de Diputados del H. Congreso de la Unión, DOF o601-1945. http://www.diputados.gob.mx/LeyesBiblio/pdf/158.pdf

Ley Orgánica del Instituto Politécnico Nacional (1981, diciembre 29). Diario Oficial de la Federación de México. Cámara de Diputados del H. Congreso de la Unión, DOF 29-121981. http://www.diputados.gob.mx/LeyesBiblio/pdf/171.pdf 
North, D. (1990). Institutions, institutional change and economic performance. Cambridge University Press. https://doi.org/10.1017/CBO9780511808678

Rossi, F. (2008). The economics of knowledge and the governance of universities' third stream activities. DIME Working paper 87.

Secretaría de Educación Pública (SEP). (2018). Manual de organización general delTecnológico Nacional de México. Diario Oficial de la Federación de México, DOF 20-12-2018.

Tecnológico Nacional de México. (2008). Reglamento interior de trabajo del personal docente de los institutos tecnológicos. https://www.tecnm.mx/pdf/jur\% $\% \mathrm{C}_{3} \% \mathrm{ADdico} /$ REGLAMENTO_DOCENTE.pdf

Tecnológico Nacional de México. (2014). Programa Institucional de Innovación y Desarrollo 2013-2018. http://www.dgest.gob.mx/piid-2013-2018

Universidad Autónoma de Baja California (UABC). (1957). Ley orgánica de la Universidad Autónoma del Estado de Baja California. http://www.uabc.mx/institucion/normatividad. html

Universidad Autónoma de Baja California (UABC). (1982). Estatuto del personal académico de la Universidad Autónoma de Baja California. http://www.ordenjuridico.gob.mx/Estatal/ BAJA\%20CALIFORNIA/Estatutos/BCEST01.pdf

Universidad Autónoma de Baja California (UABC). (2014). Modelo Educativo de la UABC. http://www.uabc.mx/enfermeria/documentos/modedu/modedu_vabc2013.pdf

Universidad Autónoma de Baja California (UABC). (2017). Reglamento de Propiedad Intelectual de la Universidad Autónoma de Baja California. http://sriagral.uabc.mx/ Externos/AbogadoGeneral/Reglamentos/ReglamentosInstitucionales/20_Reg_Prop_ Intelectual.pdf

Universidad Autónoma de Baja California (UABC). (2019a). Estatuto General de la Universidad Autónoma de Baja California. http://sriagral.uabc.mx/Externos/AbogadoGeneral/ Reglamentos/Estatutos/02_EstatutoGeneralUABC_19-11-2019.pdf

Universidad Autónoma de Baja California (UABC). (2019b). Plan de Desarrollo Institucional 2019-2023. http://pedagogia.mxl.vabc.mx/transparencia/PDI/PDI_UABC_2019-2023. pdf

Universidad Nacional Autónoma de México (UNAM). (1970). Estatuto del personal académico de la Universidad Nacional Autónoma de México. http://www.abogadogeneral.unam. $\mathrm{mx} /$ sites/default/files/2018-05/171.pdf

Universidad Nacional Autónoma de México (UNAM). (2017). Plan de Desarrollo Institucional 2015-2019. https://www.rector.unam.mx/

Vertova, G. (2014). The State and National Systems of Innovation: A Sympathetic Critique. Levy Economics Institute Working Paper Collection No. 823. http://www.levyinstitute. org/pubs/wp_823.pdf 


\title{
Capítulo 4
}

\section{Cooperación de la Universidad de Baja California con el entorno. Perspectiva de los usuarios}

\author{
Rodolfo García Galván y Alicia Alelí Chaparro Caso-López
}

La cooperación de las organizaciones del conocimiento (universidades y centros públicos de investigación) con su entorno regional, ha sido un fenómeno que se ha venido estudiando -más extensamente- desde finales de los 1970, registrando un crecimiento exponencial en los 30 años siguientes, principalmente, en la cooperación que involucra a las empresas de los sectores basados en la ciencia y la tecnología (García-Galván, 2012). De esta manera, el marcado sesgo hacia el estudio de las relaciones universitarias con el sector productivo, no ha dejado fuera por completo al análisis de las interacciones con el sector social (organizaciones no gubernamentales, comunidades y grupos organizados, ni tampoco se ha desvinculado a las funciones y tareas universitarias de las diversas necesidades del sector público (gobierno en sus diferentes ámbitos). Sin embargo, lo que puede advertirse es que la investigación relacionada a la cooperación universitaria con los actores del sector social y los que pertenecen al gobierno, tiene un largo trayecto por recorrer.

En virtud de lo anterior, en este capítulo se revisan ¿cuáles son las características preeminentes de los vínculos colaborativos, mediados por el servicio social y las prácticas profesionales, que se dan entre una organización del conocimiento como la Universidad Autónoma de Baja California (UABC) con los actores del entorno regional (organizaciones sociales en general, empresas y entes gubernamentales)? Asimismo, el objetivo es llevar a cabo un análisis exploratorio-descriptivo de estas actividades, a través de una metodología cuantitativa básica.

La importancia de realizar este tipo de exploraciones radica en que la UABC requiere revisar sus mecanismos y fines de cooperación ante los actores de su vecindad territorial, esto de cara al debate abierto, como lo señala De Sousa (2017), sobre las crisis de hegemonía y de legitimidad de la universidad en la producción, distribución-intercambio y uso del conocimiento universitario. Adicionalmente, sin tener la intención de realizar un estudio simétrico de las relaciones colaborativas con cada uno de los actores, resulta pertinente redimensionar la relevancia de los vínculos de la $U A B C$ con los actores sociales más vulnerables y con los diferentes ámbitos gubernamentales. 
El capítulo se encuentra estructurado de la siguiente manera: en el primer apartado se aborda el contexto institucional de las interacciones universitarias con el entorno regional; en segundo lugar, se encuentran los aspectos metodológicos donde se describen las especificidades de las unidades receptoras de los estudiantes que realizan su servicio social y sus prácticas profesionales; posteriormente, se presentan los resultados y la discusión centrados en el proceso de vinculación per se, y las relaciones con los estudiantes y los egresados universitarios.

\section{Contexto institucional de las relaciones con los actores del entorno}

Desde hace mucho tiempo, las universidades, de manera directa o indirecta, se han relacionado con las actividades productivas, sociales y gubernamentales. Algunos sistemas universitarios - como el alemán-, prácticamente se consolidaron de la mano del sector productivo; pues históricamente han estado estrechamente vinculados con las actividades empresariales. Otros sistemas universitarios como el latinoamericano surgieron y se fortalecieron del lado de las principales necesidades sociales y de los requerimientos del gobierno en cuanto a los perfiles profesionales requeridos para la gestión pública. Y, aunque en un lapso de aproximadamente 30 años, las universidades latinoamericanas y mexicanas intentaron emular las políticas universitarias del mundo anglosajón — de poner en el centro de la atención las demandas empresariales-, por su idiosincrasia, no se han alejado completamente de lo que los grupos sociales más vulnerables reclaman. En este sentido, las reflexiones de Arocena y Sutz (2005, 2010), Arza (2010), Langer (2008), y Naidorf (2014) apuntan a que las universidades y las organizaciones del conocimiento, en general, tienen una función y labor social difícil de sustituir.

La atención a los problemas multidimensionales y complejos de los grupos sociales más vulnerables, puede ser un indicativo del propio poder hegemónico y de la legitimidad de las universidades, como lo destaca De Sousa (2017). Por lo tanto, si las organizaciones del conocimiento se retraen o se alejan cada vez más de sus bases sociales, al tiempo que profundizan sus vínculos con el sector productivo (empresas grandes y gigantes), puede ser una decisión costosa en lo que se refiere al respaldo social ante cualquier ataque o presión externa. Además, ante los fuertes cuestionamientos epistémicos del rol empresarial ante el calentamiento global, el cambio climático, la especulación financiera, la excesiva concentración del ingreso y la riqueza; así como de la desigualdad y la pobreza crónicas; quizá la universidad y los centros públicos de investigación tengan que reflexionar si es conveniente seguir profundizando los nexos con el capital, o por el contrario, retomar, reconstruir y fortalecer las alianzas históricas con las masas sociales. Al final de cuentas, a las universidades latinoamericanas las financia la sociedad en general, mediante sus contribuciones a las oficinas fiscales, y en su lugar, muchas veces las grandes empresas apenas y contribuyen de manera simbólica. 
Sin embargo, no hay que pasar por alto el hecho de que el sector productivo también se compone de unidades productivas micro, pequeñas y medianas empresas (mipymes), que le dan sustento material a la mayor parte de las familias latinoamericanas y mexicanas. Se trata pues, de una base productiva estrechamente vinculada a las actividades y necesidades, económicas y sociales, del grueso de la población. En consecuencia, si bien es cierto que las universidades y los centros públicos de investigación no tienen por qué convertirse en rehenes de los intereses más excéntricos de las grandes empresas, sí tienen que atender las necesidades y problemáticas de las mipymes. Principalmente, como señala García-Galván $(2008,2012)$, se requiere intensificar la cooperación tecnocientífica de las universidades con este tipo de empresas para lograr una auténtica reconversión productiva, y alcanzar mayores niveles de productividad y competitividad. Adicionalmente, como lo sostienen Ruiz y Laguna (2018), en la carrera tecnológica no hay límites para explorar en campos inéditos; en este sentido, puede ser que una economía altamente desarrollada lidere en varios sectores económicos, pero prácticamente es una imposibilidad estar a la vanguardia en todo y para siempre. En realidad, desde hace mucho tiempo, se sabe que las mipymes siempre pueden aprovechar los huecos y los intersticios en los que a las firmas grandes o gigantes se les dificulta enormemente actuar o concretar las oportunidades, como lo señaló Penrose (1959) desde hace casi 70 años.

Por otro lado, las universidades y los centros de investigación pueden ejercer un papel protagónico en el impulso de las pequeñas empresas de base tecnocientífica (start ups, spinoffs y spin outs); al respecto, las incubadoras de empresas hospedadas en las organizaciones del conocimiento se convierten en esenciales, máxime cuando se pretende impulsar desde los centros del conocimiento una verdadera revolución tecnológica. Así, los directivos de las universidades deben ser cautos porque una auténtica revolución productiva y tecnológica, como lo establece Pérez (2004), lleva tiempo en consolidarse, y sus principales manifestaciones se comienzan a observar en el largo plazo (de 30 a 50 años).

Recapitulando, la función social de las organizaciones del conocimiento, y su fomento deliberado de las actividades productivas basadas en el conocimiento, no son tareas incompatibles y tampoco son eventos mutuamente excluyentes, pues las mipymes tienen una base social que no se puede negar. Ahora bien, si alguna o varias mipymes, en algún momento, llegaran a ser grandes o gigantes, de todas maneras las organizaciones del conocimiento siempre deben asumir el papel de ser un ambiente propicio para el surgimiento de unidades económicas que desafien el statu quo productivo. En otras palabras, las universidades pueden actuar como las plataformas que siempre están proveyendo de nuevas firmas para generar un ambiente económico de competencia económica más sana.

Aparte del fuerte vínculo que debería existir en las universidades y las mipymes, no debe pasarse por alto el rol de las organizaciones del conocimiento para formar los futuros cuadros para la acción gubernamental. De hecho, las responsabilidades de las universidades pueden ir desde preparar los recursos humanos para ofrecer, administrar y gestionar las actividades 
del sector público hasta formar a los futuros dirigentes políticos y gubernamentales. En casos más ambiciosos, como lo sostienen Ordorika y Pusher (2007), algunas grandes universidades de países como Argentina, Brasil y México pueden ser consideradas como universidades constructoras de Estado-nación.

Extrapolando esta última idea, las universidades de las entidades federativas en México podrían contribuir, enormemente, a la profesionalización y consolidación de administraciones públicas más efectivas en la prestación de los servicios públicos. Y, si hasta ahora las organizaciones del conocimiento se han desentendido de tal necesidad, es el momento en que las universidades públicas estatales se propongan revolucionar la forma en la que se gestionan o administran los recursos y los servicios públicos.

Las contribuciones universitarias al fortalecimiento de la administración pública federal, estatal y municipal pueden ir desde capacitar a los servidores públicos en la atención a las demandas y solicitudes de los ciudadanos hasta una verdadera profesionalización en el diseño y operación de las políticas gubernamentales y públicas que abarquen aspectos como el papel estratégico del mantenimiento de servicios públicos básicos como el acondicionamiento de calles, avenidas y banquetas, el alumbrado público, el agua potable y el drenaje, y el sistema de salud pública; así como el adecuado ejercicio para la administración de justicia y la prevención de la seguridad ciudadana.

A la atención prioritaria de los servicios públicos convencionales hay que agregar otros de última generación, como el aseguramiento del desarrollo sustentable (mitigación de la contaminación multidimensional, combate al cambio climático y reverdecimiento de las zonas urbanas). Adicionalmente, la administración pública requiere una mayor y más estrecha cooperación universitaria para asegurar de manera sustentable, sostenible y progresiva las fuentes de los ingresos tributarios, y es precisamente en este último rubro donde resulta prioritaria la atención a las fuentes de ingresos propios, pues a los efectos perniciosos del centralismo fiscal tienen que agregársele la improvisación, la ineficiencia y el poco profesionalismo de las autoridades estatales y municipales, para tan siquiera hacer efectivo el derecho constitucional a cobrar cierto tipo de impuestos.

Las problemáticas del sector público, descritas previamente, a veces no son reconocidas por las autoridades gubernamentales en sus diferentes ámbitos de competencia, ni por las autoridades universitarias, y esa es una condición necesaria para dar los primeros pasos en la consolidación de las oficinas recaudadoras municipales y estatales. Lo más dramático que a veces se observa en los quehaceres universitarios, es que las propias autoridades de estas organizaciones del conocimiento, únicamente se mantienen a la espera de las directrices y los guiones que establecen los gobiernos federal y estatal, sin que haya propuestas o iniciativas que surjan de las aulas, los cubículos o las oficinas universitarias.

En síntesis, si la UABC pretende ampliar y consolidar los vínculos de cooperación con los principales actores del entorno, este es el momento de poner más atención a las comunidades, organizaciones sociales y grupos poblacionales vulnerables; pero también a los re- 
cursos y capacidades tecnocientíficas de las micro, pequeñas y medianas empresas. Aunque tampoco deben pasarse por alto las enormes insuficiencias en el ofrecimiento de los servicios públicos, y en el aseguramiento de fuentes de ingresos propios, principalmente, de los gobiernos estatales y municipales. Hasta ahora, la $U A B C$ ha destinado sus mayores esfuerzos a ampliar y consolidar los vínculos con las empresas, sin que ello implique una estrategia bien planeada para favorecer de manera prioritaria a las mipymes.

En las líneas de los siguientes apartados, se hace una revisión exploratoria-descriptiva del estado que guarda la cooperación de la $U A B C$ con los usuarios del entorno (unidades receptoras de los productos, los servicios y los recursos humanos proveídos por la universidad), que se constituyen esencialmente por las empresas, las organizaciones sociales y el gobierno en sus tres niveles. Como el lector podrá observar, lo que ha ido más lejos es la cooperación con el sector productivo, quedando un largo camino por recorrer en lo que se refiere a la cooperación con el sector social, y con el gobierno, esencialmente en los ámbitos estatal y municipal.

\section{Metodología}

Para la aplicación de la encuesta se buscaron todas las unidades receptoras, registradas en la base de datos de la Coordinación de Formación Profesional y Vinculación Universitaria (CFP$\mathrm{VU})$, con las que la $U A B C$ establece relaciones de vinculación. Sin embargo, solo se logró la participación de 84 .

La aplicación de la encuesta fue de tipo censal en formato electrónico, a través de la plataforma Lime Survey. La convocatoria se realizó desde la CFPVU. El período de aplicación fue del 15 de mayo al 15 de junio de 2017.

\section{Características de las unidades receptoras}

De acuerdo con los datos recabados, 53.57\% de las unidades receptoras que respondieron la encuesta pertenece al sector empresarial, $23.80 \%$ a la sociedad civil, $16.66 \%$ al sector gubernamental y $2.38 \%$ a Instituciones de Educación Superior (IES) públicas y privadas (tabla 1).

\section{Tabla 1}

Unidades receptoras participantes por sector

\begin{tabular}{lcc}
\hline \multicolumn{1}{c}{ Actores del entorno regional } & Unidades receptoras & Porcentaje \\
\hline Sector empresarial & 45 & $53 \cdot 57 \%$ \\
Sociedad civil & 20 & $23.80 \%$ \\
Gobierno (Federal, Estatal y Municipal) & 14 & $16.66 \%$ \\
IES públicas y privadas & 2 & $2.38 \%$ \\
Otro o indefinido & 3 & $3.57 \%$ \\
\hline Total & 84 & 100 \\
\hline
\end{tabular}




\section{Áreas de conocimiento a las que pertenecen los programas educativos atendidos en las unidades receptoras}

Las unidades receptoras, dependiendo del sector y necesidades, convocan la participación de estudiantes de distintos programas educativos. De acuerdo con la información recabada, de los estudiantes que realizan actividades de vinculación el $28.93 \%$ pertenecen al área de ciencias económico-administrativas, $25.78 \%$ a las ciencias de la ingeniería y la tecnología, $19.49 \%$ a las ciencias sociales, $9.43 \%$ a las ciencias de la educación y humanidades, $8.80 \%$ a las ciencias de la salud, $4.40 \%$ a las ciencias naturales y exactas, y el $3.14 \%$ restante a las ciencias agropecuarias.

\section{Resultados y Discusión}

Los resultados se presentan en cuatro grandes rubros: proceso de vinculación, relación con los estudiantes, relación con los egresados y valoración de los servicios de la UABC.

\section{Proceso de vinculación $U A B C$-unidades receptoras}

Origen de la vinculación

El 52.38\% de los representantes de las unidades receptoras señaló que los nexos se dieron mediante el acercamiento de esta con la UABC, el 34.52\% que se realizó a partir del acercamiento de los estudiantes, el $10.71 \%$ a través del acercamiento de algún docente; finalmente, la promoción interna de la UABC y medios electrónicos fueron referidos por el $1.19 \%$ de los participantes. Evidentemente, esto denota una enorme área de oportunidad para las autoridades de la universidad, pues el nivel de la promoción se mantiene cercano a cero.

\section{Trámites burocráticos de la vinculación}

El 20.24\% de las UR indicó que los trámites de la UABC para la participación de los estudiantes en las actividades colaborativas no son fáciles, el $52.38 \%$ los consideró medianamente fáciles, y solo el $27.38 \%$ señaló que son muy fáciles. En este rubro también existe un gran espacio para mejorar la gestión física y digitalizada de las actividades de vinculación universitaria.

Relevancia de la vinculación

El $91.67 \%$ de los informantes de las UR consideró que es muy importante para su organización establecer acciones de vinculación con la UABC. De hecho, por la complementariedad de activos, de capacidades tecnológicas y la mitigación de riesgos inherentes a la investigación científico-tecnológica, para algunas organizaciones la cooperación con las organizaciones del conocimiento es indispensable. 


\section{Relación con los estudiantes}

\section{Apoyo a los estudiantes}

Se destaca que los principales beneficios aportados a los estudiantes al llevar a cabo actividades de vinculación son: la capacitación (34.36\%), la facilitación de materiales y equipo de trabajo (23.31\%), y finalmente, $20.25 \%$ apoyo económico para el transporte (figura1). En este sentido, una mejor y más amplia capacitación es uno de los frutos que se obtienen mediante la educación dual en las UR.

\section{Figura 1}

Apoyo para los estudiantes por parte de las UR

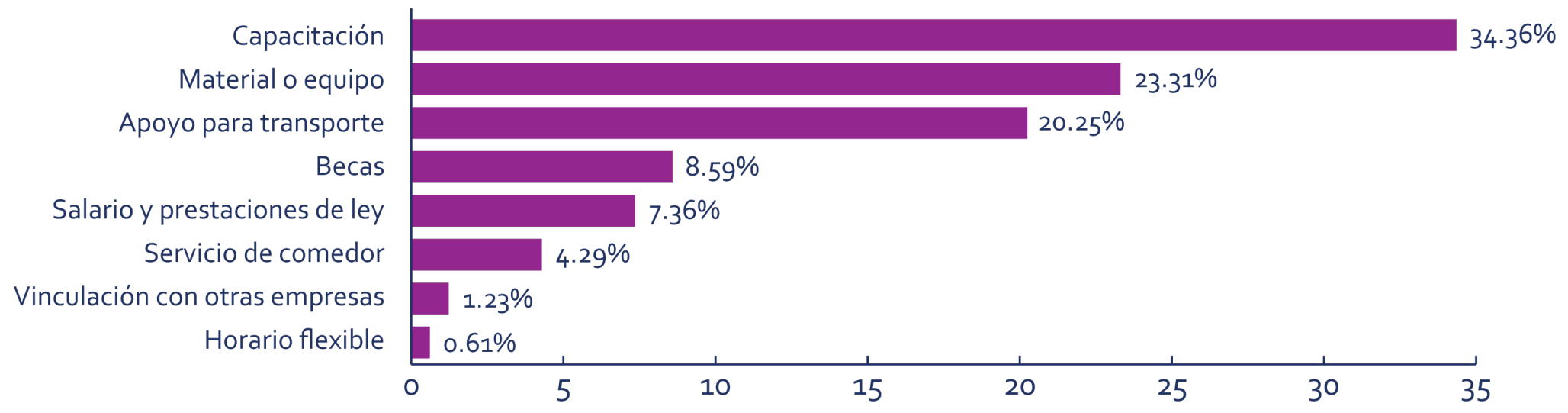

\section{Actividades realizadas}

Con relación a las actividades que se desarrollan en las UR, predominan las estancias y prácticas profesionales con el 94.04\%. De este modo, según los datos, la UABC y sus respectivas unidades académicas no han ido más allá de los mecanismos tradicionales como las prácticas profesionales y el servicio social. Por consiguiente, queda una enorme brecha para el aprovechamiento de otras alternativas de cooperación con los actores del entorno.

\section{Valoración del desempeño de los estudiantes en las UR}

El 50\% de los participantes señaló que los estudiantes cuentan con buen desempeño en relación a conocimientos, habilidades, valores, compromiso, creatividad y emprendimiento. Asimismo, una elevada proporción de UR considera un nivel de excelencia (tabla 2).

Valoración de las capacidades

El 61.9\% de los informantes señaló que los estudiantes de la UABC están parcialmente capacitados para realizar las actividades que les son asignadas en la UR, mientras que el $38.10 \%$ indicó que están muy capacitados. 
Tabla 2

Valoración del desempeño de los estudiantes de la UABC según los UR

\begin{tabular}{lcccc}
\hline \multicolumn{1}{c}{ Rubro } & Deficiente & Suficiente & Bueno & Excelente \\
\hline Conocimientos & o(0.00\%) & $19(22.62 \%)$ & $49(58.33 \%)$ & $16(19.05 \%)$ \\
\hline Habilidades & $1(1.19 \%)$ & $14(16.67 \%)$ & $50(59.52 \%)$ & $19(22.62 \%)$ \\
\hline Actitudes & $2(2.30 \%)$ & $12(14.29 \%)$ & $38(45.24 \%)$ & $32(38.10 \%)$ \\
\hline Valores & $1(1.19 \%)$ & $9(10.71 \%)$ & $40(47.62 \%)$ & $34(40.48 \%)$ \\
\hline Compromiso & $4(4.76 \%)$ & $13(15.48 \%)$ & $36(42.86 \%)$ & $31(36.90 \%)$ \\
\hline Creatividad & $1(1.19 \%)$ & $13(15.48 \%)$ & $50(59.52 \%)$ & $20(23.81 \%)$ \\
\hline Emprendimiento & $5(5.95 \%)$ & $21(25.00 \%)$ & $39(46.43 \%)$ & $19(22.62 \%)$ \\
\hline
\end{tabular}

\section{Contratación de estudiantes}

De acuerdo con la información proporcionada por las UR, el $80.95 \%$ de los estudiantes de la $U A B C$ que han realizado alguna actividad de vinculación en su unidad huésped terminan logrando algún tipo de contrato laboral. Esto es importante, porque las estancias de los estudiantes en las organizaciones el entorno suele ser decisivas, para conocer todas sus potencialidades y entonces optar por su contratación. Sin embargo, según lo referido por los informantes, el $61.9 \%$ consideró que existen aspectos de formación académica de los estudiantes que la $U A B C$ debería mejorar.

\section{Aspectos a mejorar por la $U A B C$ en la formación de estudiantes}

Las respuestas de los informantes clave de las UR se distribuyen de la siguiente manera: $50 \%$ contestó que deberían mejorar las actitudes relacionadas con la proactividad y la competitividad, $21.89 \%$ consideró que las habilidades y conocimientos del idioma inglés tienen que fortalecerse, $21.89 \%$ opinó que deben mejorar las competencias en redacción, y $18.75 \%$ mencionó que se tiene que mejorar la actitud profesional.

\section{Relación con los egresados}

Un aspecto altamente relevante, fue la información que las UR proporcionaron respecto a la contratación de egresados de la $U A B C$, sobre todo acerca de la preparación que tienen y el desempeño que demuestran a nivel profesional.

\section{Contratación de egresados}

El $86.9 \%$ de los informantes de las UR indicaron que han contratado egresados de la UABC. Respecto al desempeño profesional de los contratados, sobresalen aspectos relacionados con el conocimiento, las habilidades propias de la profesión, la productividad y las actitudes, los cuales fueron calificados entre bueno y excelente. En la tabla 3 se presentan los porcentajes de las valoraciones sobre cada aspecto. 


\section{Tabla 3}

Desempeño de los egresados de la UABC contratados en unidades receptoras

\begin{tabular}{lcccc}
\multicolumn{1}{c}{ Rubro } & Deficiente & Suficiente & Bueno & Excelente \\
\hline Productividad & $0(0.00 \%)$ & $5(6.85 \%)$ & $40(54.79 \%)$ & $28(38.36 \%)$ \\
\hline Responsabilidad & $0(0.00 \%)$ & $3(4.11 \%)$ & $34(46.58 \%)$ & $36(49.32 \%)$ \\
\hline Conocimientos & $0(0.00 \%)$ & $3(4.11 \%)$ & $48(65.75 \%)$ & $22(30.14 \%)$ \\
\hline Habilidades & $0(0.00 \%)$ & $5(6.85 \%)$ & $40(54.79 \%)$ & $28(38.36 \%)$ \\
\hline Actitudes & $0(0.00 \%)$ & $6(8.22 \%)$ & $37(50.68 \%)$ & $30(41.10 \%)$ \\
\hline Valores & $0(0.00 \%)$ & $3(4.11 \%)$ & $31(42.47 \%)$ & $39(53.42 \%)$ \\
\hline Creatividad & $1(1.37 \%)$ & $9(12.33 \%)$ & $34(46.58 \%)$ & $29(39.73 \%)$ \\
\hline Emprendimiento & $3(4.11 \%)$ & $14(19.18 \%)$ & $33(45.21 \%)$ & $23(31.51 \%)$ \\
\hline Iniciativa & $3(4.11 \%)$ & $10(13.70 \%)$ & $35(47.95 \%)$ & $25(34.25 \%)$ \\
\hline Liderazgo & $4(5.48 \%)$ & $16(21.92 \%)$ & $32(43.84 \%)$ & $21(28.77 \%)$ \\
\hline
\end{tabular}

\section{Servicios contratados con la UABC}

En la encuesta también se recabó información relacionada con los servicios que se contratan a la universidad, así como su valoración. Sin embargo, pese a la gran presencia de la UABC, a lo largo y ancho de Baja California, sorprende que solo el 16.7\% de los usuarios (UR) hayan contratado algún tipo de servicio. Respecto al tipo de servicio contratado destaca que el $57.1 \%$ son cursos de capacitación y de formación continua; en tanto que los servicios con una mayor carga de competencias y conocimientos tecnocientíficos (asesorías especializadas, pruebas de laboratorio, incubadoras de empresas de base tecnológica, así como los proyectos de investigación aplicada avalados por el Conacyt) son los menos solicitados.

Estos resultados no sorprenden y, de alguna manera, constituyen evidencias para corroborar lo que se ha encontrado en otras investigaciones, en el ámbito latinoamericano, nacional y regional. Por ejemplo, los trabajos de la Comisión Económica para América Latina y el Caribe (CEPAL, 2010), Arza (2010), De Fuentes y Dutrénit (2012), García-Galván (2018), y García-Galván et al. (2018) son bastante ilustrativos al respecto.

Nivel de satisfacción con los servicios contratados a la UABC

Los representantes de las UR indicaron su nivel de satisfacción con los servicios contratados a la UABC: el 42.86\% dijo estar muy satisfecho, el $21.43 \%$ parcialmente satisfechos, y el 14.29\% muy insatisfecho. Entre las razones de los representantes de las UR para sentirse parcialmente satisfechos o muy insatisfechos destacan: el bajo compromiso en el servicio a las empresas y el bajo rendimiento por parte de los estudiantes. 
Razones por las que no ha contratado servicios de la $U A B C$

Aproximadamente el $83 \%$ de los informantes de las UR indicaron no haber contratado servicios con la universidad porque no se ha necesitado, mientras que el desconocimiento de los servicios y los trámites complejos de contratación obtuvieron el $5.80 \%$ respectivamente (figura 2).

\section{Figura 2}

Razones para no contratar servicios con la $\cup A B C$

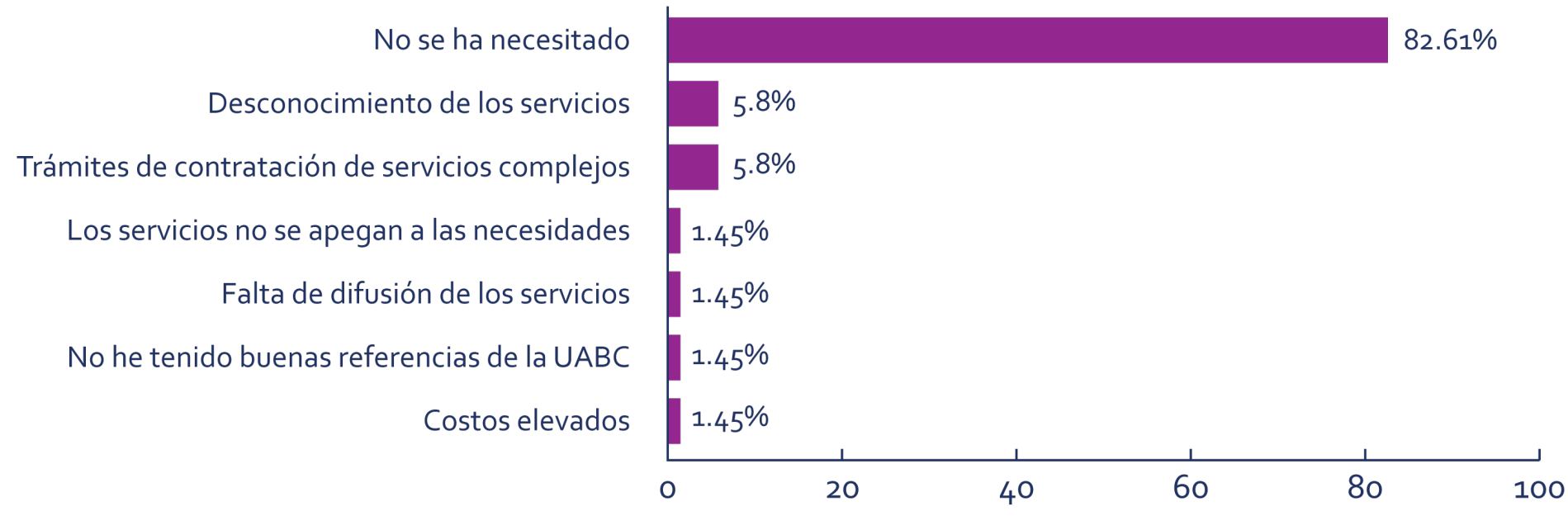

\section{Mejoras a los procesos de vinculación}

La encuesta permitió recabar información relativa a las mejorasque pueden realizarsea los procesos de vinculación que existen entre la Universidad y diferentes actores del entorno regional.

Cerca del $54 \%$ de los representantes de las UR indicó que la UABC debe mejorar diversos aspectos en materia de vinculación: el $35.56 \%$ señaló que es importante mejorar la comunicación y difusión de los procesos de vinculación que se llevan a cabo en la universidad; el $28.89 \%$ indicó que se necesita agilizar los procesos administrativos. En contrapartida, al menos resulta curioso que las UR hayan mencionado como último aspecto que requiere mejorarse, aquel relacionado con temas de emprendimiento (figura 3 ).

\section{Figura 3}

Aspectos a mejorar en materia de vinculación

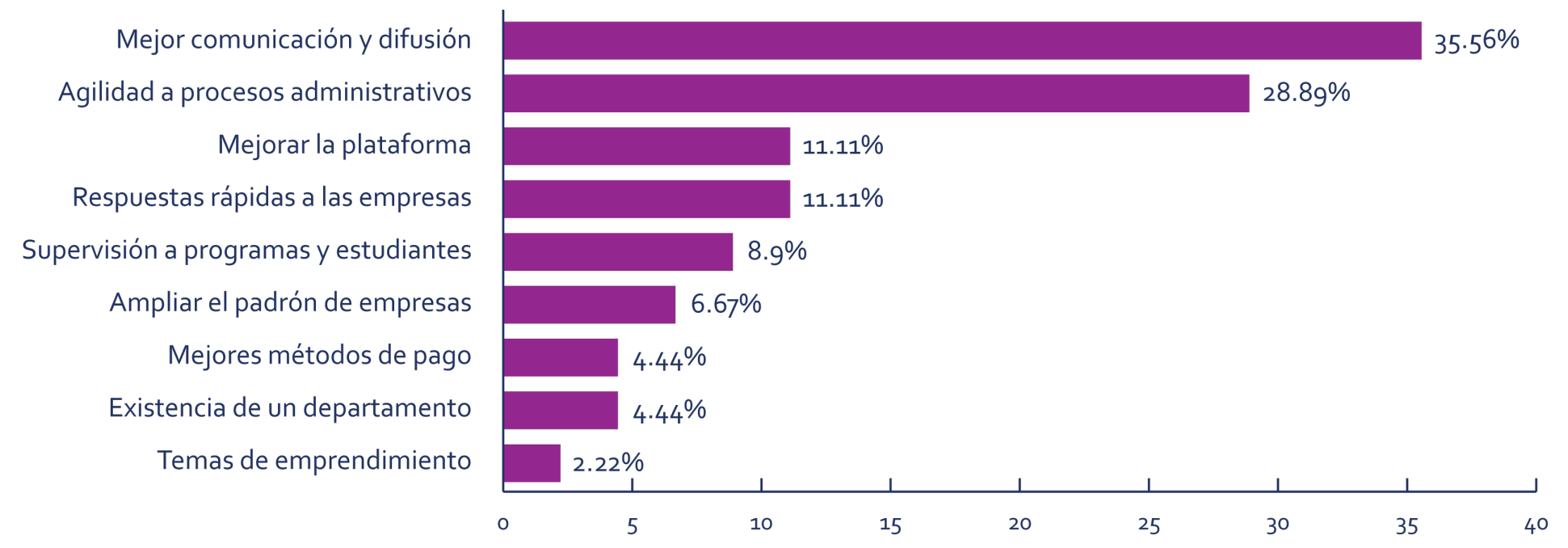




\section{Conclusiones}

En este capítulo se hizo un esfuerzo para explorary describirlas principales características de los vínculos colaborativos, mediados esencialmente por el servicio social y las prácticas profesionales, entre la UABC y los actores del entorno regional, tales como las empresas, las organizaciones no gubernamentales, comunitarias, y de grupos sociales vulnerables pero organizados; asimismo, con los diferentes ámbitos gubernamentales, a nivel federal, estatal y municipal.

Entre los hallazgos encontrados destaca que la mayoría de las unidades receptoras de futuros profesionistas se constituyen por empresas enfocadas en la industria maquiladora y manufacturera, lo cual no es ninguna sorpresa pues Tijuana y Mexicali, las principales ciudades de Baja California, sobresalen a nivel nacional e internacional por este tipo de establecimientos. Por otra parte, se encuentran los nexos con los actores sociales, aunque si se descuentan todas las asociaciones y sociedades civiles directamente relacionadas con las empresas, la cooperación auténtica con la sociedad más necesitada se mantiene en niveles muy bajos. Además, la cooperación en el ámbito gubernamental está representada principalmente por el nivel estatal, quedando relegada hasta un lejano tercer lugar los vínculos colaborativos con los gobiernos municipales.

De alguna manera, los resultados mencionados abonan al análisis crítico de que las organizaciones del conocimiento se han volcado en el fomento de la cooperación con el sector productivo, sin tener el mayor cuidado de filtros selectivos; pues prácticamente da lo mismo, si se coopera con una firma productora de insumos para el ensamblaje de armas, o si se coopera con una manufacturera de equipos médicos. Ante esto, desde nuestra perspectiva, las autoridades de la UABC al menos deberían hacer un análisis epistémico de qué tan conveniente resulta seguir esta ruta. Adicionalmente, también deberían considerarse criterios como las contribuciones de las empresas al desarrollo comunitario, sus impactos ambientales y en la salud de los bajacalifornianos; amén de que es necesario promover un mayor acercamiento con las micro, pequeñas y medianas empresas, necesariamente basadas en el conocimiento tecnocientífico.

Otro aspecto que resulta crítico es el bajo nivel de interacciones con los actores sociales, y lo que puede resultar peor es el abandono sistemático de las causas sociales más sentidas. En consecuencia, la superación de las crisis de hegemonía y de legitimidad de las universidades pasa, necesariamente, por una cada vez mayor atención a las demandas de los grupos sociales menos favorecidos. Además, es de suma importancia que universidades como la UABC contribuyan con todos sus recursos y capacidades para profesionalizar y mejorar la prestación de servicios públicos, sobre todo en los ámbitos estatal y municipal.

Finalmente, como parte de la agenda por investigar, queda pendiente ampliar y profundizar la investigación de la cooperación de la UABC echando mano de técnicas cualitativas (entrevistas) para recabar más evidencias de los principales representantes de los diferentes sectores sociales y económicos. También, sería conveniente realizar estudios micro más profundos para conocer la dinámica de la cooperación de manera más cercana. 


\section{Referencias}

Arocena, R., \& Sutz, J. (2005). Latin American Universities: From an Original Revolution to an Uncertain Transition. Higher Education, 50(4), 573-592. https://doi.org/10.1007/s10734$004-6367-8$

Arocena, R., \& Sutz, J. (2010). Weak knowledge demand in the South: learning divides and innovation policies. Science and Public Policy, 37(8), 571-582.

Arza, V. (2010). Channels, benefits and risks of public-private interactions for knowledge transfer: conceptual framework inspired by Latin America. Science and Public Policy, 37(7), 473-484. https://doi.org/10.3152/030234210X511990

Comisión Económica para América Latina y el Caribe (CEPAL). (2010). Vínculos entre universidades y empresas para el desarrollo tecnológico. CEPAL.

De Fuentes, C., \& Dutrénit, G. (2012). Best channels of academia-industry interaction for long-term benefit. Research Policy, 41(9), 1666-1682. https://doi.org/10.1016/j. respol.2012.03.026

De Sousa Santos, B. (2017). La universidad en el siglo XXI. Siglo XXI editores.

García-Galván, R. (2008). Análisis teórico de la transferencia de conocimientos universidadempresa mediante la colaboración. Economía: teoría y práctica, (29), 51-86.

García-Galván, R. (2012). Cooperación Tecnológica Interfirma y Empresa-Universidad: El Sector Biofarmacéutico en México (Tesis doctoral). Universidad Autónoma Metropolitana (UAM-Iztapalapa), México.

García-Galván, R. (2018). El papel de las instituciones y de la colaboración universidadempresa en el desarrollo: evidencias de la UAEMéx y la UABC. Paradigma Económico, 10(1), 81-118.

García-Galván, R., Cabrera, M., \& McAnally, L. (2018). La colaboración tecnocientífica de la universidad con su entorno en México: El Caso de la Universidad Autónoma de Baja California. Archivos Analíticos de Políticas Educativas, 26(140), 1-32. https://doi. org/10.14507/epaa.26.2994

Langer, A. (2008). El sistema científico y las universidades: revisión de teorías y enfoques en América Latina y Argentina. En G. Riquelme (Ed.), Las universidades frente a las demandas sociales y productivas (pp. 23-73). Miño y Dávila.

Naidorf, J. (2014). Knowledge utility: From social relevance to knowledge mobilization. Education Policy Analysis Archives, 22(89), 1-31.

Ordorika, I., \& Pusser, B. (2007). La máxima casa de estudios. Universidad Nacional Autónoma de México as a State-Building University. In P. Albach, \& J. Balán (Eds.), Transforming Research Universities in Asia and Latin America. World Class Worldwide. The Johns Hopkins University Press. https://doi.org/10.13140/2.1.4675.4083

Penrose, E. (1959). The theory of the growth of the firm. Blackwell. 
Pérez, C. (2004). Revoluciones tecnológicas y capital financiero. La dinámica de las grandes burbujas financieras y las épocas de bonanza. Siglo XXI editores.

Ruiz, A., \& Laguna, N. (2018). Winning or losing a run: The role of technological drivers at stages of development. Atlantic Review of Economics, 1(1), 1-27. 


\title{
Capítulo 5
}

\section{Factores que favorecen la empleabilidad de los egresados de las organizaciones del conocimiento en Baja California}

\author{
Dalia Lizzett Acosta Cárdenas y Juan Carlos Rodríguez Macías
}

Los problemas más frecuentes que egresados de las organizaciones del conocimiento (OC) afrontan al momento de buscar un puesto en el mercado laboral son la sobrecalificación, la concentración de la ocupación, las condiciones de precariedad laboral y el reemplazo de empleos tradicionales ocasionado por la automatización y el avance de la tecnología (Rentería-Pérez \& Malvezzi, 2008). Según la Organización para la Cooperación y el Desarrollo Económico (OCDE, 2019), alrededor del 50\% de los egresados de educación superior trabaja en un empleo que no requiere de formación profesional, y más de uno de cada cuatro egresados se emplea en la economía informal. Sin duda, esto suma al desequilibrio entre la oferta y demanda educativa, y a la ineficiencia del sector productivo para contratar capital humano.

Ante esta situación, los jóvenes necesitan adquirir nuevas habilidades para enfrentar los cambios sociales e incorporarse de manera exitosa al sector productivo (Weller, 2006). Una estrategia a la que pueden recurrir es contar con información sobre las tendencias modernas y las exigencias del mundo contemporáneo, así como considerar que los empleadores actuales requieren personas con una formación profesional especializada, con capacidades multidisciplinarias que les permitan formar, dirigir y administrar un grupo de trabajo o una empresa de cualquier ramo económico (Torres \& Huamán, 2012).

Si bien en México la tasa de egresados de educación superior aumentó 40\% aproximadamente, cuatro de cada cinco empleadores mexicanos expresaron que tuvieron dificultades para cubrir sus vacantes, ya que los candidatos que solicitan cubrir un puesto laboral no cuentan con las competencias necesarias para desempeñar sus funciones en el puesto (OCDE, 2019).

Para el presente estudio se optó por analizar las competencias transversales de los egresados de las organizaciones del conocimiento, las cuales se pueden ejercer eficazmente en cualquier profesión (Thieme, 2007), ya que comparten rasgos generales que unen a diferentes campos profesionales (Masciotra \& Medzo, 2009). En específico, se utilizó la propuesta conceptual del Proyecto Tunning, en donde se concibe a las competencias transversales 
como aquellas que incluyen habilidades, destrezas y conocimientos afines a todas las profesiones, y tienen una orientación hacia al ámbito de la educación superior (Tuning América Latina, 2007). Esta conceptualización facilita el estudio de diferentes tipos de empresas (tamaño, actividad económica, sector, etc.) y egresados de diversas áreas del conocimiento.

Con el propósito de identificar los factores relacionados con la empleabilidad de los egresados de las OC se buscó la opinión de los empleadores de recién egresados en empresas de Baja California, responsables del reclutamiento y selección de los candidatos a una vacante laboral dentro de sus organizaciones laborales. Se planteó el objetivo de analizar los factores que influyen en el nivel de demanda de competencias transversales de los recién egresados de las OC en Baja California. Para el estudio se utilizó una perspectiva metodológica cuantitativa, utilizando un diseño no experimental, transaccional, con alcance exploratorio; además, se aplicaron análisis predictivos con la finalidad de presentar un primer acercamiento al fenómeno de estudio.

En el siguiente apartado se presenta el marco conceptual, donde se aborda el tema de la empleabilidad y su relación con las competencias transversales y la relevancia que tienen para la incorporación al trabajo de los recién egresados. Posteriormente, se presenta la metodología utilizada para la recolección, procesamiento y análisis de datos; después se muestran los resultados que surgieron a partir de aplicar los análisis predictivos. Y, finalmente, se exponen las principales conclusiones del estudio.

\section{Marco conceptual}

Las organizaciones del conocimiento pueden ser consideradas como principal productor de capital humano, al ser generadoras de conocimientos generales y específicos para formar a los profesionistas que la sociedad demanda (Becker, 1964). Sin embargo, la definición de capital humano ha variado desde su surgimiento, así como sus componentes y alcances, al incorporar elementos que aumentan su poder explicativo.

Schultz (1961) utilizó por primera vez el concepto de capital humano para hacer referencia a la importancia de la educación y la experiencia en el crecimiento económico. Indicó que incluye componentes cualitativos como la habilidad, los conocimientos y los atributos, los cuales aumentan el potencial del individuo para mejorar su capacidad y la productividad en el trabajo, generando un rendimiento positivo.

Posteriormente, Becker (1964) lo definió como el conjunto de capacidades productivas que una persona adquiere por la acumulación de conocimientos generales o específicos. Al respecto, los generales son útiles para todas las empresas, mientras que los específicos pueden ser una inversión por parte del trabajador o de la empresa, y se espera que los beneficios obtenidos los capitalice quien realizó dicha inversión.

La OCDE (2007) planteó una definición más amplia al incluir las aptitudes y habilidades innatas de las personas, así como la calificación y el aprendizaje que obtienen a través de la educación y la capacitación. 
De forma más global, el capital humano también es considerado como un proceso que abarca la educación, la capacitación y las iniciativas profesionales que aumentan el conocimiento, las destrezas, las habilidades, los valores y los activos sociales de las personas, que llevan a la satisfacción laboral al mismo tiempo que mejoran su rendimiento (Marimuthu et al., 2009).

Uno de los aspectos que más influye en el capital humano es la educación, ya que de acuerdo con Becker (1964), las personas con mayor escolaridad obtienen ganancias económicas por encima del promedio. Cabe mencionar que la educación formal no es la única alternativa para invertir en el capital humano, ya que los trabajadores también aprenden mediante la capacitación que reciben dentro de las empresas. Y, aunque los empresarios solo buscan la formación suficiente para mejorar su competitividad, cuando invierten en el capital humano igualan el flujo de beneficios y costos al incrementar la productividad de sus trabajadores (Becker, 1993).

En cuanto a la relación entre la empleabilidad y las organizaciones del conocimiento, se puede decir que, a partir de la década de 1990, esta empezó a ser más estrecha, ya que la empleabilidad se utilizó como un indicador para medir la calidad educativa de las universidades a través del número de egresados que logran colocarse en un empleo formal (Teichler, 2004; 2009; Crossman \& Clarke, 2010). Esta situación llevó a cuestionar cuál es la eficacia de estas organizaciones como formadoras de recursos humanos de alto nivel.

En la Declaración Mundial de la Educación Superior en el siglo XXI de la Organización de las Naciones Unidas para la Educación, la Ciencia y la Cultura (UNESCO, 1998), se planteó que las OC formularan las reformas necesarias para: fomentar la adquisición de las competencias que contribuyeran al desarrollo cultural, social y económico de los países; favorecer el aprendizaje para toda la vida; preparar a ciudadanos más informados, provistos de sentido crítico y capacidad para analizar los problemas de la sociedad; y reforzar la vinculación con el mundo del trabajo, es decir, formar capital humano de alto nivel.

Aunque en las OC la empleabilidad empezó a utilizarse como un indicador de logro, este concepto va más allá de un fin exclusivamente estadístico (Suárez, 2016). Si bien en un inicio, ser empleable implicaba la habilidad de una persona para conseguir y conservar un empleo (Rentería-Pérez \& Malvezzi, 2008), el concepto evolucionó y se incluyeron otros aspectos que enriquecieron su definición (Hillage \& Pollard, 1998); entre ellos, el conjunto de logros y atributos personales, que aumenta la posibilidad de obtener un empleo y de tener éxito en el puesto desempeñado (Knight \& Yorke, 2003); otro aspecto fue la modalidad de trabajo, pues se puede ser asalariado o no (Bruttin, 2003), y el empleo puede estar relacionado o no con el área profesional de formación (Lees, 2002).

Posteriormente, la empleabilidad se definió como la capacidad para conseguir un empleo que satisfaga las necesidades profesionales, económicas, de promoción del trabajador en la organización y de desarrollo a lo largo de su vida (Sáez \& Torres, 2007). Para la Oficina 
Internacional del Trabajo (OIT, 2013), es el conjunto de competencias con el que cuentan las personas para aprovechar las oportunidades educativas y de formación que se le presenten, con el fin de conseguir y conservar un empleo decente. Además, implica que tengan la capacidad para transitar entre puestos y roles dentro de la misma organización, y conseguir otro empleo cuando sea necesario.

En el marco del Espacio Europeo de Educación Superior (EEES), que inició en 1998 con la Declaración de Bolonia, se incluyó a la empleabilidad como uno de los principales ejes rectores de la educación superior, porque consideraron que facilita el éxito del desarrollo profesional y se obtienen beneficios para la comunidad y la economía (García \& Pérez, 2008). Asimismo, se propuso adoptar el enfoque por competencias, ya que no solo se centra en la adquisición de conocimientos y destrezas, sino que también incluye valores y actitudes que permiten que los egresados resuelvan problemas con éxito.

La incorporación del enfoque por competencias proporcionó un lenguaje común a escala internacional y contribuyó en la definición de los perfiles profesionales (Mir, 2007). Esto sin duda ayudó a unir la formación que se recibe en las OC con el mercado laboral.

Respecto al concepto de competencias, uno de los primeros autores en utilizarlo fue McClelland (1973), quien las definió como las características subyacentes de una persona que se relacionan causalmente con el éxito de su actividad profesional. También, las identificó como una herramienta para asegurar la competitividad de las empresas, ya que sirven para evaluar los factores asociados al rendimiento en el trabajo, así como para mejorar los procesos de selección de personal. Además, indicó que las credenciales educativas o los resultados de pruebas de inteligencia de un candidato no son suficientes para predecir su éxito profesional.

Una persona competente, según Bunk (1994), es alguien que cuenta con los conocimientos, destrezas y actitudes necesarias para ejercer su profesión y resolver problemas de manera autónoma y creativa. Por su parte, Lévy-Leboyer (2000) consideró que las competencias son un repertorio de conocimientos que algunas personas dominan mejor que otras en situaciones determinadas; su enfoque está orientado a la capacidad del sujeto y el esfuerzo de la organización para mantener a su fuerza de trabajo en condiciones óptimas de empleabilidad (Escobar, 2005). Por su parte, Morín (2001) expresó que son el resultado de la historia familiar, social y cultural, y la formación profesional de las personas.

Algunos organismos internacionales también formularon su definición acerca de las competencias. La UNESCO señaló que las competencias combinan el aprendizaje que obtuvo una persona mediante la formación técnica y profesional, la aptitud para el trabajo en equipo, la iniciativa y la capacidad para asumir riesgos (Delors, 1996). La OIT (2000) las describió como el conjunto de conocimientos, procedimientos y actitudes adquiridos a través de la experiencia y que permite a las personas resolver problemas para realizar con éxito una actividad laboral. 
Ante la diversidad de conceptos sobre las competencias hay dos características que están incluidas en cualquiera de las definiciones: por un lado, están centradas en el desempeño; y, por otro lado, recuperan las condiciones específicas de la situación en donde dicho desempeño es relevante (Malpica, 1996). Otro componente por considerar es el carácter de unidad de las competencias; aunque incluyen conocimientos, habilidades y actitudes, esos elementos por separado ya no constituyen una competencia (Blanco, 2009). La evolución de la definición de competencias fue aportando elementos que van desde un conjunto de conocimientos y habilidades, hasta una combinación de varios elementos que se movilizan para dar una respuesta a la demanda de ejecución de tareas y resolución de problemas mediante la movilización de recursos tanto personales como de redes (Perrenoud, 2004).

Así como varía el concepto de competencias, también varía su clasificación. Como se mencionó al inicio del capítulo, se optó por utilizar la propuesta del Proyecto Tuning, que divide a las competencias en especificas, las cuales son propias de una disciplina en particular, y genéricas o transversales, aquellas que no están ligadas a una ocupación o sector económico, cargo o tipo de actividad productiva (Macías et al., 2017; Vargas, 2008). A su vez, las competencias transversales se distribuyen en tres grupos: (a) instrumentales, (b) interpersonales, y (c) sistémicas (tabla 1) (Tuning Project, 2003).

\section{Tabla 1}

Competencias instrumentales, interpersonales y sistémicas

\begin{tabular}{|c|c|c|}
\hline Instrumentales & Interpersonales & Sistémicas \\
\hline $\begin{array}{l}\text { Cognoscitivas } \\
\text { - Capacidad de abstracción, } \\
\text { análisis y síntesis } \\
\text { - Conocimientos generales básicos } \\
\text { - Conocimientos sobre el área de } \\
\text { estudio y la profesión } \\
\text { Metodológicas } \\
\text { - Capacidad para organizar y } \\
\text { - planificar el tiempo } \\
\text { - Habilidades de gestión de } \\
\text { información } \\
\text { - Capacidad para identificar, } \\
\text { plantear y resolver problemas } \\
\text { - Capacidad para tomar decisiones } \\
\text { Lingüísticas } \\
\text { - Capacidad de comunicación oral } \\
\text { - y escrita en la propia lengua } \\
\text { - Capacidad de comunicación en } \\
\text { un segundo idioma } \\
\text { Tecnológicas } \\
\text { - Habilidades en el uso de las TIC }\end{array}$ & $\begin{array}{l}\text { Individuales } \\
\text { - Capacidad crítica y autocrítica } \\
\text { - Compromiso ético } \\
\text { Sociales } \\
\text { - Capacidad de trabajo en } \\
\text { - equipo } \\
\text { - Habilidades interpersonales } \\
\text { - Valoración y respeto por la } \\
\text { - diversidad y multiculturalidad } \\
\text { - Habilidad para trabajar en } \\
\text { contextos interpersonales } \\
\text { - Capacidad de trabajar en un } \\
\text { equipo interdisciplinar } \\
\text { - Responsabilidad social y } \\
\text { compromiso ciudadano }\end{array}$ & $\begin{array}{l}\text { - Capacidad de aplicar los } \\
\text { conocimientos en la práctica } \\
\text { - Capacidad de investigación } \\
\text { - Capacidad de aprender y } \\
\text { actualizarse permanentemente } \\
\text { - Capacidad para actuar en nuevas } \\
\text { situaciones } \\
\text { - Capacidad para generar nuevas } \\
\text { ideas } \\
\text { - Capacidad de motivar y conducir } \\
\text { - hacia metas comunes } \\
\text { - Compromiso con su medio } \\
\text { - Hociocultural } \\
\text { - } \text { autónididad para trabajar en forma } \\
\text { - Capacidad para diseñar y } \\
\text { gestionar proyectos } \\
\text { - Compromiso con la calidad } \\
\text { Compromiso con la preservación } \\
\text { del medio ambiente }\end{array}$ \\
\hline
\end{tabular}

Nota: Elaboración propia con información de Tuning América Latina (2007). 
Las competencias instrumentales son una combinación de habilidades manuales y capacidades cognitivas, consideradas como medios o herramientas para obtener un determinado fin e incluyen, por ejemplo, habilidades lingüísticas, destrezas físicas, y comprensión cognitiva (Villa \& Poblete, 2008); su objetivo es procedimental y buscan comprender y manejar pensamientos, información, instrumentos, y metodologías. Bellocchio (2010) las consideró como herramientas para el aprendizaje y la formación. Estas competencias incluyen habilidades cognoscitivas, capacidades metodológicas y destrezas lingüísticas y tecnológicas (Tuning América Latina, 2007).

Las competencias interpersonalesserefierenala expresiónadecuada delos sentimientos propios y aceptación de los ajenos, lo que posibilita una buena interacción con los demás y la colaboración (Bellocchio, 2010); tienden a facilitar los procesos de interacción social y cooperación porque permiten al individuo comprender la complejidad de un fenómeno o realidad (Villa \& Poblete, 2008); e incluyen capacidades individuales y destrezas sociales (Tuning América Latina, 2007).

Las competencias sistémicas o integradoras están relacionadas con la combinación de imaginación, sensibilidad y habilidades que permiten ver cómo se relacionan y conjugan las partes de un conjunto o sistema (Villa \& Poblete, 2008; Geeregat et al., 2016). Requieren como base la adquisición previa de competencias instrumentales e interpersonales (Villa \& Poblete, 2008) y sirven para planificar los cambios de manera que puedan hacerse mejoras y diseñar nuevos sistemas. Estas competencias incluyen una combinación de destrezas y habilidades que suponen la comprensión, la sensibilidad y el conocimiento que permiten al individuo ver cómo las partes de un todo se relacionan y se agrupan (Tuning América Latina, 2007).

Por consiguiente, la empleabilidad depende, en gran medida, de la alineación entre las competencias de los candidatos a un empleo con la demanda del mercado de trabajo (Aguilar, et al., 2012), lo cual facilita el encuentro entre la oferta y la demanda educativa de profesionistas, provocando que la asignación del capital humano sea más eficiente y eficaz. Así, la naturaleza dinámica del mundo laboral requiere que el capital humano desarrolle competencias transversales junto con las específicas para enfrentar la obsolescencia del conocimiento técnico, la evolución de la tecnología y los cambios en la demanda de ciertos perfiles profesionales, pero también para facilitar la adaptación a las demandas del mercado laboral y a la innovación productiva. Las competencias transversales permiten a las personas ser flexibles, mejorar su presentación personal, manejar sus emociones y fortalecer su capacidad de aprender a aprender, así como enfrentar las condiciones sociales e individuales en términos de diversidad y desigualdad (Becquet \& Etienne, 2016). 


\section{Método}

\section{Participantes}

La población objetivo de este estudio estuvo conformada por empresarios empleadores de recién egresados de las OC. En total participaron 187 empresas, de las cuales solo el 76.47\% completó todo el cuestionario, es decir, la muestra final de la investigación fue de 143 empresas de los municipios de Ensenada, Mexicali y Tijuana. La ciudad que concentró a la mayor parte de las empresas fue Tijuana (78\%), mientras que $18 \%$ se situaron en Ensenada y $4 \%$ en Mexicali. No hubo participación de ninguna empresa del resto de los municipios de Baja California.

\section{Instrumento}

Se adaptó un cuestionario de autoinforme elaborado exprofeso con la finalidad de obtener la opinión de los empresarios que emplearon a recién egresados de las OC. Dicho cuestionario se conformó por un ítem informativo, una escala, dos ítems de opción múltiple, dos ítems de respuesta construida, seis ítems informativos y 13 inventarios, divididos en cinco secciones que recuperaron información contextual de los participantes y las empresas, así como de la demanda de competencias transversales. Aunque tienen un formato variado, la mayor parte consistió en preguntas cerradas de opción múltiple con respuestas previamente delimitadas. Previo a la aplicación del cuestionario, este fue sometido a una validación mediante el juicio de expertos.

Se elaboraron tres versiones del cuestionario, una a lápiz y papel, otra para responder en formato de documento portátil (pdf), y una versión para contestar en línea en cualquier dispositivo digital. En la versión para administrarse en línea solo requería un dispositivo digital (computadora, tableta o teléfono inteligente) y acceso a Internet.

\section{Procedimiento}

Para la recolección de los datos se enviaron correos electrónicos a las empresas bajacalifornianas identificadas en el Directorio Nacional de Unidades Económicas (DENUE) que proporciona el Instituto Nacional de Estadística, Geografía e Informática (INEGI). En el mensaje del correo electrónico se incluyó la presentación del estudio y la invitación para responder el cuestionario vía electrónica. El periodo convenido para responder el cuestionario fue el comprendido entre el 18 de octubre y 18 de diciembre de 2018. El primer recordatorio se envió el 29 de octubre, el segundo el 12 de noviembre y, el último, el o3 de diciembre; dando por concluida la fase de recolección de datos el día 18 de diciembre de 2018. Esta estrategia no funcionó debido a que el directorio estaba desactualizado y había errores en los registros de la dirección de correo electrónico y en el número telefónico, por lo que solo 30 participantes respondieron la encuesta por este medio. 
Debido a la escasa respuesta, se contactó por teléfono a algunas de las empresas con el fin de identificar al responsable del departamento de recursos humanos de la organización, a quien se le explicaba el contexto y los objetivos del estudio, buscando lograr su cooperación para responder el cuestionario. Una vez que se tenía una respuesta positiva, se solicitaba su correo electrónico y se enviaba el cuestionario. Sin embargo, esta estrategia tampoco funcionó pues hubo renuencia por parte de los participantes para responder.

La siguiente estrategia de recolección de datos consistió en contactar a diferentes asociaciones que colaboran con las empresas de Baja California para que fungieran como el medio para enviar el cuestionario. Estas asociaciones fueron el Consejo Nacional de la Industria Maquiladora y Manufacturera de Exportación (INDEX) zona costa, el Comité de Vinculación de Mexicali (ComVinc) y la Confederación Patronal de la República Mexicana (COPARMEX) sede Tijuana.

Para la aplicación de los cuestionarios, se convocó a personas que tuvieran experiencia en la aplicación de instrumentos de evaluación. Se seleccionó un grupo de 17 personas que contaban con grado de licenciatura o superior para que fungieran como aplicadores y se les capacitó con el fin de garantizar que se apegaran a procedimientos, tiempos y condiciones estipulados, con el fin de lograr la estandarización de la aplicación, la cual se realizó en dos eventos organizados por COPARMEX, Tijuana. El primer evento fue un desayuno empresarial realizado el 12 de marzo de 2019; y el segundo, ocurrió en un networking que se efectuó el 27 de marzo de 2019.

Después de la última aplicación del instrumento se integró una base de datos con la información de los casos que cumplimentaron el cuestionario. Posteriormente, se procedió a efectuar los análisis descriptivos, de segmentación y explicativos, con el programa Statistical Package for the Social Sciences (SPSS), versión 23.

Se determinaron los estadísticos descriptivos de las variables que integraron el cuestionario y se documentaron los porcentajes con base en las frecuencias absolutas. Las variables analizadas corresponden a los participantes y las empresas donde laboran los recién egresados, como los aspectos que se consideran al seleccionar a un candidato, la formación académica de los profesionistas recién egresados, y la vinculación entre las empresas y las organizaciones del conocimiento.

Posteriormente, se construyeron tres índices por cada tipo de competencia transversal: índice de competencias instrumentales (ICI); índice de competencias interpersonales (ICITP); e índice de competencias sistemáticas (ICSIS). Cada índice se construyó con la sumatoria de los valores absolutos de las menciones que obtuvieron por cada tipo de competencia y se dividieron según el número que incluye cada tipo de competencia transversal. Enseguida, según el puntaje obtenido, se dividieron en tres puntos de corte equivalentes entre sí, con el fin de que dieran cuenta del nivel de demanda de competencia. A cada cuartil se le asignó una etiqueta que representara el nivel de demanda, según el valor numérico que se asignó (tabla 2). 
Tabla 2

Variables, codificación y número de ítem

\begin{tabular}{cc}
\hline Nivel de demanda (etiqueta) & Valor \\
\hline Alta & $66.7-100$ \\
\hline Media & $33.4-66.6$ \\
\hline Baja & $00.0-33.3$ \\
\hline
\end{tabular}

Nota: Elaboración propia.

Se identificaron las variables asociadas a la demanda baja, media o alta de competencias instrumentales, interpersonales y sistémicas por medio de los índices creados y la técnica de minería de datos, particularmente, la técnica de segmentación, también conocida como árboles de decisión. Esta técnica permite definir y validar modelos de forma que se pueda determinar qué variables explican los cambios de una variable dependiente. Los resultados se clasifican en un árbol de decisión que muestra la estructura y relaciones de las variables para cada uno de los segmentos o subgrupos (Biggs et al., 1991). El algoritmo empleado fue Clasification And Regression Tree (CART), el cual se caracteriza por dividir las variables significativas de forma binaria (Dudley, Dilorio, \& Soet, 2000). Se calculó un árbol para cada uno de los índices de competencias instrumentales, interpersonales y sistémicas.

Después se identificaron los factores que explican la demanda de competencias transversales; para ello, se realizaron tres modelos de regresión lineal múltiple (uno por cada índice de competencia) utilizando el método de pasos sucesivos. Dicho método permitió explorar el predictor que mejor explica la variable, al seleccionar el factor con mayor correlación y, si mejora significativamente la capacidad explicativa, se busca un segundo predictor (Field, 2009).

\section{Resultados}

Una vez que se obtuvieron las variables (a partir de la técnica de segmentación), se calculó un modelo general para las competencias transversales, y tres modelos adicionales, es decir, uno por cada tipo de competencia. Esto con el fin de conocer los factores que explican la demanda de competencias transversales.

En este apartado solo se presentan los modelos que resultaron significativos, con un nivel de confianza del $95 \%$ y un margen de error del $5 \%$. En la tabla 3 se muestran las variables que se incorporaron en los modelos propuestos, así como su codificación y el número de ítem que le corresponde en el cuestionario. 


\section{Tabla 3}

Variables, codificación y número de ítem

\begin{tabular}{|c|c|c|}
\hline Variables & Código & Ítem \\
\hline Último grado de estudios del respondiente & ULTIGRA & IV \\
\hline Antigüedad de la empresa & ANTIEMPRE & $4.1 ; 4.2 ; 4.3$ \\
\hline $\begin{array}{l}\text { Número de profesionistas contratados durante } \\
\text { el año } 2018\end{array}$ & NUMPRO & 6 \\
\hline $\begin{array}{l}\text { Características académicas más importantes al } \\
\text { momento de contratar a un egresado de } O C\end{array}$ & CARACADE & $\begin{array}{l}\text { 7_a; 7_b; 7_c; 7_d; 7_e; 7_f; 7_g; 7_h; 7_i; } \\
\text { 7_j; 7_k; }\end{array}$ \\
\hline $\begin{array}{l}\text { Criterios que considera al momento de } \\
\text { contratar a un profesionista }\end{array}$ & CRITECONTRA & 9_a; 9_b; 9_c; 9_d; 9_e; 9_f; 9_g; 9_h. \\
\hline Idiomas que debe dominar además del español & IDIOMA & $\begin{array}{l}\text { 12_a; 12_b; 12_c; 12_d; 12_e; 12_f; 12_g; } \\
\text { 12_h; 12_i; 12_j; 12_k. }\end{array}$ \\
\hline $\begin{array}{l}\text { Principales razones por las que rechaza a un } \\
\text { candidato }\end{array}$ & PRINRECH & $\begin{array}{l}\text { 14_a; 14_b; 14_c; 14_d; 14_e; 14_f; } \\
\text { 14_g; 14_h; 14_i; 14_j; 14_k; 14_l; 14_m. }\end{array}$ \\
\hline $\begin{array}{l}\text { Actividades de vinculación que mantienen con } \\
\text { las } O C\end{array}$ & ACTIVINC & $\begin{array}{l}\text { 19_a; 19_b; 19_c; 19_d; 19_e; 19_f; } \\
\text { 19_g; 19_h; 19_i; 19_j; 19_k; 19_l; }\end{array}$ \\
\hline $\begin{array}{l}\text { Problemas o dificultades que ha enfrentado } \\
\text { para vincularse con las OC }\end{array}$ & PROVINC & $\begin{array}{l}\text { 20_a; 20_b; 20_c; 20_d; 20_e; 20_f; } \\
\text { 20_g; 20_h; 20_i; 20_j; 20_k; 20_l. }\end{array}$ \\
\hline
\end{tabular}

Nota: Elaboración propia.

\section{Modelo explicativo sobre la demanda de competencias transversales}

Para determinar el modelo general de la demanda de competencias transversales se introdujeron las siguientes variables: (a) número de profesionistas contratados durante el año 2018; (b) características académicas más importantes al momento de contratar a un egresado de $\mathrm{OC}_{i}$ (c) criterios que considera al momento de contratar a un profesionista; (d) idiomas que domina además del español; (e) principales razones por las que rechaza a un candidato; $(\mathrm{f})$ actividades de vinculación que mantienen con las $\mathrm{OC}_{i}$ y $(\mathrm{g}$ ) problemas o dificultades que han enfrentado para vincularse con las OC.

$$
\begin{gathered}
I C T=b_{0}+b_{1}(N U M P R O)+b_{2}(C A R A C A D E)+b_{3}(\text { CRITECONTRA })+b_{4}(I D I O M A) \\
+b_{5}(\text { PRINRECH })+b_{6}(\text { ACTIVINC })+b_{7}(\text { PROVINC })+r
\end{gathered}
$$

Donde:

ICT $=$ Índice de competencias transversales.

$b_{0}=$ Origen de la pendiente.

$b_{1}=$ Número de profesionistas recién egresados contratados durante el año 2018.

$b_{2}=$ Características académicas más importantes al contratar a un recién egresado. 
$b_{3}=$ Criterios que consideran al momento de contratar a un recién egresado.

$b_{4}=$ Idiomas que debe dominar además del español.

$b_{5}=$ Principales razones para rechazar a un candidato.

$b_{6}=$ Actividades de vinculación entre OC y empresas.

$b_{7}=$ Problemas o dificultades que ha enfrentado para vincularse con las OC.

$r=$ Error aleatorio que no se puede definir a partir de las variables incluidas en el modelo.

Al calcular este modelo se obtuvieron dos variables significativas: el apoyo con becas como actividad de vinculación y el promedio de egreso como característica más importante al momento de contratar a un egresado de OC con un valor de R de .304 de la demanda de competencias transversales (tabla 4).

\section{Tabla 4}

Resumen del modelo general de competencias transversales

\begin{tabular}{|c|c|c|c|c|c|c|c|c|c|c|}
\hline \multirow[b]{2}{*}{ Modelo } & \multirow[b]{2}{*}{$\mathrm{R}$} & \multirow[b]{2}{*}{$\mathrm{R}^{2}$} & \multirow{2}{*}{$\begin{array}{c}\mathrm{R}^{2} \\
\text { ajustado }\end{array}$} & \multirow{2}{*}{$\begin{array}{c}\text { Error estándar } \\
\text { de la } \\
\text { estimación }\end{array}$} & \multicolumn{5}{|c|}{ Estadísticos de cambio } & \multirow{2}{*}{$\begin{array}{c}\text { Durbin } \\
\text {-Watson }\end{array}$} \\
\hline & & & & & $\begin{array}{c}\text { Cambio } \\
\text { en } \mathrm{R}^{2}\end{array}$ & $\begin{array}{c}\text { Cambio } \\
\text { en F }\end{array}$ & glı & $g l 2$ & $\begin{array}{l}\text { Sig. cam- } \\
\text { bio en } \mathrm{F}\end{array}$ & \\
\hline 1 & .217 & .047 & .040 & 15.03 & .047 & 6.53 & 1 & 132 & .012 & \\
\hline 2 & .304 & .092 & .079 & 14.72 & .045 & 6.53 & 1 & 131 & .012 & 2.015 \\
\hline
\end{tabular}

Nota: $\mathrm{R}$ = Coeficiente de correlación múltiple; $\mathrm{R}^{2}=$ Coeficiente de determinación; F= F-ratio o estadístico F; gl $1=$ grados de libertad 1 y gl $2=$ grados de libertad 2 .

Por medio del método de pasos sucesivos, se encontró que el segundo modelo tiene mayor poder explicativo (9.2\%). Además, que los factores que explican la demanda de competencias transversales son: el apoyo con becas como actividad de vinculación que realiza la empresa y el promedio de egreso como característica más importante al momento de contratar a un egresado de OC. Ambos factores tienen casi el mismo peso explicativo sobre la demanda de competencias transversales, es decir, al incrementar la vinculación de los empleadores con las OC por medio de becas de apoyo, la demanda por competencias transversales se incrementa en 11.97. En el caso del promedio de egreso el efecto es en la misma dirección, solo que su aportación es siete centésimas menor al factor de apoyo con becas (tabla 5). 
Tabla 5

Determinación de los coeficientes Beta de las competencias transversales

\begin{tabular}{|c|c|c|c|c|c|c|c|}
\hline \multirow{2}{*}{ Modelo } & \multicolumn{2}{|c|}{$\begin{array}{l}\text { Coeficientes no } \\
\text { estandarizados }\end{array}$} & \multirow{2}{*}{$\begin{array}{c}\begin{array}{c}\text { Coeficientes } \\
\text { estandarizados }\end{array} \\
\text { Beta }\end{array}$} & \multirow[t]{2}{*}{$\mathrm{t}$} & \multirow{2}{*}{ Sig. } & \multicolumn{2}{|c|}{$\begin{array}{c}\text { Estadísticas } \\
\text { de colinealidad }\end{array}$} \\
\hline & B & Desv. Error & & & & Tolerancia & VIF \\
\hline Constante & 37.13 & 1.38 & & 26.90 & .000 & & \\
\hline Apoyo con becas & 11.97 & 4.63 & .215 & 2.58 & .011 & 1.000 & 1.000 \\
\hline $\begin{array}{l}\text { Promedio de egreso } \\
\text { de la licenciatura }\end{array}$ & 11.84 & 4.63 & .213 & 2.55 & .012 & 1.000 & 1.000 \\
\hline
\end{tabular}

Nota: $\mathrm{B}=$ coeficientes de regresión $\mathrm{B} ; \mathrm{t}$ = prueba $\mathrm{t}$ de Student; VIF = Factor de inflación de la varianza

\section{Modelo explicativo sobre la demanda de competencias instrumentales}

Para generar un modelo explicativo de la demanda de competencias instrumentales se incluyeron las variables que resultaron significativas en el análisis de clasificación: (a) último grado de estudios del respondiente; (b) antigüedad de la empresa; (c) número de profesionistas contratados durante el 2018; (d) características académicas más importantes al momento de contratar a un egresado; (e) principales razones por las que rechaza a un candidato; y (g) problemas o dificultades que ha enfrentado para vincularse con las OC.

$$
\begin{gathered}
I C I=b_{0}+b_{1}(U L T I G R A)+b_{2}(\text { ANTIEMPRE })+b_{3}(N U M P R O)+b_{4}(C A R A C A D E) \\
+b_{5}(\text { PRINRECH })+b_{6}(\text { PROVINC })+r
\end{gathered}
$$

Donde:

$I C I=$ Índice de competencias instrumentales.

$b_{o}=$ Origen de la pendiente.

$b_{1}=$ Último grado de estudios del respondiente.

$b_{2}=$ Antigüedad de la empresa.

$b_{3}=$ Número de profesionistas contratados durante el año 2018.

$b_{4}=$ Características académicas más importantes al contratar a un recién egresado.

$b_{5}=$ Principales razones para rechazar a un candidato.

$b_{6}=$ Problemas o dificultades que ha enfrentado para vincularse con las OC.

$r=$ Error aleatorio que no se puede definir a partir de las variables incluidas en el modelo.

Al introducir dichas variables, solo una de ellas resultó significativa: falta de conocimientos técnicos específicos como razón principal por la que se rechaza a un candidato, con un valor de R2 de .031 (tabla 6). Es decir, a medida que se incrementa la falta de conocimientos técnicos aumenta la demanda del ICI (5.76) (tabla 7). 


\section{Tabla 6}

Resumen del modelo general de competencias instrumentales

\begin{tabular}{|c|c|c|c|c|c|c|c|c|c|}
\hline \multirow[b]{2}{*}{$\mathrm{R}$} & \multirow[b]{2}{*}{$\mathrm{R}^{2}$} & \multirow[b]{2}{*}{$\begin{array}{c}\mathrm{R}^{2} \\
\text { ajustado }\end{array}$} & \multirow[b]{2}{*}{$\begin{array}{l}\text { Error estándar } \\
\text { de la estimación }\end{array}$} & \multicolumn{5}{|c|}{ Estadísticos de cambio } & \multirow{2}{*}{$\begin{array}{l}\text { Durbin } \\
\text {-Watson }\end{array}$} \\
\hline & & & & $\begin{array}{c}\text { Cambio } \\
\text { en } \mathrm{R}^{2}\end{array}$ & $\begin{array}{l}\text { Cambio } \\
\text { en F }\end{array}$ & glı & $\mathrm{gl} 2$ & $\begin{array}{l}\text { Sig. Cambio } \\
\text { en } \mathrm{F}\end{array}$ & \\
\hline .18 & .031 & .024 & $14 \cdot 42$ & .031 & $4 \cdot 35$ & 1 & 138 & .039 & 1.962 \\
\hline
\end{tabular}

Nota: $\mathrm{R}$ = Coeficiente de correlación múltiple; $\mathrm{R}^{2}=$ Coeficiente de determinación; F= F-ratio o estadístico F; gl $1=$ grados de libertad 1 y gl $2=$ grados de libertad 2.

\section{Tabla 7}

Determinación de los coeficientes Beta de las competencias instrumentales

\begin{tabular}{|c|c|c|c|c|c|c|c|}
\hline \multirow{2}{*}{ Modelo } & \multicolumn{2}{|c|}{$\begin{array}{l}\text { Coeficientes no } \\
\text { estandarizados }\end{array}$} & \multirow{2}{*}{$\begin{array}{c}\begin{array}{c}\text { Coeficientes } \\
\text { estandarizados }\end{array} \\
\text { Beta }\end{array}$} & \multirow{2}{*}{$\mathrm{t}$} & \multirow{2}{*}{ Sig. } & \multicolumn{2}{|c|}{$\begin{array}{c}\text { Estadísticas } \\
\text { de colinealidad }\end{array}$} \\
\hline & B & Desv. Error & & & & Tolerancia & VIF \\
\hline (Constante) & 32.88 & 1.42 & & 23.14 & .000 & & \\
\hline $\begin{array}{l}\text { Falta de conocimientos } \\
\text { técnicos específicos }\end{array}$ & 5.76 & 2.76 & .18 & 2.09 & .039 & 1.000 & 1.000 \\
\hline
\end{tabular}

Nota: $\mathrm{B}=$ coeficientes de regresión $\mathrm{B} ; \mathrm{t}=$ prueba $\mathrm{t}$ de Student $; \mathrm{VIF}=$ Factor de inflación de la varianza.

\section{Modelo explicativo sobre la demanda de competencias interpersonales}

En lo que respecta al modelo ICITP se corrieron las siguientes variables: (a) antigüedad de la empresa; (b) número de profesionistas contratados durante el 2018; (c) características académicas más importantes al momento de contratar a un egresado; (d) criterios que considera al momento de contratar a un profesionista; (e) principales razones por las que rechaza a un candidato; y (f) problemas o dificultades que ha enfrentado para vincularse con las $O C$.

$$
\begin{gathered}
\text { ICITP }=b_{0}+b_{1}(\text { ANTIEMPRE })+b_{2}(N U M P R O)+b_{3}(C A R A C A D E)+b_{4}(C R I T E C O N T R A) \\
+b_{5}(P R I N R E C H)+b_{6}(P R O V I N C)+r
\end{gathered}
$$

Donde:

ICITP = Índice de competencias interpersonales.

$b_{o}=$ Origen de la pendiente.

$b_{1}=$ Antigüedad de la empresa.

$b_{2}=$ Número de profesionistas recién egresados contratados durante el año 2018.

$b_{3}=$ Características académicas más importantes al momento de contratar a un egresado.

$b_{4}=$ Criterios que consideran al momento de contratar a un recién egresado. 
$b_{5}=$ Principales razones para rechazar a un candidato.

$b_{6}=$ Problemas o dificultades que ha enfrentado para vincularse con las OC.

$r=$ Error aleatorio que no se puede definir a partir de las variables incluidas en el modelo.

Al calcular el modelo explicativo de las competencias instrumentales se encontró que la única variable significativa fue el promedio de egreso como característica más importante al momento de contratar a un egresado de OC con un valor de $\mathrm{R}^{2}$ de .043 (tabla 8). Este factor resultó significativo en el modelo general para explicar las competencias transversales, pero su peso explicativo crece para el caso de las competencias interpersonales (14.55) (tabla 9).

\section{Tabla 8}

Resumen del modelo general de competencias interpersonales

\begin{tabular}{|c|c|c|c|c|c|c|c|c|c|}
\hline \multirow[b]{2}{*}{$\mathrm{R}$} & \multirow[b]{2}{*}{$\mathrm{R}^{2}$} & \multirow[b]{2}{*}{$\begin{array}{c}\mathrm{R}^{2} \\
\text { ajustado }\end{array}$} & \multirow[b]{2}{*}{$\begin{array}{l}\text { Error estándar } \\
\text { de la estimación }\end{array}$} & \multicolumn{6}{|c|}{ Estadísticos de cambio } \\
\hline & & & & $\begin{array}{c}\text { Cambio } \\
\text { en } \mathrm{R}^{2}\end{array}$ & $\begin{array}{c}\text { Cambio } \\
\text { en } \mathrm{F}\end{array}$ & gl1 & $\mathrm{gl} 2$ & $\begin{array}{l}\text { Sig. Cambio } \\
\text { en } \mathrm{F}\end{array}$ & $\begin{array}{l}\text { Durbin } \\
\text {-Watson }\end{array}$ \\
\hline .207 & .043 & .036 & 18.59 & .043 & 6.21 & 1 & 138 & .014 & 2.194 \\
\hline
\end{tabular}

Nota: $\mathrm{R}$ = Coeficiente de correlación múltiple; $\mathrm{R}^{2}=$ Coeficiente de determinación; F= F-ratio o estadístico F; gl $1=$ grados de libertad 1 y $\mathrm{gl}_{2}=$ grados de libertad 2 .

\section{Tabla 9}

Determinación de los coeficientes Beta de las competencias interpersonales

\begin{tabular}{|c|c|c|c|c|c|c|c|}
\hline \multirow[t]{2}{*}{ Modelo } & \multicolumn{2}{|c|}{$\begin{array}{l}\text { Coeficientes no } \\
\text { estandarizados }\end{array}$} & \multirow{2}{*}{$\begin{array}{c}\text { Coeficientes } \\
\text { estandarizados } \\
\text { Beta }\end{array}$} & \multirow[t]{2}{*}{$\mathrm{t}$} & \multirow[t]{2}{*}{ Sig. } & \multicolumn{2}{|c|}{$\begin{array}{c}\text { Estadísticas } \\
\text { de colinealidad }\end{array}$} \\
\hline & B & Desv. Error & & & & Tolerancia & VIF \\
\hline (Constante) & 40.47 & 1.64 & & 24.72 & .000 & & \\
\hline $\begin{array}{l}\text { Promedio de egreso } \\
\text { de licenciatura }\end{array}$ & 14.55 & 5.84 & .21 & 2.49 & .014 & 1.000 & 1.000 \\
\hline
\end{tabular}

Nota: $\mathrm{B}=$ coeficientes de regresión $\mathrm{B} ; \mathrm{t}=$ prueba $\mathrm{t}$ de Student ; VIF=Factor de inflación de la varianza.

\section{Modelo explicativo sobre la demanda de competencias sistémicas}

Para el modelo ICSIS se utilizaron las siguientes variables: (a) último grado de estudios del respondiente; (b) número de profesionistas contratados durante el 2018; (c) antigüedad de la empresa; (d) características académicas más importantes al momento de contratar a un egresado; (e) criterios que considera al momento de contratar a un profesionista; (f) principales razones por las que rechaza a un candidato; $y(\mathrm{~g})$ problemas o dificultades que ha enfrentado para vincularse con las OC. 


$$
\begin{gathered}
\text { ICSIS }=b_{0}+b_{1}(\text { ULTIGRA })+b_{2}(\text { NUMPRO })+b_{3}(C A R A C A D E)+b_{4}(\text { CRITECONTRA }) \\
+b_{5}(\text { PRINRECH })+b_{6}(\text { PROVINC })+r
\end{gathered}
$$

Donde:

ICSIS = Índice de competencias sistémicas.

$b_{o}=$ Origen de la pendiente.

$b_{1}=$ Último grado de estudios del respondiente.

$b_{2}=$ Número de profesionistas recién egresados contratados durante el año 2018.

$b_{3}=$ Características académicas más importantes al contratar a un recién egresado.

$b_{4}=$ Criterios que consideran al momento de contratar a un recién egresado.

$b_{5}=$ Principales razones para rechazar a un candidato.

$b_{6}=$ Problemas o dificultades que ha enfrentado para vincularse con las OC.

$r=$ Error aleatorio que no se puede definir a partir de las variables incluidas en el modelo.

Al calcular el modelo se obtuvo que solo dos variables fueron significativas: el número de profesionistas contratados durante el 2018 y la falta de comunicación e interacción como problemas o dificultades que han enfrentado las empresas para vincularse con las OC con un valor de $\mathrm{R}^{2}$ de .075 (tabla 10).

Para el primer modelo, representa $4.7 \%$ de la variación en la demanda de competencias sistémicas, el cual se explica por los cambios en el número de profesionistas contratados en el 2018. En el segundo modelo al incluir el factor de la falta de comunicación e interacción entre OC y empresas como problema o dificultad que han enfrentado para vincularse, el poder explicativo se incrementa (7.5\%), es decir, representa un $2.8 \%$ adicional en la explicación de la demanda de este tipo de competencias (tabla 11).

\section{Tabla 10}

\begin{tabular}{|c|c|c|c|c|c|c|c|c|c|c|}
\hline \multirow[b]{2}{*}{ Modelo } & \multirow[b]{2}{*}{$\mathrm{R}$} & \multirow[b]{2}{*}{$\mathrm{R}^{2}$} & \multirow{2}{*}{$\begin{array}{c}\mathrm{R}^{2} \\
\text { ajustado }\end{array}$} & \multirow{2}{*}{$\begin{array}{l}\text { Error estándar } \\
\text { de la estimación }\end{array}$} & \multicolumn{5}{|c|}{ Estadísticos de cambio } & \multirow{2}{*}{$\begin{array}{l}\text { Durbin } \\
\text {-Watson }\end{array}$} \\
\hline & & & & & $\begin{array}{c}\text { Cambio } \\
\text { en } \mathrm{R}^{2}\end{array}$ & $\begin{array}{l}\text { Cambio } \\
\text { en F }\end{array}$ & glı & $g / 2$ & $\begin{array}{l}\text { Sig. Cam- } \\
\text { bio en } F\end{array}$ & \\
\hline 1 & .218 & .047 & .041 & 18.97 & .047 & 6.88 & 1 & 138 & .010 & \\
\hline 2 & .274 & .075 & .061 & 18.77 & .027 & 4.06 & 1 & 137 & .046 & 2.014 \\
\hline
\end{tabular}

Resumen del modelo general de competencias sistémicas

Nota: $\mathrm{R}=$ Coeficiente de correlación múltiple; $\mathrm{R}^{2}=$ Coeficiente de determinación; F= F-ratio o estadístico F; gl $1=$ grados de libertad 1 y $\left.g\right|_{2}=$ grados de libertad 2 . 
Tabla 11

Determinación de los coeficientes Beta de las competencias sistémicas

\begin{tabular}{|c|c|c|c|c|c|c|c|}
\hline \multirow{2}{*}{ Modelo } & \multicolumn{2}{|c|}{$\begin{array}{l}\text { Coeficientes no } \\
\text { estandarizados }\end{array}$} & \multirow{2}{*}{$\begin{array}{c}\text { Coeficientes } \\
\text { estandarizados } \\
\text { Beta }\end{array}$} & \multirow[t]{2}{*}{$\mathrm{t}$} & \multirow{2}{*}{ Sig. } & \multicolumn{2}{|c|}{$\begin{array}{c}\text { Estadísticas } \\
\text { de colinealidad }\end{array}$} \\
\hline & $B$ & Desv. Error & & & & Tolerancia & VIF \\
\hline Constante & 39.70 & 1.89 & & 21.02 & .000 & & \\
\hline $\begin{array}{l}\text { Número de profesionistas } \\
\text { recién egresados contratados } \\
\text { durante el } 2018\end{array}$ & .26 & .10 & .22 & 2.70 & .008 & .999 & 1.001 \\
\hline $\begin{array}{l}\text { Falta de comunicación e } \\
\text { interacción entre OC y empresa }\end{array}$ & 8.22 & 4.08 & .17 & 2.02 & .046 & .999 & 1.001 \\
\hline
\end{tabular}

Nota: $\mathrm{B}=$ coeficientes de regresión $\mathrm{B} ; \mathrm{t}=$ prueba $\mathrm{t}$ de Student $; \mathrm{VIF}=$ Factor de inflación de la varianza

\section{Discusión y conclusiones}

La educación superior se ha centrado en el desarrollo de las competencias específicas con el fin de asegurar la pertinencia del programa académico que cursan. Sin embargo, esta formación ha descuidado la atención a las competencias transversales, la cuales los empleadores han declarado que faltan fortalecer en los recién egresados. Con referencia a este tema, los resultados de este estudio muestran que el $15.3 \%$ de los empleadores consideran como criterio para contratar a un egresado el dominio de los conocimientos teóricos relacionados con la carrera.

De las competencias transversales, las más demandadas por los empresarios de Baja California son las que corresponden a las competencias instrumentales: (a) habilidades en el uso de las TIC; (b) capacidad de comunicación oral y escrita en la propia lengua; (c) capacidad para identificar, plantear y resolver problemas; (d) capacidad para organizar y planificar el tiempo; y (e) habilidades de gestión de información. Este tipo de competencias tienen una orientación hacia las capacidades prácticas y son esenciales para el ejercicio de la profesión. Por lo tanto, resulta necesario que durante la formación académica se incrementen las actividades de vinculación con empresas y organizaciones donde los estudiantes se incorporen por medio del servicio social, prácticas o pasantías profesionales, entre otras.

En cuanto al uso de la tecnología, dentro de los programas académicos se pueden incluir simuladores virtuales de empleo, de forma que los estudiantes apliquen los conocimientos teóricos en situaciones de la vida laboral y adquieran habilidades al respecto. Asimismo, se debe procurar crear oportunidades para que los estudiantes fortalezcan la competencia de comunicación oral y escrita, a través de actividades orientadas al análisis y la reflexión crítica.

Las competencias sistémicas se ubicaron en el segundo lugar de demanda y son más complejas que las anteriores, ya que para su adquisición se requiere el dominio de las competencias instrumentales e interpersonales (Villa \& Poblete, 2008). Las competencias que 
obtuvieron mayor número de menciones fueron: (a) capacidad de aprender y actualizarse permanentemente; (b) capacidad para generar nuevas ideas; (c) habilidad para trabajar en forma autónoma; (d) capacidad para diseñar y gestionar proyectos; y (e) capacidad para actuar en nuevas situaciones. Por lo tanto, dada la naturaleza de este tipo de competencias se propone que, más que contenidos, se actualicen las actividades y técnicas de enseñanza-aprendizaje, de modo que fomenten la creatividad e innovación profesional, por ejemplo, con estrategias como: Aprendizaje Basado en Problemas (ABP), Aprendizaje Basado en Proyectos (ABPro), método de casos, trabajos de investigación, y organización de espacios para generar debate donde se asuma una postura crítica. Fomentar este tipo de actividades puede influir positivamente en la obtención de un empleo, así como para adquirir una actitud de emprendimiento o de investigación (Freire et al., 2011).

Las competencias interpersonales se ubicaron en el tercer lugar de demanda por parte de los empresarios, principalmente: (a) capacidad de trabajo en equipo; (b) habilidades interpersonales; (c) compromiso ético; (d) capacidad crítica y autocrítica; y (e) capacidad para trabajar en un equipo interdisciplinar. Cabe señalar que la capacidad de trabajo en equipo fue la competencia que se seleccionó con mayor frecuencia, lo que coincide con resultados de estudios similares (Figueras, 2013; Freire, 2007). Por lo tanto, se propone incentivar el trabajo en equipo dentro y fuera del aula en los futuros egresados, como estrategia para promover el desarrollo del resto de las competencias interpersonales. También, una recomendación es analizar qué entienden los empleadores por trabajo en equipo, para comprender si tanto empresarios como egresados y docentes le dan el mismo sentido a esta competencia.

Sobre el desarrollo de las competencias transversales se debe tomar en cuenta que se desarrollan a lo largo de la vida, por lo tanto, la aportación de las OC dependerá de variables tanto personales como sociales. En este sentido, conviene explorar en qué consisten esas variables, para propiciar el diseño de una oferta educativa más amplia. También es conveniente analizar de qué manera se incorporan y se evalúan las competencias transversales en los planes de estudio de la educación superior, pero más conveniente aún, es fomentar que los estudiantes identifiquen su importancia y la manera de articular esas competencias adquiridas con el proceso de solicitud de empleo y en las entrevistas de trabajo (Jackson, 2013). Asimismo, es necesario examinar cuál es la noción que tienen los empleadores sobre las competencias transversales, y cuál es la valoración que se les otorga en el entorno laboral, la cual puede diferir del valor que se le da a una competencia en el ámbito académico.

Además, es importante analizar las posibilidades de interacción entre las organizaciones del conocimiento y las empresas con el fin de generar una doble correspondencia entre los dos sectores que lleve a una mejor adquisición de competencias. En este sentido, se puede aprovechar de las OC su capacidad para formar capital humano de alto nivel, la generación de conocimiento y la capacidad institucional para proveer de infraestructura a empresas. En cuanto a las empresas, estas pueden aportar su habilidad para incorporar a los egresados al 
sector laboral y facilitar el acceso a equipos y maquinaria para promover el learning by doing que se menciona en la literatura sobre las competencias.

Al analizar los factores que favorecen la empleabilidad de los egresados de OC, se utilizaron modelos de regresión y los resultados muestran que el promedio de egreso de la licenciatura fue la característica académica más importante al momento de contratar a un egresado; su peso explicativo fue mayor en el modelo general de la demanda de competencias transversales y se repitió en el modelo de demanda de competencias interpersonales. Este dato coincide con los resultados del estudio elaborado por la National Association for Colleges and Employers (NACE) realizado en Estados Unidos de América, donde se encontró que el $97 \%$ de los empresarios no consideran el promedio de calificaciones como un requisito al momento de contratar, pero lo toman en cuenta para seleccionar a un candidato a un puesto de trabajo respecto a otro candidato (NACE, 2005), es decir, es un criterio de segundo orden al momento de la evaluación individual, pero ante la competencia de varios aspirantes a un mismo puesto, se convierte en un factor muy importante.

Respecto al modelo de demanda de competencias instrumentales, los resultados señalan que hay una relación lineal positiva con la falta de conocimientos técnicos específicos, es decir, en la medida que los empresarios perciban que los aspirantes carecen de este tipo de conocimientos se incrementa la demanda de competencias transversales en los egresados que aspiran a un puesto de trabajo. Los aspirantes con mayor conocimiento técnico en temas específicos tendrán mayor posibilidad de obtener un puesto de trabajo.

Al comparar los cuatros modelos, se observó que hay factores explicativos que se pueden relacionar entre sí y se encuentran en el ámbito de la vinculación entre el sector productivo y educativo. Las empresas que otorgan becas, que han contratado profesionistas recién egresados en el año anterior o consideren que les falta comunicación e interacción con las OC, demandan en mayor medida competencias transversales, y de manera específica, competencias sistémicas. Dada la naturaleza de los factores antes mencionados, se puede plantear que la experiencia en vinculación y el grado de conocimientos sobre los egresados de ciertas OC determina la demanda de competencias y los criterios para seleccionar a los aspirantes a un puesto en particular.

\section{Comentarios finales}

A partir de la información encontrada, se presenta una serie de consideraciones y recomendaciones. De manera general, se propone crear un directorio estatal de las empresas de Baja California, ya que una de las principales dificultades para llevar a cabo el estudio, fue la falta de un registro actualizado de las organizaciones y empresas empleadoras de egresados. El directorio puede fortalecer la vinculación con los organismos empresariales de la región para tener un mejor y mayor acceso a los empresarios que contratan a recién egresados de las OC. Esta ausencia limitó la realización de análisis más robustos y el poder explicativo de los factores asociados a la demanda de competencias transversales. 
En cuanto a las recomendaciones dirigidas a los empleadores se propone: (a) aumentar su participación en este tipo de estudios para generar más información; (b) aproximarse a las OC para establecer vinculación; (c) dar a conocer las actividades que los estudiantes pueden realizar en las empresas $u$ organizaciones; $(d)$ facilitar equipo y maquinaria para las prácticas de los estudiantes; (e) colaborar en la elaboración de planes y programas de estudio.

Respecto a las OC se sugiere: (a) analizar las competencias transversales que pretende desarrollar por medio de trabajo colegiado; (b) asesorar a los docentes para que orienten su método según la competencia transversal que desea desarrollar; (c) crear asignaturas optativas con valor curricular centradas en las competencias transversales; (d) desarrollar centros de investigación sobre empleabilidad donde egresados y empleadores colaboren con las $\mathrm{OC}_{i}$ (e) desarrollar instrumentos de evaluación para monitorear el logro de competencias transversales; $y(f)$ potenciar el emprendimiento en los estudiantes.

Por último, durante el proceso de elaboración de esta investigación surgieron algunas preguntas que quedan por responder. En cuanto a las empresas, persiste la duda sobre su capacidad para brindar las condiciones laborales apropiadas para la incorporación de los recién egresados que cuentan con las competencias que demandan (por ejemplo, sueldos, prestaciones o espacios de trabajo seguros). En cuanto a las OC, se cuestiona si la formación que ofrece responde a las necesidades del contexto y si dicha formación está preparando a profesionistas con la capacidad de emprender nuevos proyectos o empresas que generen nuevos empleos. 


\section{Referencias}

Aguilar, M., Villardón, L., Álvarez, M., Moro, Á., Elexpuru, I., \& Álvarez, C. (2012). Perceived employability and competence development. Procedia Social and Behavioral Sciences, 69, 1191-1197. https://doi.org/10.1016/j.sbspro.2012.12.051

Becker, G. (1964). Human capital: a theoretical and empirical analysis, with special reference to education. National Bureau of Economic Research.

Becker, G. (1993). Human Capital. A theoretical and empirical analysis with special reference to education (3a ed.). The University of Chicago Press.

Becquet, V., \& Etienne, R. (2016). Les compétences transversales en question. Education et Socialisation. Les Cahiers du CERFEE, 41. https://doi.org/10.4000/edso.1634

Bellocchio, M. (2010). Educación basada en competencias y constructivismo: Un enfoque y un modelo para la formación pedagógica del siglo XXI (2a. ed.). ANUIES.

Biggs, D., De Ville, B., \& Suen, E. (1991). A method of choosing multiway partitions for classification and decision trees. Journal of Applied Statistics, 18(1), 49-62. https://doi. org/10.1080/02664769100000005

Blanco, A. (2009). Desarrollo y evaluación de competencias en Educación Superior. Narcea.

Bruttin, A. (2003). Empregabilidade na mídia de negócios: um estudo dos sentidos em circulação (Tesis doctoral). Pontifícia Universidade Católica de São Paulo (PUC-SP), Brasil. https:// sapientia.pucsp.br/bitstream/handle/16977/1/Andre\%2oBruttin.pdf

Bunk, G. (1994). La transmisión de las competencias en la formación y perfeccionamiento profesionales de la RFA. Revista Europea de Formación Profesional, 1(94), 8-14. https:// dialnet.unirioja.es/descarga/articulo/131116.pdf

Crossman, J., \& Clarke, M. (2010). International experience and graduate employability: stakeholder perceptions on the connection. High Education, 59(5), 599-613. https://doi. org/10.1007/s10734-009-9268-z

Delors, J. (1996). La educación encierra un tesoro. Informe a la UNESCO de la Comisión Internacional sobre la Educación para el Siglo XXI. UNESCO.

Dudley, W., Dilorio, C., \& Soet, J. (2000). Detecting and explicating interactions in categorical data. Nursing-Research, 49(1), 53-56. https://libres.uncg.edu/ir/uncg/f/W_Dudley_ Detecting_1999.pdf

Escobar, M. (2005). Las competencias laborales: ¿la estrategia laboral para la competitividad de las organizaciones? Estudios Gerenciales, (96) 31-56. https://www.icesi.edu.co/ revistas/index.php/estudios_gerenciales/article/view/170

Espacio Europeo de Educación Superior (EEES). (2020). Desarrollo cronológico. http://www. eees.es/es/eees-desarrollo-cronologico

Field, A. (2009). Discovering statistics using SPSS. SAGE.

Figueras, M. (2013). Model de competències personals per a l'empleabilitat internacional dels alumnes de postgrau (Tesis doctoral). Universitat Rovira i Virgili, España. 
Freire, M. (2007). Competencias profesionales de los universitarios. Consello Social Universidad da Coruña, Universidad da Coruña.

Freire, M., Tejeiro, M., \& Pais, C. (2011). Políticas educativas y empleabilidad: ¿cuáles son las competencias más influyentes? Archivos analíticos de políticas educativas, 19(28), 1-24. https://epaa.asu.edu/ojs/article/download/911/931

García, J., \& Pérez, C. (2008). Espacio Europeo de Educación Superior, competencias profesionales y empleabilidad. Revista Iberoamericana de Educación, 46(9), 1-12. https:// rieoei.org/historico/deloslectores/2444Manjon.pdf

Geeregat, O., Cifuentes, G., \& Villarroel, M. (2016). Factores que inciden en las condiciones de empleabilidad de los egresados de Pedagogía. Actualidades investigativas en Educación, 16(1), 1-19. https://doi.org/10.15517/aie.v16i1.21935

Hillage, J., \& Pollard, E. (1998). Employability: developing a framework for policy analysis. Department for Education and Employment.

Jackson, D. (2013). Student perceptions of the importance of empoyability skill provision in business undergraduate programs. Journal of Education for Business, 88(5), 271-279. https://doi.org/10.1080/08832323.2012.697928

Knight, P., \& Yorke, M. (2003). Assesment, learning and employability. Society for research into Higher Education \& Open University Press

Lees, D. (2002). Graduate Employability. Literature Review. LTSN - learning and teaching support network. https://www.qualityresearchinternational.com/esecttools/esectpubs/ leeslitreview.pdf

Lévy-Leboyer, C. (2000). Gestión de las competencias. Ediciones Gestión.

Macías, E., Rodríguez-Sánchez, M., \&Aguilera, J.L. (2017). Lacuestión universitaria. Adquisición de competencias transversales a través de tutoría en la universidad. Universidad Complutense de Madrid.

Malpica, M. (1996). El punto de vista pedagógico. En A. Argüelles (Ed), Competencia laboraly educación basada en normas de competencia (pp. 123-140). Limusa.

Marimuthu, M., Arokiasamy, L., \& Ismail, M. (2009). Human capital development and its imapact on firm performance: evidence from developmental economics. The Journal of international Social Research, 2(8), 265-272. http://www.sosyalarastirmalar.com/cilt2/ sayi8pdf/marimuthu_arokiasamy_ismail.pdf

Masciotra, D., \& Medzo, F. (2009). Dévlopper un a gir compétent. Vers un curriculum pour la vie. De Boeck

McClelland, D. (1973). Testing for competence rather than for intelligence. American Psychologist, 28(1), 1-14. https://doi.org/10.1037/hoo34092

Mir, A. (2007). Las competencias transversales en la Universidad Pompeu Fabral. La visión de los docentes y estudiantes de segundo ciclo. Red U. Revista de Docencia Universitaria, (número monográfico I). https://doi.org/10.4995/redu.2008.6279 
Morín, E. (2001). Los siete saberes necesarios para la educación del futuro. Editorial Seix Barral. National Association of Collages and Employers (NACE) (2005). How employers see candidates. In Job Outlook report (pp.15-17). NACE Research. https://svcaa.unl.edu/ documents/how_employers_see_candidates.pdf

Oficina Internacional delTrabajo (OIT). (2000). Formación y desarrollo de los recursos humanos: orientación y formación profesional. Conferencia Internacional del Trabajo. 88a reunión.

Oficina Internacional del Trabajo (OIT). (2013). Mejorar la empleabilidad de los jóvenes: la importancia de las competencias clave. OIT. https://www.ilo.org/wcmsp5/groups/ public/---ed_emp/---ifp_skills/documents/publication/wcms_371815.pdf

Organización de las Naciones Unidas para la Educación, la Ciencia y la Cultura (UNESCO). (1998). Declaración mundial sobre la educación superior en el siglo XXI. http://www. unesco.org/education/educprog/wche/declaration_spa.htm

Organización para la Cooperación y el Desarrollo Económico (OCDE). (2007). Perspectivas de la OCDE: Capital humano: Cómo moldea tu vida lo que sabes. Resumen en español. OCDE. https://www.oecd.org/insights/38435951.pdf

Organización para la Cooperación y el Desarrollo Económico (OCDE). (2019). Higher Education in Mexico: Labour Market Relevance and Outcomes, Higher Education. OCDE. http:// www.oecd.org/fr/publications/higher-education-in-mexico-9789264309432-en.htm

Perrenoud, P. (2004). Diez nuevas competencias para enseñar. Invitación al viaje. Graó.

Rentería-Pérez, E., \& Malvezzi, S. (2008). Empleabilidad, cambios y exigencias psicosociales en el trabajo. Universitas Psychologica, 7(2), 319-334. http://www.scielo.org.co/scielo. php?pid=S1657-92672008000200002\&script=sci_abstract\&tlng=pt

Sáez, F., \& Torres, C. (2007). Documento técnico síntesis del encuentro sobre Empleabilidad. Editorial Fundipe.

Schultz, T.W. (1961). Investment in Human Capital. The American Economic Review, 51(1), 1-17. http://la.utexas.edu/users/hcleaver/330T/350kPEESchultzInvestmentHumanCapital. pdf

Suárez, B. (2016). La universidad española ante la empleabilidad de sus egresados: estrategias para su mejora. REOP 25(2), 90-10. https://doi.org/10.5944/reop.vol.25. num.2.2014.13522

Teichler, U. (2004). "Employability" or "professional relevance": Changes in the relationships between higher education and the world of work on the way towards the European higher education area. En U. Teichler (Ed.), Higher Education and the world of work (p.p 285-294). Sense Publishers.

Thieme, C. (2007). El desarrollo de competencias de empleabilidad en dos universidades chilenas. Un estudio empírico. Revista OIKOS, 11(24), 47-72. https://dialnet.unirioja.es/ servlet/articulo?codigo $=2949920$ 
Torres, M., \& Huamán, A. (2012). Las competencias laborales como variable vinculada al aprendizaje organizacional en instituciones educativas. Revista de la Facultad de Ingeniería Industrial 15(2), 45-53. http://sisbib.unmsm.edu.pe/Bibvirtual/publicaciones/ indata/v15_n2/pdf/ao7v15n2.pdf

Tuning project. (2003). Tuning Educational Structures in Europe. Informe final, proyecto piloto, fase uno. Universidad de Deusto. http://tuning.unideusto. org/tuningal/index.php?option=com_docman\&Itemid=191\&task=view_ category\&catid $=22 \&$ order $=$ dmdate_published\&ascdesc $=$ DESC

Tuning América Latina. (2007). Reflexiones y perspectivas de la Educación Superior en América Latina. Informe final del Proyecto Tuning en América latina 2004-2007. Publicaciones de la Universidad de Deusto. http://tuningacademy.org/wp-content/uploads/2014/02/ TuningLAIII_Final-Report_SP.pdf

Vargas, M. (2008). Perfiles de empleabilidad y desempeño profesional. IX Congreso Nacional de Investigación Educativa. http://www.comie.org.mx/congreso/memoriaelectronica/ vog/ponencias/at10/PRE1178332449.pdf

Villa, A., \& Poblete, M. (Dir.). (2008). Aprendizaje basado en competencias. Una propuesta para la evaluación de competencias genéricas. Universidad de Deusto/Ediciones Mensajero.

Weller, J. (2006). Inserción laboral de jóvenes: expectativas, demanda laboral y trayectorias. Boletín RedEtis no. 5. http://www.oei.es/historico/etp/insercion_laboral_jovenes_ weller.pdf 


\title{
Capítulo 6
}

\section{¿Posicionamiento o legitimidad? Estado actual y rutas para la cooperación de la Universidad Autónoma de Baja California con el sector social}

\author{
Ricardo Lindquist Sánchez y Rodolfo García Galván
}

Como algunas corrientes señalan, si el último reto del siglo XX en el ámbito de la vinculación universitaria fue consolidar los mecanismos de interacción con las empresas y las entidades gubernamentales, el primero del siglo XXI radica en fortalecer las relaciones con los sectores más vulnerables de la sociedad (De Sousa, 2007). Gracias a la vigencia y difusión de los esquemas anglosajones de vinculación, se podría pensar que la tarea consiste en construir la relación con la sociedad, pero se trata más bien de deconstruiry cuestionar la hegemonía de la vinculación con las empresas.

El movimiento estudiantil de Córdoba, Argentina, en 1918, dio origen a la vinculación en Latinoamérica y estableció como su fin predilecto la satisfacción de las demandas sociales. Insatisfechos por la opresión de las autoridades educativas y el tradicional alejamiento de la academia, los estudiantes de la Universidad Nacional de Córdoba llevaron a cabo una serie de manifestaciones que culminarían en la Reforma de Córdoba. A grandes rasgos, la Reforma representó un parteaguas en la vida interna y externa de las universidades, logrando que estas comenzaran a identificar y atender las demandas del sector social (Tünnermann, 1999).

Este primer periodo, comprendido entre 1918 y finales de la década de los setenta, retrató el auge del extensionismo social y de la difusión de la cultura. Es verdad que, como señalan algunos autores (Freire, 1978; Tünnermann, 1999), las actividades desarrolladas no hicieron un uso intensivo del conocimiento, pero sí reflejaron el cambio de visión y el compromiso entre las universidades de América Latina. Un ejemplo de ello fue la conformación de la Carta de las Universidades Latinoamericanas, en donde se enunció la responsabilidad universitaria de: (1) contribuir a la elevación del nivel espiritual de los habitantes a través de la cultura; (2) ser la expresión real de su momento histórico y (3) aspirar a convertirse en un sistema activo de funciones que beneficien a la colectividad que la sostiene (Unión de Universidades Latinoamericanas, 1951).

Un segundo periodo de la cooperación universidad-sector social se desarrolló entre la década de los ochenta y el año 2000, y tuvo como eje la intensificación de las relaciones universitarias con el sector empresarial (Campos \& Sánchez, 2006). En buena medida, el hecho 
que detonó esta transición fue la severa crisis económica experimentada en Latinoamérica a finales de los 1980 y principios de los 1990. Entre otros fenómenos, la crisis propició la reducción del presupuesto educativo, por lo que las universidades tuvieron que buscar nuevas vías para subsistir económicamente estableciendo vínculos productivos con los actores del entorno. En este sentido, y en tanto que no representaban ganancias financieras, las relaciones con el sector social fueron relegadas a un segundo y tercer término.

Haciendo un esfuerzo retrospectivo, podríamos identificar un tercer periodo comprendido desde el año 2000 a la actualidad. Este periodo se caracteriza por la incursión de nuevos fenómenos en el ámbito universitario, siendo los más notorios el desarrollo intensivo de las tecnologías y el inminente proceso de globalización. Como señala Malagón (2006), es posible que en otros países este cambio en el paradigma discursivo se encuentre cimentado en la bonanza económica y la satisfacción de las necesidades básicas de la población. En América Latina, sin embargo, el discurso tecnológico-globalizante se ha erigido sobre un campo de inequidad, pobreza e injusticia ${ }^{2}$.

Es esta disyuntiva entre los modelos extranjeros y las realidades locales la que nos lleva a cuestionarnos: ¿es pertinente seguir considerando la imagen y el posicionamiento como el principal propósito de la vinculación? En su lugar, este trabajo tiene como objetivo justificar la relevancia de la vinculación como un medio para la legitimación de las universidades. La vía metodológica para cumplir con este objetivo es la revisión de literatura (fuentes secundarias) y su respectivo cotejo con la realidad empírica identificada en un estudio sobre la cooperación de la Universidad Autónoma de Baja California (UABC) con el sector social desarrollado en 2018.

En este sentido, el presente capítulo se divide en cuatro apartados. En el primero de ellos se expone un acercamiento teórico sobre los paradigmas de posicionamiento y de legitimidad en la vinculación universitaria. En el segundo apartado se reportan los resultados de un estudio diagnóstico sobre la cooperación entre la UABC y el sector social, realizado en 2018. Posteriormente, se esbozan algunos mecanismos que la UABC podría implementar para intensificar su relación con los actores sociales menos favorecidos. Mientras que en el cuarto y último apartado se delimitan las principales conclusiones del capítulo.

\section{Marco teórico}

\section{La vinculación como medio de posicionamiento}

Uno de los elementos indispensables para comprender la búsqueda de posicionamiento que realizan las universidades es la dinámica de la economía basada en el conocimiento. Esta última puede entenderse como la transición a una sociedad postindustrial, en donde la economía

1 Datos de la Comisión Económica para América Latina y el Caribe (CEPAL, 2019) señalan que en 2017 el 30.7\% de la población de Latinoamérica vivía en condiciones de pobreza. 
deja progresivamente de basarse solo en bienes materiales (como el oro, el petróleo o los recursos naturales), para considerar también insumos inmateriales como la información y el conocimiento (Bell, 1976).

Con el cambio de narrativa hacia la economía y la sociedad del conocimiento, las universidades se han preocupado cada vez más por convertirse en actores estratégicos de la economía global (Deiaco et al., 2012). De aquel interés surgido a inicios del siglo XX por satisfacer las necesidades del entorno local, se ha transitado hacia la meta de convertirse en un punto - por diminuto que sea- de la constelación educativa global.

David Riesman, uno de los precursores norteamericanos del neoinstitucionalismo, señalaba ya desde la década de los 1950 que las instituciones educativas tendrían que desarrollar una "procesión tipo serpiente" en los años posteriores (Riesman, 1958). Esta afirmación es más vigente que nunca: las universidades serpentean con el propósito de adaptarse a los discursos y las tendencias globales. Desde luego, el movimiento y el cambio son indispensables para su supervivencia, pero dadas las condiciones que serán expuestas más adelante, da la impresión de que la universidad latinoamericana se mueve como una serpiente ciega.

Una de las tendencias que delimitan la ruta actual por la que las universidades transitan es la de los rankings y los indicadores (Altbach, 2006; Hou \& Jacob, 2017). Los rankings, a su vez, obedecen a un fenómeno previo: el de la masificación de la educación superior (Rama, 2009). Desde la década de 1980, la demanda en educación superior ha crecido de manera exponencial ${ }^{2}$, generando que la educación superior se convierta en un negocio rentable para la iniciativa privada, y que la dinámica de la competencia se geste con rapidez. Así, la lógica de los rankings se hace evidente: si cada día hay más universidades es indispensable contar con cifras y datos que nos ayuden a saber cuál elegir.

A pesar de su utilidad práctica, autores como Soh (2016) identifican una serie de deficiencias que ponen en tela de juicio la rigurosidad de los rankings:

1. La asignación de valores. No queda claro con base en qué criterios las agencias de rankings otorgan un mayor peso (puntuación) a ciertos rubros por encima de otros. Comúnmente, los indicadores bibliométricos tienen mayor ponderación que el número de convenios sostenidos con los actores de la sociedad, por citar un ejemplo.

2. Redundancia en indicadores. Por lo general, las agencias de rankings buscan la pulcritud de la medición, pero no dan un sustento teórico sólido a aquello que miden. Esto propicia que algunos indicadores sean redundantes. Como señala Soh (2016), la saturación del número de indicadores podría ser una estrategia para aparentar un estudio más completo.

3. Discrepancia entre los sistemas. Todos los rankings afirman medir el nebuloso término de la "excelencia académica", pero no existe una congruencia entre las universidades que 1970 a 15.93 en 2010, reflejando un incremento inusitado en tan solo cuatro décadas. 
aparecen en sus listas. Es común encontrar que en las primeras posiciones -aunque en distintas combinaciones- siempre figuran las mismas universidades (tal es el caso del MIT, Harvard, Oxford, Stanford, Caltech). Sin embargo, la lista de las universidades que se encuentran en las cincuenta o cien posiciones siguientes suelen ser diametralmente distintas.

El efecto de los rankings, y de lo que algunos llaman frontalmente capitalismo académico (Galceran, 2013; Ibarra, 2003; Slaughter \& Leslie, 1997), es la consolidación de una dinámica educativa cooptada por el productivismo y el reduccionismo (Vera, 2018). Por productivismo entendemos la búsqueda de que todo proceso educativo — sea en el ámbito de la docencia, la investigación o la vinculación- ofrezca productos terminados. En este sentido, la lógica subyacente es que a mayor productos mayor calidad y que a mayor calidad mejor posicionamiento (Vera, 2018).

Esta posición productivista genera un reduccionismo en la visión educativa. Uno de sus síntomas evidentes es que la capacidad intelectual de los académicos universitarios se aboque a conseguir el mayor número de productos educativos (egresados, tutorados, ponencias, publicaciones, viajes, estancias, etc.) para convertirse en académicos más "rentables". Esto lleva, desde luego, a la saturación laboral y a la concentración en un solo sector del panorama educativo (Vera, 2018).

Parecería en este punto que nos hemos olvidado de la vinculación. Todo lo contrario: hemos expuesto brevemente los factores que, a nuestro parecer, la orientan hacia el sector empresarial. Analicemos en primera instancia el productivismo. Si consideramos que las universidades buscan que todas sus actividades detonen en productos, podremos comprender por qué se privilegia la cooperación con las empresas. Al vincularse con estas, las universidades consiguen los siguientes productos: (1) ingresos pecuniarios que reducen su inercia financiera, (2) convenios de cooperación que posibilitan que los estudiantes lleven a cabo estancias profesionales, y (3) capital reputacional con los potenciales empleadores de sus egresados (Vega et al., 2011).

El reduccionismo, por su parte, obstaculiza la vinculación de forma indirecta. Estudios como los de Lindquist (2018) y de Morales-Páez y García-Galván (2020) corroboran de forma empírica que los académicos universitarios reducen sus actividades de vinculación debido a la sobrecarga laboral y al exceso de trámites burocráticos. Además, y en tanto que no pueden prescindir totalmente de hacer vinculación, los académicos optan por actores con los que pueden colaborar invirtiendo menor tiempo en ello, como sus pares en otras instituciones de educación superior (IES).

A partir de lo anterior, podríamos identificar una secuencia lógica en el discurso. La dinámica de la sociedad del conocimiento ha llevado a las universidades a buscar un mejor posicionamiento, el cual se consigue obteniendo indicadores que permitan subir peldaños en 
los rankings; la búsqueda de indicadores provoca productivismo y reduccionismo académico; el productivismo y el reduccionismo conducen a que todos los procesos educativos -en docencia, investigación o vinculación-estén orientados en conseguir "mejores números".

Naturalmente, sería ingenuo proponer que las universidades se distancien del macro-discurso de la sociedad del conocimiento y la globalización educativa. Sin embargo, es indispensable comprender que dichos fenómenos pueden representar una visión, mas no la ontología de la universidad. Volviendo a la metáfora de Riesman (1958) sobre la serpiente, podríamos decir que la sociedad y la economía basadas en el conocimiento representan el suelo sobre el que la serpiente se mueve, mas no sus ojos. Sus ojos deben ser los ojos de la misión filosófica y del sentido educativo de ser (Moncada, 2008).

\section{La vinculación como medio de legitimidad}

Si bien el discurso de la sociedad del conocimiento es global, su regionalización se torna indispensable para comprender la forma en que las universidades lo asimilan (De Sousa, 2007; Malagón, 2006). En el caso concreto del continente americano, es posible distinguir un norte y un sur. Estados Unidos y Canadá son parte del primero, mientras que México y los países de Centro y Sudamérica son actores clave de las epistemologías [del sur] propias del segundo (De Sousa, 2007). En efecto, podemos encontrar que ambas regiones tienen una visión distinta de la sociedad del conocimiento, así como de la pertinencia y la legitimidad de las actividades universitarias.

Para los países del norte, la pertinencia universitaria está relacionada con la cultura, las relaciones políticas y los valores, mientras que en los del sur se asocia con los vínculos exitosos con los actores del entorno —sociedad, industria y gobierno- (Malagón, 2006; Pérez \& Bermudez, 2015). Uno de los factores que podrían explicar esta dinámica es que en los países del norte la relación entre los actores del entorno y las universidades se encuentra asentada desde hace décadas (Torres \& Schugurensky, 2002). Al tiempo que en el sur la relación universidad-entorno aún es incipiente y se encuentra focalizada en los sectores empresariales y gubernamentales (Malagón, 2006).

La visión sobre la legitimidad también es distinta en el norte y en el sur. De los discursos del norte provienen acepciones de la legitimidad que la asocian con la confianza "interacadémica". Desde esta perspectiva, los rankings, indicadores y acreditaciones son formas de buscar legitimidad (y no precisamente posicionamiento):

¿Por qué se plantea en el siglo XX la necesidad de evaluar y acreditar la calidad de la educación superior si antes funcionaban el mérito y el prestigio? Si bien la respuesta más sencilla es del orden de lo cuantitativo (una vertiginosa demanda de estudiantes y una proliferación de universidades tanto publicas como privadas), debemos observar los motivos de fondo: la necesidad de identificarse como ins- 
titución válida, legitima, seria y responsable, es decir, de obtener reconocimiento en tanto tal y, al mismo tiempo, obtener la confianza por parte de sus demandantes y pares. Esta búsqueda por la identidad, el reconocimiento y la confianza entre una institución de es y sus demandantes de servicios, y entre instituciones pares, produjo como consecuencia la creación de sistemas y organismos evaluadores y acreditadores. (Villanueva, 2011, p.60)

En la cita anterior se ejemplifica una conclusión ampliamente difundida -aunque débilmente teorizada-: que, en el ámbito educativo, la legitimidad es sinónimo de estar bien evaluado-acreditado. Con dicha premisa se daría por hecho que el productivismo y el reduccionismo académico (Vera, 2018) son efectos ineludibles que se deben sortear para tener una universidad más legitima.

No obstante, esta perspectiva de la legitimidad es, en muchos sentidos, imprecisa. En el ámbito legal, en donde se acuña la discusión original sobre lo legítimo, se sabe que la legitimidad se divide en dos tipos: la de ejercicio (endógena) y la sustantiva (exógena). La legitimidad de ejercicio (endógena) implica que la figura que ejerce el poder en una institución goza de un soporte jurídico que lo faculta para hacerlo. En este caso podríamos pensar en los rectores universitarios, o en los miembros de juntas y consejos de gobierno; si algún académico decidiera autoproclamarse como rector sin seguir la ruta normativa, no tendría legitimidad endógena para hacerlo (Rúa, 2013).

La legitimidad sustantiva (exógena), por su parte, es definida por Rúa (2013) como: "aquella que se refiere al ejercicio del poder en sí, y que está orientada al cumplimiento de los objetivos definidos como propios en el modelo institucional adoptado" (p.97). En este sentido, la legitimidad implica que la institución cumple con los objetivos para los que fue creada. En otras palabras, la universidad no es legítima porque es bien evaluada, sino porque cumple con sus funciones sustantivas (Nun, 2002).

En este punto habrá quienes puedan sugerir que los rankings son instrumentos de legitimidad en tanto que miden el cumplimiento de las funciones universitarias. Sin embargo, como se muestra en la tabla 1, el núcleo de las funciones no forma parte de los indicadores evaluados. En su lugar, y al considerarlos sus ejes de referencia, las agencias de rankings propician que las universidades se esfuercen por conseguir: (1) altas cifras de productividad académica; (2) promoción de la cooperación internacional; (3) contratación de académicos especializados y (4) que tanto la investigación como la vinculación generen ingresos económicos para la universidad, con lo que la cooperación se realiza prácticamente solo con aquellos actores que pueden pagar por los servicios académicos: la industria y el gobierno. 


\section{Tabla 1}

Indicadores considerados en los principales rankings

\begin{tabular}{|c|c|}
\hline Ranking & Indicadores \\
\hline Shangai & $\begin{array}{l}\text { - Egresados de la institución que han ganado premios Nobel u otras medallas } \\
\text { - Profesores activos de la institución que han ganado premios Nobel u otras medallas } \\
\text { - Investigadores altamente citados } \\
\text { - Artículos publicados en Nature o Science } \\
\text { - Desempeño académico per cápita de la institución (puntuación total dividida el } \\
\text { número de académicos) }\end{array}$ \\
\hline $\begin{array}{l}\text { The Times } \\
\text { World University } \\
\text { Rankings }\end{array}$ & $\begin{array}{l}\text { - Encuesta de reputación } \\
\text { - Ratio docentes-alumnos } \\
\text { - Ratio doctorados-licenciados } \\
\text { - Académicos con doctorado } \\
\text { - Demanda estudiantil } \\
\text { - Ingresos económicos por investigación } \\
\text { - Productividad por investigación } \\
\text { - Número de citas académicas } \\
\text { - Movilidad estudiantil internacional } \\
\text { - } \text { Covilidad académica internacional } \\
\text { - Ingresos por transferencia de conocimiento con la industria }\end{array}$ \\
\hline OS World University & $\begin{array}{l}\text { - Citas por facultad } \\
\text { - Movilidad estudiantil internacional } \\
\text { - Profesores con movilidad y reputación internacional } \\
\text { - Número de estudiantes } \\
\text { - Reputación entre los empleadores } \\
\text { - Reputación académica (opinión de un grupo de expertos conformado por la agencia } \\
\text { de rankings) }\end{array}$ \\
\hline
\end{tabular}

Nota: Elaboración propia con base en la información proporcionada en los portales electrónicos de cada ranking.

En este trabajo no consideramos que la perspectiva del norte hable de legitimidad, sino que el término se emplea como una prótesis discursiva para ornamentar la búsqueda de imagen y posicionamiento. En su lugar, somos afines a la noción de legitimidad expuesta desde el sur por De Sousa (2007). Para el sociólogo brasileño, la universidad ha experimentado primero una crisis de hegemonía, que detonó en una crisis de legitimidad. Se habla de una crisis de hegemonía en tanto que la universidad se ha visto desplazada como el actor central del conocimiento en la sociedad.

Estudios pioneros, como los de Gibbons et al. (1997), han demostrado que la producción y reproducción de conocimiento ya no concierne solo a las universidades, sino que existe un modo dos de producción del conocimiento en cuya dinámica se encuentran inmersas las empresas y algunos laboratorios científicos pertenecientes a la industria o el Estado. Además, la universidad pública se ha visto afectada por factores como: (1) el crecimiento exponencial de instituciones de educación superior privadas, (2) el descontento generado por la ausencia 
de empleos para los egresados (inflación académica), y (3) el desarrollo intensivo de las tecnologías, que posibilitan el autodidactismo y las modalidades de aprendizaje no presencial (De Sousa, 2007; Navarrete, 2012; Rahona, 2006).

En suma, los aspectos mencionados con anterioridad demuestran el núcleo de la crisis de legitimidad enunciada por De Sousa (2007): cada vez es menos evidente que la universidad es una institución socialmente imprescindible. Quien, a pesar de lo expuesto en al apartado anterior, argumente que los rankings son un ejemplo de lo contrario - de que la universidad, como institución, goza de buen prestigio- debe considerar que las agencias de rankings no contemplan la opinión de la sociedad. En vez de ello, agrupan la percepción de un nicho de académicos que si bien son parte de la sociedad no representan sus intereses y necesidades (Mullins, 2011).

Una de las respuestas más frecuentes al promover que las demandas sociales formen parte de la agenda universitaria es la defensa de la autonomía. Para determinados sectores, la autonomía de la universidad implica que ningún actor externo debe regir el quehacer universitario. Desde nuestra perspectiva, esto representa una confusión del término, por lo que creemos de utilidad abordar de forma breve la noción de autonomía.

En 1998, la Asociación Internacional de Universidades, definió el principio de autonomía universitaria de la siguiente manera:

El principio de autonomía puede ser definido como el necesario grado de independencia de interferencia externa que la universidad necesita con respecto a su organización interna, su gobierno, la distribución de sus recursos financieros, la generación de ingresos de fuentes no públicas, el reclutamiento de su personal, la fijación de las condiciones de estudio y, finalmente, la libertad de conducir enseñanza e investigación. (IAU, 1998, p.2)

Como señala Bernasconi (2014), la autonomía no es un fin, sino un medio que garantiza la libertad de la universidad en su gobierno, su forma de organización interna, sus finanzas, la elección del personal académico, sus reglas y procedimientos y el ejercicio de la investigación y enseñanza. De esta manera, el hecho de que exista -y se respete- la autonomía interna institucional, no supone que la universidad sea un ente autónomo de la sociedad. Además, resulta curioso que la presencia de actores empresariales-gubernamentales en mecanismos de gobierno universitario, así como en los comités para la conformación de planes de estudios y competencias (véase el Proyecto Tuning, 2014), no representen una inquietud para los defensores de la autonomía universitaria.

Es impreciso pensar las demandas sociales son un detrimento de la autonomía universitaria. De hecho, dichas demandas no conforman una lista de nuevos rubros que la universidad debe satisfacer [a diferencia de los rankings-indicadores y el paradigma de la búsqueda 
de posicionamiento] sino un llamado a que la universidad cumpla con las funciones para las que fue fundada (Lindquist, 2018).

Hasta el momento hemos discutido y llegado a las siguientes conclusiones. Primero, que hay dos paradigmas de la vinculación: el que busca la imagen-posicionamiento y el que busca recuperar la legitimidad. Segundo, que el paradigma de la imagen-posicionamiento ha propiciado el productivismo y reduccionismo académico que impera en las universidades. Tercero, que existen dos tipos de legitimidad: la de ejercicio (endógena) y la sustantiva (exógena). Cuarto, que las universidades latinoamericanas experimentan una crisis de legitimidad sustantiva (o exógena).

\section{La cooperación con el sector social como estrategia para recuperar la legitimidad sustantiva}

Una vez analizados los argumentos que fundamentan que la universidad experimenta una crisis de legitimidad sustantiva (De Sousa, 2007; Vallaeys, 2014), es relevante abocarnos a las posibles soluciones. Desde nuestra perspectiva, una de las medidas trascendentales para tener una universidad más legítima es el fortalecimiento de la cooperación con el sector social. Esto implicaría, en primera instancia, que la universidad vuelva los ojos hacia los sectores menos favorecidos de la sociedad; no solo desde una perspectiva asistencialista, sino con una visión de auténtico compromiso por mejorar la calidad de vida de los habitantes de la región.

La primera interrogante que podría surgir en este sentido está relacionada con los quiénes: ¿acaso no son las empresas parte de la sociedad? Como puntualiza Aguilar (2006), la noción de sociedad que permea hasta nuestros días se sustenta en la idea gramsciana de que todo aquello que no forma parte del gobierno es sociedad. Esto explica que algunas universidades reporten en sus discursos una cooperación activa con la sociedad, y al mostrar las evidencias se observe un acercamiento mayoritario con las empresas.

En efecto, en este trabajo consideramos que el término más propicio para distinguir a los actores mencionados es el de Tercer Sector, el cual puede entenderse como:

Un espacio de acción autónomo distinto del gobierno y de las empresas privadas, conformado por organizaciones o asociaciones no lucrativas, en el que se atienden demandas sociales y comunitarias no satisfechas por los otros actores. (Lindquist, 2018, p.31)

Una segunda pregunta estaría relacionada entonces con el por qué: ¿por qué la cooperación con el tercer sector o sector social representaría un aliciente para la legitimidad universitaria? Con el propósito de responder dicha interrogante, citamos a continuación algunos de los estudios internacionales que avalan los beneficios de este proceso de cooperación. 
Uno de los primeros beneficios observables es el de la pertinencia de los contenidos académicos. Como se aprecia en la figura 1, Collins et al. (2007) detallan que al colaborar con el tercer sector/sector social la universidad fortalece: (1) el proceso curricular, en tanto que detecta y corrobora, en tiempo real, las necesidades formativas del entorno; (2) el proceso formativo, al contribuir a que los estudiantes cuenten con una visión nítida sobre las problemáticas que deberán resolver cuando egresen como profesionales; y (3) el proceso de investigación, en la medida en que posibilita que la producción de conocimiento tenga como referente los problemas concretos de la sociedad.

Un segundo tópico, estrechamente ligado con el anterior, es el del fortalecimiento de la vinculación como función sustantiva. Como lo sostiene Malagón (2006), a diferencia de sus pares anglosajonas y europeas, la universidad latinoamericana es una instancia dedicada principalmente a la formación de recursos humanos. La investigación es una actividad secundaria, que no se desarrolla de forma intensiva salvo en las universidades nacionales que cuentan con un presupuesto nutrido (Aboites, 2010). En efecto, la sociedad en general tiene claro que la universidad enseña e investiga, pero no tiene la misma claridad cuando se le pregunta cuál es el objetivo de su tercera función. Esto podría obedecer a la débil presencia de la universidad en el ámbito social. Es cierto que la universidad divulga y realiza actividades de extensión pero el impacto social del conocimiento producido por sus académicos aún no es contundente.

\section{Figura 1}

Beneficios de la cooperación con el sector social

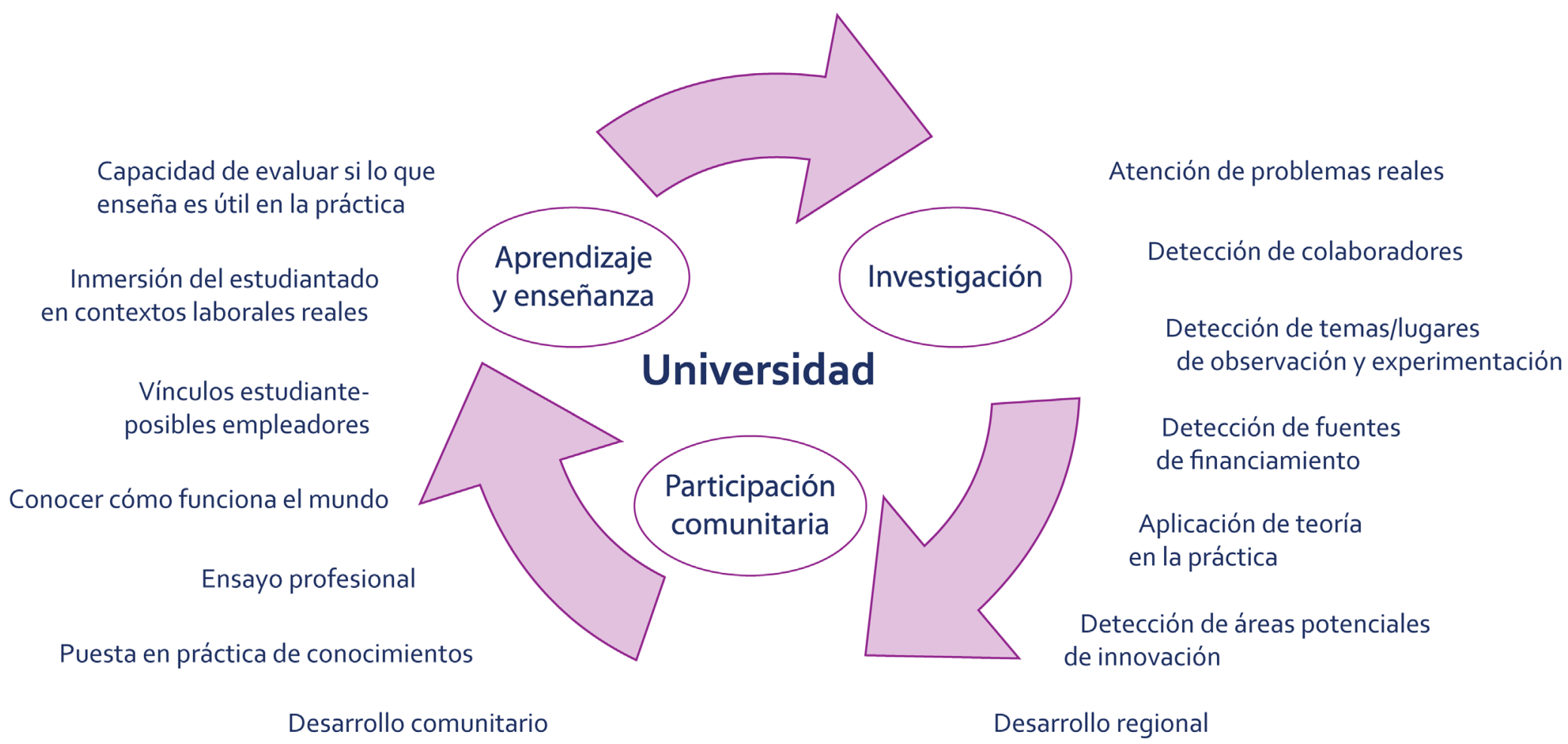

Nota: Recuperado de Collins et al. (2007), traducción libre. 
Finalmente, la cooperación con el sector social podría representar una estrategia para fortalecer el postulado fundacional común de resolver las problemáticas de la sociedad (Lindquist, 2018). En esencia, este principio rige las tres funciones sustantivas dela universidad: (1) al formar profesionales, la universidad garantiza que la dinámica social conserve el equilibrio; (2) al producir conocimiento, posibilita que existan insumos para conocer el entorno social y natural y resolver conflictos; $y$ (3) al vincularse, trabaja de manera activa para que dicho conocimiento tenga un impacto para mejorar la calidad de vida de los ciudadanos.

A pesar de los beneficios mencionados en la literatura, las universidades - por los factores que se abordaron en el primer apartado- continúan privilegiando la cooperación con actores empresariales y gubernamentales. En los siguientes apartados, se presentan evidencias empíricas de un estudio realizado en la UABC con el propósito de conocer las características de la cooperación entre la universidad y su entorno, en general, y entre la universidad y el sector social, en particular.

\section{Metodología}

Los resultados que se muestran a continuación se desprenden de un estudio cuantitativo de alcance exploratorio, llevado a cabo en la UABC en 2018, y cuyo objetivo general fue caracterizar la cooperación mediada por el conocimiento entre la UABC y el Tercer Sector.

Con este propósito, se admnistró un cuestionario en línea para conocer la percepción de los académicos sobre este proceso. El único criterio de inclusión consistió en que los académicos pertenecieran al Sistema Nacional de Investigadores (SNI), con el propósito de garantizar que la cooperación que realizan se encuentre mediada por el conocimiento. En total, se contó con la respuesta de 75 profesores-investigadores, lo que representa el $20 \%$ de la población.

Para el diseño del instrumento se tomaron como referencia los trabajos de Alcántar et al. (2006), Carro (2004), García y McAnally (2016), y Montes (2002), los cuales han explorado, en distintos momentos, la vinculación de la $U A B C$ con su entorno. Así mismo, se consideraron aportaciones como las de Butcher (2014) y Vallaeys (2014) para focalizar la cooperación de la UABC con el sector social.

En este sentido, el cuestionario se compuso de cinco apartados: (1) Datos de identificación; (2) Posicionamiento y experiencias personales respecto a las actividades de cooperación UABC-entorno; (3) percepción sobre las condiciones institucionales para la cooperación UABC-entorno; (4) características de la cooperación UABC-sector social; y (5) la cooperación UABC-entorno en prospectiva (visión a futuro). 


\section{Resultados}

\section{Características de los académicos que se vinculan}

Uno de los primeros indicadores que cobran relevancia en el estudio es la edad promedio de los participantes. Del total de académicos que respondieron, más del 50\% tienen entre $31 \mathrm{y}$ 40 años. Esto podría implicar, como señala Castro-Martínez et al. (2016), que la juventud y su respectiva energía es un detonante de la vinculación; así, mientras que las universidades con plantas académicas jóvenes tienen actividades de vinculación más numerosas, las de plantas académicas maduras tienen menos, pero más consolidadas.

En cuanto a las áreas disciplinares de mayor vinculación, es posible observar que aquellas relacionadas con la tecnociencia demuestran un mayor interés en temas asociados a la cooperación con el entorno. Así lo demuestra la alta tasa de participación de académicos adscritos a la Facultad y el Instituto de Ingeniería, así como al Instituto de Investigaciones Oceanológicas.

Con relación a la pertenencia al Sistema Nacional de Investigadores (SNI), criterio contemplado para garantizar que la cooperación sea mediada por el conocimiento, el grueso de los académicos (53\%) se encuentra en el nivel 1, son candidatos el 32\%, son nivel 2 el $13.30 \%$ y solo el $1 \%$ son nivel 3 . En cuanto a la antigüedad de los académicos en el SNI, se obtuvo como resultado que dos ítems presentaron una correlación negativa estadísticamente significativa. Así, entre más antigüedad tienen los académicos en el SNI menos consideran que la UABC debería poseer agentes promotores de enlace altamente especializados para intensificar la cooperación con el entorno y menos se vislumbran yendo más lejos en actividades de vinculación.

Esto último, podría interpretarse a través de dos vertientes: (1) que los académicos de mayor experiencia presentan más renuencia al cambio por la dificultad que implicaría adaptarse a este y (2) que dichos académicos, por su cercanía a la jubilación, no tienen ya expectativas, a mediano o largo plazo, relacionadas con la vinculación.

\section{Posicionamiento y experiencias personales respecto a las actividades de cooperación UABC-entorno}

A primera vista, la cooperación con el entorno, y la percepción que tienen los académicos sobre la misma, es positiva. Prueba de ello es que el $88 \%$ de los académicos han realizado actividades de cooperación o difusión durante el último año, y que el $77 \%$ considera importante que la $\cup A B C$ realice actividades de cooperación con su entorno. De esta manera, se demuestra que la práctica de la vinculación es un elemento ineludible en el quehacer académico, junto a las actividades de investigación y docencia.

No obstante, como se muestra en la figura 2, la mayor parte de la cooperación realizada por los participantes no rebasa las fronteras de la academia. 


\section{Figura 2}

Distribución de los actores con los que interactúa el personal académico

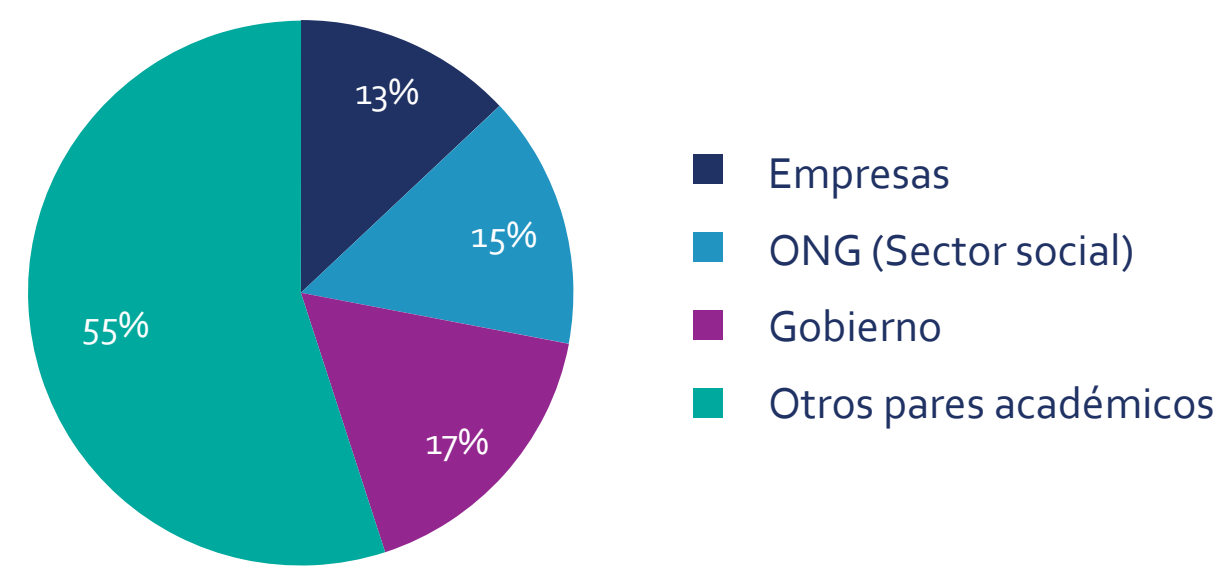

Nota: Elaboración propia con base en los resultados de la encuesta.

Que los académicos estrechen colaboraciones sobre todo con otros pares (al interior o fuera de la universidad) puede reflejar, según Castro-Martínez et al. (2016), el apego a una forma de cooperación que les permite "cumplir" con dicha función sustantiva sin la necesidad de salir del cubículo. Esto adquiere sentido si se observan con detenimiento los mecanismos de cooperación más recurridos por los participantes (figura 3).

\section{Figura 3}

Mecanismos de cooperación más utilizada

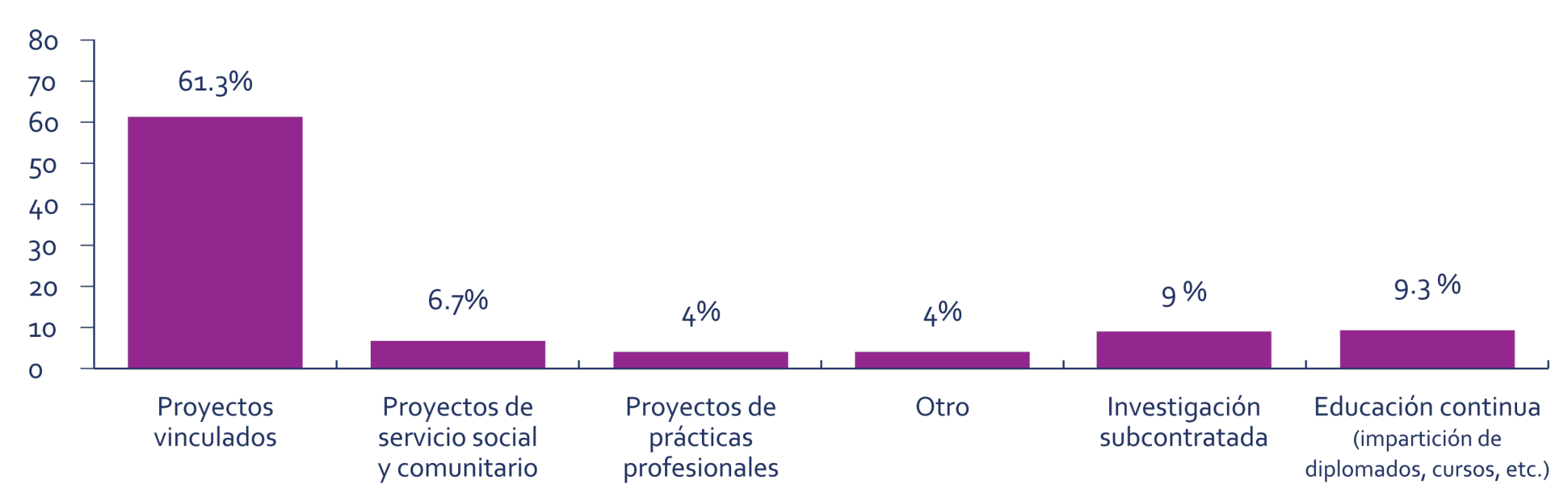

Nota: Elaboración propia con base en los resultados de la encuesta.

Sobre las satisfacciones que han representado la cooperación con el entorno, los participantes destacan el desarrollar productos de investigación (33.30\%), por encima de formar recursos humanos (29.30\%) o solucionar problemas específicos (25.30\%). Esto adquiere sentido, en tanto que la relación con otros académicos suele implicar la producción de nuevo conocimiento, y no su aplicación. Así mismo, es posible comprobar que, como lo mencionan García-Galván y McAnally (2016), son pocos los académicos que atribuyen a las remuneraciones económicas su principal motivación. 
Sin embargo, el $85 \%$ de los participantes aceptó haber tenido experiencias negativas generadas por los ejercicios de vinculación. La mayoría se concentran en dos grandes ejes: la presencia de procesos administrativos lentos (44\%) y la saturación laboral (21.30\%).

Los obstáculos, que serán abordados más adelante, representan algunos de los principales problemas que los académicos reportan a nivel internacional (Bender, 2008; Emiliozzi et al., 2011; Tomé \& Hernández, 2015).

\section{La cooperación de la UABC con el sector social}

A diferencia de otros estudios realizados en la propia UABC (Carro, 2004; Montes, 2002), una porción considerable (64\%) de los participantes señaló haber cooperado con el sector social durante el último año, aunque el vínculo se dio por iniciativa propia y no de las autoridades universitarias. No obstante, es necesario señalar que dichos trabajos carecen de claridad conceptual y a menudo asocian el sector social con el conjunto de los actores del entorno, incluyendo al gobierno y el sector productivo.

A diferencia de la cooperación con el entorno en general, en donde se observa el predominio de las áreas del conocimiento ligadas a la tecnociencia, los ejercicios de cooperación con el sector social se desarrollan sobre todo en las Ciencias Agropecuarias y las Ciencias de la Salud (figura 4).

\section{Figura 4}

Cooperación con el sector social según el área de conocimiento

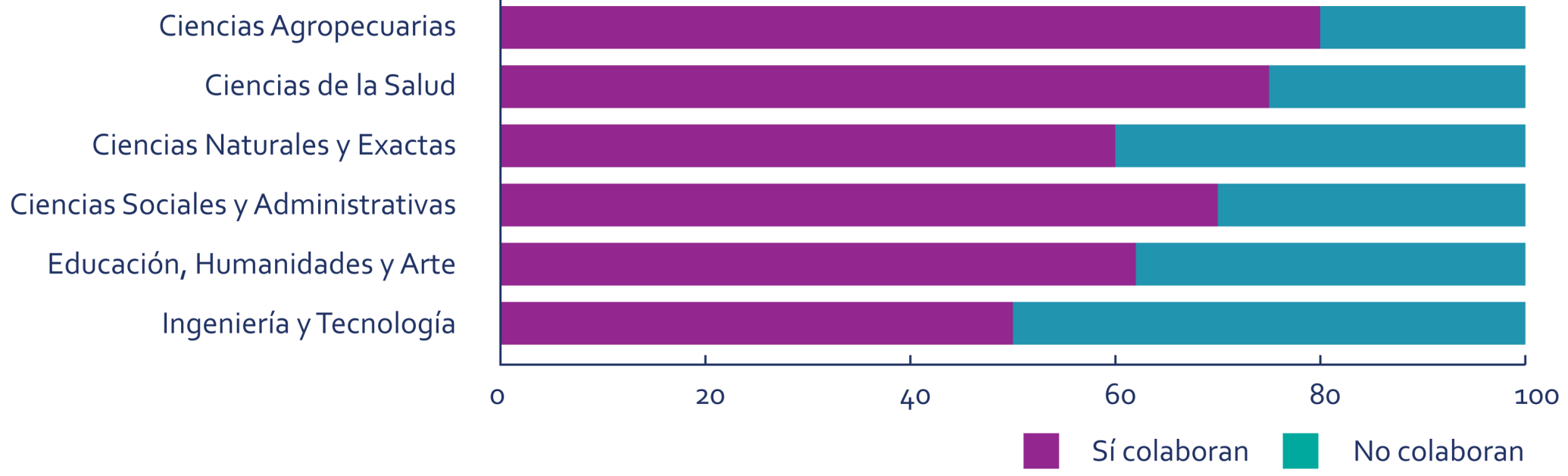

Nota: Elaboración propia con base en los resultados de la encuesta.

Llama la atención, en este sentido, que buena parte de los académicos pertenecientes al área de Educación, Humanidades y Arte, así como a las Ciencias Sociales y Administrativas, no cooperen con el sector social. Esto último, considerando posturas como la de Vallaeys (2014), quien señala que el campo de acción de las humanidades debe radicar en la transformación de aquellos individuos que han conseguido llegar a la universidad, pero también en contribuir en la emancipación de quienes no han podido acceder a ella. 
A pesar de que el $67 \%$ de los académicos señalaron haber cooperado con el sector social durante los últimos dos años, la mayor parte, como se muestra en la tabla 2, está inconforme con el impulso que la UABC le ha dado a la cooperación con dicho sector, así como con el peso que este tiene en los diversos esquemas de incentivos.

\section{Tabla 2}

Valores medios de los reactivos tipo Likert

\begin{tabular}{|c|c|c|}
\hline Reactivos & Media & Moda \\
\hline $\begin{array}{l}\text { Considero que la vinculación de la UABC (o la unidad académica) con su entorno es } \\
\text { importante. }\end{array}$ & 4.64 & 5 \\
\hline $\begin{array}{l}\text { Considero que la UABC debería poseer agentes promotores/de enlace altamente } \\
\text { especializados para intensificar la cooperación con el entorno. }\end{array}$ & 4.33 & 5 \\
\hline $\begin{array}{l}\text { Considero que las organizaciones del tercer sector poseen conocimiento que puede } \\
\text { ser valioso para la UABC. }\end{array}$ & $4 \cdot 31$ & 5 \\
\hline $\begin{array}{l}\text { Considero que mis actividades de vinculación con el entorno han contribuido a } \\
\text { mejorar la calidad de la formación de los estudiantes y de la investigación que se } \\
\text { realiza en la UABC. }\end{array}$ & 4.22 & 5 \\
\hline $\begin{array}{l}\text { Considero que la estructura organizacional debería actualizarse y reestructurarse } \\
\text { para intensificar la cooperación UABC-entorno, en general y UABC-tercer sector, en } \\
\text { particular. }\end{array}$ & 4.07 & 5 \\
\hline $\begin{array}{l}\text { Considero que la normatividad institucional debería actualizarse para intensificar la } \\
\text { cooperación UABC-entorno, en general y UABC-tercer sector, en particular. }\end{array}$ & 4.05 & 5 \\
\hline Me vislumbro yendo más lejos en la cooperación con el entorno en los próximos años. & 4.01 & 5 \\
\hline $\begin{array}{l}\text { Considero que la comunidad universitaria en general tiene percepción positiva acerca } \\
\text { de la cooperación de la UABC con el entorno. }\end{array}$ & $3 \cdot 56$ & 3 \\
\hline $\begin{array}{l}\text { Considero que la cooperación UABC-entorno se encuentra debidamente plasmada en } \\
\text { documentos normativos (reglamentos) y de planeación estratégica (PDI). }\end{array}$ & $3 \cdot 32$ & 4 \\
\hline $\begin{array}{l}\text { Considero que conozco los procedimientos institucionales para establecer convenios } \\
\text { de cooperación con el entorno. }\end{array}$ & 3.29 & 4 \\
\hline $\begin{array}{l}\text { Considero que la UABC se ha esforzado lo suficiente para identificar las principales } \\
\text { necesidades del tercer sector. }\end{array}$ & 2.81 & 3 \\
\hline $\begin{array}{l}\text { Considero que la cooperación con el tercer sector ha tenido el mismo impulso } \\
\text { institucional que la establecida con otros actores (gobierno, empresas, academia). }\end{array}$ & 2.80 & 3 \\
\hline $\begin{array}{l}\text { Considero que las actividades de vinculación con el tercer sector tienen peso en los } \\
\text { esquemas de incentivos nacionales/institucionales (SNI, PROMEP, PRODEP). }\end{array}$ & 2.75 & 2 \\
\hline
\end{tabular}

Nota: Se utilizó una escala de actitud, cuyos parámetros de respuesta fueron: "Totalmente en desacuerdo" (1), "En desacuerdo" (2), "Indeciso" (3), "De acuerdo" (4), y "Totalmente de acuerdo" (5). 
A pesar de la percepción negativa que existe en torno al impulso institucional y los respectivos esquemas de incentivos, los académicos en general reconocen que las organizaciones del tercer sector (sector social) poseen conocimiento que podría ser útil para la propia universidad. En este sentido, cabe preguntar qué elementos podrían detonar en una intensificación de la cooperación con dicho sector. Como respuesta, los participantes han señalado el tener menos carga laboral (34.70\%) y una gestión de procesos administrativos más eficiente (30\%) (figura 5).

\section{Figura 5}

Mejoras necesarias para fortalecer la cooperación con el sector social

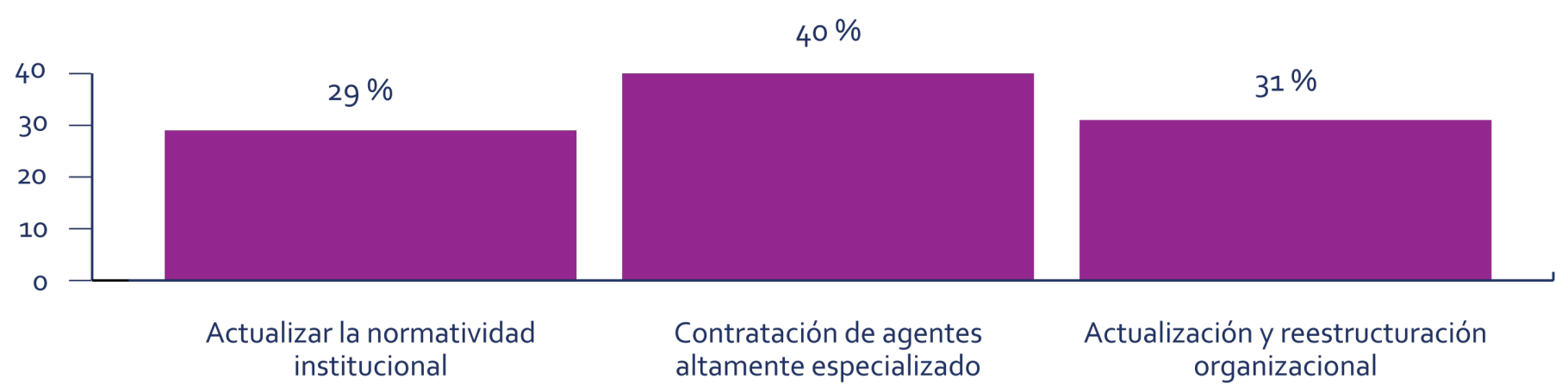

Nota: La suma de los porcentajes no es 100, debido a que los participantes pudieron elegir varias opciones de respuesta.

Además, los participantes señalan que los mecanismos idóneos para intensificar la cooperación con el sector social son los proyectos de investigación conjunta (61.60\%) y, en menor medida, el servicio social (23.30\%). Esto último, como lo indican Hernández y Magaña (2007), es crucial, en tanto que evidencia la disposición de los académicos de homologar la capacidad de ambos actores (universidad-sector social) para producir conocimiento de forma conjunta; y relegan la postura común - contractual, en palabras de De la Cruz y Sasia (2008) - en donde la universidad responde al sector social otorgándole acceso a estudiantes (recursos humanos) sin garantizar que dicha experiencia enriquezca el proceso formativo de los mismos.

\section{Conclusiones}

Los resultados expuestos hasta ahora contribuyen a sustentar las hipótesis teóricas que postulamos en los primeros apartados. En primer lugar, demuestran que existe una paradoja en el ámbito de la vinculación: por un lado -en el marco de la dinámica de la sociedad y economía del conocimiento- se les pide a los académicos que se mantengan vinculados, pero factores institucionales como la sobrecarga laboral o la burocracia en procesos administrativos, los orillan a desarrollar una vinculación intracubicular. Esto contribuye, en sintonía con el productivismo académico señalado por Vera (2018), a que se obtengan productos académicos (artículos, ponencias, capítulos de libro) de manera exprés. 
Otro de los datos que llaman la atención es que los académicos colaboren con las empresas, el gobierno y el sector social casi en la misma frecuencia. En suma, la cooperación con dichos actores representaría el $45 \%$, con lo que se observan indicios de la crisis de hegemonía señalada por (De Sousa, 2007), en donde actores distintos a la universidad pueden sostener relaciones mediadas por el conocimiento.

Así mismo, resulta interesante la respuesta asociada a las principales satisfacciones que la vinculación genera a los académicos. Contrario a la lógica de la tercera función sustantiva, los académicos se sienten satisfechos con sus actividades vinculantes en tanto que les permiten obtener productos de investigación, dejando en los últimos lugares de respuesta la solución de problemáticas del entorno. Esto podría obedecer a la presión intrainstitucional por obtener productos académicos que reditúan en el engrosamiento curricular y el relativo aumento de ingresos económicos.

No deja de llamar la atención el hecho de que las disciplinas relacionadas a las Ciencias Sociales y las Humanidades tengan una débil cooperación con el sector social, optando en su lugar por establecer lazos con sus pares académicos. Sin embargo, esto refleja la lógica universitaria en el rubro de la legitimidad: se propicia la legitimidad interna-endógena mediante el desarrollo de productos de investigación (aunque no necesariamente de conocimiento), a pesar de que este alejamiento del entorno social conlleve el debilitamiento de la legitimidad externa-exógena.

A pesar de la encrucijada en la que se encuentran, los académicos tienen una perspectiva favorable con relación al sector social. En sus propias palabras, el sector social posee conocimiento que puede ser de utilidad para los actores universitarios, pero consideran necesario que las autoridades universitarias y las instancias nacionales que regulan la ciencia le den mayor peso en los esquemas de incentivos.

También es posible observar que esta dinámica es legitimada por los propios académicos, en la medida en que algunos de ellos han hecho de los incentivos y el currículum su principal objeto de trabajo. A diferencia de otros sectores que han decidido renunciar a esquemas como el SNI, a cambio de seguir realizando actividades que, en su propia filosofía, consideran socialmente pertinentes.

Mucho podrá decirse sobre las posibles rutas y mecanismos para fortalecer la cooperación con el sector social. Pero ninguna de ellas podrá llevarse a buen término sin un cambio en la visión de universidad. Mientras la atención se mantenga en conseguir productos académicos (humanos o cognitivos) para posicionarse ante la competencia, los esfuerzos para cooperar con el sector social conservarán su estatus de actividad residual y de extensionismo filantrópico.

Desde nuestra perspectiva, y como lo hemos advertido en apartados anteriores, la universidad debe buscar un punto medio. Por una parte, debe ser capaz, como lo ha sido hasta el momento, de garantizar su legitimidad endógena (interacadémica) y pertenecer con ello 
a los esquemas nacionales de acreditación que le permiten mantenerse en el ejercicio. Pero también es indispensable que considere la legitimidad externa y revalúe sus ideales filosófi$\cos$ (de tenerlos).

Un primer paso en este sentido consistiría en transitar de una universidad regida por documentos programáticos (planes de desarrollo y misiones/visiones administrativas) a una sustentada en su modelo educativo. Parecería, en la actualidad, que los modelos educativos se han convertido en documentos de lejana consulta para las autoridades universitarias. Por nuestra parte, consideramos que el modelo educativo es el instrumento idóneo para fungir como un rompeolas teórico que distinga la pertinencia o inaplicabilidad, según sea el caso, de las tendencias educativas.

De no llevar a cabo dichas reformas, la universidad podría enfrentarse a una severa crisis. La universidad seguirá desgastando su imagen social, hasta el punto en el que pueda dejar de considerarse imprescindible para los actores que la sostienen económicamente. 


\section{Referencias}

Aboites, H. (2010). La encrucijada de la universidad latinoamericana. En R. Leher (Ed.), Por una reforma radical de las universidades latinoamericanas (pp. 95-120). CLACSO.

Aguilar, R. (2006). Las organizaciones de la sociedad civil en México: su evolución y principales retos. Universidad Iberoamericana.

Alcántar, V., Arcos, J., \& Mungaray, A. (2006). Vinculación y posicionamiento de la Universidad Autónoma de Baja California con su entorno social y productivo. Universidad Autónoma de Baja California.

Altbach, P. (2006). The dilemmas of ranking. International Higher Education, 42(2-3).

Bell, D. (1976). El advenimiento de la sociedad post-industrial. Alianza Universidad.

Bender, C. (2008). Exploring Conceptual Models for Community Engagement at Higher Education Institutions in South Africa. Perspectives in Education, 26(1), 81-95.

Bernasconi, A. (2014). Autonomía universitaria en el siglo XXI: nuevas formas de legitimidad ante las transformaciones del Estado y la Sociedad. Páginas de Educación, 7(2), 1-27.

Butcher, J. (2014). Tercer sector y desarrollo en México. En A. Girón (Ed.), Del "vivir bien" al "buen vivir" entre la economía feminista, la filantropía y la migración hacia la búsqueda de alternativas (p. 200). Colección de libros de la Revista Problemas del Desarrollo, Universidad Nacional Autónoma de México, Instituto de Investigaciones Económicas.

Campos, G., \& Sánchez, G. (2006). La vinculación universitaria y sus interpretaciones. Ingenierías, 9(30), 18-25.

Carro, H. (2004). Diagnóstico de la vinculación en la Universidad Autónoma de Baja California: Entrevistas a directores de unidades académicas. Universidad Autónoma de Baja California.

Castro-Martínez, E., Olmos, J., \& Fernández de Lucio, I. (2016). La Vinculación CienciaSociedad: Estereotipos y Nuevos Enfoques. Journal of Technology Management \& Innovation, 11(2), 121-129.

Collins, R., Curtis, O., Curtis, S., \& Stevenson, L. (2007). Community engagement as a cornerstone enabling learning and teaching and research in the postmodern world. The Australian Journal of University Community Engagement, 2(2), 87-107.

Comisión Económica para América Latina y el Caribe (CEPAL). (2019). Panorama Social de América Latina. Naciones Unidas.

De La Cruz, C., \& Sasia, P. (2008). La responsabilidad de la universidad en el proyecto de construcción de una sociedad. Nueva Época, 13(2), 17-51.

DeSousa, B. (2007). La universidad en el sigloXXI. Para una reforma democráticayemancipatoria de la universidad. CIDES-UMSA, ASDI y Plural Editores.

Deiaco, E., Hughes, A., \& McKelvey, M. (2012). Universities as strategic actors in the knowledge economy. Cambridge Journal of Economics, 36(3), 525-541. 
Emiliozzi, S., Vasen, F., \& Palumbo, M. (2011). Desafíos para la vinculación entre la universidad pública y demandas de actores sociales y gubernamentales. Espacio Abierto Cuaderno Venezolano de Sociología, 20(2), 329-341.

Freire, P. (1978). La educación como práctica de la libertad. Siglo XXI Editores.

Galceran, M. (2013). Entre la academia y el mercado. Las universidades en el contexto del capitalismo basado en el conocimiento. Athenea Digital, 13(1), 155-167.

García-Galván, R., \& McAnally, L. (2016). Bases institucionales de la vinculación tecnocientífica en universidades mexicanas: los casos de la UABC y de la UAEMéx. 10 Congreso Internacional de Educación Superior. La Habana, Cuba.

Gibbons, M., Limoges, C., Nowotny, H., Schwartzman, S., Scott, P., \& Trow, M. (1997). La nueva producción de conocimiento. Ediciones Pomares-Corredor.

Hernández, N., \& Magaña, H. (2007). El concepto de servicio social en estudiantes de la universidad autónoma de Tlaxcala. Memorias Del IX Congreso Nacional de Investigación Educativa.

Hou, Y-W., \& Jacob, J. (2017). What contributes more to the ranking of higher education institutions? A comparison of three world university rankings. The International Education Journal: Comparative Perspectives, 16(4), 29-46.

Ibarra, E. (2003). Capitalismo académico y globalización: la universidad reinventada. Educación Social, 24(84), 1059-1067.

International Association of Universities (IAU). (1998). Academic Freedom, University Autonomy and Social Responsibility. IAU Policy Statement.

Lindquist, R. (2018). La colaboración mediada por el conocimiento entre la UABC y el Tercer Sector. Universidad Autónoma de Baja California.

Malagón, L. (2006). La vinculación Universidad-Sociedad desde una perspectiva social. Educación y Educadores, 9(2), 79-93.

Moncada, J. (2008). La universidad: un acercamiento histórico-filosófico. Ideas y Valores, (137), 131-148.

Montes, C. (2002). La vinculación de la Universidad Autónoma de Baja California vista desde sus unidades académicas. Universidad Autónoma de Baja California.

Morales-Páez, M., \& García-Galván, R. (2020). Colaboración tecnocientífica academiaempresa. Un análisis de la percepción de profesores-investigadores. Economía, Teoría y Práctica, 28(52), 173-208.

Mullins, P. (2011). Beneath the Ivory Tower: The Archaeology of Academia. The Journal of Higher Education, 82(3), 353-355.

Navarrete, E. (2012). Jóvenes universitarios mexicanos ante el trabajo. Revista Latinoamericana de Población, 6(10), 119-140.

Nun, J. (2002). Democracia: ¿gobierno del pueblo o gobierno de los políticos? Fondo de Cultura Económica. 
Pérez, B., \& Bermudez, E. (2015). Sistema regional de innovación para el desarrollo territorial: propuesta de modelo cuádruple hélice en Colombia. Revista Brasileira de Planejamento e Desenvolvimento, 4(1), 40-64.

Rahona, M. (2006). ¿La posesión de un título universitario facilita el acceso de los jóvenes al primer empleo? Una aproximación para el caso español. Revista del Ministerio de Trabajo y Asuntos Sociales, (61), 105-121.

Rama, C. (2009). La tendencia a la masificación de la cobertura de la educación superior en América Latina. Revista Iberoamericana de Educación, (50), 173-195.

Riesman, D. (1958). Constrant and variety in American Education. Doubleday Anchor.

Rúa, C. (2013). La legitimidad en el ejercicio del poder político en el estado social de derecho. Una revisión desde el caso colombiano. Revista lus et Praxis, 19(2), 85-122.

Slaughter, S., \& Leslie, L. (1997). Academic Capitalism, Politics, Policies and the entrepeneurial University. The Johns Hopkins University Press.

Soh, K. (2016). The seven deadly sins of world university ranking: a summary from several papers. Journal of Higher Education Policy and Management, 39(1), 104-115.

Tomé, A., \& Hernández, C. (2015). La vinculación de las instituciones de educación superiorcon el sector social. XX Congreso Internacional de Contaduría, Administración e Informática. Universidad Nacional Autónoma de México, México.

Torres, C., \& Schugurensky, D. (2002). The political economy of higher education. In the era of neoliberal globalization: Latin America in comparative perspective. Higher Education, 43(4), 429-455.

Tuning América Latina. (2014). Reflexiones y perspectivas de la Educación Superior en América Latina. Comisión Europea / Universidad de Deusto.

Tünnermann, C. (1999). Historia de las universidades de América Latina. Editorial Universitaria Centroamericana.

Unión deUniversidades Latinoamericana (1951). Carta de las Universidades Latinoamericanas odeGuatemala.RevistadelaUniversidaddeMéxico.https://www.revistadelauniversidad. mx/articles/e345f535-714d-420c-bf6c-b7oc2a4c0024/carta-de-las-universidadeslatinoamericanas-o-de-guatemala

Vallaeys, F. (2014). La responsabilidad social universitaria: un nuevo modelo universitario contra la mercantilización. Revista Iberoamericana de Educación Superior, 5(12), 105-117.

Vega, J., Manjarrés, L., Castro, E., \& Fernández, I. (2011). Las relaciones universidad-empresa: tendencias y desafíos en el marco del espacio iberoamericano del conocimiento. Revista Iberoamericana de Educación, (57), 109-124.

Vera, H. (2018). Los cuatro jinetes de la evaluación: productivismo, reduccionismo, cuantofrenia y simulación. Revista De La Educación Superior, 47(187), 25-48. https:// doi.org/10.36857/resu.2018.187.417

Villanueva, E. (2011). Acreditación Universitaria: Confianza y legitimidad. Revista Iberoamericana de Educación, (57), 53-70. 


\title{
Capítulo 7
}

\section{Servicio social universitario como forma de cooperación con los actores sociales: Estudio en la Universidad Autónoma de Baja California}

\author{
Viviana Medrano Gallegos y Alicia Alelí Chaparro Caso-López
}

México es uno de los pocos países que establece el servicio social como una actividad obligatoria para que el estudiante universitario reciba su título profesional. Los primeros antecedentes de esta actividad se remontan a la época de la colonia, cuando las iglesias prestaban servicio a favor de las comunidades con un fin asistencialista. En el siglo XIX, el Estado desarrolló un vínculo más estrecho entre la educación superior y la sociedad, a través del servicio de estudiantes de ciencias de la salud y educación. Durante el movimiento revolucionario de Justo Sierra en 1910, se promovió la vinculación de las Instituciones de Educación Superior (IES), con las problemáticas sociales del país, especialmente para atender a los sectores de la sociedad menos favorecidos. A partir de 1945, el servicio social se estableció formalmente, a nivel constitucional, como una actividad académica y obligatoria en todas las universidades del país (Castañón, 2009).

De acuerdo con la Ley Reglamentaria del Artículo $5^{\circ}$ Constitucional Mexicano (1945), esta actividad se establece como el "trabajo de carácter temporal y mediante retribución que ejecuten y presten los profesionistas y estudiantes en interés de la sociedad y el Estado" (Art. 53). La realización de esta actividad permite que el estudiante participe en proyectos académicos que impliquen un ejercicio de su práctica profesional y desarrolle una mayor conciencia social al atender las necesidades específicas de la comunidad en la que se inserta (Robles et al., 2012).

Asimismo, de acuerdo con el Reglamento para la prestación del servicio social de los estudiantes de las instituciones de educación superior en la república mexicana (1981), esta actividad persigue los siguientes objetivos:

I. Desarrollar en el prestador una conciencia de solidaridad y compromiso con la sociedad a la que pertenece;

II. Convertir esta prestación en un verdadero acto de reciprocidad para con la misma, a través de los planes y programas del sector público;

III. Contribuir a la formación académica y capacitación profesional del prestador del servicio social. (Art. 3) 
A partir de este marco normativo, actualmente el servicio social se realiza en todas las universidades del país (públicas, privadas y tecnológicas), a fin de que los estudiantes retribuyan a la sociedad por la educación recibida (Navarrete et al., 2010). En virtud de lo anterior, se han realizado algunos estudios a nivel institucional en universidades públicas del país. En la Universidad Autónoma de Tlaxcala (UATx), Hernández y Magaña (2007) investigaron la relación de los estudiantes con los responsables del programa, los planes de estudio y cómo conciben esta práctica académica. La muestra se conformó por 701 estudiantes que aún no realizaban su servicio social y 659 estudiantes que ya lo habían finalizado. Los autores, identificaron que los desafíos que enfrentan los universitarios al participar en estos programas se asocian a la falta de recursos económicos para desplazarse, así como problemas con sus superiores o compañeros. Además, ambos grupos de estudiantes relacionaron esta actividad académica con los conceptos "trabajo" y "aprendizaje", pero al concluirla, esta opinión disminuye. Asimismo, las palabras: conocimiento, responsabilidad y compromiso, tuvieron mayor relevancia y significado para los que ya concluyeron el programa.

Por otra parte, en la Universidad Autónoma de Yucatán (UADY), se realizó un estudio para determinar la calidad de los programas de servicio social. A través de un grupo de expertos (responsables de esta actividad en la universidad), se diseñó un instrumento para evaluar con base en la opinión de los estudiantes los siguientes criterios: vinculación profesional, responsabilidad social, congruencia del proyecto y supervisión, desempeño en el proyecto, beneficiarios del proyecto y resultados. Hubo 626 participantes, entre estudiantes y pasantes. Los autores identificaron que los prestadores de servicio social consideran que los programas son de calidad y valoraron positivamente los criterios de responsabilidad social y vinculación profesional. Sin embargo, el criterio de resultados sociales del programa no fue tan bien valorado, lo cual denota que los prestadores no identificaron la contribución social de los programas (Navarrete et al., 2010).

En la Universidad Autónoma de Baja California (UABC), Aguirre et al. (2016) desarrollaron un estudio con el propósito de indagar acerca de la contribución comunitaria y académica del servicio social, así como las oportunidades de mejora. Desde un enfoque cualitativo, utilizando técnicas de recolección de datos como la investigación documental, grupos de discusión y entrevistas dirigidas tanto a prestadores de servicio social vigentes y no vigentes, además de docentes y responsables de los programas, de 29 licenciaturas. Los autores encontraron que los estudiantes asociaban esta actividad como un espacio para aplicar y reforzar los conocimientos adquiridos en beneficio de las necesidades de la comunidad. Manifestaron que, a través de esta actividad académica, desarrollaron habilidades como: administrar un presupuesto, mejorar la compresión lectora, manejar grupos y organizar proyectos. También, señalaron la aplicación y desarrollo de los valores de responsabilidad, respeto y sensibilidad. Otro aspecto significativo, fue el beneficio del trabajo interdisciplinario, ya que los estudiantes opinaron que este les permitió aprender de otras áreas y desarrollar nuevas 
habilidades. No obstante, los autores urgieron a la necesidad de involucrar a los prestadores en actividades en beneficio directo de las comunidades más necesitadas. Esto se ve obstaculizado por la falta de acompañamiento y supervisión del prestador, pues en ocasiones desempeñan actividades más de tipo administrativo que no contribuyen a su formación profesional.

A través de los estudios realizados en la UATX, la UADY y la UABC, se puede identificar la relevancia de la evaluación institucional del servicio social, pues a través de ella se identifican tanto las fortalezas como las áreas de oportunidad para la mejora. Sin embargo, se ha identificado que son pocas las IES en México que realizan estudios empíricos para valorar esta actividad a nivel institucional. Al respecto, la Asociación Nacional de Universidades e Instituciones de Educación Superior (ANUIES, 1994) ha señalado que existe una "carencia de programas de evaluación adecuados a la magnitud de la actividad, lo que ha llevado a un desconocimiento del impacto social [...] que se genera en beneficio de la comunidad, de instancias gubernamentales y de las IES" (p.28). Si bien, en distintas universidades del país se realizan estudios evaluativos al respecto, de acuerdo con la ANUIES (2010), un alto porcentaje de las universidades (80\%) tienen poca información sobre el impacto que está teniendo la participación de los estudiantes al vincularse con la sociedad.

Sin embargo, distintos autores han señalado que los estudiantes frecuentemente se encuentran dentro de la misma universidad realizando actividades que no se relacionan con su perfil profesional (Aguirre et al., 2016; Martuscelli \& Martínez, 2005; Mungaray \& Ocegueda, 1999; Robles et al., 2012; Sánchez \& Mungaray, 2000). Gran parte desempeñan actividades administrativas que no tienen como propósito la aplicación de conocimientos y habilidades profesionales para aportar algún beneficio a la comunidad, por lo que no pueden ser consideradas actividades de servicio social. Como consecuencia, en ocasiones este último se llega a concebir solamente como un requisito de egreso (ANUIES, 2010; Cano, 2004; Sánchez, 2002), pues las actividades que los prestadores desempeñan no son acordes con las carreras universitarias. Asimismo, como señalaron Escalante et al. (2017), los estudiantes se privan de experiencias de aprendizaje y no desarrollan un sentido de conciencia social. Por lo tanto, cabe cuestionarse si las mismas universidades están abriendo mayores espacios para que los universitarios presten sus servicios dentro de la misma institución y no generen un impacto en el exterior.

En el caso específico de la UABC, en su reglamento institucional de servicio social, a diferencia de la mayoría de las IES públicas, sostiene que el universitario puede realizar esta actividad en unidades académicas de la institución, siempre y cuando tengan como finalidad atender alguna necesidad social (UABC, 2007). Actualmente, de acuerdo con lo señalado en el Modelo Educativo UABC, el servicio social es:

conjunto de actividades formativas y de aplicación de conocimientos que realizan los alumnos del nivel de técnico superior universitario y el de licenciatura, 
de manera obligatoria y temporal, en beneficio o interés de los sectores menos favorecidos o vulnerables de la sociedad. (UABC, 2013, p. 80)

A diferencia de otras universidades, el servicio social de la $U A B C$ se distingue porque está conformado por dos etapas: una comunitaria y una profesional, que en su conjunto contribuyen a la formación integral del estudiante en un proceso continuo (UABC, 2013), al llevarse a cabo durante las etapas que conforman el trayecto universitario: básica, disciplinar y terminal. En la etapa básica, el estudiante realiza el servicio social comunitario, o primera etapa, el cual tiene como propósito contribuir a la formación valoral del estudiante a través de la realización de actividades que beneficien los sectores de su comunidad. Durante la etapa disciplinar o etapa terminal, el estudiante realiza su servicio social profesional, o segunda etapa. Esta última es equivalente al servicio social que se lleva a cabo en otras IES del país. En el Artículo $13^{\circ}$ del Reglamento de servicio social de la UABC se describe como:

conjunto de actividades que realicen los alumnos que cursen estudios de TSU y de licenciatura, tendientes a la aplicación de conocimientos, habilidades, aptitudes y valores que hayan obtenido y desarrollado en el proceso de su formación universitaria. (UABC, 2007, p. 5)

Es así, que en la $U A B C$, se tiene como visión a futuro, que la comunidad educativa tenga una actitud de servicio que le permita desarrollarse de forma plena como profesionistas éticos y comprometidos para atender las necesidades de la sociedad, a nivel regional, nacional y mundial. Respecto a los objetivos, busca contribuir a la formación de profesionistas con alto sentido de responsabilidad social sobre el quehacer del servicio social profesional. En cuanto a su política, busca dar atención de calidad a los usuarios, a través de una operatividad por parte del sistema y de los procesos necesarios para realizarlo.

Administrativamente, el servicio social tiene una duración de 480 horas, y para iniciarlo, se estipula que el estudiante debe cubrir el $60 \%$ de los créditos, de acuerdo con su plan de estudios (UABC, 2007). Por otra parte, si el alumno tiene $85 \%$ o más de sus créditos, y no lo ha realizado, al momento de su reinscripción solo podrá inscribirse a tres materias como máximo. Uno de los principios orientadores de la UABC es la flexibilidad curricular, la cual permite brindar a los estudiantes la oportunidad de asociar el servicio social al currículo. Es decir, los estudiantes tienen oportunidad de vincular esta actividad a una unidad de aprendizaje (materia o asignatura), la cual debe abordar contenidos relacionados con las actividades llevadas a cabo en el servicio social (UABC, 2010).

Asimismo, para liberar y obtener créditos, el estudiante puede realizar el servicio social simultáneamente con proyectos de vinculación con valor en créditos (PVVC). Estos consisten en realizar una actividad de vinculación, que se asocia a unidades de aprendizaje, opta- 
tivas u obligatorias, con el propósito de reforzar competencias necesarias para su profesión. Además, al igual que las prácticas profesionales, el servicio social profesional es una opción de titulación (UABC, 2010). Esta flexibilidad curricular se respalda en el humanismo, el constructivismo y la educación a lo largo de la vida, con lo cual se busca fortalecer la formación integral del alumno al vincularse con el sector productivo (UABC, 2013). Por lo tanto, se destaca la flexibilidad curricular de la universidad al permitir asociar la práctica del servicio social con unidades de aprendizaje, lo que contribuye a relacionar los conocimientos con situaciones reales propias de la profesión, y además la oportunidad de ofrecer el servicio social como opción de titulación.

No obstante, la $U A B C$ busca que los programas de servicio social no solo tengan un impacto en la formación de los estudiantes, sino en la sociedad, tal como lo marcan los reglamentos a nivel federal. Al respecto, cabe señalar que, en el estado de Baja California, según el Consejo Nacional de Evaluación de la Política de Desarrollo Social (Coneval, 2019), el 22.2\% de su población se encuentra en situación de pobreza. Por lo que, a través del servicio social que realizan los universitarios de la UABC cada semestre, se puede contribuir a revertir los índices de la población que tiene acceso limitado a los servicios de salud, educación, abastecimiento de agua y otros servicios básicos. A este respecto, la matrícula de estudiantes en la última década se ha mantenido alrededor de los 60 ooo estudiantes cada semestre. Si se multiplicara el número de estudiantes de UABC que realizan su servicio social en todos los campus distribuidos en los cinco municipios del estado, por la cantidad de horas en la que prestan su servicio, deberíamos esperar un impacto social altamente significativo (UABC, 2020).

\section{Evaluación del servicio social en la UABC}

Con base en el apartado anterior, podríamos resumir que el servicio social es una actividad académica de carácter constitucional que pretende atender a los sectores más necesitados y contribuir a la formación profesional del estudiante. Sin embargo, a pesar de su importancia como actividad académica obligatoria, son pocos los estudios y evaluaciones a nivel institucional que dan cuenta de la operación y resultados de esta actividad formativa. En la UABC, existe una carente evaluación sistemática y continua del servicio social que permita identificar si cumple sus propósitos de formación y de atención a la comunidad. La única fuente de información que existe es la recabada a través de la Encuesta Anual de Ambiente Organizacional (EAAO) realizada por la Coordinación General de Planeación Institucional (UABC, 2019), y en la que en uno de sus apartados se recupera información al respecto. Otro insumo para analizar el servicio social son los resultados del estudio institucional Evaluación del Modelo de Vinculación de la UABC (Chaparro et al., 2018), en el que también existe una sección dirigida a recabar datos acerca del tema. Con base en ambas fuentes, a continuación, se realiza un ejercicio de integración de la información extraída, con el objetivo de brindar un panorama sobre la situación histórica del servicio social en la UABC. 


\section{Resultados del servicio social en la Encuesta Anual de Ambiente Institucional}

Con el propósito de indagar a mayor profundidad cómo se llevan a cabo las actividades académicas en la institución, la UABC aplicó del 2005 al 2018 la Encuesta Anual de Ambiente Organizacional (EAAO) a los distintos actores de la comunidad escolar, entre los cuales se encontraban los estudiantes que realizaban su servicio social. Con base en los reportes de dicha encuesta, a continuación, se presenta una recopilación de la información concentrada al respecto; aunque la información es limitada. Sin embargo, resulta interesante realizar una revisión de la evolución de los resultados, pues estos se reportaron durante 12 años.

Información con la que cuentan los prestadores

El primer dato que es digno de analizar es el referente a la información con la que los prestadores contaron para realizar su servicio social. Lo anterior, implica tanto aspectos relativos a procesos administrativos, requisitos para el registro, así como la información sobre unidades receptoras, entre otro tipo de elementos que el prestador requiere para poder elegir y transitar por el programa de manera exitosa. Este aspecto es muy importante, si se toma en cuenta que de ello depende que el estudiante tenga más consciencia del compromiso social que representa y la relevancia de realizar el servicio social en una unidad receptora en la que atienda una demanda de la comunidad. En este sentido, se esperaría que todos los prestadores contaran con la información necesaria para llevarlo a cabo.

Sin embargo, como se presenta en la figura 1, de forma histórica el porcentaje de prestadores que ha reportado contar con la información necesaria para realizar su servicio social presenta un incremento en los últimos años. En un principio, en 2005, solo el $43.2 \%$ de los prestadores reportó haber contado con la información necesaria, y este porcentaje fue incrementando ligeramente de manera anual hasta llegar a 63.4\% durante 2018. No obstante, esto

\section{Figura 1}

Porcentaje de prestadores que reporta haber contado con la información necesaria para realizar el servicio social

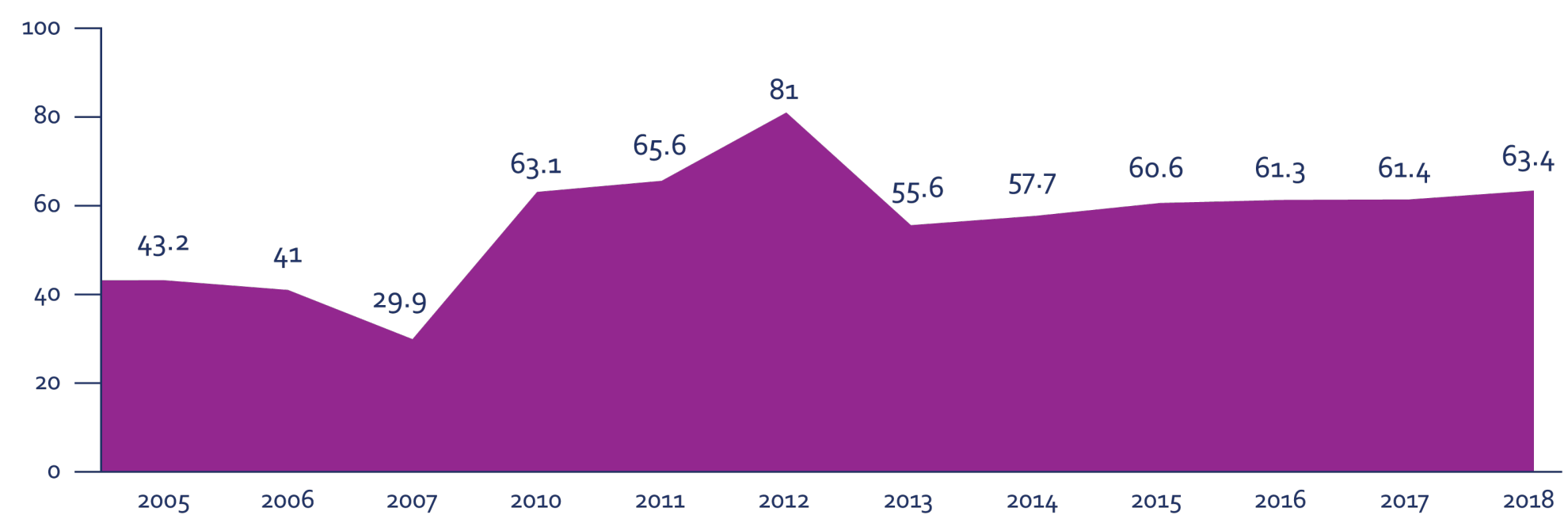

Nota: Elaboración propia a partir de la información recuperada del portal oficina de Planeación y Desarrollo Institucional de la UABC (2019). 
significa que una cantidad considerable de prestadores, cercano al 40\%, no contó con la información necesaria. Esto es neurálgico, si se considera que para que un prestador realice de manera congruente sus actividades de servicio social, como acciones en pro del beneficio comunitario, lo primero que se requiere es tener claridad sobre lo que es y lo que implica realizarlo.

\section{Beneficio en la formación académica}

Otro dato que proporciona la EAAO, es lo relativo a qué tanto el prestador considera que el servicio social ha beneficiado su formación profesional, lo cual puede observarse en la figura 2. Los datos históricos entre 2004 y 2018 muestran un incremento en la cantidad de prestadores que reconocen el valor de este programa en su formación profesional. Como es evidente, en los primeros años ni siquiera el $50 \%$ de los prestadores valoraban el sentido formativo del programa. Sin embargo, poco a poco ha ido mejorando esta percepción, llegando actualmente a un $88.1 \%$ de los prestadores que reconocen que participar en el servicio social contribuye a su formación. Esto se interpreta de manera positiva y significa que la universidad ha logrado que sus prestadores participen en programas que verdaderamente resulten en un aprendizaje, fortaleciendo las competencias que han adquirido durante su trayecto formativo.

\section{Figura 2}

Porcentaje de prestadores que considera que el servicio social ha beneficiado su formación profesional

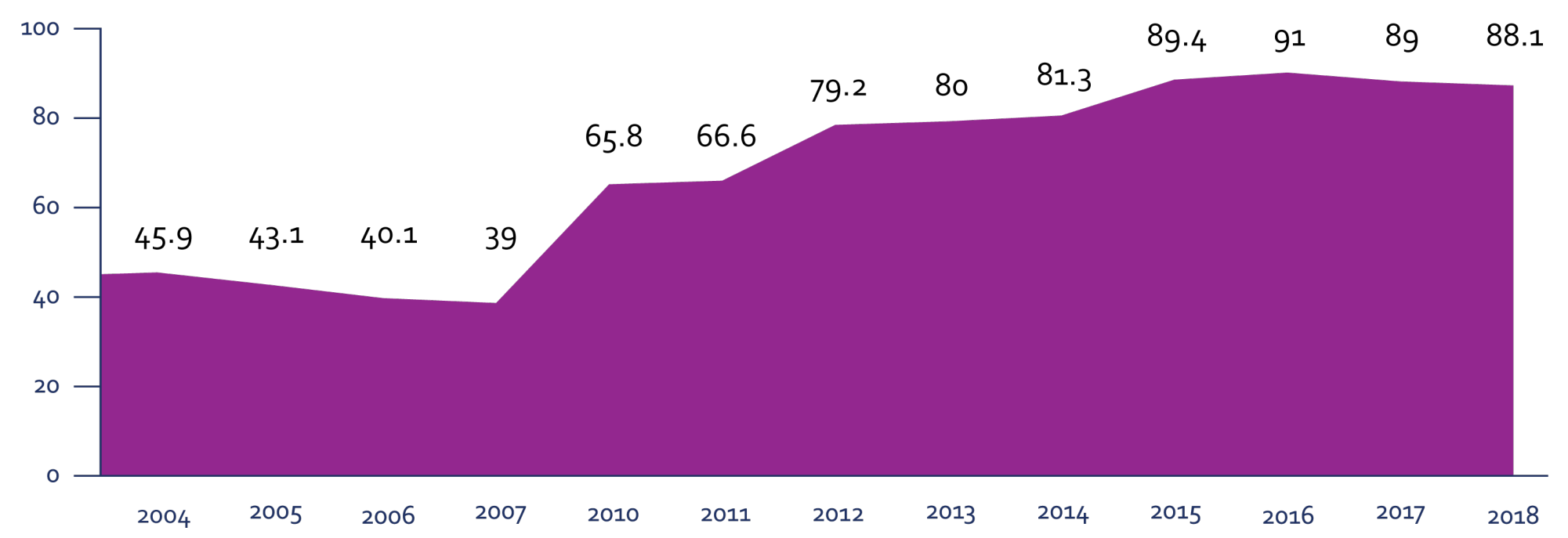

Nota: Elaboración propia a partir de la información recuperada del portal oficina de Planeación y Desarrollo Institucional de la UABC (2019).

Vinculación de las actividades realizadas con el programa educativo En la figura 3 se presenta la información histórica respecto a la vinculación de las actividades realizadas durante el servicio social con el programa académico cursado. Al igual que en los datos presentados en las figuras anteriores, en los primeros años de aplicación de la 
encuesta, un porcentaje menor al 50\% de los prestadores consideraba que las actividades que realizaban en el servicio social se vinculaba con su programa académico. No obstante, gradualmente este porcentaje fue incrementándose, llegando en 2018 a un $88.8 \%$ de prestadores que reconocieron esta vinculación. Estos resultados son congruentes con los presentados en la figura 2, pues en general actualmente y durante los últimos años, cerca del $90 \%$ de los prestadores en $U A B C$ valoran la participación en el servicio social como una actividad formativa que guarda congruencia con el programa académico cursado. Esto significa que se está logrando fortalecer la formación de sus prestadores.

\section{Figura 3}

Porcentaje de prestadores que reportan que las actividades realizadas en el servicio social se vinculaban con su programa académico

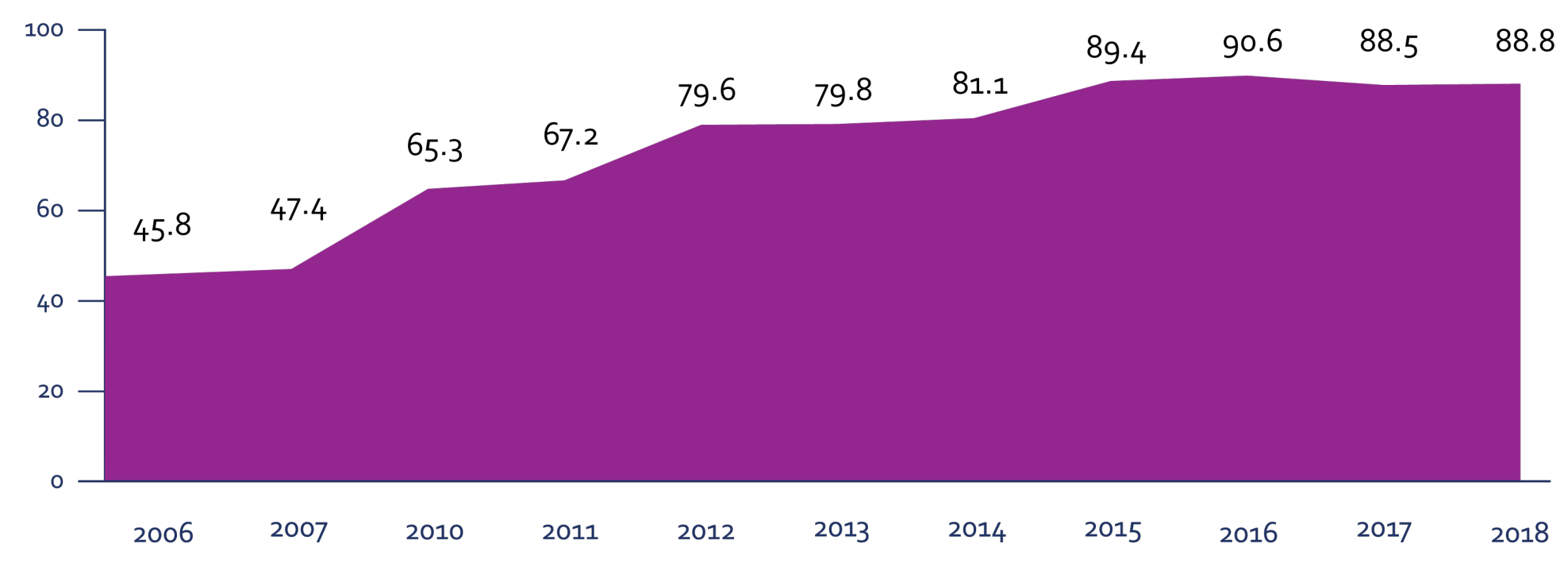

Nota: Elaboración propia a partir de la información recuperada del portal oficina de Planeación y Desarrollo Institucional de la UABC (2019).

\section{Satisfacción general de los prestadores}

Congruentes con los resultados anteriores son los datos que se presentan en la figura 4 , en la cual se muestra el porcentaje de prestadores que están satisfechos con el servicio social realizado. Se observa que menos del $50 \%$ de los prestadores estaban satisfechos, aunque este porcentaje ha ido incrementándose anualmente hasta llegar a un $87.7 \%$ en 2018 . Es decir, en los últimos cuatro años, cerca del 90\% de los prestadores de servicio social que han contestado la EAAO, han respondido que se sienten satisfechos con el programa en el que han participado. Si tomamos los resultados anteriormente presentados en los que se describe en qué medida esta actividad contribuye a su formación y está relacionada con su programa educativo, es entonces de esperarse que un alto porcentaje de los estudiantes se sientan satisfechos con el servicio social realizado. 


\section{Figura 4}

Porcentaje de prestadores que están satisfechos con el servicio social realizado

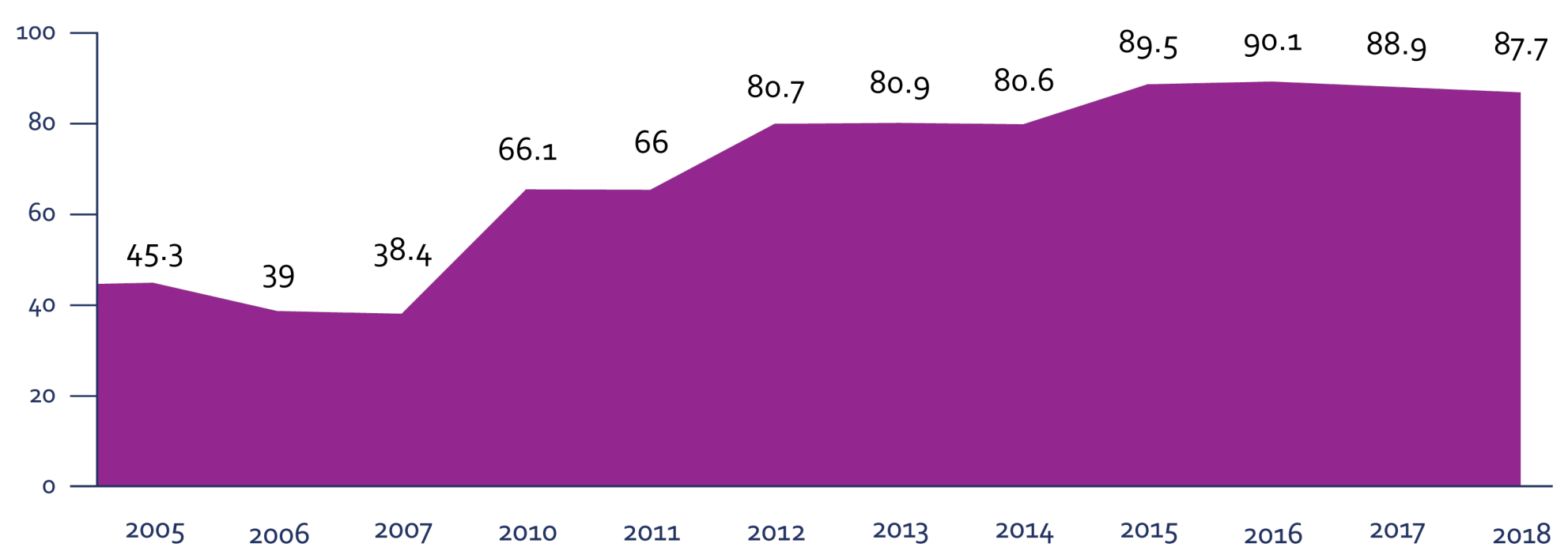

Nota: Elaboración propia a partir de la información recuperada del portal oficina de Planeación y Desarrollo Institucional de la UABC (2019).

Los resultados anteriores muestran que, si bien el programa de servicio social de la UABC está cumpliendo su cometido en el sentido formativo, no lo cumple en el sentido informativo y administrativo, pues como se mostró en la figura 1, un alto porcentaje de prestadores no cuenta con la información necesaria para llevarlo a cabo. Esto se traduce entonces, como un área de oportunidad que la universidad debe atender. Sin embargo, más allá de esto, es interesante identificar cómo en ninguna de las preguntas de la EAAO se indaga sobre el carácter social que cumple el programa, es decir, la percepción de los prestadores respecto a la oportunidad de poner en práctica lo aprendido en apoyo a la comunidad; así como de establecer vinculación con sectores en los que los servicios profesionales de los egresados pueden ser ejercidos. Por lo tanto, se requiere más información sobre el impacto social de los programas de servicio social que llevan a cabo los estudiantes de los 133 programas educativos.

\section{Resultados del servicio social en la Evaluación del Modelo de Vinculación de la UABC}

Durante 2017 se llevó a cabo un estudio a nivel institucional en el que se evaluó el Modelo de vinculación de la UABC (Chaparro et al., 2018). Uno de los apartados incluidos en esta evaluación fue el correspondiente al servicio social en opinión de los 1592 prestadores que participaron en el estudio, los cuales provenían diversos campus (Mexicali, Tijuana, Ensenada, así como unidades periféricas). Este estudio, a diferencia de la EAAO, recuperó información más específica, como se verá a continuación.

\section{Significado del servicio social}

Como se muestra en la figura 5, el primer dato que se recupera es el relativo al significado que tiene el servicio social para los prestadores. La mayoría (57.2\%) consideró que es una 
oportunidad para aprender. Este dato resulta congruente con lo presentado en las figuras 2 y 3 de la EAAO, en la que la mayoría de los estudiantes expresaron que las actividades realizadas resultaban formativas y se vinculaban con el programa educativo. Importante dato también resulta el que más de la mitad de los encuestados identifiquen en el servicio social una oportunidad para relacionarse con el mundo laboral. Aunque sería deseable que este número fuera aún mayor, es de reconocerse la cantidad de estudiantes que perviven esta oportunidad de vinculación. Estos dos aspectos resultan relevantes y positivos en términos del alcance del programa. Sin embargo, si se toma en cuenta que la acción formativa del servicio social debe estar en consonancia con la contribución hacia la sociedad, se destaca que solo un $26.3 \%$ de los prestadores encuestados lo reconozca como una forma de contribuir a esta. Lo anterior significa que son pocos los prestadores que reconocen la importancia de contribuir a la sociedad a partir de los conocimientos adquiridos en el aula. En resumen, los prestadores reconocen en el servicio social su contribución a la formación profesional, pero no a la sociedad.

\section{Figura 5}

Significado del servicio social para los prestadores

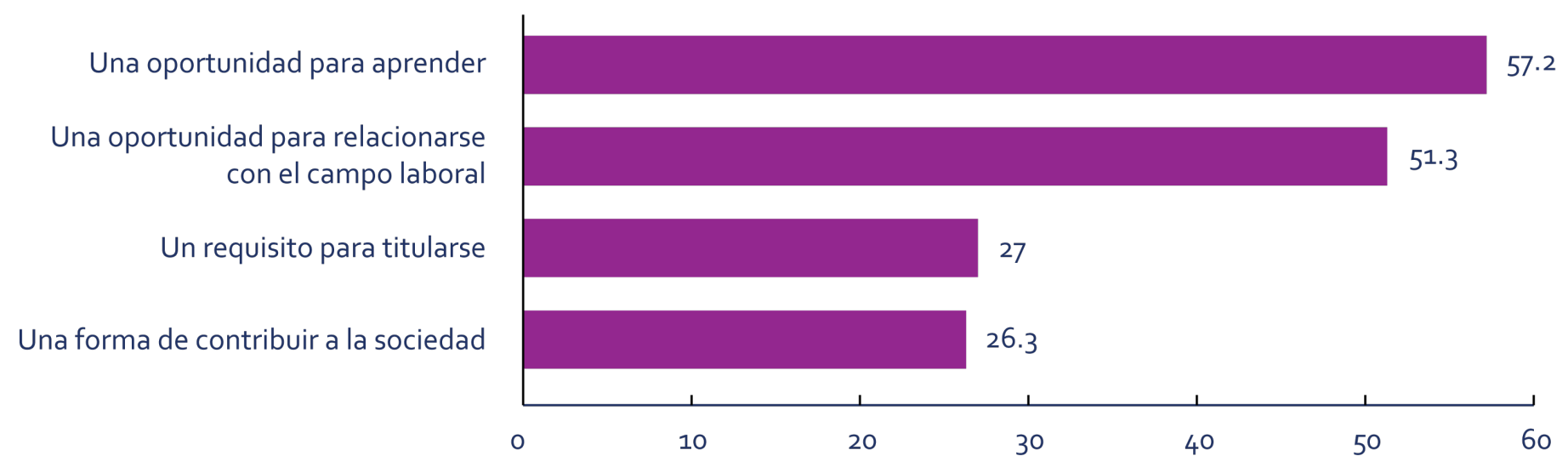

Nota: Las barras representan porcentajes no excluyentes. $\mathrm{N}=1592$ Elaboración propia a partir de la información recuperada de Chaparro et al. (2018).

\section{Objetivo del servicio social}

En consonancia con el resultado anterior, se presentan los resultados sobre el objetivo del servicio social (figura 6) en la opinión de los prestadores. Destaca que cerca del $70 \%$ considera que el objetivo es adquirir y aplicar competencias, es decir, tiene un carácter formativo, tal como los resultados de la EAAO y del rubro anterior. Únicamente un $26.9 \%$ consideró que su objetivo es contribuir o ayudar a la comunidad. Esto significa, que los estudiantes reconocen más un valor formativo que social en esta experiencia. 


\section{Figura 6}

Objetivo del servicio social según la opinión de los prestadores

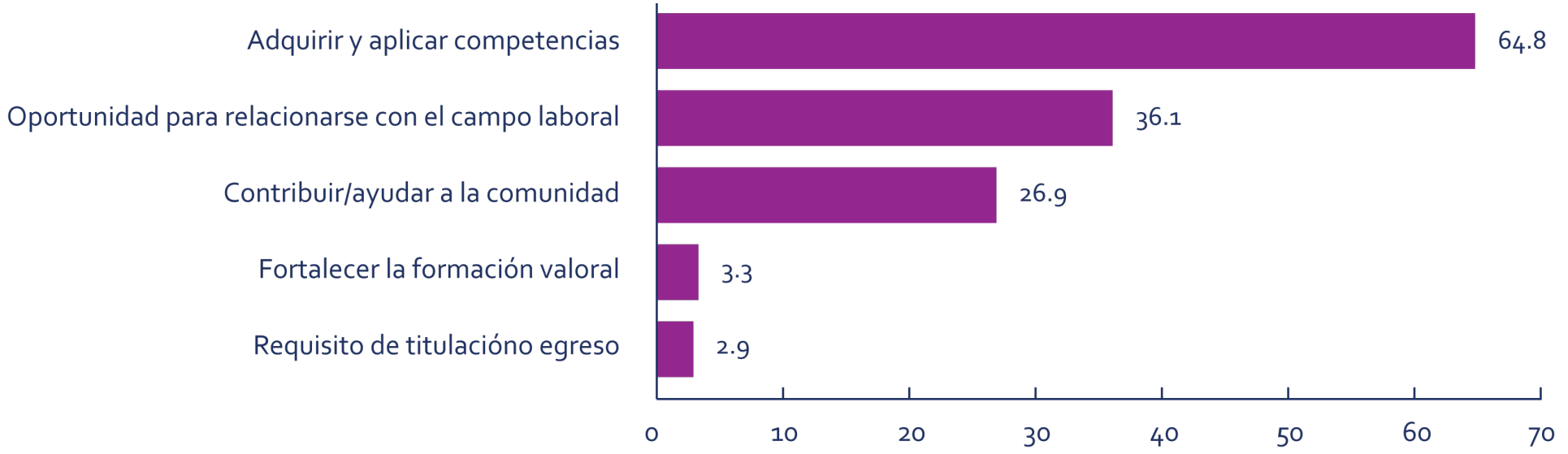

Nota: Las barras representan porcentajes no excluyentes. $\mathrm{N}=1592$ Elaboración propia a partir de la información recuperada de Chaparro et al. (2018).

\section{Razón para elegir el programa}

En la sección de resultados de la EAAO, en la figura 1 se presentó el porcentaje de estudiantes que referían contar con la información suficiente para realizar su servicio social. Como se mostró, un porcentaje cercano al $40 \%$ de los estudiantes afirmó que no contó con esa información. Es probable que esos resultados se asocien con los mostrados en la figura 7, en la que se presentan las razones por las que se eligió el programa de servicio social. Se puede observar que solo una tercera parte de los estudiantes lo eligió porque las actividades se relacionaban con su carrera. Es probable que algunos estudiantes no contaran con información suficiente para saber si el programa se relacionaba con su carrera y, por lo tanto, otra tercera parte haya referido que lo eligieron por la ubicación.

\section{Figura 7}

Razón principal por la que los prestadores eligieron el programa de servicio social en el que participan

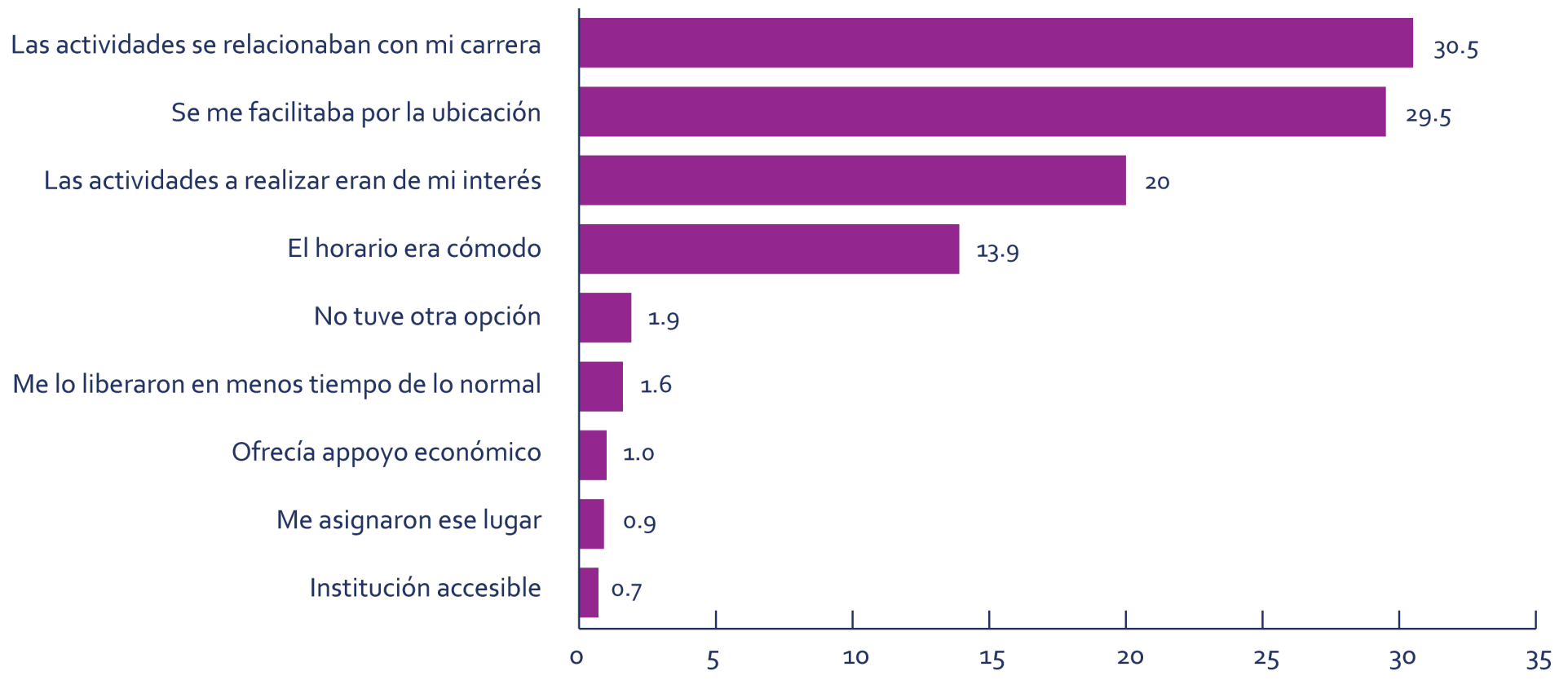

Nota: Las barras representan porcentajes no excluyentes. $\mathrm{N}=1592$ Elaboración propia a partir de la información recuperada de Chaparro et al. (2018). 


\section{Unidad receptora}

La figura 8 ilustra un aspecto ampliamente relevante, pues muestra las unidades receptoras en las que los prestadores han realizado su servicio social. Como se puede observar, más del $40 \%$ de los prestadores lo han realizado en la $U A B C$, lo que indica que una amplia proporción de los estudiantes no lo realizan fuera de la universidad, lo que limita sus posibilidades de vinculación y de contacto con las problemáticas reales del contexto comunitario a las que estos pueden dar atención.

Si bien, la normativa de la UABC marca que el prestador puede realizar su servicio social dentro de la universidad si se atiende problemáticas comunitarias, es muy poco probable que estas impliquen un acercamiento con el contexto. Por lo tanto, la universidad está perdiendo una oportunidad valiosísima de vinculación con el exterior y de aprendizaje en situaciones reales. Asimismo, la figura 8 también muestra que más del $25 \%$ de las actividades, se realizan en alguno de los tres niveles de gobierno: federal, estatal y municipal. El que aproximadamente el $80 \%$ de los universitarios se encuentren realizando su servicio social en la misma universidad y en el sector gubernamental, y que solamente un $26.9 \%$ considere que el objetivo del programa es contribuir o ayudar a la comunidad, señalan la necesidad de indagar cuáles son las actividades que están desempeñando los prestadores en estas instancias. Por lo tanto, se puede interpretar que entonces la mayoría de estos programas son considerados espacios para aplicar sus conocimientos, pero no en beneficio del sector comunitario, lo cual se relaciona con los resultados de la figura 5 y 6.

\section{Figura 8}

Unidad receptora en la que los prestadores realizan el servicio social

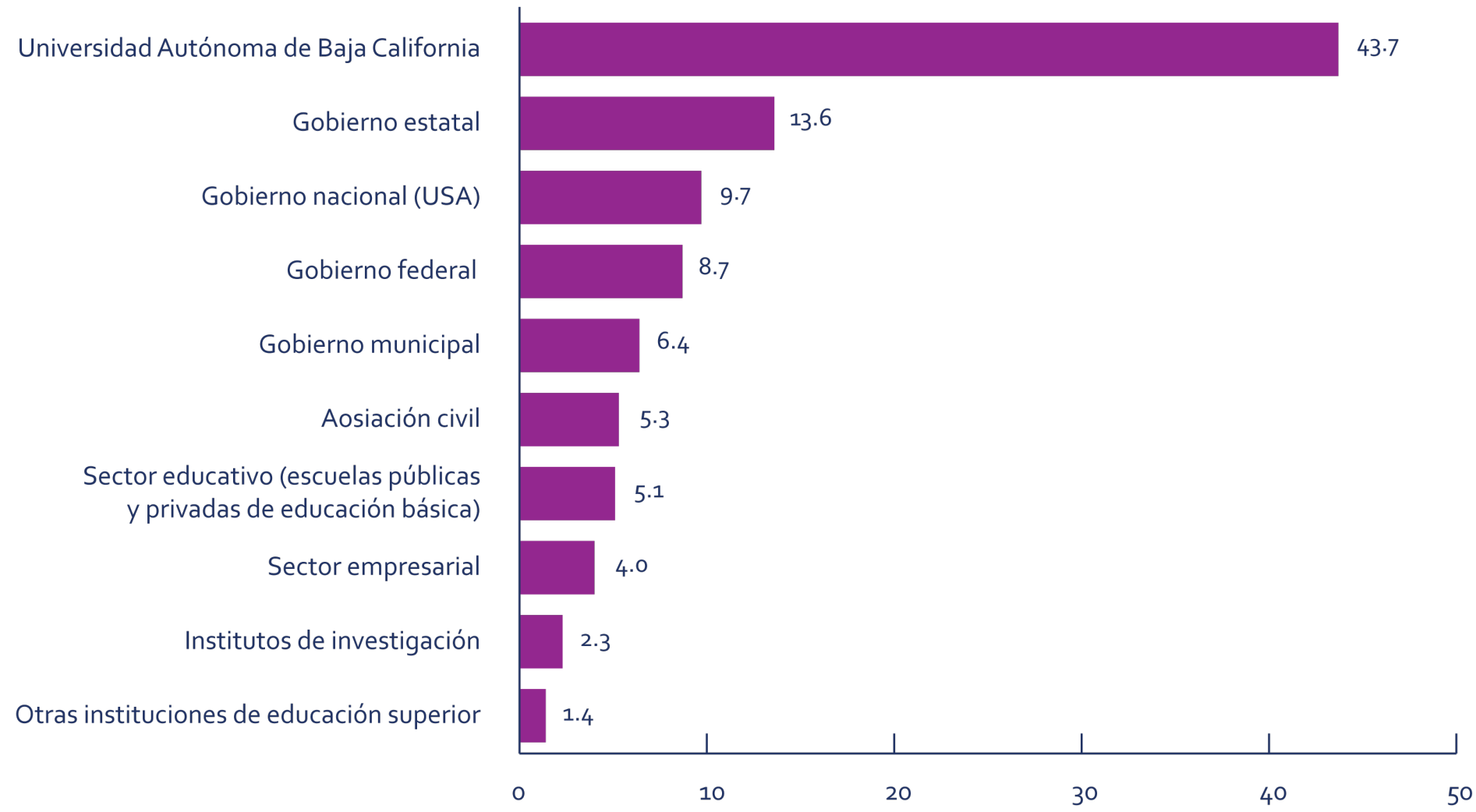

Nota: Las barras representan porcentajes no excluyentes. $\mathrm{N}=1592$ Elaboración propia a partir de la información recuperada de Chaparro et al. (2018). 


\section{Atención a necesidades sociales}

Los resultados de la figura 9 señalan que más de la tercera parte de los estudiantes encuestados (42.6\%) opinaron que, al participar en el programa de servicio social, no se atendió una necesidad social. A partir de estos hallazgos, se puede inferir que los estudiantes tienen esta opinión debido a que carecen de información sobre cómo elegir un programa que les permita aplicar competencias propias de su profesión y que tenga como objetivo contribuir a la comunidad, tal como se muestra en la figura 1. Asimismo, con base en las figuras 2 y 3 , los prestadores reconocen en el servicio social más su valor formativo que social, por lo que otra interpretación puede estar orientada a que buscan espacios que tengan por objetivo principal el contribuir a su formación profesional, lejos de la contribución social.

El que los estudiantes realicen actividades que no atiendan necesidades sociales se puede considerar un resultado alarmante, debido a que el propósito principal de esta actividad académica no se está cumpliendo y es concebida por los estudiantes como un espacio solo para su formación y no como una forma de retribuir a la sociedad por la educación que están recibiendo. De igual manera, en consonancia con la figura 6 , solamente un $26.9 \%$ considera que el objetivo del servicio social sea ayudar a la comunidad, por lo que una vez más se demuestra que los estudiantes de la UABC conciben esta actividad como formativa, lejos de su propósito social.

\section{Figura 9}

Las actividades realizadas por los prestadores atendieron alguna necesidad social

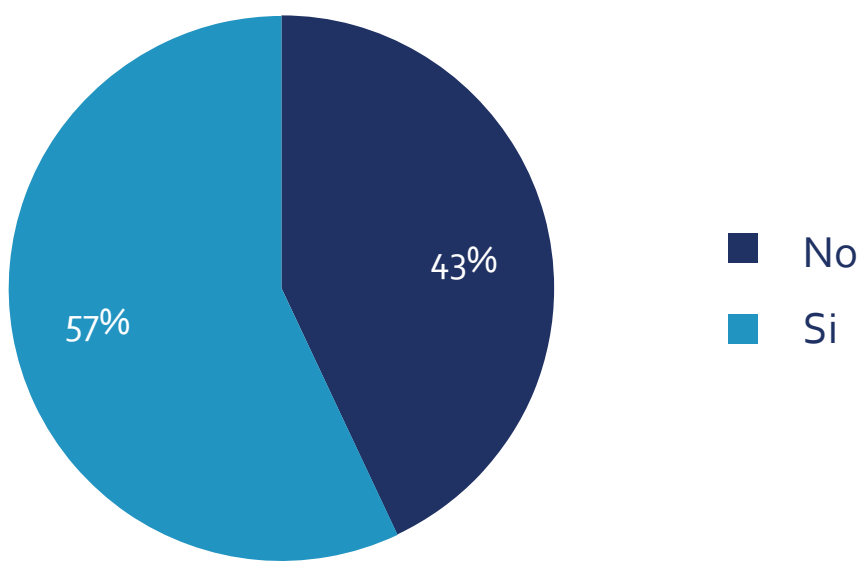

Nota: Elaboración propia a partir de la información recuperada de Chaparro et al. (2018).

\section{Conclusiones}

La EAAO y el apartado del Modelo de vinculación de la UABC (Chaparro et al., 2018) son instrumentos los cuales, a través de los resultados de su aplicación, nos permiten indagar sobre el trabajo realizado por los prestadores de servicio social en la comunidad. Con base en las evidencias anteriores, se presentan las conclusiones derivadas de dichos resultados. 


\section{Falta de conciencia social}

Respecto al carácter social, solamente una cuarta parte de los encuestados describe el servicio social como una forma de contribuir a la sociedad, y también una cuarta parte considera que su objetivo es contribuir a la comunidad. Aunado a ello, más de una tercera parte señalan que al participar en el programa no se atendió una necesidad social. Por lo tanto, un bajo porcentaje de los estudiantes asocia esta práctica como una actividad académica a favor de la comunidad. Es importante que, desde la definición de esta actividad a nivel institucional, se destaque su función social, ya que se define principalmente como la aplicación de conocimientos, habilidades, aptitudes y valores (UABC, 2007). Si bien, el fortalecimiento de la formación del estudiante es importante, si por parte de la institución y del universitario no se concibe como una actividad retributiva, es difícil que se pueda lograr un impacto significativo en las comunidades, principalmente en el $22.2 \%$ de la población que se encuentra en situación de pobreza en el estado, de acuerdo con el Coneval (2019). Con base en lo anterior, es necesario que, desde la misma filosofía institucional, se establezca el concepto del servicio social como una actividad que tiene como prioridad la contribución social.

Los resultados coinciden con los estudios de Navarrete et al. (2010) y Aguirre et al. (2016). En ambos estudios se puede identificar que los prestadores no aprecian la contribución social derivada de su servicio y que se requieren mayores esfuerzos para involucrar a los estudiantes en actividades en beneficio directo de las comunidades más necesitadas. Esto se ve obstaculizado, ya que en ocasiones desempeñan actividades administrativas que no contribuyen propiamente a su formación profesional. Asimismo, coincide con la investigación de Hernández y Magaña (2007), quienes reportaron que los estudiantes carecen también de darle un sentido social a esta experiencia académica.

Otra posible interpretación, es que los programas que ofrece la universidad no tienen como finalidad específica atender el desarrollo social o no se adhieren a alguno de los Programas Universitarios de Atención Comunitaria y sus distintas líneas de acción, o no cuentan con información para elegirlo. Lo antes expuesto, puede derivar en que los estudiantes no tengan la oportunidad o el conocimiento necesario para elegir, dentro de la gama de opciones, algún programa de servicio social que sea de beneficio para la población.

Conviene destacar que, de acuerdo con los resultados de la EAAO, durante el periodo 2010 al 2018 (a excepción del 2015), más de la mitad de los estudiantes reportaron que se sienten satisfechos con su participación. Asimismo, consideran que el servicio social fortalece las competencias propias de su carrera, ya que las actividades están vinculadas con su profesión. Por tanto, se puede inferir que hay aceptación por parte de los universitarios en cuanto a esta perspectiva formativa y si los programas no se dirigen directamente al beneficio social, parece no ser algo que consideren significativo. 


\section{El servicio social como una actividad administrativa dentro de la universidad}

El Reglamento de servicio social institucional sostiene que se puede realizar en unidades académicas de la misma universidad, siempre y cuando tenga como finalidad atender las necesidades de la sociedad (UABC, 2007). No obstante, se destaca que más de una tercera parte de los estudiantes lo realizan dentro de la misma máxima casa de estudios.

Lo anterior, coincide con lo señalado por diversos autores con relación a que los estudiantes muchas veces realizan actividades que no se relacionan con su futura profesión, principalmente desempeñando actividades administrativas (Aguirre et al., 2016; Martuscelli \& Martínez, 2005; Mungaray \& Ocegueda, 1999; Robles et al., 2012; Sánchez \& Mungaray, 2000). Estas no tienen como propósito la aplicación de conocimientos y habilidades profesionales para aportar algún beneficio a la comunidad, por lo que no pueden ser consideradas actividades del servicio social y esto deriva a que en ocasiones se llegue a concebir este programa solamente como un requisito de egreso (ANUIES, 2010; Cano, 2004; Sánchez, 2002).

Además, es cuestionable que desde el 2010, los estudiantes se sienten satisfechos con el servicio social realizado. Si un alto porcentaje se encuentra en la misma universidad realizando actividades administrativas carentes de propósito social y sienten satisfacción al realizarlas, se puede interpretar que los estudiantes se encuentran y buscan un estado de zona de confort para realizarlo sin un esfuerzo real por involucrarse con el entorno.

Lo anterior, aunado a que una tercera parte señala que eligieron el programa porque se les facilitaba la ubicación y una décima parte eligieron el programa porque el horario les era cómodo, por lo que realizar actividades administrativas dentro de la universidad parece ser una opción atractiva para no desplazarse a comunidades lejanas para realizar su servicio.

Por otra parte, en el caso particular de los estudiantes de Ciencias de la Salud, la opción de prestar servicio en la universidad puede parecerles viable, ya que la falta de recursos económicos para desplazarse a zonas rurales puede ser un desafío (Hernández \& Magaña, 2007).

\section{El servicio social que se presta en el sector gubernamental}

Más de una tercera parte en su conjunto presta su servicio social en el gobierno mexicano (en su nivel federal, estatal o municipal) y en el gobierno nacional estadounidense. Los hallazgos anteriores pueden ser una respuesta a la línea de acción establecida en El Plan Estatal de Desarrollo (Gobierno del Estado de Baja California, 2014), la cual señala que el gobierno del estado vincule sus áreas con la prestación del servicio social.

Sin embargo, estos resultados son cuestionables, ya que solo una décima parte participó en asociaciones civiles y en el sector educativo. Por lo que es importante indagar si estos programas del sector gubernamental están dirigidos a la atención de comunidades o quiénes son los beneficiados, ya que se puede considerar un porcentaje alto quienes hacen su servicio social en este sector. 
Asimismo, es importante que la universidad amplíe su oferta en cuanto a los programas de servicio social, para que los prestadores tengan oportunidad de elegir aquellos dirigidos a otros sectores, ya que el sector gubernamental está teniendo gran predominancia en comparación con el sector comunitario.

\section{El servicio social como oportunidad para conseguir empleo}

De acuerdo con la EAAO, principalmente desde el 2010, la mayoría de los prestadores consideran que las actividades se relacionan con las materias cursadas y que derivado de su participación se ha beneficiado su desempeño académico o formación profesional. Gran parte de los estudiantes asocian la práctica del servicio social como una oportunidad para aprender. Más de la mitad considera que el objetivo de esta actividad académica es adquirir y aplicar competencias y una tercera parte considera que la razón principal por la que eligieron el programa fue porque las actividades se relacionaban con su carrera.

Los resultados anteriores, denotan que los universitarios relacionan el servicio social principalmente como una actividad que les permite desarrollar y aplicar competencias profesionales, lo cual se puede atribuir a que institucionalmente se define al servicio social como la aplicación de conocimientos, habilidades, aptitudes y valores (UABC, 2007). Esta filosofía institucional parece impactar significativamente en la forma como los estudiantes conciben el servicio social. No obstante, como se ha mencionado anteriormente, tal aplicación de competencias parece no estar destinada a la retribución social. Una posible interpretación es que es concebida como una actividad similar a las prácticas profesionales, las cuales tienen como fin el convertirse en una posible oportunidad para insertarse al campo laboral.

Al respecto, la mitad de los encuestados consideran que el servicio social es una oportunidad para relacionarse con el campo laboral y una tercera parte que es su objetivo principal. Asimismo, resalta que desde el Plan Estatal de Desarrollo 2014-2019 se estableció la propuesta de que el servicio social "se considere curricularmente para que los jóvenes tengan mayor oportunidad de conseguir un empleo" (Gobierno del Estado de Baja California, 2014, p.134).

Por lo tanto, es importante que desde las líneas de acción por parte del gobierno estatal y los documentos institucionales que rigen el servicio social, se promueva su práctica como una forma de contribuir socialmente a través de las competencias relacionadas con la carrera universitaria, pero señalar enfáticamente que su finalidad principal no es que los estudiantes se inserten al campo laboral. 


\section{Referencias}

Aguirre, L., Rodríguez, J., \& Caso, J. (2016). Potencial de aprendizajes en el servicio social universitario. Revista Internacional de Aprendizaje en la Educación Superior, 3(1), 87-98. https://doi.org/10.37467/gka-revedusup.v3.503

Asociación Nacional de Universidades e Instituciones de Educación Superior (ANUIES). (1994). Programa Nacional de Extensión de la Cultura y los Servicios. Asociación Nacional de Universidades e Instituciones de Educación Superior.

Asociación Nacional de Universidades e Instituciones de Educación Superior (ANUIES). (2010). El servicio social de la educación superior. Punto de articulación con el entorno. Asociación Nacional de Universidades e Instituciones de Educación Superior.

Cano, C. (2004). Reflexiones sobre el futuro del servicio social universitario. Reencuentro, (40), 1-10. http://www.redalyc.org/pdf/340/34004011.pdf

Castañón, M. (2009). El servicio social como un prestigio oculto de la universidad. El caso de la UPN. Universidad Pedagógica Nacional.

Chaparro, A., García, R., \& Martínez, M. (2018). Evaluación del Modelo de Vinculación de la $U A B C$. Universidad Autónoma de Baja California.

Consejo Nacional de Evaluación de la Política de Desarrollo Social (Coneval). (2019). Pobreza en México. En Medición de la pobreza. https://www.coneval.org.mx/Medicion/Paginas/ Pobrezalnicio.aspx

Escalante, M., Aguirre, L., \& Caso, J. (2017). Repensar el servicio social universitario en sus dimensiones formativa, humanista y social. En E. Luna \& G. Cordero (Coords.), Contribuciones a la evaluación educativa desde la formación doctoral (p. 176-204). Editorial Universitaria.

Gobierno del Estado de Baja California. (2014). Plan Estatal de Desarrollo 2014-2019. http://www.copladebc.gob.mx/PED/documentos/Actualizacion\%2odel\%20Plan\%20 Estatal\%20de\%2oDesarrollo\%202014-2019.pdf

Ley Reglamentaria del Artículo $5^{\circ}$ Constitucional Mexicano (1945). Relativo al ejercicio de las profesiones en el Distrito Federal. Diario Oficial de la Federación. DOF 26-05-1945.

Hernández, N., \& Magaña, H. (2007). El concepto de servicio social en estudiantes de la Universidad Autónoma de Tlaxcala. Ponencia presentada en Congreso Nacional de Investigación Educativa, México. http://www.comie.org.mx/congreso/memoriaelectronica/ vog/ponencias/at10/PRE1178756857.pdf

Martuscelli, J., \& Martínez, C. (2005). El servicio social en el ámbito de la ciencia, la tecnología y la innovación. Universidad Nacional Autónoma de México.

Mungaray, A., \& Ocegueda, J. (1999). El servicio social en la educación superior en México. Comercio exterior, 390-398. http://revistas.bancomext.gob.mx/rce/magazines/281/11/ RCE11.pdf 
Navarrete, A., Barrera, M., \& Martín, M. (2010). Evaluación de proyectos de servicio social en una universidad mexicana. Revista Internacional de Investigación en Educación, 2(4), 371-381. http://www.redalyc.org/pdf/2810/281021692009.pdf

Reglamento para la Prestación del Servicio Social de los Estudiantes de las Instituciones de Educación Superior en la República Mexicana (1981). Diario Oficial de la Federación. DOF 03-30-81. https://www.gob.mx/sep/documentos/reglamentos

Robles, M., Celiz, M., Navarrete, C., Rossi, L., Gilardi, M., \& Barragán, B. (2012). El servicio social. En J. Narro, J. Martuscelli, \& E. Barzana (Coord.), Plan de diez años para desarrollar el Sistema Educativo Nacional. Dirección General de Publicaciones y Fomento Editorial. http://www.planeducativonacional.unam.mx

Sánchez, A. (2002). Los retos de la educación superior: Hacia una política de estado. En Educación, Ciencia y Cultura. Memoria del VII Congreso lberoamericano de Derecho Constitucional. UNAM-IIJ. https://archivos.juridicas.unam.mx/www/bjv/libros/1/341/19. pdf

Sánchez, M., \& Mungaray, A. (2000). Problemática del servicio social y propuestas para su mejoramiento. Asociación Nacional de Universidades e Instituciones de Educación Superior.

Universidad Autónoma de Baja California (UABC). (2007). Reglamento de Servicio Social de la Universidad Autónoma de Baja California. Universidad Autónoma de Baja California. http://www.uabc.mx/formacionbasica/documentos/reglamss.pdf

Universidad Autónoma de Baja California (UABC). (2010). Lineamientos y directrices específicos para regular el cabal cumplimiento del servicio social universitario. Universidad Autónoma de Baja California. http://www.uabc.mx/formacionbasica/documentos/ lineamientosss2010.pdf

Universidad Autónoma de Baja California (UABC). (2013). Modelo Educativo 2013. Universidad Autónoma de Baja California. Universidad Autónoma de Baja California. http://www. uabc.mx/planeacion/cuadernos/ModeloEducativodelaUABC2014.pdf

Universidad Autónoma de Baja California (UABC). (2019). Evaluaciones del desempeño institucional. http://www.uabc.mx/planeacion/

Universidad Autónoma de Baja California (UABC). (2020). Sistema Institucional de Indicadores. http://www.uabc.mx/planeacion/sii/ 
151 
Qartuppi, S. de R.L. de C.V. está inscrita de forma definitiva en el Registro Nacional de Instituciones y Empresas Científicas y Tecnológicas (RENIECYT) con el número 1600052.

Qartuppi, S. de R.L. de C.V. es miembro activo de la Cámara Nacional de la Industria Editorial Mexicana (CANIEM) con número de registro 3751.

Cooperación de las organizaciones del conocimiento con el entorno productivo y social de Baja California

Esta obra se terminó de producir en enero de 2021.

Su edición y diseño estuvieron a cargo de:

\section{Qartuppi}

Qartuppi, S. de R.L. de C.V. http://www.qartuppi.com 
$=$ 
Cooperación de las organizaciones del conocimiento con el entorno productivo y social de Baja California es un trabajo colectivo que consta de siete capítulos en los que se exponen las reflexiones y los hallazgos de destacados investigadores que muestran, no solo el resultado de su trabajo, sino el panorama de vinculación en la Universidad Autónoma de Baja California (UABC).

Es un ejercicio que permite retroalimentar la tarea de la vinculación y el quehacer académico, y una lectura obligada para quienes toman decisiones en torno al desarrollo de la vinculación universitaria.

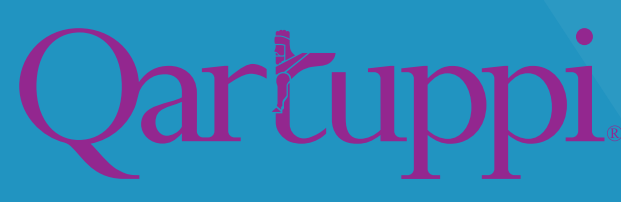

ISBN 978-607-8694-04-4
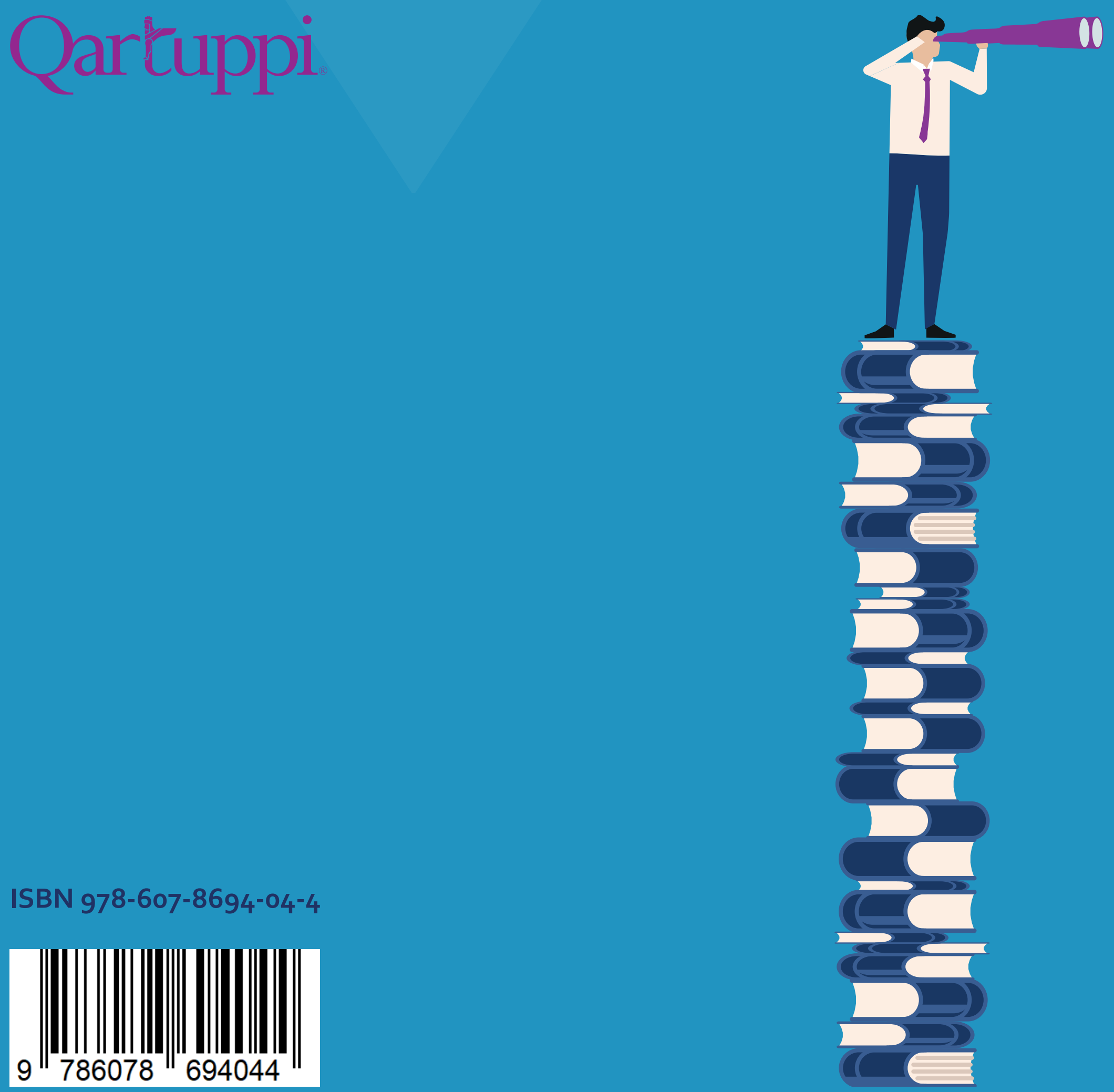